\title{
EDUCACIÓN COMPROMETIDA CON LOS OBJETIVOS DE DESARROLlO SOSTENIBLE: CALIDAD, EQUIDAD EDUCATIVA Y METODOLOGÍA APRENDIZAJE SERVICIO
}

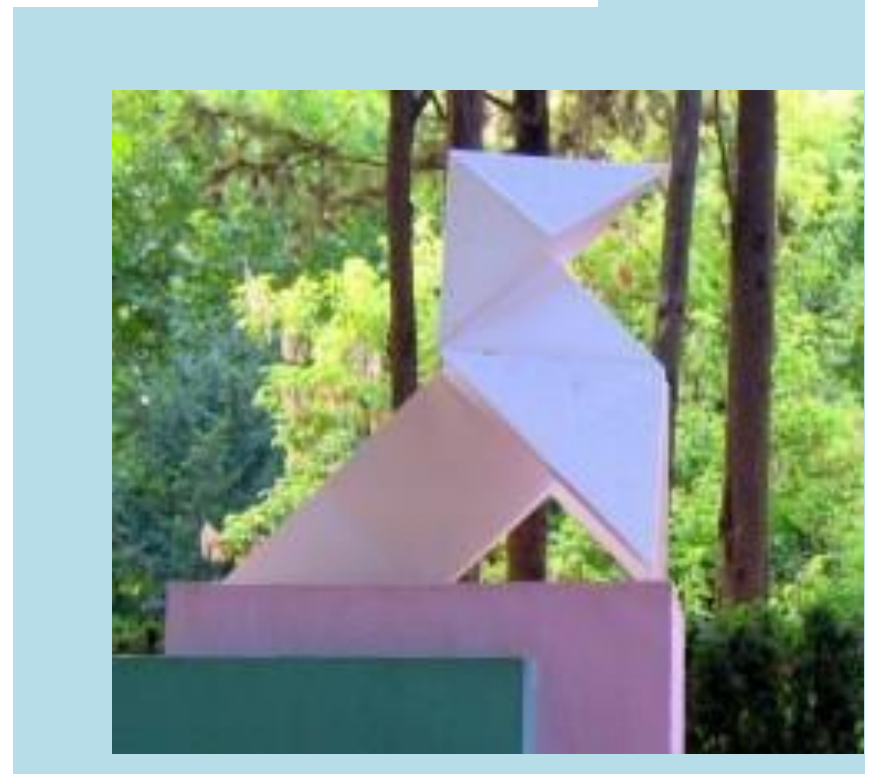




\title{
EDUCACIÓN COMPROMETIDA CON LOS OBJETIVOS DE
} Desarrollo Sostenible: CAlidad, EQUIDAD

\section{EDUCATIVA Y METODOLOGÍA APRENDIZAJE SERVICIO}

\author{
Marta Liesa Orús (Coordinadora), \\ Sergio Cored Bandrés, \\ Verónica Sierra Sánchez, \\ Silvia Anzano Oto, \\ Cecilia Latorre Cosculluela, \\ Raquel Pérez-Ordás, \\ María Mairal Llebot, \\ Sandra Vázquez Toledo, \\ Natalia Sobradiel Sierra y \\ Lucía Forcadel Aznar.
}


Facultad de Ciencias Humanas y de la Educación. Universidad de Zaragoza. Huesca

(C) Marta Liesa Orús (Coord.), Sergio Cored Bandrés, Verónica Sierra Sánchez, Silvia Anzano Oto, Cecilia Latorre Cosculluela, Raquel Pérez-Ordás, María Mairal Llebot, Sandra Vázquez. Toledo, Natalia Sobradiel Sierra y Lucía Forcadel Aznar $1^{a}$ edición. Huesca, 2021

Edita: Facultad de Ciencias Humanas y de la Educación. Universidad de Zaragoza. ISBN 978-84-18321-15-3

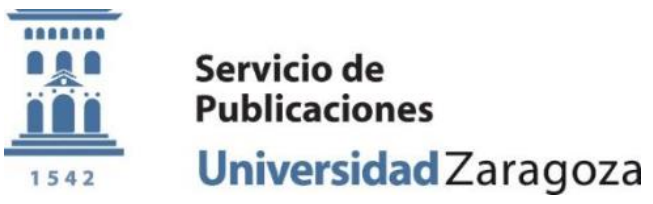




\section{Prólogo}

Es motivo de satisfacción la publicación de esta obra, que supone una nueva cosecha de ideas en torno a la metodología del Aprendizaje-Servicio (ApS). Desde hace un par de décadas, profesores/as de la Facultad de Ciencias Humanas y de la Educación de Huesca en la Universidad de Zaragoza hemos sido pioneros en poner en marcha proyectos que se apoyaban en esta metodología y que eran implementados en el entorno próximo por estudiantes de Magisterio. Entre muchas otras cuestiones, estos proyectos permitían a nuestros estudiantes desarrollar competencias propias de su título universitario y, a la vez, realizar un servicio en su comunidad próxima.

Este año la temática de este evento se ha ampliado, aunque nunca ha perdido la esencia de su núcleo central: la metodología de Aprendizaje-Servicio. Sin duda, la pandemia de la COVID-19 ha condicionado nuestra manera de enseñar y aprender y hemos querido recoger en este libro las buenas prácticas educativas que se han llevado a cabo en este período y que, además, han sido respetuosas con los objetivos de desarrollo sostenible de la agenda 2030, apoyándose en las metodologías de Aprendizaje-Servicio y potenciando la calidad y la equidad educativa y los ODS en tiempos de COVID.

El Aprendizaje-Servicio sigue constituyendo hoy en día una de las principales vías metodológicas para fomentar en tipo de aprendizaje global y significativo en el alumnado, desarrollando todas las competencias transversales. Es, en definitiva, una metodología por y para la formación integral de los discentes. Además de lograr mayor formación profesional y personal por parte de nuestros estudiantes, esta técnica contribuye, aunque sea modestamente, a devolver a la sociedad la confianza que ha depositado en nosotros como organización promotora de conocimiento y de compromiso social. El ApS representa un aprendizaje significativo y 
bidireccional entre quien realiza el servicio y quien se beneficia de su ayuda. Partiendo de esta realidad, nuestro compromiso con este texto se centra en el desarrollo y divulgación de prácticas de Aprendizaje-Servicio que potencien la calidad y la equidad y sean respetuosas con los ODS en tiempos de COVID en diferentes lugares del mundo y en distintos contextos educativos.

Como Vicerrectora del Campus de Huesca, perteneciente a la Universidad de Zaragoza, y Coordinadora de la Titulación del Grado de Magisterio, es un honor que este año se haya elevado la categoría de las Jornadas a una modalidad de Congreso Internacional y hayamos tenido el placer de invitar a compañeros/as de nuestro país y de otros países y compartir nuestras ideas con profesorado de la Universidad Católica del Uruguay, de la Universidad Autónoma de Barcelona (España), de la Universidad de Zaragoza (España), de la Universidad de Andorra, de México y Argentina, entre otros. Todas estas ponencias de realidades educativas tan diversas y tan lejanas, han sido enriquecidas por experiencias prácticas en las escuelas y otras instituciones que abogan, día tras día, por contribuir a una educación sostenible y de calidad.

Marta Liesa Orús,

Vicerrectora del Campus de Huesca,

y Cecilia Latorre Cosculluela,

Coordinadora del Grado de Magisterio Facultad de Ciencias Humanas y de la Educación. 


\section{Índice}

CAPÍTULO 1 APRENDIZAJE SERVICIO

La contribución y didáctica de los Objetivos de Desarrollo Sostenible, desde el proyecto de "La

Ciudad de las Niñas y los Niños" de Huesca, en su décimo aniversario .11

La planificación estratégica en la consecución de los ODS en tiempos de COVID .22

El Aprendizaje-Servicio en Educación Superior como estrategia para promover hábitos saludables en los centros educativos

Metodología Aprendizaje Servicio Virtual y Competencias de Tecnologías de la Información, Aprendizaje y la Comunicación en Tiempos de Covid y Colegio en Casa. Orientación a los Alumnos/as Universitarios: Experiencia Didáctica

Didáctica y aplicación de los ODS en el ámbito universitario. La experiencia de la Universidad de Zaragoza para la Facultad de Ciencias Humanas y de la Educación ....

Los Objetivos de Desarrollo Sostenible. Alcance y dimensión ambientalista .59

\section{CAPÍTULO 2 EXPERIENCIAS Y BUENAS PRÁCTICAS.}

Autoevaluación psicológica en situación de confinamiento como experiencia de aprendizaje aplicado.

Con la mirada puesta en los Objetivos de Desarrollo Sostenible: aprendizaje cooperativo en la universidad para construir una sociedad inclusiva

"Fármacos musicales": una solución a la docencia en pandemia .96

Contextualización escolar de la enseñanza musical del Maestro de Educación Infantil en tiempos de Covid-19 
Análisis, estrategias y acciones de mejora emprendidas con el alumnado con discapacidad ante la pandemia por COVID19

Tendiendo redes para la inclusión educativa en la Universidad Nacional de Córdoba 165

Bienestar emocional a través de la educación musical en tiempos de pandemia. Una revisión teórica

El estilo motivacional docente en Educación Física: una oportunidad para la mejora de la calidad de la docencia y los procesos motivacionales del alumnado

Principios pedagógicos del juego digital activo como material educativo

La evaluación en tiempos de pandemia: análisis de una experiencia en la formación del grado de magisterio en Educación Infantil .208

CAPÍTULO 3 RESPONSABILIDAD SOCIAL E INCLUSIÓN

Twitter una nueva ventana a la sociedad, una apuesta de las universidades españolas y francesas

Educación de adultos de las personas con síndrome de Down o con otras discapacidades intelectuales en entornos inclusivos.....

Recursos educativos abiertos en la educación superior: la implementación de software no privativo para una enseñanza inclusiva

Experiencias singulares en momentos de problemáticas globales: la inclusión en tiempos de pandemia desde los servicios de orientación

Teletrabajo sostenible: seguridad, salud y bienestar. .264

Método, orientación y evaluación del bienestar con el programa NEREU: Educación para la Salud de familias y niños/as. Implicación con los Objetivos de Desarrollo Sostenible 


\section{CAPÍTULO 1}

APRENDIZAJE SERVICIO 


\title{
La contribución y didáctica de los Objetivos de Desarrollo Sostenible, desde el proyecto de "La Ciudad de las Niñas y los Niños" de Huesca, en su décimo aniversario
}

\author{
Annabella Salamanca Villate \\ Azucena Lozano Roy \\ Ester Ayllón Negrillo \\ Lidia Bañares Vázquez \\ Raquel Pérez-Ordás \\ Universidad de Zaragoza
}

Palabras clave: Tonucci; Huesca; Aprendizaje Servicio; ODS. saludables; intervención.

\section{Introducción}

La Resolución 70/1 de la Asamblea General de Naciones Unidas ("Transformar nuestro mundo: la Agenda 2030 para el Desarrollo Sostenible"), aprobó en el 2015, los 17 Objetivos de Desarrollo Sostenible (ODS), como un conjunto de acciones globales para erradicar la pobreza, proteger el planeta y asegurar la prosperidad para todos. Los ODS, constituyen un gran reto y a la vez una oportunidad, porque parten del ahora y miran hacia el futuro "satisfacer las necesidades del presente sin comprometer la capacidad de las futuras generaciones" (Brundlandt, 1987, p.29; Sachs, 2015).

Bajo esta perspectiva generacional, son los ciudadanos, desde la primera infancia, pasando por los adolescentes, que más adelante serán adultos y se harán mayores, los que han de adquirir protagonismo en la construcción de mejores ciudades que brinden bienestar a las personas y a la sociedad (Cámara, 2015). El protagonismo infantil, representado en las la niña y el niño como persona y ciudadano. 
Un conjunto de personas que se agrupan con el objetivo de manifestar libremente sus pensamientos, sus sentimientos y sus emociones, y de apropiarse de los diferentes escenarios públicos en los que ellas desean arriesgarse a opinar, a intervenir, y a ejercer su ciudadanía. (Gallego, 2015, p. 157)

En la gran mayoría de los países, la planificación y proyección de las ciudades no ha tenido en cuenta a los niños y a las niñas, es una realidad presente que busca respuesta.

Repensar la ciudad, quererla de manera diferente, adecuada a todos, incluidos los niños, es una necesidad urgente; no para volver atrás, no para esperar un retorno al clima romántico del pueblo o del vecindario de hace cuarenta o cincuenta años, sino para prepararse a favor de un futuro diferente. (Tonucci, 2015, p.113-114)

En España en el año 1990, (se pone en práctica la Convención de los Derechos del Niño) por primera vez desde su nacimiento, y de acuerdo con Tonucci (2015) las niñas y niños pasan "de ser tutelados a ser ciudadanos" y "no son ya futuros ciudadanos, adultos en formación, sino ciudadanos" (p.10-11). De la urgente necesidad, de preocuparse en consultar, implicar y escuchar a la infancia, surge el Proyecto de La Ciudad de las Niñas y los Niños (LCNN), fundamentado por el psicopedagogo italiano Francesco Tonucci, desde el año 2000 y al que se encuentran vinculadas más de 200 ciudades en todo el mundo.

LCNN es un proyecto internacional de participación ciudadana, que pretende tomar al niño y a la niña como parámetros de la construcción de la ciudad: "Quien sea capaz de contemplar las necesidades y deseos de los niños, no tendrá dificultades en tener en cuenta la necesidad del anciano, del minusválido, de personas de otras comunidades" (Tonucci, 1999).

En Huesca, La Ciudad de las Niñas y los Niños, inicio su andadura en el 2001, con la presentación del Proyecto al Ayuntamiento por un grupo de profesoras de la Facultad de Ciencias Humanas y de la Educación de la Universidad de Zaragoza. En 2011, el alcalde planteó al Pleno del Ayuntamiento la adhesión de LCNN de Huesca (LCNNH) al proyecto internacional. Y en la actualidad (2021), LCNN de Huesca, en convenio con el Ayuntamiento, cumple diez años. Durante este tiempo, las propuestas y acciones que se ha venido trabajando están enmarcadas en la 
iniciativa global de la sostenibilidad, respecto de la cual Tonucci hace referencia de la siguiente manera:

Repensar la ciudad significa tener un proyecto de futuro, preparar, como dicen los ecologistas, un desarrollo sostenible. Un desarrollo controlado, no egoísta, que encuentre en sí mismo la fuerza y la energía suficientes para garantizar su futuro y el de las próximas generaciones. El niño es la garantía natural del desarrollo sostenible: él debe hacerse mayor, capaz de resolver problemas, y jamás podrá hacerlo si no le aseguramos autonomía, posibilidad de riesgo y de crecimiento, posibilidad de relaciones lúdicas y espontáneas. (Tonucci, 2015, p.113-114)

Al considerar que las niñas y niños son capaces por medio de su participación activa de provocar cambios en la ciudad y su comunidad, el proyecto LCNN se constituye en una valiosa experiencia de aprendizaje-servicio (ApS), (Montes, Tapia y Yaber, 2011). Para poder llevar a cabo esta labor se ha dotado de órganos como el Consejo (niñas y niños de $5^{\circ}$ y $6^{\circ}$ de primaria), Grupo Gestor (Ayuntamiento y Facultad) y Grupos de apoyo (maestros, familias, universitarios y otros). Los niños elegidos para el consejo permanecen en él dos años, este órgano participativo se constituye con igual número de niños y niñas. El Consejo asesora al Ayuntamiento sobre acciones y actividades posibles tras debatir sobre los problemas de la ciudad y las necesidades.

El trabajo, que se presenta a continuación, de una parte, hace una recopilación de todas las propuestas y acciones del proyecto en la ciudad Huesca, durante sus primeros diez años. De otra parte, relaciona el quehacer de LCNN con las metas de la iniciativa global de la Agenda 2030 y 10 de sus ODS.

\section{Objetivos}

El objetivo general de este trabajo es analizar y cuantificar la contribución de LCNN de Huesca (durante sus primeros 10 años) a los Objetivos de Desarrollo Sostenible (ODS).

Los objetivos específicos son: 
- Identificar y estimar el peso relativo de las actividades del proyecto LCNNH que han contribuido a cada ODS.

- Estimar la medida en que se ha trabajado cada ODS desde el proyecto, así como su evolución temporal.

\section{Metodología}

Para el estudio de la contribución a los ODS de LCNN de Huesca se han seguido los siguientes pasos:

1. Elaboración de un listado con todas las propuestas y acciones realizadas por LCNN de Huesca a lo largo de los años 2011 a 2020. Para ello, se consultaron las memorias del Proyecto desde el 2012 hasta 2020 y se agruparon las acciones en torno a 5 ejes: a) celebración y promoción del juego infantil, b) autonomía, movilidad y compromiso medioambiental, c) adecuación urbanística, mejoramiento del entorno e infraestructuras, d) atención al bienestar emocional, la empatía y acompañamiento durante la pandemia y e) investigación, formación y difusión.

2. Identificación de las metas y ODS más afines con las propuestas de acción y el proceso participativo llevado a cabo por el Consejo de las niñas y niños y sus Comisiones de trabajo en los diferentes ámbitos de actuación. Se seleccionaron 10 de los 17 ODS y se especificaron las metas más afines con Proyecto. Las 42 acciones de La Ciudad de las Niñas y los Niños que aparecen en la lista, se han relacionado con 20 metas de 10 ODS. La selección se realizó mediante criterio experto de dos investigadores del Área de Ciencias Experimentales y el Área de Ecología de la Universidad de Zaragoza.

3. Elaboración de una matriz de datos (Excel), con una doble información. Por un lado, el/los ODS con los que está relacionada cada actividad desarrollada y, por otro, el número de actividades vinculadas con cada ODS a lo largo del tiempo.

4. Para identificar y estimar el peso relativo de las actividades de LCNN en los ODS, se contabilizaron todas las acciones realizadas correspondientes a cada ODS. A partir de ahí, se elaboró un gráfico de barras que representa el número de actividades realizadas para cada ODS. 


\section{Resultados}

En la tabla 1 se indican las actividades desarrolladas por el proyecto y se agrupan en 5 ejes de actuación, que son los siguientes: 1. Promoción y celebración del juego infantil; 2. Autonomía, movilidad y compromiso ambiental; 3. Adecuación urbanística, mejoramiento del entorno e infraestructuras; 4. Atención al bienestar emocional: empatía y acompañamiento durante la pandemia; 5. Investigación, formación y difusión. La recopilación de acciones llevadas a cabo en cada eje de actuación se detalla en la tabla 1.

Tabla 1. Acciones del Proyecto de La Ciudad de las Niñas y los Niños de Huesca entre 2011 y 2021 agrupadas en 5 ejes de actuación

$\begin{array}{cc}\text { I. PROMOCIÓN Y CELEBRACIÓN DEL JUEGO } & \text { II. AUTOMÍA, MOVILIDAD Y COMPROMISO } \\ \text { INFANTIL } & \text { MEDIOAMBIENTAL }\end{array}$

Colaboración y trabajo con las Ludotecas Municipales

El Guirigay

El gran juego de la pajarita oscense

Celebración del Día del Juego

Carrito de los Helados Juguetones

Creación de un listado de juegos

Juegos durante la pandemia

Vídeo: Desescalada de Pantallas escalda de juegos

Juego de líneas

Espacios de juego en el entorno de todos los colegios

Proyecto de recuperación de solares

Planificación compartida del Parque del Encuentro

Pensando la placeta

Mejora de la calle Valentín Carderera
Caperucita camina sola por Huesca

Caminos escolares seguros, Juegos de líneas y señalización. Comercio amigo y Espacio amigo de los niños

Proyecto Vamos Juntos a la Escuela

Sensibilización de Conductores

Mejora del camino al Colegio C.E.I.P. ALCORAZ.

Análisis de los espacios potencialmente jugables

Señalización y trazado de los caminos escolares

Participación en Huesca +Inclusiva

\section{ATENCIÓN AL BIENESTAR EMOCIONAL: EMPATÍA Y ACOMPAÑAMIENTO DURANTE LA PANDEMIA}

Mensaje de ánimo para Huesca

Participación en el Acto de homenaje: "A los que nos faltan"

Dibujos de ánimo a los pacientes de Hospitales y Residencias

Video llamadas a las Residencias de Adultos Mayores. 


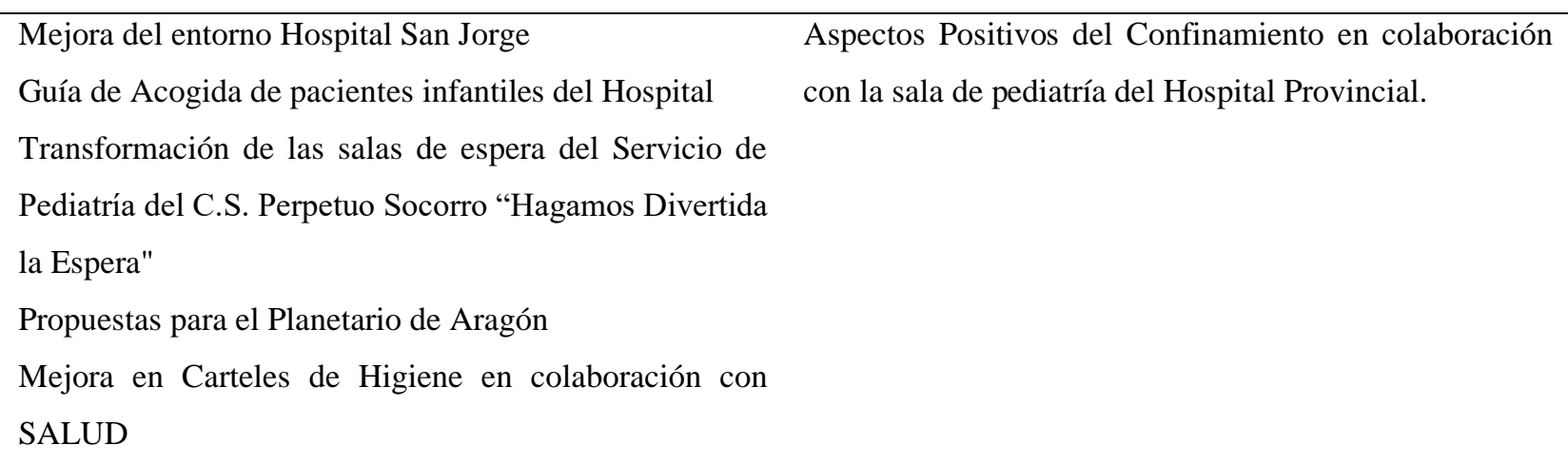

\section{INVESTIGACIÓN, FORMACIÓN Y DIFUSIÓN}

Formación con los maestros y maestras de todos los colegios de Huesca y con las con familias de los consejeros.

Estancia de investigación.

Investigaciones.

Trabajos Fin de Grado y Fin de Master

Proyecto de innovación

Participación en congresos, jornadas y encuentros

Redes y convenios

En la tabla 2 se recogen las metas de los ODS que se han trabajado desde el proyecto, a partir de la opinión experta de los miembros del equipo.

Tabla 2. La Agenda 2030 y la Ciudad de las Niñas y los Niños de Huesca

\section{Metas y ODS en las que ha trabajado el Proyecto de LCNN de Huesca}

3. Salud y Bienestar.

Promover y proteger nuestra propia salud y la de nuestro entorno.

4. Educación de calidad.

Meta 4.3. Contribuir a la calidad en la enseñanza universitaria

Metas 4.3 y 4.4. Aumentar los jóvenes y adultos con competencias profesionales.

Meta 4.5. El acceso igualitario a la enseñanza.

Meta 4.7. Alumnos con conocimientos teóricos y prácticos de una educación para el desarrollo sostenible y los estilos de vida sostenibles. 
Meta 4.a Las necesidades de los niños y las personas con discapacidad, para crear entornos de aprendizaje seguros, no violentos, inclusivos y eficaces para todos.

Meta 4.c Aumentar la oferta de docentes calificados.

5. Igualdad de Género.

Meta 5.2. Todas las formas de no violencia contra las mujeres y las niñas.

Meta 5.5. La participación plena y efectiva de las mujeres y la igualdad de oportunidades de liderazgo.

10. Reducción de las desigualdades

Meta 10.2 y 10.3. La inclusión social y de igualdad de oportunidades de todas las personas independiente de su condición.

11. Ciudades y Comunidades sostenibles.

Meta 11.2 y 11.7. El transporte y movilidad sostenibles para todos. El mejoramiento de la seguridad vial, el acceso a zonas verdes y espacios públicos, prestando especial atención a las necesidades de las mujeres, los niños, las personas con discapacidad y las personas mayores.

Meta 11.3. La urbanización inclusiva y sostenible y la planificación y la gestión participativas.

Meta 11.4. La protección del patrimonio cultural y natural.

12. Producción y Consumo responsables

Meta 12.5. La prevención, reducción, reciclado y reutilización de los materiales.

Meta 12.8. El desarrollo sostenible y los estilos de vida en armonía con la naturaleza.

\section{Acción por el Clima}

Meta 13.3. La educación y la sensibilización sobre el cambio climático.

15. Vida de ecosistemas terrestres

Meta 15.1. El uso sostenible de los ecosistemas terrestres como bosques y ecosistemas de agua dulce, entre otros.

16. Paz, justicia e instituciones sólidas 
Meta 16.7. Propuestas y acciones inclusivas, participativas que respondan a necesidades reales.

\section{Alianzas para lograr objetivos}

Meta 17.16. Movilizar e intercambiar conocimientos y valores con visión en las personas y el planeta.

La figura 1 muestra la dedicación del proyecto de LCNN de Huesca a los distintos ODS, estimada a partir del número de actividades realizadas por ODS en el periodo 2011-2021. Se observa que hay 3 ODS sobre los que se han realizado más de 40 actividades: ODS 5: Igualdad de género; ODS 4: Educación de calidad; ODS 10: Reducción de las desigualdades. Con más de 30 acciones, el ODS 3: Salud y Bienestar.

Figura 1. Contribución del proyecto de La Ciudad de las Niñas y los Niños de Huesca a los ODS estimada en número de actividades realizadas entre 2010 y 2021 para cada ODS.

OBJETIVO 17. Alianzas para lograr objetivos. OBJETIVO 16. Paz, justicia e instituciones sólidas.

OBJETIVO 15. Vida de ecosistemas terrestres. OBJETIVO 13. Acción por el Clima.

OBJETIVO 12. Producción y Consumo responsables. OBJETIVO 11. Ciudades y Comunidades sostenibles OBJETIVO 10. Reducción de las desigualdades. OBJETIVO 5. Igualdad de Género. OBJETIVO 4. Educación de calidad. OBJETIVO 3. Salud y Bienestar.

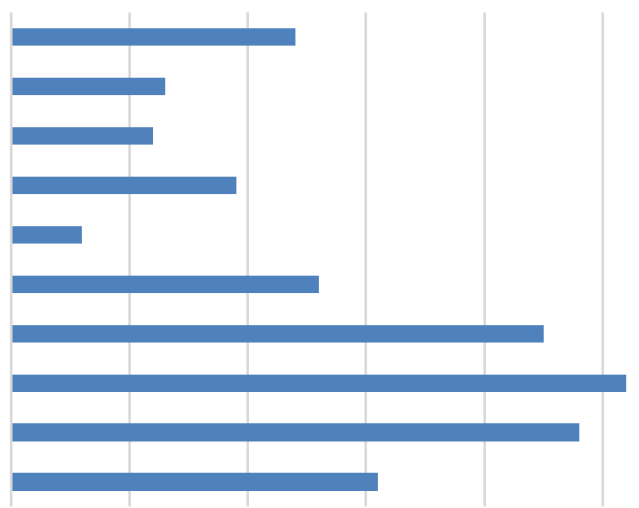

$\begin{array}{lllll}10 & 20 & 30 & 40 & 50\end{array}$

Número de actividades entre 2011-2021

La figura 2 informa sobre las acciones del proyecto que más han contribuido a los ODS. Se observa que las acciones del bloque "Investigación, formación y difusión” constituyen más del $30 \%$ de la contribución del proyecto a los ODS. En torno al 20\% han contribuido cada uno de los bloques "Promoción y celebración del juego infantil", "Adecuación urbanística, mejora del entorno e infraestructuras" y "Autonomía, movilidad y compromiso medioambiental”.

Figura 2. Contribución relativa (\%) de las acciones del proyecto, agrupadas por bloques, a los ODS. 


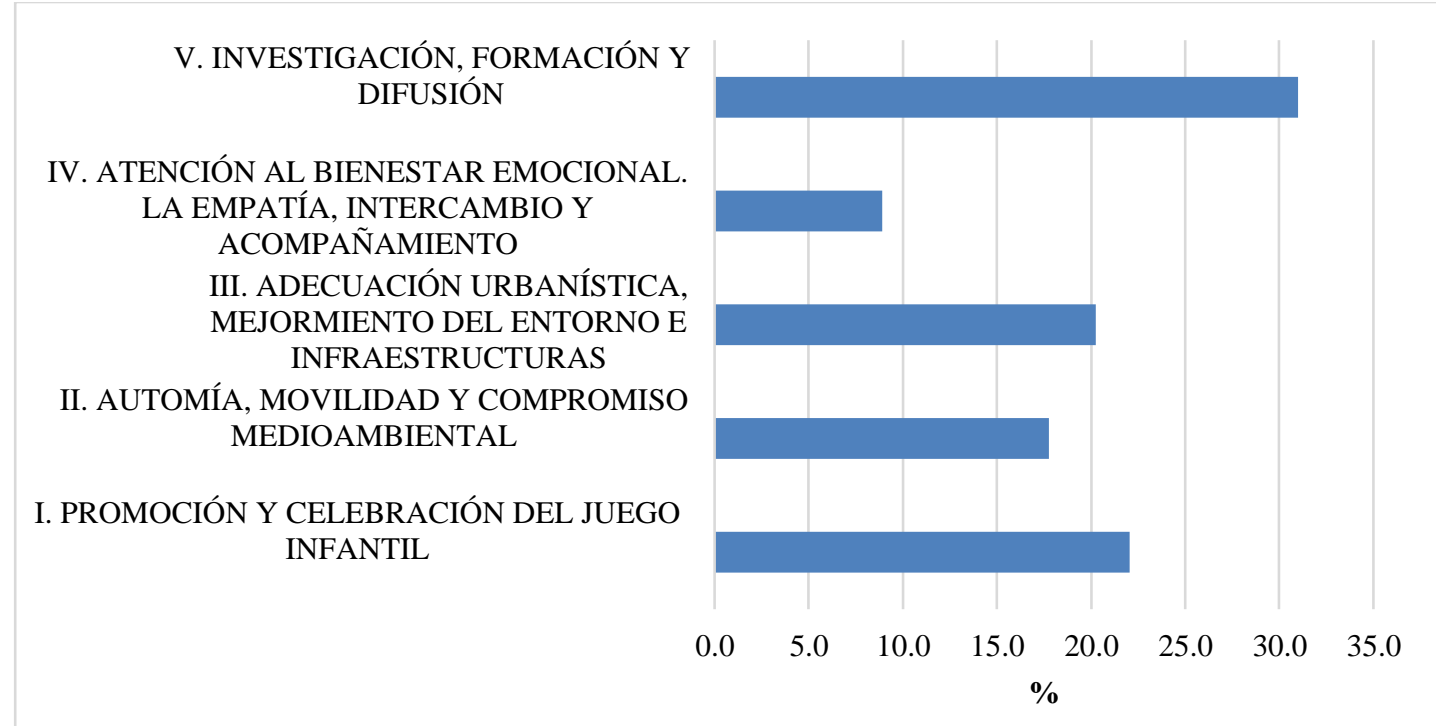

\section{Discusión}

Las niñas y los niños, la infancia, es uno de los sectores sociales que se han de ver más beneficiados por los Objetivos de Desarrollo Sostenible que persigue la Agenda 2030 (Unicef, 2016). Su participación es un eje articulador de nuevas formas de establecer las relaciones entre personas, y entre ellos mismos y su entorno (Cámara, 2015). Del análisis efectuado sobre el quehacer del proyecto de la ciudad de las niñas y los niños de Huesca en sus primeros 10 años de vida, se desprende que, efectivamente, los ODS que más actividades han concentrado están relacionados con la igualdad de género (ODS 5), la educación de calidad (ODS 4) y la reducción de las desigualdades (ODS 10) (tabla 2, figura 1). Todos ellos están relacionados con la dimensión social de la sostenibilidad que, en este caso se ha dirigido a promover en las niñas y niños valores como la inclusión social o la igualdad de género, fundamentales para construir una sociedad estructurada que quiera lograr un estado de bienestar para sus habitantes a través de generación de espacios armónicos que permitan el desarrollo físico y mental (Aragón, 2020). Algunos ejemplos de las acciones llevadas a cabo por LCNN de Huesca, en este sentido son la celebración del Día del Juego y el desplazamiento por las calles y colegios del Carrito de los Helados Juguetones.

Sin embargo, lo que distingue al proyecto LCNN de otras iniciativas, es la voz y los cauces que da a las niñas y niños para que sean actores activos en la construcción de la sociedad sostenible, en este caso la ciudad de Huesca sostenible. Las niñas y niños de Huesca, a través de sus propuestas 
trabajadas en el Consejo y sus comisiones, han desarrollado numerosas acciones que han promovido ODS como "3. Salud y bienestar" y "11. Ciudades y comunidades sostenibles". A modo de ejemplo se pueden citar, Proyecto "Vamos Juntos a la Escuela" iniciativa dirigida a que los niños y niñas puedan moverse con seguridad y autonomía por las calles, recuperen el uso y disfrute del espacio público de la ciudad. Otro ejemplo es La Guía de Acogida para los pacientes infantiles del Hospital San Jorge de Huesca. Así mismo, otro ejemplo es el Proceso de transformación participativa de las salas de espera del Servicio de Pediatría del C.S. Perpetuo Socorro "Hagamos Divertida la Espera" diseñada con la participación activa de las niñas y niños.

También es destacable la experiencia del Proyecto durante el confinamiento COVID de marzo a mayo de 2020, con el desarrollo de propuestas como la realización de Video llamadas a las Residencias de Adultos Mayores con el fin de animarles, acompañarles y compartir un momento intergeneracional.

La Ciudad en su conjunto, también se ha beneficiado del mejoramiento del entorno e infraestructuras, en acciones como la Planificación compartida en la transformación del Parque del Encuentro, Pensando la Placeta y la mejora de la calle Valentín Carderera.

El Proyecto también ha llevado a cabo acciones centradas en la dimensión ambiental, en el ámbito de los ODS 11, 12, 13 y 15. Y en el apoyo y en la estrategia de colaboración y alianzas se conecta con otras instituciones y organizaciones (ODS 17).

Al considerar que las niñas y niños son capaces por medio de su participación activa de provocar cambios en la ciudad y su comunidad, el proyecto LCNN se constituye una valiosa experiencia de aprendizaje-servicio (ApS).

\section{Conclusiones}

El proyecto LCNN de Huesca ha tenido una estrecha vinculación con los ODS de la Agenda 2030 a lo largo de esta década, tanto con los más directamente relacionados con la formación y desarrollo humano de las propias niñas y niños, como -lo que resulta más original del proyecto LCNN- los que contribuyen a la sostenibilidad del conjunto de la sociedad y de la ciudad, a partir de las propuestas y de las actividades desarrolladas por las propias niñas y niños. 


\section{Referencias}

Aragón, M. (2020). Ciudad y bienestar: la tensión entre la urbanización y el habitar. Revista Costarricense de Psicología, 39(1), 5-18.

Brundlandt, G.H. (1987). Our common future. Report of the World Commission on Environment and Development. United Nations Organization.

Càmara, A. M. N. (2015). El activismo infantil en la ciudad desde un consejo de participación. In Pedagogía social: acción social y desarrollo. Benemérita Universidad Autónoma de Puebla.

Gallego-Henao, A. M. (2015). Participación infantil. Historia de una relación de invisibilidad. Revista Latinoamericana de Ciencias Sociales, Niñez y Juventud, 13(1), 151-165.

La Ciudad de las Niñas y los Niños de Huesca. (2012 - 2020). Memorias finales de curso.

Montes, R., Tapia, M. y Yaber, L. (2011). Manual para docentes y estudiantes solidarios. CLAYSS. Recuperado de http://www.clayss.org.ar/04_publicaciones/Natura2013.pdf

Sachs, J. D., \& Vernis, R. V. (2015). La era del desarrollo sostenible. Deusto.

Tonucci, F. (1999). Los niños como punto de partida para salvar las ciudades. En La educación infantil a debate: actas del primer Congreso Internacional de Educación Infantil. Fondo Editorial de Enseñanza (FEDE), 153-160.

Tonucci, F. (2015). La ciudad de los niños. Graó.

UNICEF (Fondo de las Naciones Unidas para la Infancia) (2016a), Estado Mundial de la Infancia 2016: una oportunidad para cada niño, Nueva York. 


\title{
La planificación estratégica en la consecución de los ODS en tiempos de COVID
}

\author{
Victoria Bordonaba Juste \\ Universidad de Zaragoza
}

Palabras clave: ODS; valor; planificación estratégica; organizaciones

\section{Introducción}

Las alianzas entre organizaciones han demostrado en muchas ocasiones ser eficaces en la obtención de sinergias. Esta cuestión resultaría ser clave para conseguir las metas y objetivos propuestos en los ODS 2030. Destacarían las metas relativas al medioambiente, a la educación o la igualdad de género, entre otras, en las que estas colaboraciones de trabajo pueden resultar en una auténtica transformación social (Red Española del Pacto Mundial, 2019).

En el último informe de la Plataforma Acción Social (2020), se destaca la importancia de las relaciones de colaboración entre las entidades que conforman el Tercer Sector con otra serie de organizaciones (como Administraciones públicas) e incluso con la Sociedad en general y con empresas. De la misma forma, el Plan Estratégico del Tercer Sector 2017-2021 puso de manifiesto la importancia de las relaciones con los agentes clave como una de las principales metas estratégicas de las entidades pertenecientes al Tercer Sector.

Entre las diferentes relaciones de colaboración, las fundamentadas en una colaboración en la dirección hacen referencia a las sinergias derivadas de compartir conocimientos, capacidades y prácticas en todos los niveles, desde la dirección general hasta las direcciones funcionales. Son en estas últimas donde las entidades no lucrativas pueden apreciar las ventajas de colaborar con empresas y otras organizaciones, mediante una transferencia de su know-how.

En la dirección de marketing, las entidades no lucrativas tienen mucho por aprender todavía, ya que en muchas ocasiones no desarrollan una gestión estratégica del marketing o lo 
desarrollan de una forma muy limitada, solo en un nivel operativo. En esas ocasiones se limitan a usar las variables de marketing (ej. Relaciones públicas, publicidad,...) puntualmente sin tener una verdadera planificación estratégica.

En la actualidad, las empresas se orientan a nivel estratégico según los principios de la Lógica Dominante del Servicio (Service-dominant Logic o SDL) (Vargo y Lusch, 2004). La clave del SDL es la creación de valor. Y, ¿cuáles son las premisas básicas para crear valor?

El valor es creado por los clientes mediante el uso o consumo de los productos o servicios. Es lo que se conoce como co-creación. Las empresas van a facilitar ese valor, dándoles los bienes y servicios con los que los clientes obtengan mayor valor. E incluso interaccionan con el cliente de forma que ambas partes contribuyan a la creación de valor y que esta relación sea mutuamente beneficiosa (Vargo y Lusch, 2008). Hay que tener en cuenta que el marketing no se centra exclusivamente en la relación empresa-cliente, sino que en su conceptualización estratégica es un conjunto de instituciones y procesos para crear, comunicar, entregar e intercambiar ofertas que tengan valor no solo para los clientes, sino también para todos los stakeholders y la sociedad en general (American Marketing Association, 2017). En la actualidad las organizaciones se rigen por esta premisa del SDL: los stakeholders interactúan y colaboran entre ellos para crear valor conjuntamente.

\section{Los ODS y la dirección estratégica en las ONGs}

Al trasladar esta premisa (colaboración de los stakeholders para co-crear valor) al tercer sector, en este epígrafe vamos a planificar cómo entidades-usuarios-socios (actuales y potenciales) van a interactuar para crear valor para todas las partes.

Primero, el marketing de redes sociales se ha puesto al servicio de las organizaciones para crear vínculos a corto, medio y largo plazo al generar un gran valor percibido por parte de los usuarios y la sociedad, consiguiendo un mayor engagement y satisfacción. El reto para las entidades no lucrativas consiste en sustituir las acciones de marketing directo que han realizado tradicionalmente solo a nivel operativo (ej. campañas publicitarias, eventos, relaciones públicas, contact centers,...), por un plan de marketing a nivel estratégico, en el que todas las herramientas 
de marketing se integran para una misma finalidad social, y en el que los usuarios y la sociedad se convierten en co-productores de ese servicio para lograr los beneficios.

Segundo, las ventajas de la multicanalidad o integración de los canales de comunicación y compra con los clientes, pueden ser transferidas a las organizaciones no lucrativas. Hasta ahora, el contacto físico resultaba esencial con los usuarios de estas organizaciones. A raíz de la situación generada por la COVID-19, esta situación se vuelve insostenible, teniendo que priorizar los canales online. Algunas experiencias pioneras, como el Servicio multicanal de empleo desarrollado por Cruz Roja han demostrado la eficacia de estas innovaciones digitales.

Después de implantar esta planificación, las entidades tendrán que medir los beneficios conseguidos por el voluntariado para la consecución de los ODS de la Agenda 2030. Para ello, recientemente se ha propuesto un nuevo enfoque para medir el performance de los voluntarios en el marco de las empresas que tengan en marcha un programa de voluntariado en los ODS (Kuoni, 2020).

Siguiendo este enfoque, se plantea que las entidades no lucrativas también deben cuantificar el valor de los socios y voluntarios, implantando una métrica que le permita medir el performance de las campañas en los ODS. La métrica de marketing utilizada por las empresas para medir el valor del cliente puede trasladarse a las entidades no lucrativas. Entre ellas destacará el análisis del engagement generado en la campaña.

\section{Metodología: aplicación del Aprendizaje- Servicio (APS)}

Este trabajo forma parte del proyecto de Aprendizaje- Servicio llevado a cabo desde la Facultad de Economía y Empresa de la Universidad de Zaragoza. En concreto, combina un proceso de aprendizaje y de servicio para alumnos matriculados en el Trabajo Fin de Grado (TFG) que se tutorizan desde esta Facultad con ONGs de la Comunidad Autónoma de Aragón. Los estudiantes elaboran su TFG como resultado de la colaboración con una ONG, desarrollando competencias de gestión y evaluación de organizaciones.

Mediante la metodología APS (Amat y Miravet, 2010), se realiza una propuesta para una ONG de Zaragoza para conseguir el objetivo n.4 ‘Educación de calidad' con la colaboración del 
Departamento de Marketing de la Facultad de Economía y Empresa de la Universidad de Zaragoza, los usuarios de una ONG y la sociedad zaragozana. Durante la pandemia provocada por la COVID19, esta ONG ha desarrollado varias campañas de captación de fondos para suplir la falta de material informático y alcanzar una educación de calidad para todos los niños zaragozanos.

El planteamiento inicial requiere de una segmentación de mercados para identificar los principales mercados de una ONG: ciudadanos (socios-donantes, socios-voluntarios y potenciales donantes) y usuarios del servicio. Es muy relevante que las organizaciones identifiquen a sus donantes, especificando no sólo sus datos sociodemográficos sino también de comportamiento.

Según Kuonki (2020), para poder integrar el voluntariado en la Agenda 2030, es necesario conocer primero su perfil. Las principales características a analizar son las características sociodemográficas (edad, sexo...), gasto (donativos), frecuencia, tipo de campañas en las que ha participado/ha mostrado interés y canal utilizado por el socio. Con estos datos, y trasladando el aprendizaje de nuestros alumnos de la Facultad, conseguiríamos la elaboración y manejo de una base de datos con la que poder analizar, por un lado, los perfiles de los donantes, y por otro, de los usuarios de los servicios (Tabla 1).

Tabla 1. Perfil del socio y del potencial donante

\begin{tabular}{|c|c|c|c|}
\hline Variable & Socio-donante & Socio-voluntario & Ciudadano (Potencial donante) \\
\hline Características sociodemográficas & $\checkmark$ & $\checkmark$ & $\checkmark$ \\
\hline Gasto & $\checkmark$ & & \\
\hline Frecuencia & $\checkmark$ & $\checkmark$ & \\
\hline Interés por tipo de campaña & $\checkmark$ & $\checkmark$ & $\checkmark$ \\
\hline $\begin{array}{l}\text { Canal de comunicación con la } \\
\text { organización }\end{array}$ & $\checkmark$ & $\checkmark$ & $\checkmark$ \\
\hline
\end{tabular}

Fuente: elaboración propia

La planificación estratégica de marketing incluye primero un objetivo de captación de nuevos socios y otro de retención y fidelización con los socios y voluntarios de la entidad. Para ello, se propone cuantificar, temporalizar estos 3 objetivos, concretándolos para las campañas realizadas durante este curso escolar referidas al ODS n.4: 
- $\quad$ aumento del número de voluntarios

- $\quad$ aumento de las donaciones

- aumento de la visibilidad de las campañas

Para conseguir estos objetivos se plantea un programa de marketing digital que comprende la ampliación de los canales de comunicación y convive con herramientas tradicionales de mailing directo. Con ello, conseguirán reducir los costes presupuestarios y el tiempo de ejecución de la campaña.

El cambio más importante es el desarrollo de un programa de marketing digital a través de redes sociales, destacando la colaboración de influencers. Los influencers de las redes sociales (influencers, en adelante) actúan como un nuevo actor que va a desarrollar relaciones tanto con la organización como con sus stakeholders. En el caso de las ONGs, destacaremos las relaciones entre la entidad y sus socios y voluntarios a través de la creación de contenido. Es conveniente que los influencers que nos ayuden a conseguir los objetivos propuestos fueran celebrities con amplia visibilidad en las redes (ej. deportistas famosos). Aquí es donde vuelve a tener importancia el proceso Aprendizaje-Servicio, ya que los conocimientos en branded-content podrán ser traslados a la relación ONG-influencer, en la que se propone a los influencer una serie de actividades de comunicación para conseguir los objetivos estratégicos de la entidad.

Las ONGs no deben utilizar las herramientas de branded-content exactamente igual que las empresas. En este caso, los especialistas en marketing deben adaptarlas a la singularidad de las ONGs para que prevalezcan los valores a transmitir y el público objetivo se identifique no solo con el influencer sino también con los valores sociales de estas entidades (Stride y Lee, 2017).

La identificación con el influencer tendrá dos niveles: por un lado, la similitud real o percibida entre el ciudadano y el influencer y la similitud deseada (Schouten et al., 2020). En el caso de las celebrities, la identificación que suelen presentar los usuarios es la que se refiere al deseo de parecerse a ellos. Por tanto, la ONG elegirá el influencer en función del mercado objetivo de la campaña (socios, voluntarios y ciudadanos en general). De forma que cuando tenga identificadas sus características (presentadas en la anterior tabla 1), podrá determinar cuales tienen en común y cuáles desearían tener, identificando más adecuadamente que influencer puede ayudarle a conseguir sus objetivos. Además de la identificación, se recomienda a las ONG que el 
influencer elegido presente una altísima credibilidad y que los ciudadanos puedan percibir el ajuste con la causa social perseguida por la ONG (Schouten et al., 2020).

La credibilidad del influencer (y por ende, la de la ONG a la que representa) es un concepto crucial en marketing. La teoría compromiso-confianza (Morgan y Hunt, 1994) demuestra que la credibilidad permite desarrollar relaciones mutuamente beneficiosas para todas las partes. Así, las ONGs deberán elegir fuentes con ciertas cualidades, en especial experiencia (honestidad, integridad y credibilidad) y confiabilidad (conocimiento, experiencia y habilidades).

La credibilidad y la similitud con el influencer no son suficientes para que el mensaje emitido sea eficaz y aumente la probabilidad de éxito de la campaña. También se necesita que el público objetivo perciba un ajuste entre el mensaje del influencer y la marca a la que representa (Schouten et al., 2020). Para una ONG resultará crucial que los ciudadanos perciban que el influencer realiza las campañas por una motivación puramente altruista, no para conseguir únicamente la mejora de su imagen. Para ello, suele ser interesante que las actividades del influencer tengan relación con la causa social.

\section{Conclusiones}

Las entidades tienen que adaptar las relaciones con sus usuarios y con la Sociedad a la nueva situación creada tras la COVID-19. En este trabajo se ha profundizado en la gestión que las ONGs deben desarrollar de las relaciones tanto con sus socios como con la ciudadanía en general. En concreto, se ha destacado la importancia de la integración de los canales de comunicación, priorizando los canales online y permitiendo que la entidad se comunique con él a través de su canal preferido. Las ventajas derivadas de poner en marcha una planificación estratégica del marketing serían, por un lado, el análisis del comportamiento del socio por cada canal, lo que permitirá fidelizarlo para próximas campañas. Y por otro lado, la comunicación no intrusiva con el ciudadano (socio actual o potencial), aumentando su satisfacción y engagement.

\section{Referencias}

Amat, F. y Miravet, M. (2010). El Aprendizaje Servicio en la Universidad: una estrategia en la formación de ciudadanía crítica. Asociación Universitaria de Formación del Profesorado 
American Marketing Association (2017). Definition of Marketing (https://www.ama.org/thedefinition-of-marketing-what-is-marketing/ )

Kuonki (2020). La medición del Voluntariado para la Agenda 2030. En Plan de Acción para integrar el voluntariado en la Agenda 2030. Secretaría del Plan de Acción. Strategic Agenda.

Morgan, R. M. y Hunt, S. D. (1994). The commitment-trust theory of relationship marketing. Journal of marketing, 58(3), 20-38. http://doi.org/10.2307/1252308

Ministerio de Derechos Sociales y Agenda 2030. ODS Agenda 2030. https://www.agenda2030.gob.es/

Red Española del Pacto Mundial (2019). Las ONG ante los Objetivos de Desarrollo Sostenible https://www.pactomundial.org/wp-content/uploads/2019/05/Las-ONG-ante-losObjetivos-de-Desarrollo-Sostenible.pdf

Plataforma de ONG de Acción Social (2020). Informe El Tercer Sector de Acción Social en España 2019: Nuevos horizontes para un nuevo contexto sociopolitico. Ministerio de Sanidad, Consumo y Bienestar. https://www.plataformaong.org/tercer-sector-accion-social.php

Schouten, A.P.; Janssen, L. y Verspaget, M. (2020). Celebrity vs. Influencer endorsements in advertising: the role of identification, credibility, and Product-Endorser fit. International Journal of Advertising, 39 (2), 258-281. http://doi.org/10.1080/02650487.2019.1634898.

Stride, H. y Lee, S. (2007). No Logo? No Way. Branding in the Non-Profit Sector. Journal of Marketing Management, 23 (1-2), 107-122. http://doi.org/10.1362/026725707X178585

Vargo, S.L. y Lusch, R.F. (2004). Evolving to a new dominant logic for marketing. Journal of Marketing, 68 (January), 1-17. http://doi.org/10.1509/jmkg.68.1.1.24036

Vargo, S. L. y Lusch, R. F. (2008). Service-dominant logic: continuing the evolution. Journal of the Academy of marketing Science, 36(1), 1-10. http://doi.org/10.1007/s11747-007-0069-6 


\title{
El Aprendizaje-Servicio en Educación Superior como estrategia para promover hábitos saludables en los centros educativos
}

\author{
Miguel Ángel Tapia Serrano
}

Universidad de Extremadura

Palabras clave: actividad física; aprendizaje servicio; hábitos saludables; pantalla y sueño.

\section{Introducción}

Las sociedades actuales han experimentado grandes transformaciones y cambios sociales que han puesto de manifestado nuevas formas de información y comunicación entre las personas (Domínguez, 2005; López-Fernández, y Benítez-Porres 2018). Dado que instituciones básicas como las escuelas o universidades no escapan a estos cambios, surge la necesidad de preparar a las personas para enfrentarse a las nuevas exigencias y retos de la sociedad que garanticen su inclusión social (Parra y Jesús, 2009). De esta manera, comienzan a surgir nuevos modelos pedagógicos y metodologías activas capaces de contribuir a la mejora de la preparación académica del alumnado, con el objetivo de adaptar estas nuevas metodologías de enseñanza-aprendizaje a las demandas de la sociedad (Chiva-Bartoll, Pallarés-Piquer, y Gil-Gómez, 2018).

En esta búsqueda, surge el Aprendizaje-Servicio (ApS) como un modelo formativo idóneo para responder a las necesidades actuales de la sociedad (Lough, 2018). Esta metodología está basada en los preceptos de John Dewey, quien tiene por objetivo conseguir una educación cooperativa, donde se integra trabajo, servicio y aprendizaje. El ApS tiene su origen en Norteamérica desde donde se ha expandido al resto del mundo, incluido España (Sotelino, 2015). Se trata de una metodología didáctica basada en el aprendizaje de conocimientos a la vez que se presta un servicio a la comunidad, para atender alguna necesidad presente en la misma (Bravo et al., 2020). Es una experiencia que combina la acción; en la cual, a través de una actividad de 
servicio a la comunidad, el alumnado aplica contenidos, desarrolla competencias y resuelve problemas reales, dentro de un marco académico (Capella, et al., 2015).

Hay evidencias que han manifestado innumerables beneficios (ej., contribución a los objetivos de desarrollo sostenible, conocimiento de los problemas sociales, etc.) de las experiencias formativas basadas en el ApS, lo que ha llevado a implementar esta metodología en diferentes ámbitos, etapas educativas y áreas de conocimiento (Puig, Batlle, Bosch, y Palos, 2007; Rodríguez-Gallego, 2014; Santos-Pastor et al., 2020; Tapia, 2010). En las aulas universitarias, cada vez están surgiendo nuevas propuestas de ApS con el objetivo de favorecer la formación de los estudiantes universitarios, mediante un aprendizaje más participativo y conectado con las demandas de la sociedad (Salam, Iskandar, Ibrahim, y Farooq, 2019). Concretamente, este tipo de experiencias son muy importantes en los estudiantes de Grado en Educación Primaria ya que pueden favorecer su posterior transferencia en sus aulas (López-Fernández, y Benítez-Porres, 2018). Dado que la actividad física y el deporte es un elemento promotor de salud y calidad de vida en las personas, se está comenzando a desarrollar experiencias de ApS en la universidad mediante este comportamiento saludable (Pérez-Ordaz et al., 2021; Santos-Pastor et al., 2020).

Además, desarrollar experiencias de $\mathrm{ApS}$ sobre promoción de hábitos saludables en jóvenes puede favorecer el aprendizaje de nuevos conocimientos relacionados con educación para la salud, contribuir a la participación activa del alumnado en su propio aprendizaje, estimular el empoderamiento de la comunidad para la práctica de actividad física y promoción de hábitos saludables, así como adquirir el sentido de la responsabilidad personal y cuidado del propio del cuerpo (Santos-Pastor et al., 2020). Así pues, investigaciones anteriores han demostrado que el ApS es una metodología válida para fomentar la actividad física en la sociedad y en la universidad (Pérez-Pueyo et al., 2019). Por ejemplo, un programa de ApS, basado en la promoción de actividad física y realizado desde la universidad, contribuyó al proceso de enseñanza-aprendizaje a la vez que se mejoraban comportamientos saludables (Pérez-Pueyo et al., 2019). Sin embargo, un número muy limitado de estudios en Educación Superior que han realizado experiencias de ApS, basadas en la promoción de comportamientos saludables, en centros educativos.

Por ello, en la presente experiencia, realizada desde las prácticas del Grado en Educación Primaria, se desarrolló un programa de promoción de la actividad física y otros hábitos 
relacionados con la salud, utilizando una metodología basada en el ApS, en niños de $3^{\circ}$ de Educación Primaria.

\section{Descripción de la experiencia/Objetivo}

Esta experiencia de ApS surge en un colegio de Educación Primaria de Cáceres. El equipo directivo, los maestros y las familias detectaron que los niños de Educación Primaria permanecían mucho tiempo sentados en los recreos, dedicaban mucho tiempo a las pantallas, no se alimentaban correctamente, etc. Por ello, el equipo directivo de dicho centro educativo expuso esta problemática a un alumno en prácticas del Grado de Maestro en Educación Primaria, buscando ayuda para acometer un proyecto de ApS. El alumnado en prácticas, junto a la ayuda de toda la comunidad educativa, fue el encargado de implementar este programa de ApS cuyo objetivo fue la promoción de actividad física y otros comportamientos relacionados con la salud como la reducción del tiempo de pantalla y la mejora de la higiene del sueño en niños de Educación Primaria. Para ello, se utilizaron las recomendaciones establecidas en estos tres comportamientos (Tremblay et al., 2016). Estas recomendaciones establecen que los niños deben realizar al menos 60 minutos diarios de actividad física de moderada a vigorosa intensidad, no exceder en más de 2 horas por día el tiempo recreativo dedicado a las pantallas (ej.: jugar a los videojuegos, ver la televisión, usar el teléfono móvil, ordenador y/o tabletas con una finalidad recreativa) y dormir entre 9 y 11 horas diarias.

Figura 1. Recomendaciones de actividad física, pantallas y sueño en niños.

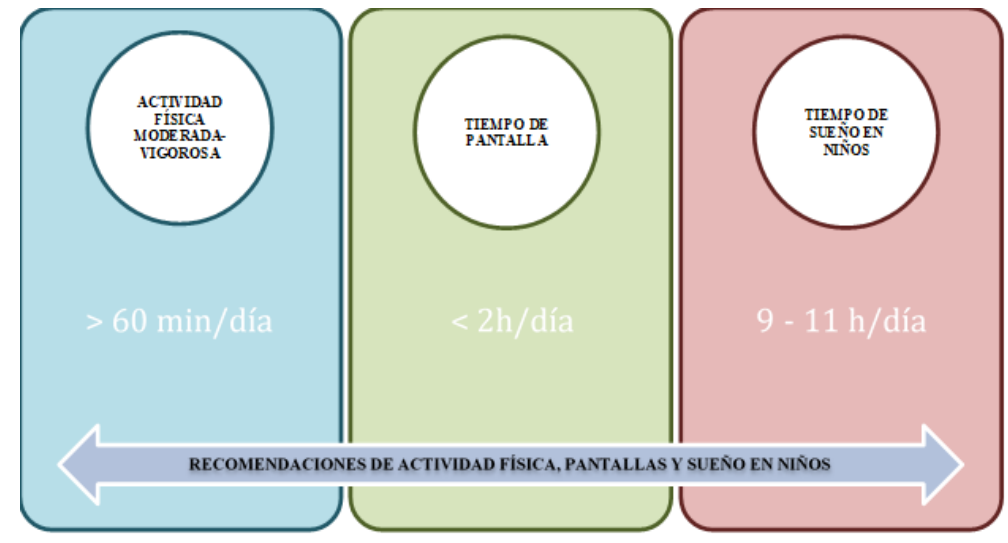




\section{Contexto}

Las prácticas en el Grado en Educación Primaria pueden ser un escenario ideal para el desarrollo de experiencias profesionales que le capaciten para desenvolverse en la sociedad del Siglo XXI. Durante este periodo, el alumnado tiene la oportunidad de poner en práctica los conocimientos adquiridos durante su formación, por lo que pueden experimentar distintas metodologías de enseñanzas y experimentar sus consecuencias.

Aprovechando este periodo de prácticas, en el presente trabajo se muestra una experiencia de ApS, durante el primer trimestre del curso escolar 2019-2020. Esta experiencia forma parte de las prácticas de un alumno del Grado en Educación Primaria en la Universidad de Extremadura.

En el proyecto de promoción de la actividad física y otros hábitos saludables participaron un total de 66 estudiantes, 33 niños y 33 niñas, pertenecientes al $3^{\circ}$ curso de Educación Primaria, cuyas edades oscilaron entre los 8 y los 9 años. La mayoría de los estudiantes eran de familias con un estatus social medio alto (Junta de Extremadura, 2018).

Tras una reunión inicial con las familias, el equipo directivo del centro educativo y los tutores de los alumnos, se decidió implementar el programa de promoción de la actividad física y hábitos saludables dentro del Plan de Acción Tutorial. La tutoría es un elemento dinamizador e integrador de toda acción educativa que se imparte solo en algunos centros educativos. Tiene una duración de 60 minutos, a lo largo de los cuáles el maestro dialoga e interactúa con su alumnado acerca de sus intereses, preocupaciones, problemas personales, académicos, etc. Además, algunos estudios han apuntado que la tutoría puede ser un espacio para trabajar contenidos vinculados con la educación para la salud y la promoción de hábitos saludables (Murillo et al., 2014; Sevil et al., 2019).

En Educación Primaria, estas horas de tutorías son impartidas por los tutores, quienes establecen el número de clases y la temporalización del Plan de Acción Tutorial. Por ello, se requirió su colaboración para llevar a cabo dicha experiencia de ApS. Aunque el presente programa se realizó únicamente en las tutorías, también se trató de implicar a las familias en el desarrollo de algunas acciones (ej., a través de reuniones al inicio, durante y al final del programa, mediante trípticos en los que se les detallaban algunas recomendaciones, a través de salidas y actividades 
con sus hijos, etc.). De igual modo, cabe destacar que, aunque el programa se llevó a cabo solo en tutorías, las acciones desarrolladas también se extendieron al recreo y a su tiempo de ocio.

\section{Aplicación y resultados}

Tras confirmar el problema a través de una evaluación diagnóstica en el que se evaluó el tiempo de actividad física, sueño y pantallas, se llevaron a cabo 10 clases, en el Plan de Acción Tutorial, sobre promoción de comportamientos saludables. El desarrollo de todas las clases que componen esta experiencia de ApS pueden consultarse en un libro elaborado para el profesorado de este centro educativo (Tapia-Serrano et al., 2020). Esto pretende favorecer la sostenibilidad de esta experiencia, una vez implementada por el alumno en prácticas. Como se ha mencionado anteriormente, en el proyecto participaron los diferentes agentes involucrados (familias, profesorado y alumnado) con el objetivo de adecuar esta experiencia de ApS a sus intereses y necesidades.

Tabla 1. Distribución de las clases impartidas durante el proyecto de ApS.

\begin{tabular}{|c|c|c|}
\hline $\begin{array}{l}\mathbf{N}^{0} \text { de } \\
\text { clase }\end{array}$ & Nombre de la clase & Objetivos \\
\hline 1 & Evaluar nuestro estilo de vida & Conocer comportamientos saludables y de riesgo \\
\hline 2 & ¿Qué comemos? & Identificar qué alimentos son saludables y cuáles no \\
\hline 3 & ¿Qué es el tiempo de pantalla? & Conocer los efectos nocivos del tiempo de pantalla excesivo \\
\hline 4 & $\begin{array}{l}\text { ¿Qué podemos hacer para llevar un } \\
\text { estilo de vida saludable? }\end{array}$ & Identificar acciones para adoptar hábitos saludables \\
\hline 5 & La actividad física & Conocer los beneficios y recomendaciones de actividad física \\
\hline 6 & Recreos divertidos & Identificar nuevas alternativas de ocio en el recreo \\
\hline 7 & Efectos nocivos del azúcar & Identificar los efectos negativos del exceso de azúcar \\
\hline 8 & $\begin{array}{l}\text { Niños saludables, familias } \\
\text { saludables }\end{array}$ & $\begin{array}{l}\text { Promover conocimientos y hábitos saludables en las familias y } \\
\text { su comunidad }\end{array}$ \\
\hline 9 & Demostramos nuestro aprendizaje & $\begin{array}{l}\text { Identificar los beneficios, riesgos y recomendaciones de } \\
\text { actividad física, sueño y pantallas }\end{array}$ \\
\hline 10 & ¿Han mejorado nuestros hábitos? & $\begin{array}{l}\text { Evaluar los hábitos saludables después de la experiencia } \\
\text { didáctica }\end{array}$ \\
\hline
\end{tabular}


En muchas ocasiones, los tutores no saben qué tipo de contenidos y/o actividades desarrollar con su alumnado en la tutoría. Por tanto, nuestra experiencia educativa, refleja una posibilidad de aprovechar este espacio educativo, como es la tutoría en Educación Primaria, para promover los hábitos saludables de los jóvenes. Producto de nuestra experiencia educativa, son varias las aplicaciones prácticas que podemos mencionar:

1. Carácter interdisciplinar: se han desarrollado contenidos comunes a otras áreas como como la Educación Física y/o Ciencias Naturales. Los contenidos desarrollados permiten establecer conexiones con elementos curriculares de otras asignaturas, lo cuál puede ser un elemento positivo a la hora de utilizar la tutoría como un espacio de promoción de hábitos saludables. Incluso, puede ser un proyecto interdisciplinar que pueda desarrollarse a nivel de centro, implicando así a todos los profesores del centro educativo.

2. Adaptarse a otros cursos: aunque se ha desarrollado con niños de $3^{\circ}$ de Educación Primaria, esta experiencia puede adaptarse a otras edades. Para ello, es importante conocer los elementos curriculares del currículum para el curso en el que se pretende desarrollar. Además, es conveniente también conocer el nivel madurativo de los alumnos y, acorde a ello, establecer actividades adaptadas a su nivel de desarrollo cognitivo.

3. Implicar a las familias: se puede fomentar aún más la participación de las familias a través de convivencias o talleres donde los padres deban participar con sus hijos/as. Una actividad que resultaría enriquecedora y no se pudo llevar a cabo por motivos logísticos, sería un taller de cocina de alimentos saludables, en el que participasen los padres con sus hijos. En este taller se podrían elaborar diferentes comidas saludables, de manera que los propios padres aprendan diferentes técnicas culinarias consideradas saludables para, después, poderlas elaborar en casa.

4. Evaluación del programa: es recomendable evaluar los hábitos saludables al inicio y final del programa, a través de cuestionarios válidos y fiables, para conocer los efectos de la experiencia. En este proyecto se llevaron a cabo informes al centro educativo con los hábitos del alumnado para que todos los agentes educativos fuesen conscientes de los cambios provocados por la intervención. Sensibilizar a la comunidad educativa y ofrecerle cuestionarios para evaluar estos hábitos saludables, así como herramientas didácticas de intervención, es fundamental para mejorar la sostenibilidad de estos programas.

5. Flexibilidad: Es conveniente también resaltar la flexibilidad con la que se desarrolló la experiencia educativa. Es importante que el alumnado pueda verbalizar sus intereses y 
preferencias para adecuar los contenidos a desarrollar. Así pues, involucrar al alumnado en el diseño de las actividades o que sean ellos quienes propongan los contenidos a desarrollar puede ser una estrategia eficaz para aumentar la participación en las actividades.

\section{Conclusiones}

Dado que los niños pasan la mayor parte del día en el colegio, cada vez hay más evidencias de que la escuela es el lugar más idóneo para promocionar hábitos saludables. Mediante esta experiencia de $\mathrm{ApS}$, el alumnado no solo mejoró la adopción de algunos comportamientos saludables, sino que también el profesorado y las familias aprendieron diferentes estrategias de educación para la salud. Todos los participantes y agentes de la comunidad educativa mostraron una gran satisfacción del proyecto llevado a cabo. Además, es importante resaltar que la promoción de los hábitos relacionados con la salud sería conveniente desarrollarla en todos los cursos de Educación Primaria. Por ello, para el futuro, sería interesante desarrollar este proyecto en todo el centro educativo, involucrando a todos los cursos y profesores del colegio. Para ello, sería adecuado que cada profesor realizase las adaptaciones necesarias en función de los contenidos curriculares para cada curso, edad e interés del alumnado.

Finalmente, tras la experiencia educativa, se puede concluir que las experiencias de ApS desde las prácticas de Educación Primaria pueden ser un excelente vehículo para el aprendizaje del alumnado universitario a la vez que se presta un servicio a la comunidad. Dentro de los Objetivos de Desarrollo Sostenible, en este proyecto se trabajaron el Objetivo de Desarrollo Sostenible -3: Salud y bienestar y Objetivo de Desarrollo Sostenible -4: Educación de calidad.

Financiación o apoyos: Los autores desean agradecer a las escuelas, a los niños y a sus padres que se ofrecieron generosamente a participar en este estudio. También agradecemos a todos los miembros de personal que participaron en el trabajo de campo por su esfuerzo y gran entusiasmo.

\section{Referencias}

Capella, P. C., Gil -Gómez, J., Martí-Puig, Manuel, \& Chiva-Bartoll, Ó. (2015). Estudio de caso múltiple con historias de vida en el grado de educación infantil: aprendizaje-servicio en la 
didáctica de la educación física. Profesorado. Revista de Currículum y Formación de Profesorado, 19(1), 334-348.

Chiva-Bartoll, O., Pallarés-Piquer, M., \& Gil-Gómez, J. (2018). Aprendizaje-servicio y mejora de la Personalidad Eficaz en futuros docentes de Educación Física. Revista Complutense de Educación, 29(1), 181-197. http://dx.doi.org/10.5209/RCED.52164

Domínguez, R. (2005). Nuevas Tecnologías y Educación en el siglo XXI. Revista científica electrónica de Educación y Comunicación en la Sociedad del Conocimiento, 4, 212-230. http://dx.doi.org/10.5209/RCED.52164

Junta de Extremadura, 2018. Extremadura Stadistics Institute. Portal Ciudad. URL https://ciudadano.gobex.es/web/ieex

López-Fernández, I., \& Benítez-Porres, J. (2018). El Aprendizaje Servicio en la Universidad: una experiencia en el marco de una asignatura del Grado en Educación Primaria. REDU. $\begin{array}{llll}\text { Revista de Docencia } \quad \text { Universitaria, } & \text { 16(2), }\end{array}$ https://doi.org/10.4995/redu.2018.9127

Lough, B.J. (2018). Global service-learning in institutions of higher education: concerns from a community practice. Globalisation, Societies and Education, 16(1), 66-77. https://doi.org/10.1080/14767724.2017.1356705

Bravo, L. E., Marcos-Merino, J. M., Borrego, E. C., \& Gallego, R. E. (2021). Análisis de proyectos de aprendizaje-servicio diseñados por maestros en formación inicial. Campo Abierto. Revista de Educación, 40(1), 5-19. https://doi.org/10.17398/0213-9529.40.1.5

Murillo, B., García-Bengoechea, E., Julián, J. A., \& Generelo, E. (2014). Empowering adolescents to be physically active: Three-year results of the Sigue la Huella intervention. Preventive Medicine, 66, 6-11. https://doi.org/10.1016/J.YPMED.2014.04.023

Parra, L. \& Jesús, D. (2009). Las necesidades educativas especiales como necesidades básicas. Una reflexión sobre la inclusión educativa. Revista Latinoamericana de Estudios Educativos, 39(3-4), 201-223. 
Pérez-Pueyo, Á., Hortigüela-Alcalá, D., González-Calvo, G., \& Fernández-Río, F. J. (2019). Muévete conmigo, un proyecto de aprendizaje servicio en el contexto de la educación física, la actividad física y el deporte. Publicaciones: Facultad de Educación y Humanidades del Campus de Melilla, 49(4), 181-196. doi:10.30827/publicaciones.v49i4.11735

Puig, J.M., Batlle, R., Bosch, C., \& Palos, J. (2007). Aprendizaje Servicio. Educar para la ciudadanía. Editorial Octaedro.

Pérez-Ordás, R., Nuviala, A., Grao-Cruces, A., \& Fernández-Martínez, A. Implementing ServiceLearning Programs in Physical Education; Teacher Education as Teaching and Learning Models for All the Agents Involved: A Systematic Review. Int. J. Environ. Res. Public Health 2021, 18, 669. https://doi.org/10.3390/ijerph18020669

Rodríguez-Gallego, M.R. (2014). El Aprendizaje-Servicio como estrategia metodológica en la Universidad. Revista Complutense de Educación, 25(1), 95-113. https://doi.org/10.5209/rev_RCE

Salam, M., Iskandar, D. N. A., Ibrahim, D. H. A., \& Farooq, M. S. (2019). Service learning in higher education: A systematic literature review. Asia Pacific Education Review, 20(4), 573-593. https://doi.org/10.1007/s12564-019-09580-6

Santos-Pastor, M., Cañadas, L., \& Martínez, L. F. (2020). Limitaciones del aprendizaje-servicio en la formación inicial en actividad físico-deportiva. Retos: Nuevas Tendencias en Educación Física, Deporte y Recreación, 37, 509-517.

Sevil-Serrano, J., García-González, L., Abós, Á., Generelo, E., \& Aibar, A. (2019). Can high schools be an effective setting to promote healthy lifestyles? Effects of a multiple behavior change intervention in adolescents. Journal of Adolescent Health, 64, 478-486. https://doi.org/10.1016/j.jadohealth.2018.09.027

Sotelino, A. (2015). A aprendizaxe-servizo en perspectiva. John Dewey como referente histórico. Sarmiento. Anuario Galego de Historia da Educación, 18, 145-162. https://doi.org/10.17979/srgphe.2015.18-19.0.4048 
Tapia, N. (2010). La propuesta pedagógica del Aprendizaje-Servicio: Una perspectiva latinoamericana. Tzhoecoen, 5, 23-43.

Tapia-Serrano, M. A., Sevil-Serrano, J., Sánchez-Oliva, D., Vaquero-Solís, M., y Sánchez-Miguel, P. A. (2020). Promoción de comportamientos saludables en niños y niñas de Educación Primaria desde el plan de acción tutorial. Wanceulen SL.

Tremblay, M. S., Carson, V., Chaput, J. P., Connor Gorber, S., Dinh, T., Duggan, M., ... \& Zehr, L. (2016). Canadian 24-hour movement guidelines for children and youth: an integration of physical activity, sedentary behaviour, and sleep. Applied Physiology, Nutrition, and Metabolism, 41(6), 311-327. https://doi.org/10.1139 


\title{
Metodología Aprendizaje Servicio Virtual y Competencias de Tecnologías de la Información, Aprendizaje y la Comunicación en Tiempos de Covid y Colegio en Casa. Orientación a los Alumnos/as Universitarios: Experiencia Didáctica
}

\author{
Raquel Pérez Ordás \\ Annabella Salamanca Villate \\ Ester Ayllon Negrillo \\ Universidad de Zaragoza
}

Palabras clave: Innovación docente, evaluación educativa, adaptación curricular, E-learning, colaboración.

\section{Introducción}

El Aprendizaje Servicio (ApS) es un recurso educativo que combina procesos de aprendizaje y de servicio a la comunidad en un solo proyecto estructurado, donde los participantes (en este caso alumnado de la Facultad de Ciencias Humanas y de la Educación de Huesca), aprenden al trabajar en necesidades reales del entorno (en este caso con colegios cercanos) con la finalidad de ayudar o contribuir. El proyecto que presentamos se desarrolla desde una asignatura principalmente vinculada con las Tecnologías de la Información y la Comunicación y Tecnologías del Aprendizaje y la Comunicación (TIC/TAC) y la elaboración de recursos didácticos. La asignatura es "La educación en la sociedad del conocimiento" y es impartida en el Graduado en Magisterio en Educación Primaria, en el primer curso. Se trata de una asignatura de formación básica, obligatoria de 6 créditos, impartida en las Facultades de Educación en la Universidad de Zaragoza.

En el trabajo que se presenta se utilizó la metodología ApS (Martínez, 2010). Gracias a la implicación activa del alumnado en el proceso de aprendizaje, se logra mejorar los resultados educativos y resolver problemas del entorno social (MacPhail y Sohun, 2019; Marttinen, Daum, 
Banville y Fredrick, 2020; Peralta, Marvell y Cotton, 2020; Santos-Pastor, Martínez-Muñoz y Cañadas, 2019).

Desde este proyecto se organizan unas propuestas de ApS donde invitamos a colegios de primaria a participar. Los alumnos/as se ponen en contacto con los centros educativos, valoran sus necesidades y les elaboran materiales relacionados con las TIC/TAC que puedan necesitar para sus aulas, sus espacios o sus proyectos educativos. Es un proyecto que se lleva desarrollando por el profesorado de esta asignatura desde hace tiempo. Sin embargo, en esta ocasión, la oportunidad de aprendizaje fue diferente, al desarrollarse el proyecto en situación de confinamiento (Covid19), con la escolarización trasladada a las casas y donde toda la comunicación y recursos utilizados por el profesorado y alumnado, ha precisado de las nuevas tecnologías. Algunos autores ya venían aportando esta idea de unir las tecnologías digitales con proyectos de ApS, como Escofet (2020) o desarrollando proyectos de innovación sobre ApS en el ámbito virtual donde el objetivo era adaptar el ApS a la modalidad "a distancia” (Cáceres-Piñaloza, 2020; García-Gutiérrez, Ruiz-Corbella y Del Pozo, 2016; Cotino, 2020).

En este caso, se ofreció a los centros educativos la posibilidad de elaborar material que pudiera servirles para impartir su docencia online o aportar recursos a su alumnado. De esta manera se facilitó la preparación de: Presentaciones interactivas, diseño de pósteres e infografías, mapas conceptuales y mentales, gamificación, ludificación y actividades de investigación, creación de blogs, libros interactivos u otros recursos multimedia, recursos de programación y software constructivista, preparación de sesiones para el alumnado o producción audiovisual stop motion, audacity, creación/grabación de audios o videos, preparación/adaptación de materiales para favorecer la accesibilidad de la comunicación con pictogramas, preparación de sesiones, materiales, gymkanas, actividades con QR o realidad virtual, entre otros y además propusimos (si era posible), que la temática tuviera que ver con el bienestar en general (físico, social, emocional y mental).

Con este proyecto nos planteamos las siguientes hipótesis:

- Se consiguen mejoras en las actitudes del futuro maestro con la utilización de las TIC/TAC como recurso educativo, al aplicar la metodología Aprendizaje servicio; 
- Se produce un beneficio para los agentes sociales (colegios, profesores, alumnos/as de las instituciones educativas que participen);

- Se encuentran propuestas de mejora para los proyectos aplicados (tras análisis de los propios programas).

\section{Descripción de la experiencia/Objetivo}

Objetivos del proyecto:

El planteamiento del desarrollo de este proyecto conecta directamente con el objetivo de desarrollo sostenible: oportunidades de aprendizaje (objetivo 4 ODS: Educación de Calidad). Además, los objetivos específicos de este proyecto para nuestro alumnado fueron:

- Hacer partícipe al alumno/a de su propio aprendizaje de manera integral, y favorecer su motivación a través del desarrollo de un proyecto basado en el desarrollo de la metodología Aprendizaje Servicio.

- Realizar un trabajo en equipo consciente y responsable, con reparto de roles, seguimiento del proceso y heteroevaluación.

- Poner en práctica competencias profesionales reales con la aplicación del proyecto en centros educativos reales.

- Trasladar los aprendizajes adquiridos en la asignatura a situaciones reales.

- Desarrollar un trabajo de colaboración y solidaridad elaborando recursos para los centros educativos.

- Y como objetivos transversales el proyecto pretende:

- Buscar la motivación del alumno/a hacia el propio aprendizaje y desarrollo profesional, partiendo del contacto real con centros educativos.

- Buscar la motivación del alumno/a hacia acciones de colaboración y trabajo en equipo.

- Como objetivos propios de la asignatura, se desarrollaron los siguientes:

- Elaborar material didáctico que contemple la utilización integrada de las TIC/TAC.

- Dominar la búsqueda y selección de recursos didácticos en Internet.

- Saber utilizar herramientas de TIC/TAC.

Contribución a las competencias del alumnado: 
Respecto a la contribución a las competencias del alumnado de Ciencias de la Educación, con el proyecto ApS TIC/TAC, son muchas las que se desarrollan, dado el carácter del proyecto que aúna, los beneficios implícitos de la metodología ApS, del trabajo en equipo, de la utilización de nuevas tecnologías y recursos educativos y el contacto real con los centros educativos (principalmente de infantil y primaria). No obstante, destacamos las competencias que consideramos que más específicamente se abordan (Guía didáctica “La educación en la Sociedad del Conocimiento", Curso 2020-2021):

Competencias generales:

- CG7 - Colaborar con los distintos sectores de la comunidad educativa y del entorno social. Asumir la dimensión educadora de la función docente y fomentar la educación democrática para una ciudadanía activa y comprometida, atendiendo especialmente a la promoción de los valores de la dignidad humana, la igualdad entre hombres y mujeres, la libertad y la justicia.

- CG10 - Reflexionar sobre las prácticas de aula para innovar y mejorar la labor docente. Adquirir hábitos y destrezas para el aprendizaje autónomo y cooperativo y la promoción entre sus futuros alumnos/as. Asumir la necesidad del desarrollo profesional continuo mediante la reflexión, la autoevaluación y la investigación sobre la propia práctica.

- CG11 - Conocer y aplicar en las aulas las tecnologías de la información y de la comunicación como valor añadido a las actividades de enseñanza-aprendizaje guiado y autónomo. Discernir selectivamente la información audiovisual que contribuya a los aprendizajes, a la formación cívica y a la riqueza cultural.

- Competencias transversales:

- CT 5 - Implicar al alumnado en su aprendizaje y en su trabajo.

- Competencias específicas:

- CE 13 - Promover el trabajo cooperativo y el trabajo y esfuerzo individuales.

- CE 17 - Conocer y aplicar experiencias innovadoras en educación primaria. 


\section{Aplicación y resultados}

El procedimiento para el desarrollo del proyecto, se estructuró en seis pasos que se describen a continuación.

1. Establecer relaciones con el colegio (profesor implicado)

2. Esbozar y planificar el proyecto

3. Presentar al centro la propuesta

4. Preparar el proyecto

5. Aplicación de la propuesta en el centro

6. Evaluación multifocal

En primer lugar, se procedió a contactar con los centros educativos, explicarles el proyecto y ponernos a su disposición para colaborar con ellos en la elaboración de materiales para el uso en sus aulas o centros. Se les ofrecía entre otras posibilidades poder elaborar los siguientes recursos:

- Presentaciones interactivas: powtoon, genial.ly...

- Diseño de pósteres e infografías: canva, piktochart, easel.ly...

- Gamificación, ludificación y actividades de investigación: WebQuest, mentimenter, plickers, kahoot...

- Creación de blogs, libros interactivos u otros recursos multimedia u otros.

- Creación artística: preparación de sesiones para el alumnado o producción audiovisual stop motion, audacity, creación/grabación de audios o videos.

- Materiales ARASAAC: preparación/adaptación de materiales para favorecer la accesibilidad de la comunicación con pictogramas.

- QR y Realidad virtual: preparación de sesiones, materiales, gymkanas, actividades.

- Otros: EJ. (curso de formación en algún programa TIC/TAC)

El trabajo de ApS siguió un proceso sistematizado, para planificar el proyecto, esbozarlo y evaluarlo (Battle, Puig, Bosch y Palos, 2007; Campos, 2017). Las fases fueron las que se muestran en la Tabla 1. 
Tabla 1. Etapas y Fases desarrolladas en el proyecto ApS-TIC/TAC.

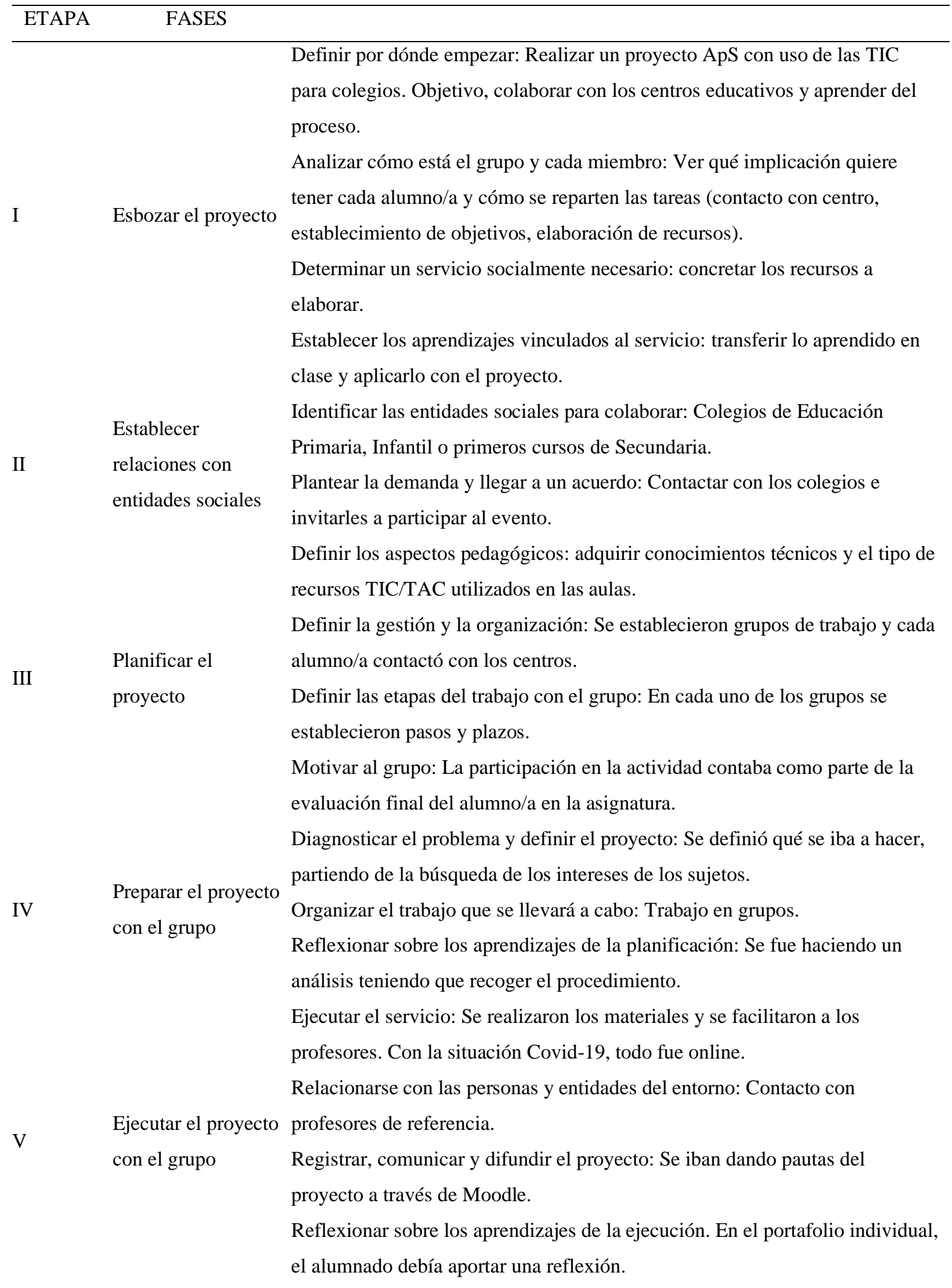


VI

proyecto con el grupo

VII

Evaluación
Evaluar los resultados del servicio: El profesor del centro educativo, aportaba una evaluación del proyecto-alumnado.

Evaluar el conjunto de los aprendizajes adquiridos: En el portafolio individual, el alumnado debía aportar una reflexión.

Proyectar perspectivas de futuro: Se plantearon por parte del alumnado propuestas de mejora para próximos eventos.

Celebrar la experiencia compartida: No se realizó debido a la situación covid19.

Evaluar el grupo y cada chico/chica: La evaluación partió de la implicación en el proyecto por parte del profesor universitario y del centro educativo.

Evaluar el trabajo en red con las entidades: El profesor del centro.

multifocal
Evaluar la experiencia en tanto que proyecto ApS: Se propusieron puntos de mejora e inconvenientes.

Autoevaluarse como educador en el proceso vivido: Reflexionaron sobre la participación individual de cada uno en el proceso.

Ejemplo de proyecto desarrollado por una alumna en el curso 2019-2020 en modalidad online:

A modo de ejemplo, exponemos el proyecto de una de las alumnas, que elaboró diferentes tipos de actividades TIC/TAC con diversos programas y aplicaciones para más de un área de aprendizaje y con objeto de desarrollar diversas competencias con el alumnado.

1. Kahoot de Ciencias Naturales (plantas y animales): Este Kahoot constaba de 25 preguntas que servían como repaso de animales vertebrados-invertebrados, tipos tanto de plantas como de animales, lo que come cada animal... (Aplicación Kahoot) CIENCIAS NATURALES.

2. Quizz de Ciencias Naturales sobre el cuerpo humano: Gamificación de una ronda de preguntas ya que ellos mismos podían clicar en las preguntas, si acertaban pasaban a la siguiente y si fallaban volvían a la misma pregunta, lo que les permitía rectificar y aprender cual era la correcta. Eran un total de 15 preguntas donde se repasaba los diferentes huesos, músculos, aparatos, órganos de los sentidos... (Aplicación Genial.ly) CIENCIAS NATURALES (Figura 1).

\section{Figura 1. Ejemplo de Quizz de Ciencias Naturales.}



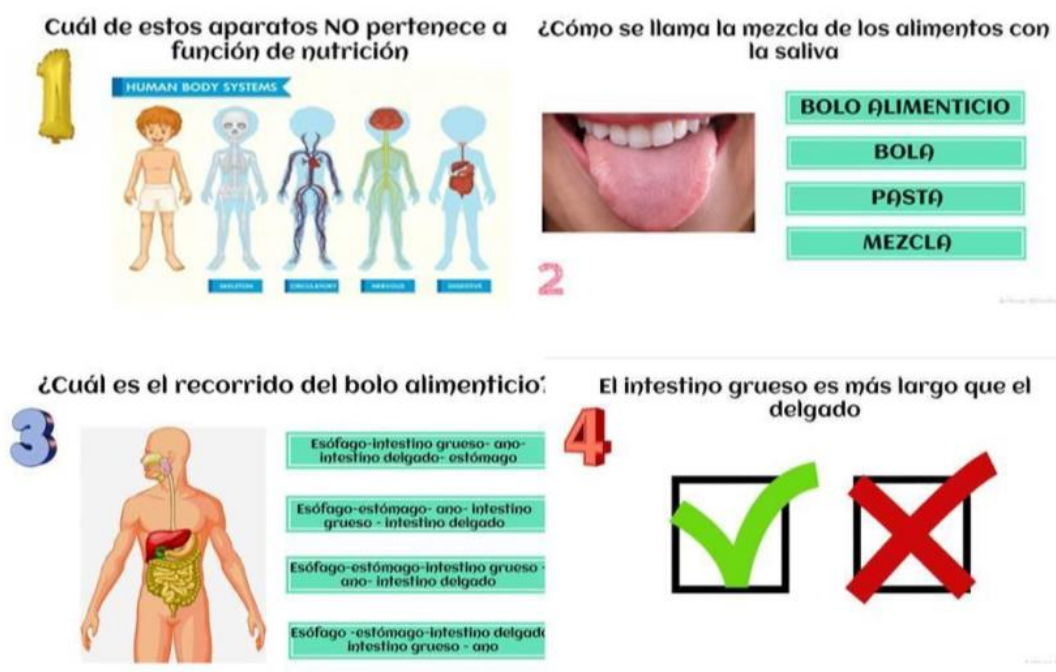

3. Kahoot de Ciencias Sociales sobre la Atmósfera y el agua: Destinadas a un repaso sobre los diferentes instrumentos de medida, los ríos, las corrientes, los mares, la capa de ozono, factores atmosféricos... (Aplicación Kahoot) CIENCIAS SOCIALES.

4. Scape Room de Matemáticas: Gamificación, podían jugar dentro de cada pantalla, pensando y resolviendo cada problema que se les presentaba para poder descifrar el código del candado que les pedía. Al final debían enviar a su profesora al Classdojo que tenían en su curso, la respuesta para ver quien había hecho los problemas bien o ver dónde habían fallado. (Aplicación Genial.ly) MATEMÁTICAS.

5. Visual Thinking de Matemáticas: Esta herramienta servía para exponer unas ideas y conceptos de manera atractiva y esquemática. En él se explica brevemente la educación financiera con sus diferentes puntos. (Aplicación Canva) MATEMÁTICAS.

6. Explicación de los demostrativos dentro del área de Lengua. (Aplicación Power Point) LENGUA.

La mayoría de recursos sirvieron para repasar contenidos abordados en clase por los niños/as y recoger información para poder evaluar el proceso de aprendizaje del alumnado. Las actividades y recursos englobaban un repaso de varios criterios del currículo de diferentes áreas. La alumna de la Facultad de Educación desarrolló los recursos y estos fueron facilitados al docente 
del centro educativo, quien los utilizó de manera online con sus alumnos/as en esa situación de confinamiento vivido.

La alumna realizó también una autoevaluación, ya que la consideraba clave para su propia formación y valoró positivamente:

- Abarcar las necesidades que manifiesta la tutora.

- Crear contenido dinámico con apps innovadoras.

- Utilizar diferentes tipos de recursos en más de una materia.

- Hacer un ApS de más de un área.

\section{Resultados y conclusiones}

El proyecto resultó y está resultando positivo sobre todo para la formación del alumnado universitario. Las fases del proyecto implicaron al alumnado en todo el proceso. Esto llevó implícita la adquisición de objetivos y competencias propias de la asignatura universitaria, pero también al trabajar en equipo, tomar decisiones, autoliderazgo, resolución de problemas, comunicación, etc., se adquirieron otro tipo de competencias y habilidades. Analizando si las hipótesis planteadas se han cumplido, aun sin haber terminado la investigación, sí que recogemos feedback positivo del alumnado en cuanto a las actitudes hacia las TIC/TAC, al poder ver su uso en el contexto educativo real. La evaluación que el profesorado realiza sobre las propuestas de los alumnos/as también indica interés, beneficio y satisfacción. Y en último lugar, tras las reflexiones recogidas consideramos que debemos reforzar propuestas de mejora para los proyectos aplicados.

Concluyendo podemos decir que la metodología ApS es muy enriquecedora para la formación del alumnado. Consideramos también interesante dar difusión a nuestro proyecto y los resultados obtenidos. Creemos que la experiencia mejora tanto la implicación de la Facultad con los centros educativos, como la implicación del alumnado en el proyecto y con la realidad docente y la motivación. 


\section{Referencias}

Battle, R., Puig, J., Bosch, C. y Palos, J. (2007). Aprendizaje Servicio. Educar para la ciudadanía. Octaedro.

Cáceres-Piñaloza, K. F. (2020). Educación virtual: Creando espacios afectivos, de convivencia y aprendizaje en tiempos de COVID-19. CienciAmérica, 9(2), 38-44. http://dx.doi.org/10.33210/ca.v9i2.284

Campos, A. (2017). Enfoques de enseñanza basados en el aprendizaje. Ediciones de la U.

Cotino, L. (2020). La enseñanza digital en serio y el derecho a la educación en tiempos del coronavirus. Revista de educación y derecho. Education and law review, 21, 1-29 https://doi.org/10.1344/REYD2020.21.31283

Escofet, A. (2020). Aprendizaje-servicio y tecnologías digitales: ¿una relación posible? RIED. Revista Iberoamericana de Educación a Distancia, 23(1), 169-182. http://dx.doi.org/10.5944/ried.23.1.24680

García-Gutiérrez, J., Ruiz-Corbella, M. \& Del Pozo, A. (2016). Cuando la comunidad se expande: ciudadanía global y aprendizaje-servicio virtual (APSV). Educación y Diversidad, 10(1), 63-75. https://www.researchgate.net/profile/Juan-GarciaGutierrez/publication/321383105 CUANDO LA COMUNIDAD SE EXPANDE CIU DADANIA GLOBAL Y APRENDIZAJESERVICIO_VIRTUAL/links/5a3a1648458515889d2bd4cf/CUANDO-LACOMUNIDAD-SE-EXPANDE-CIUDADANIA-GLOBAL-Y-APRENDIZAJE-

Guía didáctica "La educación en la Sociedad del Conocimiento", Curso 2020-2021 (s.f.). $\begin{array}{lllllll}\text { Recuperado } & \text { el } & 20 & \text { de } & \text { abril } & \text { del }\end{array}$ https://sia.unizar.es/documentos/doa/guiadocente/2020/26605_es.pdf

MacPhail, A. y Sohun, R. (2019). Interrogating the enactment of a service-learning course in a physical education teacher education programme: Less is more? European Physical Education Review, 25(3), 876-892. https://doi.org/10.1177/1356336X18783922 
Martínez, M. (2010). Aprendizaje servicio y responsabilidad social de las universidades. Ediciones Octaedro.

Marttinen, R., Daum, D. N., Banville, D., \& Fredrick, R. N. (2020). Pre-service teachers learning through service-learning in a low SES school. Physical Education and Sport Pedagogy, 25(1), 1-15. https://doi.org/10.1080/17408989.2019.1670153

Peralta, L., Marvell, C. \& Cotton, W. (2020). A Sustainable Service-Learning Program Embedded in PETE: Examining the Short-Term Influence on Preservice Teacher Outcomes. Journal of Teaching in Physical Education, 1(aop), 1-10. https://doi.org/10.1123/jtpe.2019-0055

Santos-Pastor, M.L., Martínez-Muñoz, F. y Cañadas, L. (2019). La evaluación formativa en el aprendizaje servicio. Una experiencia en actividades físicas en el Medio Natural. Revista de Innovación y Buenas Prácticas Docentes, 8, 110-118. 


\title{
Didáctica y aplicación de los ODS en el ámbito universitario. La experiencia de la Universidad de Zaragoza para la Facultad de Ciencias Humanas y de la Educación
}

\author{
Annabella Salamanca Villate \\ Azucena Lozano Roy \\ José Antonio, Julián Clemente \\ Universidad de Zaragoza
}

Palabras clave: Facultad, Aprendizaje Servicio, Sostenibilidad, Estrategias

\section{Introducción}

Es sabido que la educación superior es un componente clave en el cumplimiento de los Objetivos de Desarrollo Sostenible (ODS) de las Naciones Unidas. Recientemente, en la convención realizada en Roma (2020), para analizar los logros de la Declaración de Bolonia, se actualizó el compromiso de desarrollar un Espacio Europeo de Educación Superior (EEES) más inclusivo, innovador, interconectado y resiliente (López, Ollo y Simón, 2020). Un compromiso, que está vinculado con los ODS, que constituyen importantes desafíos sociales, económicos, y medioambientales. Para que la sociedad pueda afrontar estos desafíos, son esenciales, la educación, la investigación, la innovación y el liderazgo (SDSN, 2017), componentes todos del ámbito universitario que se consolida como una piedra angular para alcanzar la Agenda 2030.

Las instituciones de educación superior en su labor de generación y difusión del conocimiento tienen la posibilidad de promover cambios importantes relacionados con la sostenibilidad y bienestar, a través de sus variadas actividades educativas y de aprendizaje, así como de investigación con impacto social en la comunidad. En concordancia con estas características y la posibilidad de inducir cambios, la Conferencia de Rectores de las Universidades Españolas (CRUE) y la Universidad de Zaragoza (UZ), con sus diferentes centros -incluida la Facultad de Ciencias Humanas y de la Educación (FCHE)- han asumido la importante labor de 
integrar los ODS en la cotidianidad de sus actividades vinculadas al territorio y comunidad a la que pertenecen.

Nuestra sociedad se caracteriza por rápidos cambios en el conocimiento y la información (Ruiz, 2010), lo que implica un aprendizaje para el cambio que se centre, no en la educación para el desarrollo sostenible (EDS) (UNESCO, 2009), sino en la educación como desarrollo sostenible (Aramburuzabala, García-Peinado y Elvias, 2013). Una educación que prepare profesionales y ciudadanos unidos en una misión global con visión de futuro, preparados además en competencias de comunicación verbal, adaptación, emprendimiento, resiliencia y cooperación.

En el ámbito académico de la educación superior a nivel europeo, nacional y autonómico, la Facultad de Ciencias Humanas y de la Educación (FCHE) es un centro de la Universidad de Zaragoza (UZ) localizado en Huesca, que implementa y desarrolla su modelo formativo con metodologías acordes con la sostenibilidad, como el aprendizaje-servicio (ApS), una metodología que enseña a los estudiantes a cuestionar la sociedad desde un punto de vista crítico, que tiene presentes el desarrollo sostenible y el cambio social (Baldwin, Buchanan y Rudisill, 2007; Dominici, 2018) y que además brinda los conocimientos, habilidades y actitudes que preparan al estudiante para escenarios reales (Sagardia, Urdin, y Fernández, 2017).

\section{Descripción de la experiencia/Objetivo}

El presente trabajo, forma parte de la propuesta de implementación de los ODS en la FCHE, con un planteamiento en constante construcción, que está abierto al mejoramiento por parte de todos y cada uno de los implicados.

La propuesta se estructura teniendo en cuenta las singularidades de la FCHE como su tamaño, su contexto, su misión y visión, sus fortalezas en investigación y formación, su disponibilidad y posibilidades, sus valores, sus prioridades y las necesidades del entorno local en el que desarrolla su actividad. Esta iniciativa se ha enriquecido con las contribuciones y avances de otros centros de la Universidad de Zaragoza, de otras universidades y otras organizaciones con las que nuestra institución comparte alianzas y que han iniciado el proceso de implementación de los ODS en otro momento. 
El dinamismo de la FCHE, su calidad en el recurso humano, su buen hacer y experiencia, así como la intencionalidad bien reflexionada, son los cimientos que sustentan esta propuesta.

\section{Objetivos}

El objetivo general es incorporar y vivir los Objetivos de Desarrollo Sostenible, a partir de una estrategia multinivel que permita una formación en sostenibilidad.

Los objetivos específicos son:

- Proveer a los estudiantes del conocimiento, experiencias, habilidades y la motivación para entender y abordar los ODS como una filosofía de vida individual y colectiva.

- Registrar y actualizar las líneas de trabajo en ODS, que ha venido realizando la facultad, tanto en investigación, como en sensibilización y transferencia social.

- Facilitar el diálogo y la acción entre áreas de conocimiento para iniciar y continuar sinergias y colaboraciones que impulsen la implementación de los ODS.

- Acoger y propiciar iniciativas de todo el personal del centro para visibilizar y vivenciar los ODS en el día a día, mejorando y naturalizando los espacios.

\section{Aplicación y Resultados}

La estrategia de implementación de los ODS para la FCHE, contempla cuatro niveles/aspectos relacionados con la educación, la investigación, la comunicación y el mejoramiento y optimización de espacios. Estos niveles se concretan en acciones que se conectan con las metas más afines de los ODS impulsados por la universidad. La escala temporal de las acciones a desarrollar abarca:

- el trabajo que ha venido realizando la FCHE a lo largo del tiempo (el antes).

- la visibilidad y conciencia de los ODS en el día a día de la FCHE de ahora en adelante (el presente y el futuro).

- la proyección de acciones sostenibles en el tiempo para alcanzar los máximos logros posibles de cara a la Agenda 2030. 
La propuesta parte de las líneas de trabajo que desarrolla la Facultad como centro educativo que incorpora, consolida y visibiliza los ODS en su quehacer. Estas líneas de trabajo se presentan en la tabla 1. Posteriormente, cada línea de trabajo se relaciona con las metas más afines de cada uno de los ODS y con propuestas concretas que constituyen las acciones y estrategias de la FCHE hacia la Agenda 2030 (tabla 2).

Tabla 1. Líneas de trabajo de la FCHE para la implementación de los ODS. A cada línea se le asigna un código que será utilizado en la tabla 2.

\footnotetext{
A.a Grados en Magisterio en Educación Infantil y Primaria.

A.b Máster Universitario en Profesorado de Educación Física para E.S.O., Bachillerato, Formación Profesional y Enseñanzas Deportivas.

A.c Máster Universitario en Estudios Avanzados sobre el Lenguaje, la Comunicación y sus Patologías.

A.d Grupos de investigación.

A.e Líneas de investigación de TFG’s y TFM.

A.f Organización, desarrollo y difusión de eventos (Conferencias, Congresos, Jornadas...)

A.g La gestión del centro en sus diferentes aspectos: servicios universitarios, instalaciones, adquisiciones, recursos, humanos y gestión académica y de estudiantes.
}

Tabla 2. Líneas de trabajo y propuestas de acción de la FCHE para la implementación de los ODS de la Agenda 2030.

\begin{tabular}{ll}
\hline Metas de los ODS & \multicolumn{1}{c}{ Acciones propuestas para la FCHE } \\
\hline & $\begin{array}{l}\text {-Incorporar los ODS en la FCHE como un } \\
\text { objetivo de centro, tanto en la web como en una } \\
\text { cartelera preparada exclusivamente para esto y } \\
\text { ubicada estratégicamente. }\end{array}$ \\
VISIBILIZACIÓN & \\
DE LOS ODS & -Crear un lema identificativo desde la FCHE que \\
& $\begin{array}{l}\text { acompañe a las actividades que se realizan } \\
\text { relacionadas con los ODS. }\end{array}$ \\
\end{tabular}


ERRADIGACIÓNDE

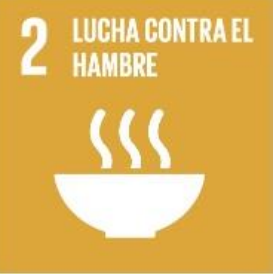

BuENASALUd

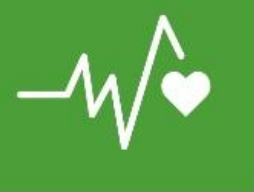

EDUCACIÓNDE GALIDAD

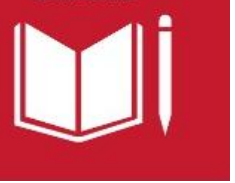

- 1.a. y 2.a. Fomentar la reflexión y

concienciación sobre una buena utilización de los recursos y un consumo responsable.

-Proteger nuestra propia salud y la de nuestro entorno y promover el bienestar en todas las edades.

\section{- 4.3. Contribuir a la calidad en la} enseñanza universitaria.

- 4.4. Aumentar los jóvenes y adultos con competencias profesionales.

- 4.5. Brindar acceso igualitario a la enseñanza.

- 4.7. Formar alumnos con conocimientos teóricos y prácticos de una educación como desarrollo sostenible y los estilos de vida sostenibles.

- 4.a Construir y adecuar instalaciones educativas que tengan en cuenta las diferentes necesidades para crear entornos de aprendizaje seguros, no violentos, inclusivos y eficaces para todos.
-Incluir en la web los resultados gráficos del registro de TFG's y TFM que se relacionan con los ODS.

Aa, Ad, Ae, Af, Ag

- Generar acciones y escenarios propicios para la sensibilización y la reflexión.

- Vincular a los contenidos, la utilización de herramientas y material gratuito sobre los ODS de Naciones Unidas.

$\mathrm{Aa}, \mathrm{Ab}, \mathrm{Ad}, \mathrm{Ae}, \mathrm{Af}, \mathrm{Ag}$

-Proponer actividades que favorezcan la movilidad de los alumnos entre clases o en clases y que permitan aumentar la Salud y bienestar.

$\mathrm{Aa}, \mathrm{Ab}, \mathrm{Ac}, \mathrm{Ad}, \mathrm{Ae}, \mathrm{Af}, \mathrm{Ag}$

- Hacer alusión a los ODS en las Guías Docentes de cada asignatura (como un objetivo, una actividad, etc.), una vez incorporados los ODS, proponer un lema alusivo e identificativo para la facultad.

- Desarrollar un taller formativo en ODS a nuestros estudiantes en primer curso.

Valorar y saber ¿con qué? conocimientos entran y con qué conocimientos salen de facultad en materia de sostenibilidad.

- Indicar la vinculación con los ODS de cada uno de los eventos científicos que se realicen (congresos, cursos, seminarios, conferencias, etc.). 
- 4.c Aumentar la oferta de docentes

calificados.

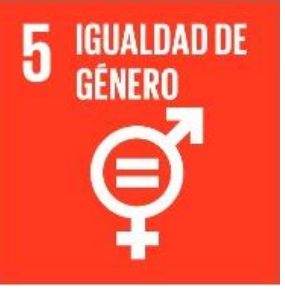

-5.2. Sensibilizar y educar en todas

las formas de no violencia contra las mujeres y las niñas.

-5.5. Ofrecer participación plena y efectiva de las mujeres y la igualdad de oportunidades de liderazgo.

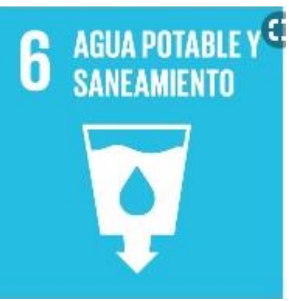

-6.3 Cuidar el agua mediante la sensibilización y concienciación de acciones para mejorar su calidad y reducir su contaminación.

\section{-7.3. Mejorar la eficiencia} energética, mediante la adecuación de instalaciones y la optimización de recursos. GRECIMIENTOECONÓMICO

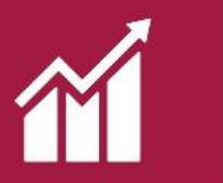

(0) INNOVACIÓNE

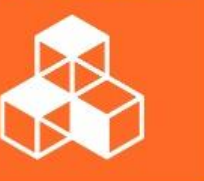

fiables, sostenibles, resilientes y de calidad, para apoyar el bienestar
- Propiciar la participación estudiantil, favoreciendo sus iniciativas y empoderando a la juventud.

Aa, Ae, Af, Ag

Vincular a los contenidos, la utilización de herramientas y material gratuito sobre los ODS de Naciones Unidas con el fin de sensibilizar y dar a conocer el cuidado de los recursos.

Aa, Ae, Ag

-Hacer una recopilación de las transformaciones e inversión realizadas en la FCHE en cifras y datos (mejoramiento de infraestructuras del edificio, cobertura, infraestructura de red y equipos entre otros...)

Aa, Ab, Ac, Ad, Ae, Af, Ag

-Realizar acciones que fomenten la sostenibilidad y sensibilización ambiental de todos los miembros de la FCHE.

-Propiciar eventos y acciones desarrolladas con metodología ApS, que contribuyan a la solución de problemas reales, al trabajo en equipo y al emprendimiento.

Aa, Ab, Ac, Ad, Ae, Af, Ag
-Crear espacios naturalizados aprovechando la luz natural disponible . 
REDUGCIÓNDELA DESIGUALDAD
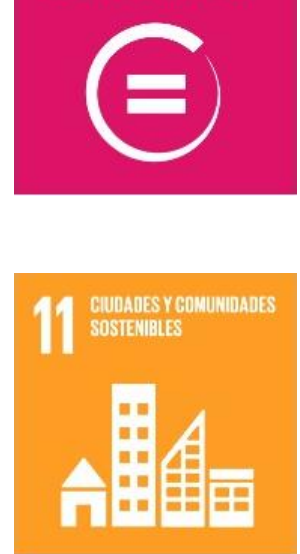

19 BONSUMO humano, con acceso asequible y

equitativo para todos.

9.5 Aumentar la investigación

científica y el fomento de la

innovación.

9.c Aumentar el acceso a la

tecnología de la información y las

comunicaciones.

-10.2 y 10.3. La inclusión social y de igualdad de oportunidades de todas las personas independiente de su condición.

-11.2 y 11.7. Involucrar a la Facultad en el transporte y movilidad sostenibles para todos.

-11.4. Proteger del patrimonio cultural y natural.

-12.5. Informar y practicar la prevención, reducción, reciclado y reutilización de los materiales. -12.8. Orientar acciones hacia un desarrollo sostenible y los estilos de vida en armonía con la naturaleza.
- Llevar una relación de los proyectos de investigación con temáticas vinculados a los ODS.

-Introducir una jornada de divulgación de trabajos y experiencias al inicio de curso que sirva para dar visibilidad a la actividad realizada por las alumnas y alumnos de los últimos cursos para los alumnos de primer curso.

-Fomentar líneas de investigación de TFG's, TFM, con contenidos en ODS: Podría hacerse un reconocimiento a los mejores trabajos relacionados con ODS

Aa, Ab, Ac, Ad, Ae, Af, Ag

-Recopilar información de lo que significan los ODS para nuestros alumnos, personal docente investigador y PAS y saber si tienen propuestas desde su quehacer relacionadas con los ODS.

-Crear y mantener un registro actualizado con cifras y datos de las temáticas de los TFG's, y TFM que se han realizado en la FCHE y que tienen un contenido relacionado con ODS.

Aa, Ab, Ac, Ad, Ae, Af, Ag

-Informar, orientar y promover la disposición correcta de residuos y el uso adecuado de contenedores. 
cambio glimático

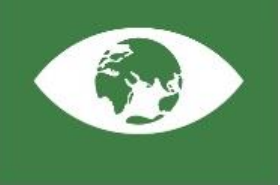

FLORA YFAUNA

ACUÁTICAS
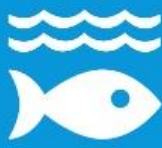

TLORA YFAUNA

TERRESTRES

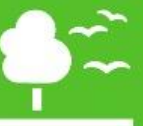

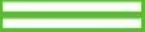

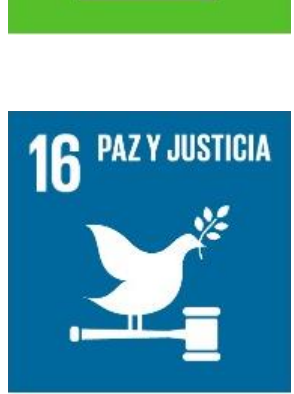

alaAZZAS PARAEL

LOGRODELOSOBJETIVOS

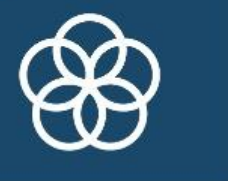

-13.3. Educación, sensibilizar sobre nuestro papel frente al cambio climático.

-14.1. Contribuir a la sensibilización y concienciación en la prevención y reducción de la contaminación acuática producida por actividades realizadas desde la tierra que luego impactan en los sistemas acuáticos.

-15.1. Favorecer la conservación, el restablecimiento y el uso sostenible de los ecosistemas terrestres (bosques..), los ecosistemas de agua dulce y los servicios que proporcionan

-16.7. Favorecer las decisiones inclusivas, participativas y representativas que respondan a necesidades reales.

-17.16 Propiciar y efectuar alianzas entre múltiples interesados que movilizan e intercambian conocimientos (a nivel local, nacional e internacional) tanto de principios como de valores, con una visión y unos objetivos compartidos en materia de objetivos de la Agenda 2030.
$\mathrm{Aa}, \mathrm{Ab}, \mathrm{Ac}, \mathrm{Ae}, \mathrm{Af}, \mathrm{Ag}$

-Emitir mensajes alusivos a los ODS por la pantalla de la Facultad (El día de la Tierra, vídeos cortos alusivos a los ODS y la Agenda 2030, etc.)

-Alentar y apoyar el empoderamiento de la Juventud frente a iniciativas de ODS y participar activamente en las propuestas desde los campus de Zaragoza y Teruel.

$\mathrm{Aa}, \mathrm{Ab}, \mathrm{Ac}, \mathrm{Ad}, \mathrm{Ag}, \mathrm{Ae}, \mathrm{Ag}$

-Relacionado con las propuestas de acción de los ODS $4,10,11$ y 12

\section{Aa, Ab, Ac, Ad, Ag, Ae, Ag}

-Fortalecer las relaciones de intercambio con otras Facultades y con otras universidades, que enriquezcan la acción conjunta de los ODS hacia la Agenda 2030

En síntesis, la propuesta desarrolla 4 estrategias de aplicación transversal relacionadas con un conjunto de acciones concretas: 
- Estrategia de Educación-aprendizaje, que se centra en la adaptación de las Guías Docentes, formación en sostenibilidad de los estudiantes y actividades de sensibilización.

- Estrategia de investigación, la cual comprende la adecuación a los ODS de TFG, TFM, proyectos de investigación y eventos científicos.

- Estrategia para promover la conciencia sobre ODS entre el personal de la facultad, favoreciendo su difusión en la web, pantallas y carteleras institucionales; generando estadísticas sobre el cumplimiento de los objetivos y realizando actividades de salud y bienestar con estudiantes y personal del centro.

- Estrategia para la Adecuación de las instalaciones y mejoramiento del entorno, promoviendo la naturalización de la Facultad, el reciclaje de residuos y el vínculo de los estudiantes con el espacio universitario.

\section{Futura línea de trabajo}

Nuestra Facultad ya se ha sumado a la iniciativa global de la responsabilidad y sostenibilidad que generan los ODS, consciente de su importante labor como formadora de maestros replicadores de una educación en la sostenibilidad. En esta línea busca integrarse en la estrategia de la Universidad de Zaragoza, denominada "La Universidad camina hacia los ODS" y en alcanzar los máximos resultados frente a los retos que plantea la Agenda 2030.

\section{Conclusiones}

La FCHE ha planificado una intensa agenda de actividades en pos de los ODS adaptada a su particular contexto físico, educativo y social que se despliega en los ámbitos de una docencia aprendizaje, investigación, difusión y adecuación y mejoramiento del entorno para vivenciar y proyectar en sus profesionales una formación en la sostenibilidad.

La incorporación de los ODS en la Facultad es una oportunidad para comprometerse formalmente en una iniciativa global necesaria para el bienestar de todos a todo nivel, ya que permite descubrir, fortalecer la participación y conectar vínculos para ganar credibilidad en el proyecto común de la Agenda 2030. 
Ser un centro integrado en la sostenibilidad que educa a sus estudiantes en el ApS, es garantía de cualificación de profesionales y ciudadanos comprometidos con la sociedad en la atención de problemas reales y la búsqueda de soluciones. En definitiva, se trata de crear un vínculo entre los estudiantes y el espacio de la Facultad en el que estarán inmersos al menos durante 4 años, de tal manera que lo hagan suyo con su aportación y cuidado.

\section{Bibliografía}

Aramburuzabala, P., García-Peinado, R., \& Elvias, S. (2013). Educación desde y para la Justicia Social: una Experiencia de Aprendizaje-Servicio en la Formación de Maestros. En M.C. Pérez y M.M. Molero (Comps.), Variables psicológicas y educativas para la intervención en el ámbito escolar, 257-265. Asociación Universitaria de Educación y Psicología.

Baldwin, S. C., Buchanan, A. M., \& Rudisill, M. E. (2007). What teacher candidates learned about diversity, social justice, and themselves from service learning experiences. Journal of Teacher Education, 58(4), 315-317.

Dominici, P. (2018). For an inclusive innovation. Healing the fracture between the human and the technological in the hypercomplex society. European Journal of Futures Research, 6(1), 1-10. https://doi.org/10.1007/s40309-017-0126-4

López, H., Ollo, A., \& Simón, K. (2020). Futuro Universitario Europeo. Universidad Pública de Navarra.

Ruiz, A. G. (2010). La enseñanza de la ciencia en una sociedad con incertidumbre y cambios acelerados. Enseñanza de las Ciencias: revista de investigación y experiencias didácticas, $28(3), 315-326$.

Sagardia, A., Urdin, J., \& Fernández, I. (2017). Active-collaborative learning as best practices in the development of cross-curricular competencies in Basque Country vocational training. Educar, 54(2), 331-349. https://doi.org/10.5565/rev/educar.880

SDSN Australia, New Zealand \& Pacifc Edition. (2017). Getting Started with the SDGs in Universities: A Guide for Universities, Higher Education Institutions, and the Academic 
Sector.

www.ap-unsdsn.org/wp-content/uploads/2017/08/University-SDG-

Guide_web.Pdf

UNESCO. (2009). Higher education, research \& innovation: changing dynamics. Disponible en: http://www.iesalc.unesco.org. 


\title{
Los Objetivos de Desarrollo Sostenible. Alcance y dimensión ambientalista
}

\author{
Elena Cruz Hernández \\ Madeleine Catoira Monteagudo \\ Universidad Central "Marta Abreu" de Las Villas
}

Palabras clave: Medio ambiente; exigencias; Primera Infancia.

\section{Introducción}

El medio ambiente, está sufriendo, igual que el mundo las agresiones que por muchos años han generado el hombre y el propio envejecimiento del planeta Tierra. Para mitigar estos daños, muchos sectores de la sociedad enfocan sus acciones de trabajo, en función de lograr revertir el deterioro de los entornos donde hay vida. Un sector social, dedicado a esta tarea, es el educacional, por su marcada influencia en la comunidad, la familia y los miles de niños, jóvenes y adultos, que reciben en un ambiente educativo, las lecciones más sabias, sobre el cuidado y protección del medio ambiente. Barcena (2016) agregando a la labor de educar otro enfoque afirma: "La educación es la base para mejorar nuestra vida y el desarrollo sostenible” (pág. 5). Sin lugar a dudas, el tema de la protección al medio ambiente, ha inundado, los espacios educativos, en la última década y se fortalece, con la tendencia de otorgarle un marcado enfoque de desarrollo sostenible.

Muchas investigaciones, que abordan el alcance y la dimensión ambientalista específicamente en el sector educacional, reflejan de forma coincidente que el cuidado al medio ambiente encuentra en los espacios educativos una plataforma apta para implementar estrategias en función de su cuidado y protección. Surgiendo así el concepto de educación ambiental para el desarrollo sostenible, asumido y ampliamente debatido por estudiosos del tema. Roque (2003) considera que: "La educación ambiental también crece con la voluntad política de los gobiernos y de las instituciones educacionales" (pág. 8). Esta idea, demuestra que la fortaleza y el alcance de 
esta temática, está enlazada directamente al deseo del hombre y la intención de enfocar esfuerzos conjuntos, para alinear el trabajo, bajo un fuerte enfoque ambiental.

De igual forma Novo (2009) plantea que: “El corazón de la educación ambiental está inscrito al desarrollo y la sostenibilidad de la sociedad y a sus políticas educacionales" (pág. 59). Dicho planteamiento, reafirma, que la necesidad y sensibilización del hombre por cuidado del medio ambiente, debe vincularse a los procesos educativos, para sembrar en cada uno, la convicción, de que, el cuidado del medio ambiente es tarea de todos. Por otra parte, Cabelé (2016) expresa que: "El concepto de Educación Ambiental, en el contexto educativo, permite el desarrollo de valores, viabiliza relaciones de trabajo, permite acciones de solidaridad y contribuye al fomento de correctos patrones de conducta" (pág. 16). En total acuerdo, con esta idea, el tratamiento al concepto de educación ambiental, en los diferentes contextos educativos, es una vía para despertar el interés, por el estudio y cuidado del medio ambiente. Su vínculo con las diferentes disciplinas de estudio, permiten la planificación de acciones y estrategias posibles de implementar en las comunidades más afectadas por la acción del Hombre.

De más actualidad, aparece Consuegra (2020) quien plantea que: "La educación no debe estar ajena a la determinación de formas, vías y alternativas para impulsar el cuidado al medio ambiente a través de los procesos educativos" (pág. 2). En estos criterios, encontramos, argumentos que fortalecen la pertinencia, de tratar el cuidado del medio ambiente, en los contextos educativos, para aprovechar de este marco, el conocimiento de los profesionales de la educación y su competencia, en la planificación, orientación, ejecución y evaluación de acciones que, en estrecha relación con los planes temáticos que imparten, posibiliten dar tratamiento a temas relacionados con el cuidado, del medio ambiente y la educación ambiental para el desarrollo sostenible.

Por esta razón, el tratamiento a los temas referidos al cuidado del medio ambiente, en diferentes niveles educativos, se ha convertido, en punto de partida para despertar en todos, una alta sensibilidad por cuidar el entorno que nos rodea. Sin embargo, el hombre en su afán por dominar y explotar los recursos naturales no se había percatado de que a la par del progreso científico, tecnológico y el crecimiento explosivo de la población mundial se han generado graves problemas en el medio ambiente, graves e irreversibles en muchos casos. En estas circunstancias, 
los esfuerzos por lograr frenar la agresión al medio ambiente unen en todo el mundo a muchos profesionales.

A partir del creciente daño constatado, se ha generado un movimiento mundial, que promueve acciones para utilizar de forma racional los recursos naturales, sin embargo, aún no se logran resultados alentadores. Cada año, diversos medios de comunicación identifican entre los impactos ocasionados por el cambio climático: la degradación de los suelos, afectaciones a la cobertura forestal, contaminación, pérdida de la diversidad biológica, deterioro de los ecosistemas, carencia y dificultades con el manejo, la disponibilidad y calidad del agua y más grave aún el deterioro de las condiciones higiénicas sanitaria en los asentamientos humanos. Dicha situación influye directamente en la calidad de vida de la especie humana y en la relación y equilibrio, que debe existir, entre naturaleza-sociedad. Urge entonces un cambio en la conducta responsable del hombre, la cual debe asumir con un marcado enfoque ambientalista.

El desarrollo científico tecnológico alcanzado por la humanidad y en Cuba específicamente, en los momentos actuales, resalta la imperiosa necesidad de formar profesionales con un alto nivel de sensibilidad por el cuidado y protección del medio ambiente. En sintonía con esta idea, la formación integral, de los profesionales de la Educación, asumen una responsabilidad superior, pues son los maestros, los encargados de multiplicar en cada institución educativa, las manifestaciones de cuidado y conservación del medio ambiente, acometiendo acciones educativas, en función de expandir, la necesidad, de revertir, los males sociales, que demuestran una clara incidencia en el deterioro, del medio que nos rodea.

Para abordar esta temática de la Educación Ambiental y actuar en correspondencia con el llamado que realiza Cuba, en función de fortalecer y multiplicar las intenciones dirigidas a enfrentar al cambio climático y garantizar así, el desarrollo económico y social, y lograr, sobre todo, salud y supervivencia para la especie humana en todo el planeta, es importante encontrar vías novedosas, que despierten interés en estudiantes y profesores. En el Plan de Estado para el enfrentamiento al cambio climático aprobado por Cuba llamado "Tarea Vida", muestra la voluntad política del gobierno para dar respuesta al objetivo 13 de los Objetivos de Desarrollo Sostenible. En dicho plan es claro el objetivo dirigido a: "Proteger la vida humana y su calidad, en condiciones de un clima cambiante; para ello involucra a todos los sectores de la sociedad y se aplica a nivel nacional y local" (Tarea Vida, 2017). 
Las tareas y acciones presentes en este Plan de Estado, constituyen verdaderas guías de trabajo y resultan muy estimulante sus propuestas para el desarrollo de actividades en los estudiantes y profesores, pues vinculan sus intenciones a tratamiento de los Objetivos y Metas, de la Agenda 2030, por su amplia dimensión y representación de muchos sectores de la sociedad, que requieren de un medio ambiente sano, para alcanzar logros reales hasta el 2030. En este sentido, es necesario integrar principios, valores y prácticas sostenibles en todas las facetas de la educación ambiental y el aprendizaje, pues esta iniciativa educa comportamientos hacia una sociedad ambientalmente saludable (UNESCO, 2012, pág. 15). Tal encomienda, es asumida, en Cuba, desde la Educación de la Primera Infancia y transita hasta el nivel superior y atraviesa los procesos de enseñanza-aprendizaje, como una estrategia de permanente cumplimiento.

Para el Ministerio de Educación Superior en Cuba, se ha convertido en un reclamo, el trabajo con los Objetivos de Desarrollo Sostenible y su tratamiento en todos los espacios universitarios. Por este motivo, los 17 Objetivos de Desarrollo Sostenible son objetivos de trabajo para todos. Los profesionales de la Educación, encargados de formar integralmente a los nuevos profesionales de este importante sector de la sociedad, asumen el reto de incorporar en las estrategias educativas, acciones que permitan el trabajo con la Agenda 2030 y acciones encaminadas al cuidado y protección del medio ambiente. Uniendo estos temas priorizados, consideramos oportuno, dar tratamiento a los objetivos de la Agenda 2030 que contengan un enfoque ambientalista, específicamente en los profesionales de la Primera Infancia.

\section{Descripción de la experiencia/Objetivo}

En Cuba, el tratamiento a la educación ambiental específicamente en las universidades, está respaldada por la Estrategia Ambiental del Ministerio de Educación Superior, identificado con las siglas (MES) según esta estrategia:

“El Ministerio de Educación Superior, desde la gestión sistemática de los procesos, persigue, el logro de una universidad integrada, innovadora, más revolucionaria y pertinente, que impacte de manera significativa en el desarrollo humano y sostenible de la sociedad cubana, a partir de la formación integrales de profesionales comprometidos con la Revolución, su país y su territorio" (MES, 2017). La estrategia mencionada constituye un documento, de obligada consulta para todos los profesionales de la educación, para el nivel universitario, en esta se reflejan los 
fundamentos que sustentan, la necesidad de dar tratamiento a los contenidos de las diferentes asignaturas que se imparten, con un enfoque sostenible y ambientalista, tratado, desde los procesos de enseñanza y aprendizaje.

La experiencia profesional que se presenta rodea la misión de los profesionales de la Primera Infancia en el contexto laboral universitario. Por tal motivo, el profesional de la Primera Infancia en Cuba, que enfoca su labor a formar nuevas generaciones de educadores para enseñar a los niños y niñas de la Primera Infancia, tiene como misión mantener una elevada preparación, que le permita incidir de forma integral en la formación de las futuras generaciones de profesionales, donde no puede faltar la educación ambiental con un marcado enfoque sostenible. La investigadora Vilches (2010) plantea que: "Entre educación ambiental y educación para el desarrollo sostenible, existen objetivos comunes enfocados al desarrollo de tres grandes ámbitos. Medio ambiente, sociedad y economía, con una dimensión subyacente de cultura” (2010 pág. 9).

El criterio anterior eleva su vigencia y en la actualidad, continúa sumando a investigadores e instituciones a la causa mundial, enfocada a garantizar calidad de vida en un medio ambiente sano, sostenible y con metas de desarrollo alcanzables. Con la llegada de la COVID-19, las actividades de autosuperación, se han fortalecido y en condiciones de Teletrabajo o trabajo a distancia, se han planificado para cada docente un número elevado de horas para la autosuperación. Aprovechando esta posibilidad, se encontraron temas sugerentes, de especial interés para docentes y estudiantes. De estas propuestas surge el estudio de la Agenda 2030, para el Desarrollo Sostenible y dentro de esta, el estudio y profundización del Objetivo \#13: Acción por el Clima.

De las ideas planteadas, en la introducción y alineados a la posibilidad de profundizar en temas sugeridos por los propios profesionales de la Primera Infancia, para desarrollar la autopreparación a distancia, derivamos el objetivo de nuestro trabajo, que se enfoca esencialmente a analizar los objetivos y metas de la Agenda de Desarrollo Sostenible con enfoque ambientalista para su tratamiento en los diferentes contextos de actuación de los profesionales de la Primera Infancia. Como resultados de este trabajo se determinan exigencias para dar tratamiento a los objetivos y metas de la Agenda de Desarrollo Sostenible, en los diferentes contextos de actuación de los profesionales de la Primera Infancia, las cuales permitirán elevar su preparación e implementar conceptos relacionados con la Educación Ambiental, en su labor profesional cotidiana. 


\section{Contexto}

El cuidado del medio ambiente, la protección y consumo racional de los recursos naturales, la constante preocupación, por lograr un desarrollo sostenible y el desarrollo de una conciencia ambientalista en el hombre, son temas, muy tratados, entre los profesionales de la Primera Infancia. Dicha preocupación se une al esfuerzo, por garantizar procesos educativos de calidad como garantía de vida para las futuras generaciones. Consecuentes con esta idea, el currículo Preescolar Cubano, se perfecciona, bajo los criterios de obtener un currículo más flexible, contextualizado e integrador, con el fin de elevar la calidad del proceso educativo y la atención integral de todos los niños y niñas de la Primera Infancia, donde todos los momentos de la vida del niño constituyan espacios idóneos para su desarrollo.

Por esta razón es un deber de todos los profesionales de la Primera Infancia, actuar en correspondencia con el momento histórico que se vive, que demanda una preparación a la altura de las exigencias educativas actuales, enfocadas en el logro de una educación de calidad. Para trabajar en correspondencia con el logro de una conciencia ambientalista, en primer lugar, en los profesionales de la Primera Infancia, se impone en primer lugar, divulgar, debatir y analizar sistemáticamente los 17 objetivos propuestos por la Agenda 2030, así como sus 169 metas y profundizar en aquellos objetivos y metas, con enfoque ambientalista.

\section{La Agenda 2030 para el Desarrollo Sostenible. Objetivos y Metas.}

La Agenda 2030 para el Desarrollo Sostenible, fue aprobada en septiembre de 2015 por la Asamblea General de las Naciones Unidas. Los 17 objetivos presentes en esta, también son una herramienta de planificación para los países, tanto a nivel nacional como local. Gracias a su visión a largo plazo, constituirán un apoyo para cada país en su senda hacia un desarrollo sostenido, inclusivo y en armonía con el medio ambiente, a través de políticas públicas e instrumentos de presupuesto, monitoreo y evaluación.

Para su implementación varias organizaciones mundiales se han unido en un solo reclamo, por un mundo mejor, sostenible y de paz. La UNESCO, asume un papel protagónico en este sentido, pues sus prioridades fundamentales se enmarcan en una educación de calidad y para todos, en la construcción de un mundo sostenible de sociedades justas, que valoren el conocimiento, 
promuevan la paz ensalcen la diversidad y defiendan los derechos humanos, mediante la educación para cooperar en la respuesta a los desafíos interconectados del siglo XXI, propósitos estos consecuentes con los objetivos de la Agenda 2030.

A pesar de contar esta Agenda con 17 objetivos y 169 metas a lograr, todo gira en función de favorecer la vida del hombre en el mundo y preservar la especie humana, al respecto, Bokoba (2015), Directora General de la UNESCO, expresó: “Todos los seres humanos nacen libres e iguales en dignidad y derechos" (pág. 14). Precisamente al respeto de los derechos humanos va dirigida esta Agenda que busca, la vida humana en armonía y el desarrollo sostenible como la vía necesaria para prolongar su existencia. El primer paso para lograr cumplir con la implementación de la Agenda 2030, está relacionado, con la divulgación de su contenido, para posteriormente contextualizar cada uno de sus objetivos y metas. A continuación, se enuncian cada uno de sus objetivos:

1. Poner fin a la pobreza en todas sus formas en todo el mundo.

2. Poner fin al hambre, lograr la seguridad alimentaria y la mejora de la nutrición y promover la agricultura sostenible.

3. Garantizar una vida sana y promover el bienestar para todos en todas las edades.

4. Garantizar una educación inclusiva, equitativa y de calidad y promover oportunidades de aprendizaje durante toda la vida para todos.

5. Lograr la igualdad entre los géneros y empoderar a todas las mujeres y las niñas.

6. Garantizar la disponibilidad de agua y su gestión sostenible y el saneamiento para todos.

7. Garantizar el acceso a una energía asequible, segura, sostenible y moderna para todos.

8. Promover el crecimiento económico sostenido, inclusivo y sostenible, el empleo pleno y productivo y el trabajo decente para todos.

9. Construir infraestructuras resilientes, promover la industrialización inclusiva y sostenible y fomentar la innovación.

10. Reducir la desigualdad en y entre los países.

11. Lograr que las ciudades y los asentamientos humanos sean inclusivos, seguros, resilientes y sostenibles.

12. Garantizar modalidades de consumo y producción sostenibles. 
13. Adoptar medidas urgentes para combatir el cambio climático y sus efectos.

14. Conservar y utilizar en forma sostenible los océanos, los mares y los recursos marinos para el desarrollo sostenible.

15. Promover el uso sostenible de los ecosistemas terrestres, luchar contra la desertificación, detener e invertir la degradación de las tierras y frenar la pérdida de la diversidad biológica.

16. Promover sociedades pacíficas e inclusivas para el desarrollo sostenible, facilitar el acceso a la justicia para todos y crear instituciones eficaces, responsables e inclusivas a todos los niveles.

17. Fortalecer los medios de ejecución y revitalizar la Alianza Mundial para el Desarrollo Sostenible.

Los 17 objetivos revelan cuánto se puede lograr, en función de elevar la calidad de vida, de todos los seres humanos del mundo. Estos constituyen, además una verdadera oportunidad, para alcanzar de forma sostenible, mejoras significativas en la convivencia en la región de América Latina y el Caribe. Esta nueva Agenda es la expresión de los deseos, aspiraciones y prioridades de la comunidad internacional para los próximos 15 años. La Agenda 2030 es una agenda transformadora, que se convierte en un compromiso universal, adquirido tanto por países desarrollados como en desarrollo, en el marco de una alianza mundial reforzada, que toma en cuenta los medios de implementación para realizar el cambio y la prevención de desastres por eventos naturales extremos, así como la mitigación y adaptación al cambio climático.

Una mirada al tema de la Educación Ambiental, se expande, por diferentes sectores de la sociedad alrededor de todo el mundo. En Cuba, un grupo de científicos e investigadores llevan a cabo un proyecto relacionado con el desarrollo sostenible, conocido como la Tarea Vida. Este es un Plan de Estado, para el enfrentamiento al cambio climático, aprobado por el Consejo de Ministros y tratado, con adecuaciones, en todos los niveles educativos. Dicho Plan, está inspirado en el pensamiento del líder histórico de la Revolución Cubana. Castro (1992), en la Cumbre de La Tierra en Río de Janeiro, expresó: "Una importante especie biológica está en riesgo de desaparecer por la rápida y progresiva liquidación de sus condiciones naturales de vida: el hombre” (pág. 4).

Por esta razón, los profesionales de la Primera Infancia, que tienen a su cargo la formación integral de las futuras generaciones de Educadoras de la Primera Infancia y cuya influencia 
educativa llegan a la familia, la comunidad y a los niños y niñas, tienen la alta responsabilidad, de otorgarle a su labor, un elevado enfoque ambientalista. Para lograr esta meta, su autopreparación juega un papel determinante. Sobre esta idea, Martínez (2004) considera que: "La preparación permanente permitirá acceder a un nivel superior para lograr un quehacer educativo más efectivo, o para estar actualizado en el devenir de la ciencia pedagógica" (p. 18). Sin lugar a dudas, la etapa de aislamiento social, o cuarentena a causa de la COVID-19, ha permitido, cambiar la dimensión de su preparación en incluir en sus horas de estudio, otras temáticas en ocasiones, poco tratadas, en condiciones y contextos de vida normales.

Dicho empeño, permitió reunir criterios para definir las exigencias, que constituyen puntos de partida, para garantizar el cumplimiento del ODS\#13, de la Agenda de Desarrollo Sostenible en los profesionales de la Primera Infancia. Para lograr su concreción, consideramos, las experiencias reconocidas, por el destacado investigador cubano y Jefe del Proyecto Nacional: La Educación Ambiental en el Sistema Nacional de Educación el Doctor en Ciencias Pedagógicas Ismael Santos Abreu. Santos (2009), en uno de sus materiales dirigidos a la orientación, para implementar acciones de cuidado al medio ambiente en los contextos educativos plantea: "Es importante, contar con la guía certera, la preparación idónea, los medios necesarios y los intereses profesionales suficientes para que la educación ambiental inunde todos los espacios educativos" (p. 8). De estas ideas, pensamos, que una guía, pudieran constituir las exigencias, para garantizar el enfoque ambientalista en la labor de los profesionales de la Primera Infancia.

\section{Exigencias}

1. Estudiar todos los Objetivos de Desarrollo Sostenibles presentes en la Agenda 2030, para contextualizar sus metas y objetivos a los entornos laborales de los Profesionales de la Primera Infancia, prestando especial atención en el ODS \#13.

2. Incorporar a la mayor cantidad de asignaturas posibles, objetivos relacionados con el ODS \#13, en aras de establecer puntos de contacto entre las metas de este objetivo y los objetivos de la asignatura y lograr acciones de internacionalización del currículo.

3. Estimular desde las Estrategias Educativas para los años académicos, el desarrollo de actividades de impacto comunitario, relacionadas con el cuidado y protección del medio 
ambiente y el desarrollo de Trabajos Científicos Estudiantiles, relacionados con el cuidado del medio ambiente.

4. Crear con los estudiantes interesados en desarrollar investigaciones relacionadas con el tema del medio ambiente, un Grupo Científico Estudiantil, que realice actividades afines y promueva el cumplimiento del ODS \# 13, de la Agenda 2030.

5. Contextualizar el ODS \#13 de la Agenda a los propósitos del currículo de la Primera Infancia considerando que el proceso de perfeccionamiento ha fortalecido su carácter integral, flexible y contextualizado.

6. Incluir en los programas de superación de los Profesionales de la Primera Infancia, temas relacionados el cuidado del medio ambiente, el impacto del cambio climático.

\section{Aplicación y resultados}

Las exigencias enunciadas se consideraron, en la planificación de las actividades académicas en la Modalidad de Educación a Distancia, implementada por las condiciones impuestas a causa de la COVID-19. Los docentes encontraron en las Redes Sociales la posibilidad de trabajar en grupos mediante WhatsApp, la Plataforma Moodle de la Universidad y el correo electrónico. A partir de implementar las exigencias se obtuvieron los siguientes resultados:

1. Docentes y estudiantes, descargaron en diferentes medios tecnológicos la Agenda 2030 y estudiaron todos los Objetivos de Desarrollo Sostenibles presentes en la Agenda 2030, para contextualizar sus metas y objetivos a los entornos laborales de los profesionales de la Primera Infancia y en las instituciones educativas donde realizan práctica pre-profesional las estudiantes, prestando especial atención en el ODS \#13.

2. Se incorporaron al $100 \%$ de las asignaturas del currículo de la carrera Licenciatura en Educación. Preescolar, objetivos relacionados con el ODS \#13 y se determinaron las acciones necesarias para enfocar la internacionalización del currículo con miras a un desarrollo sostenible.

3. En las Estrategias Educativas de Desarrollo Integral para los estudiantes de todos los años académicos, se diseñaron actividades de impacto comunitario, relacionadas con el cuidado y protección del medio ambiente y el desarrollo de Trabajos Científicos Estudiantiles, relacionados con el ODS\# 13. 
4. Se creó un Grupo Científico Estudiantil, para que promueva el cumplimiento del ODS \# 13, el cuidado del medio ambiente, específicamente en los entornos donde ejercen labores educativas estudiantes y docentes de la Primera Infancia.

5. Se Contextualizó el ODS \#13 de la Agenda a los propósitos del currículo de la Primera Infancia considerando los espacios de investigación e intercambio profesional que ofrece el proceso de perfeccionamiento, lo que ha fortalecido su carácter integral, flexible y contextualizado.

6. Se inició un programa de superación para los Profesionales de la Primera Infancia, con temas enfocados al cuidado del medio ambiente, el impacto del cambio climático, llamado: Enfoque Sostenible de Educación para la Primera Infancia.

\section{Conclusiones}

Para dar enfoque ambientalista a la labor educativa de los profesionales de la Primera Infancia es oportuno analizar todos los objetivos y metas de la Agenda de Desarrollo Sostenible, en función de contextualizar su contenido a los diferentes escenarios laborales donde se desempeñan los profesionales de la Primera Infancia.

El ODS\# 13 de la Agenda de Desarrollo Sostenible, constituye un objetivo más de trabajo, a cumplir por todos los profesionales de la Primera Infancia, en función de lograr una conciencia hacia el cuidado y protección del medio ambiente, que permite la transformación de nuestro entorno, en un ambiente que garantice calidad de vida.

Las exigencias para trabajar con el ODS \# 13, guían el trabajo de los Profesionales de la Primera Infancia en aras de otorgar un enfoque ambientalista a la labor educativa que realizan, en la formación de futuros profesionales de este nivel educativo.

\section{Referencias}

Barcena, P. (2016). Objetivos de la Agenda 2030 para el Desarrollo Sostenible. http://www.un.org/sustainabledevelopment/es. 
Bokova, I. (2015). Informe sobre el cumplimiento de los derechos humanos, con especial atención en los derechos a la Educación, la Ciencia y la Cultura. UNESCO, http:// www.unesco.informe.derechos humanos. Org.com/

Cabelé, E. (2016). Educación para el desarrollo sostenible en la modalidad no formal: bases teórico-práctico para una estrategia en la actividad constructiva de Cuba. Tesis de Doctorado. Universidad de la Habana. La Habana. Cuba.

Castro, F. (1992). Discurso pronunciado en la Conferencia de las Naciones Unidas sobre Medio Ambiente y Desarrollo en Río de Janeiro, Brasil. Periódico Granma, (p.4).

Consuegra, G. (2020). Un acercamiento a la conceptualización de la educación ambiental para el desarrollo sostenible. Revista Cubana de Educación Superior, 39 (2).

Martínez, F. (2005). El proyecto educativo del centro infantil. La Habana: Editorial Pueblo y Educación.

Ministerio de Educación Superior (2017). Estrategia Ambiental del Ministerio de Educación Superior. Documento Digitalizado. Dirección de Ciencia y Técnica, La Habana. Cuba.

Novo, M. (2009). La Educación Ambiental, una genuina educación para el desarrollo sostenible. Disponible en: http://revistaeducación.mec.es/re2009.htm

Plan de Estado para el enfrentamiento al cambio Climático: Tarea Vida (2017). El Plan de Estado para el Enfrentamiento al Cambio Climático en la República de Cuba. Disponible en: http://www.cubaenergia.cu/tarea-vida

Roque, M. (2003). Una Concepción educativa para el desarrollo de una cultura ambiental desde la perspectiva cubana. Ponencia al IV Congreso de Educación Ambiental, CIGEA, La Habana. Cuba.

Santos, I. (2009). La educación ambiental para el desarrollo sostenible. En L. Gómez (Presidencia), La Orientador de la Educación Ambiental para el cuidado del Medio 
Ambiente, una visión desde la investigación educativa. Panel desarrollado en el Congreso Pedagogía, La Habana, Cuba.

UNESCO (2012): Forjar la educación del mañana: Decenio de las Naciones Unidas de la Educación para el Desarrollo Sostenible-Informe 2012 (Abreviado).

Vilches, A., Gil., \& Cañal, P. (2010). Educación para la sostenibilidad y educación ambiental. Investigación en la Escuela, $71 . \quad$ Disponible en: http://www.uv.es/Vilches/Documentos/EDS\%20Y\%20EA.pdf 
푸:-Universidad Congreso internacional sobre buenas prácticas ODS durante el COVID: Aprendizaje Servicio, calidad y equidad

\title{
CAPÍtULO 2
}

\section{EXPERIENCIAS Y BUENAS}

\author{
PRÁCTICAS
}




\title{
Autoevaluación psicológica en situación de confinamiento como experiencia de aprendizaje aplicado
}

\author{
Javier Rodríguez Árbol \\ Casandra Isabel Montoro Aguilar \\ Universidad de Jaén
}

Palabras clave: evaluación psicológica; adaptación digital; confinamiento.

\section{Introducción}

Uno de los apartados curriculares obligatorios del Grado en Psicología está orientado al aprendizaje de los fundamentos de la evaluación psicológica y sus aplicaciones en la práctica profesional. De entre las numerosas competencias a desarrollar por cualquier profesional de la psicología, independientemente de su área de ejercicio, sobresale por su importancia y transversalidad la capacidad de obtener información de forma sistemática y confiable acerca de la situación a abordar. La corrección en la realización del proceso de evaluación psicológica determinará la toma de decisiones sobre las características de la intervención a desarrollar y permitirá efectuar una valoración de la efectividad de la misma (Haynes, Godoy, \& Lázaro, 2014), así como realizar el seguimiento de la evolución de la persona que recibe el servicio. Por tanto, la evaluación psicológica no sólo es un requerimiento técnico, sino un imperativo ético. En relación con los aspectos deontológicos implicados en la práctica profesional de la psicología, las medidas y precauciones que deben tomarse cuando se está indagando en la vida de personas reales y tratando datos de carácter personal (Pastor Morales \& Río Sánchez, 2018) a veces dificultan desarrollar experiencias de evaluación reales en el contexto de los estudios de grado, especialmente cuando se cuenta con un elevado número de estudiantes por grupo. Una alternativa habitual en la docencia universitaria es redirigir las actividades de evaluación hacia el propio estudiante, convirtiéndose así en evaluador y evaluado de forma simultánea; si bien esta opción no deja de 
tener sus inconvenientes, como por ejemplo el no poder abordar determinados fenómenos de interés para la formación de futuros profesionales de la psicología, especialmente aquellos relacionados con la salud mental y el desarrollo de trastornos mentales.

En este contexto de la salud mental está cobrando cada vez más fuerza la denominada perspectiva transdiagnóstica (Pérez-Álvarez, 2017), término que engloba una amplia variedad de propuestas teóricas alternativas a los sistemas clasificatorios tradicionalmente empleados en psiquiatría y psicología (como son los sistemas CIE y DSM). La principal característica común de estas propuestas emergentes es el énfasis en la identificación de dimensiones (en sustitución de los síntomas discretos) relacionadas con la salud mental y su evaluación. Aunque el leitmotiv de la perspectiva transdiagnóstica es precisamente trascender el uso de categorías, aún no se ha conseguido elaborar ninguna propuesta que prescinda completamente de las mismas y lo común es que las dimensiones se articulen en función de conceptos clínicos clásicos como depresión y ansiedad. La ubicuidad de estos constructos psicológicos, presentes incluso en las propuestas teóricas más innovadoras, señala la importancia que conlleva para la adecuada formación de los profesionales de la salud mental el conocer los procedimientos y técnicas dirigidos a evaluarlos.

La irrupción de la pandemia COVID-19 y la adopción de medidas restrictivas como el confinamiento estricto iniciado a mediados de marzo de 2020 abrió la posibilidad de observar los efectos psicológicos colaterales en la población general. Estudios previos permitían prever que una crisis sanitaria global tendría un impacto importante en la salud mental (p.e. Bai et al., 2004), con variables como la depresión y la ansiedad como dimensiones protagonistas. Por tanto, una práctica de autoobservación en estas circunstancias podría proporcionar una experiencia de entrenamiento en la evaluación de los mencionados constructos.

\section{Descripción de la experiencia/Objetivo}

Debido a la rápida sucesión de los acontecimientos ocurridos a partir del 11 marzo y al hecho de que el decreto de Estado de Alarma se hiciera público coincidiendo con el fin de semana, fue fundamental la coordinación y comunicación constante entre los componentes del equipo docente para el diseño, adaptación e implementación de la actividad que aquí se describe. Tras valorar la inviabilidad de las actividades prácticas propuestas para el resto del semestre se optó por planear una experiencia de aprendizaje que, pudiendo ser auto-aplicada, favoreciera el desarrollo 
de las competencias previstas a cubrir por la asignatura. Por la situación de confinamiento a la que iba a estar expuesta la totalidad de la población (a priori durante dos semanas) y el progresivo aumento de toma de consciencia acerca de la crisis global que se estaba atravesando, se decidió que el diseño de la actividad iba a ser longitudinal, permitiendo experimentar las ventajas e inconvenientes que plantean las técnicas de evaluación cuantitativas en una tarea de seguimiento, así como interiorizar la importancia de realizar mediciones en distintos momentos temporales para evaluar adecuadamente la evolución de cualquier proceso. De esta manera, se establecieron tres puntos temporales de evaluación mediante técnicas estandarizadas que proporcionaban una medida cuantitativa de las variables psicológicas de interés (ansiedad, depresión y nivel de salud auto-percibida). Los tres puntos de evaluación se establecieron de la siguiente forma: el 16 de marzo de 2020 como fecha inicial de autoevaluación, para obtener un nivel basal del estado al inicio del confinamiento y poder valorar el grado de evolución de las variables de interés, el 23 de marzo como punto de evaluación intermedio y el 30 de marzo como punto de evaluación final (a priori la fecha en la que se terminaba el confinamiento). Adicionalmente, en la primera fecha de autoevaluación se instruyó en la aplicación de una serie de instrumentos destinados a evaluar factores disposicionales que podían mediar en el impacto psicológico que el confinamiento pudiera ocasionar y que cubrían distintos apartados del abanico de técnicas que formaban parte del currículo de la asignatura. Estos factores incluían aspectos cognitivos, rasgos de personalidad y estrategias predominantes de afrontamiento del estrés.

La evaluación se complementó con un autorregistro diario a realizar mediante una herramienta diseñada ad hoc y compuesta por ítems en formato de escala Likert (Corbetta, 2007) y apartados de tipo cualitativo (Figura 1). El objetivo de incluir esta herramienta en la actividad de evaluación, además de señalar la importancia de recopilar información acerca del estado afectivo en distintos momentos del día, era dirigir la atención hacia aquellos comportamientos que pudieran tener una función moduladora en dicho estado, con la intención de facilitar la identificación de conductas adaptativas y desadaptativas, dentro de las limitaciones inevitables. Adicionalmente, la aplicación durante dos semanas de una técnica de autorregistro también permitía al alumnado conocer de primera mano las ventajas e inconvenientes de prescribir una técnica de este tipo, así como cuestiones técnicas a tener en cuenta en su utilización (previsión de efectos de desmotivación, pérdida de información relevante por falta de pulcritud en la aplicación, etc.). 


\section{Contexto}

La experiencia se desarrolló con los tres grupos de estudiantes matriculados en el curso 2019/2020 en la asignatura Evaluación Psicológica Aplicada, del Grado en Psicología de la Universidad de Jaén (lo que suponía un total de 225 personas). La propuesta de actividad se diseñó por el equipo docente tras el anuncio de la declaración de Estado de Alarma por crisis sanitaria COVID-19, el 14 de marzo de 2020. Las instrucciones se facilitaron el primer día lectivo bajo confinamiento. Las únicas vías posibles de comunicación con el alumnado eran telemáticas, por lo que se hizo uso intensivo de las herramientas que facilitaba la plataforma de docencia digital ILIAS de la Universidad de Jaén.

\section{Aplicación y resultados}

Una vez seleccionadas las variables psicológicas que iban a ser evaluadas y los instrumentos para ello, se realizó una adaptación digital de los mismos. Asimismo, se construyó ad hoc un modelo de herramienta de evaluación para llevar a cabo el autorregistro diario (Figura 1) que se facilitó al alumnado. Con el objetivo de favorecer la adhesión a la actividad se estableció una fecha de entrega intermedia consistente en subir a la plataforma de docencia virtual los registros directos realizados durante las dos semanas de evaluación propuestas. Se estableció como fecha límite para esta primera entrega el 3 de abril y su cumplimiento satisfactorio estaba recompensado con el porcentaje de la nota final correspondiente a "Participación". A este respecto, una de las ventajas de la plataforma virtual ILIAS es que permite la subida de documentos por el alumnado garantizando su privacidad, de forma que sólo el profesorado correspondiente puede acceder a dichos documentos y a la vez quedan registradas digitalmente la fecha y la hora de la entrega, así como los datos identificativos del autor de los mismos.

Posteriormente se facilitaron las instrucciones para interpretar los resultados cuantitativos proporcionados por los instrumentos estandarizados, así como las indicaciones para plasmar el resultado de la evaluación en formato de informe psicológico, el cual conformaba la entrega final y del cual dependía el grueso de la calificación de la actividad. Asimismo, el documento de entrega final incluía un apartado para recopilar el feedback del alumnado con respecto al grado de satisfacción con la actividad realizada y otro apartado de reflexión en el que se invitaba a realizar 
recomendaciones para afrontar situaciones de crisis como la actual, en base a las conclusiones obtenidas durante el periodo de la autoevaluación. La resolución de dudas e incidencias se vehiculó a través del foro de la plataforma de docencia virtual y del correo electrónico, incidiendo en las ventajas de la primera herramienta para el beneficio general y la optimización de los recursos docentes, ya que las dudas y respuestas allí expresadas eran accesibles a todo el grupo. Más del 90\% del alumnado matriculado realizó de forma satisfactoria la actividad. En líneas generales, el feedback recibido del alumnado ponía en valor la posibilidad de realizar una autoevaluación en una situación real, entendiendo la utilidad de las herramientas y las características y requisitos del proceso de evaluación psicológica; como aspecto negativo se señalaba la amplia duración del periodo de autorregistro ( 2 semanas) y la consecuente demanda de atención y tiempo que implicaba la tarea.

\section{"Lecciones" aprendidas}

De esta experiencia profesional quizás resalta en primer lugar el carácter potenciador del aprendizaje que puede tener el hecho de contextualizar la enseñanza de técnicas de evaluación en un marco más amplio que el de las características y normas de aplicación estrictas, lo que facilita el establecer relaciones con la utilidad real que tienen dichas técnicas y procedimientos para los profesionales de la psicología y sus usuarios. También facilita la identificación del tipo de fenómenos que permiten analizar y valorar de forma más adecuada las conclusiones que el proceso de evaluación puede proporcionar para la intervención psicológica eficaz. Desde este punto de vista, parece deseable invertir recursos en diseñar experiencias de aprendizaje que integren distintas técnicas y formatos de evaluación para el abordaje comprehensivo de una misma situación, poniendo el foco en el proceso. A este respecto, es importante realizar una planificación correcta del mismo, anticipando las dificultades que el alumnado se puede encontrar y proporcionando instrucciones lo más detalladas posibles de los apartados que puedan implicar mayor dificultad. Esta cuestión es aún más saliente en el contexto de la docencia online, donde las posibilidades de interacción natural alumnado-docente se ven seriamente mermadas.

A la hora de abordar tareas complejas y que resultan nuevas para el alumnado es conveniente canalizar la comunicación y resolución de dudas de forma que se optimice el tiempo invertido en ello. La herramienta de creación de foros que traen incorporadas las plataformas de 
docencia virtual como ILIAS o Moodle facilitan esta cuestión. Sin embargo, el estudiantado no siempre está familiarizado con el funcionamiento y la etiqueta digital (o normas adecuadas de uso) de los foros, seguramente por el desarrollo y popularidad de otro tipo de medios y formatos de comunicación digital en la última década. Por esto, puede resultar conveniente dedicar el tiempo necesario a explicar al alumnado de forma explícita las normas y el porqué del uso preferente de esta herramienta, pues puede revertir en una experiencia docente mucho más satisfactoria y amable.

Aunque la autoevaluación evita varias de las dificultades e implicaciones éticas que conlleva el realizar una evaluación a terceras personas, no está exenta de consideraciones deontológicas y hay que prestar atención a la posibilidad de que pueda conllevar efectos indeseados para determinadas personas. Por ejemplo, se ha observado que ciertos factores disposicionales (como la tendencia a la autofocalización negativa ante situaciones de estrés) pueden predisponer al aumento de experiencias afectivas de tipo negativo durante la autoobservación (Pritchard, Wilson, \& Yamnitz, 2007), por lo que es recomendable proporcionar al alumnado instrucciones profilácticas a este respecto, así como facilitar vías de comunicación individuales y confidenciales que permitan la identificación de casos sensibles.

\section{Conclusiones}

La situación de confinamiento domiciliario derivada del Estado de Alarma por la crisis sanitaria COVID-19 requirió de un esfuerzo colectivo a todos los niveles y en todos los segmentos de la sociedad. En el área de formación, los docentes de todos los niveles educativos se encontraron con la necesidad de realizar una adaptación sobre la marcha de las actividades didácticas con los recursos disponibles, casi siempre limitados. Sin embargo, lo excepcional de la situación también proporcionó una oportunidad para observar en tiempo real la reacción de las personas de todo tipo y condición a una situación de crisis global, facilitando una experiencia de aprendizaje para el alumnado de psicología difícil de reproducir en circunstancias normales. La incorporación de las herramientas digitales y la utilización adecuada de los canales de comunicación telemática resultaron fundamentales para la optimización de los recursos personales docentes y evitar la duplicación de esfuerzos. 
En esta experiencia educativa se ha realizado una adaptación de instrumentos disponibles para su uso con fines docentes y originalmente diseñados para ser aplicados con papel y lápiz, con el objetivo de poder ser usados en las circunstancias vividas durante el confinamiento. En el ámbito profesional, siguiendo las tendencias tecnológicas imperantes, las herramientas de evaluación psicológica tradicionales de papel y lápiz (tests y cuestionarios) van dejando paso progresivamente a instrumentos diseñados ex profeso en formato digital, que son presentados y cumplimentados mediante dispositivos electrónicos (ordenadores personales, tabletas o smartphones). Sin embargo, el hecho de que sean empresas privadas las propietarias de los derechos de reproducción de algunos de los instrumentos más populares (con la consecuente barrera económica de acceso) dificulta las experiencias de aprendizaje del alumnado con este tipo de herramientas técnicas. Puesto que una gran parte de los instrumentos de evaluación psicológica se desarrollan en el ámbito académico y posteriormente sus derechos son cedidos a empresas especializadas para su explotación económica, es importante que la Comunidad Universitaria reflexione acerca de la necesidad que existe de acceso con fines pedagógicos a la tecnología propia del área de estudio y que se exploren posibles alternativas en cuanto a licencias de propiedad intelectual se refiere.

Figura 1. Herramienta de autorregistro diario.

\begin{tabular}{|c|c|c|c|c|c|c|}
\hline $\begin{array}{l}\text { Periodo del día } \\
\text { (indicar hora de } \\
\text { registro) }\end{array}$ & $\begin{array}{l}\text { Grado de } \\
\text { bienestar } \\
\text { percibido (del } 1 \\
\text { al 10, donde } 10 \\
\text { es un bienestar } \\
\text { máximo) }\end{array}$ & $\begin{array}{l}\text { Grado de ansiedad } \\
\text { percibido (del } 1 \text { al } \\
\text { 10, donde } 10 \text { es } \\
\text { ansiedad muy } \\
\text { elevada). } \\
\text { Indicar además si se } \\
\text { identifican alguno de } \\
\text { los fenómenos } \\
\text { asociados vistos en } \\
\text { clase (fuertes } \\
\text { palpitaciones, } \\
\text { pensamientos } \\
\text { rumiativos, etc.) }\end{array}$ & $\begin{array}{l}\text { Estado de ánimo (del } \\
1 \text { al 10, donde } 10 \text { es } \\
\text { un estado de ánimo } \\
\text { excelente). } \\
\text { Indicar además si se } \\
\text { identifican algunos } \\
\text { de los fenómenos } \\
\text { asociados vistos en } \\
\text { clase. (sentimiento de } \\
\text { desesperanza, } \\
\text { abatimiento, } \\
\text { pensamientos } \\
\text { negativos etc.) }\end{array}$ & $\begin{array}{l}\text { En caso de que el } \\
\text { grado de bienestar, } \\
\text { y ánimo fueran } \\
\text { bajos, o ante } \\
\text { niveles altos de } \\
\text { ansiedad indicar si } \\
\text { se realizó algún } \\
\text { tipo de actividad } \\
\text { encaminada a } \\
\text { modificar estos } \\
\text { niveles. }\end{array}$ & $\begin{array}{l}\text { Actividades } \\
\text { realizadas } \\
\text { previamente al } \\
\text { registro en el } \\
\text { periodo y hora } \\
\text { indicados. }\end{array}$ & $\begin{array}{l}\text { ¿Crees que tu estado } \\
\text { de ánimo, bienestar y } \\
\text { ansiedad } \\
\text { experimentada han } \\
\text { dependido de algún } \\
\text { factor concreto? Si es } \\
\text { así, indicar cuál. }\end{array}$ \\
\hline \multicolumn{7}{|l|}{ Por la mañana } \\
\hline \multicolumn{7}{|l|}{ Al mediodía } \\
\hline \multicolumn{7}{|l|}{ A media tarde } \\
\hline \multicolumn{7}{|l|}{$\begin{array}{l}\text { Antes de ir a la } \\
\text { cama }\end{array}$} \\
\hline \multicolumn{7}{|c|}{ OBSERVACIONES: } \\
\hline
\end{tabular}

\section{Referencias}

Bai, Y., Lin, C.-C., Lin, C.-Y., Chen, J.-Y., Chue, C.-M., \& Chou, P. (2004). Survey of stress 
reactions among health care workers involved with the SARS outbreak. Psychiatric Services, 55(9), 1055-1057.

Corbetta, P. (2007). Metodología y técnicas de investigación social. McGraw-Hill/Interamericana de España, SAU.

Haynes, S. N., Godoy, A., \& Lázaro, A. G. (2014). Cómo elegir el mejor tratamiento psicológico. Ediciones Pirámide.

Pastor Morales, J. M., \& Río Sánchez, C. del. (2018). Ética profesional en salud mental: guía de actuación ético-deontológica y legal en Psicología Clínica y Psiquiatría. Ediciones Pirámide.

Pérez-Álvarez, M. (2017). El turno transdiagnóstico y el retorno de la psicopatología: el tema de nuestro tiempo en psiquiatría. Cuad Psiquiat Comunitaria, 14(1), 35-52.

Pritchard, M. E., Wilson, G. S., \& Yamnitz, B. (2007). What predicts adjustment among college students? A longitudinal panel study. Journal of American College Health, 56(1), 15-22. https://doi.org/10.3200/JACH.56.1.15-22 


\title{
Con la mirada puesta en los Objetivos de Desarrollo Sostenible: aprendizaje cooperativo en la universidad para construir una sociedad inclusiva
}

\author{
Azahara Jiménez-Millán \\ Carmen María Hernández-Lloret \\ María García-Cano Torrico \\ José Luis Álvarez-Castillo \\ Universidad de Córdoba
}

Palabras clave: Objetivos de Desarrollo Sostenible, Aprendizaje cooperativo, sociedad inclusiva, experiencia didáctica, universidad.

\section{Introducción}

La actual situación de migraciones en España la ha posicionado en un país tan multicultural como Alemania, Francia o Reino Unido encontrándose ante el reto de construir una sociedad democrática, abierta y plural y huir de valores que encarnen el autoritarismo, el racismo o xenofobia, semillas de conflictividad y violencia (Ovejero, 2018). En este sentido, la educación juega un papel clave en la construcción de una anhelada sociedad inclusiva:

No olvidemos que trabajar cooperativamente constituye un auténtico entrenamiento para una democracia real, que por fuerza tiene que ser participativa, tolerante, solidaria y capaz de integrar a las personas diferentes, sea cual sea el criterio de tal diferencia. Por consiguiente, el aprendizaje cooperativo es un eficaz antídoto contra todo sectarismo y fundamentalismo, sobre todo porque contribuye a satisfacer la necesidad de pertenencia del alumnado y a aumentar la aceptación social y la ayuda mutua (Ovejero, 2018, p.170). 
En esta línea se halla de manera prioritaria el conjunto de los Objetivos de Desarrollo Sostenible (ODS) definidos por Naciones Unidas. Principalmente, los objetivos y acciones planteadas en el marco de esta experiencia contribuyen al cumplimiento del objetivo número 4 centrado en una 'Educación de calidad', concretamente, entre sus metas, se opta por avanzar en algunas de ellas como la número 4.7. De aquí a 2030, asegurar que todos los alumnos adquieran los conocimientos teóricos y prácticos necesarios para promover el desarrollo sostenible, entre otras cosas mediante la educación para el desarrollo sostenible y los estilos de vida sostenibles, los derechos humanos, la igualdad de género, la promoción de una cultura de paz y no violencia, la ciudadanía mundial y la valoración de la diversidad cultural y la contribución de la cultura al desarrollo sostenible; y el ODS 16 "Paz, justicia e instituciones sólidas” y más específicamente, la meta 16.7. Garantizar la adopción en todos los niveles de decisiones inclusivas, participativas y representativas que respondan a las necesidades.

En comparación con otras formas de estructurar el aprendizaje en el aula desde una perspectiva de aprendizaje individual (individualista y competitiva) (Iglesias, González y Fernández-Río, 2017), los enfoques colaborativos promueven un aprendizaje de mayor calidad, una comprensión más profunda del contenido del curso, más creatividad, mayor retención de material y mayor satisfacción de los estudiantes (Gaudet et al., 2010; Johnson, Johnson y Smith, 2014; Poort, Jansen y Hofman, 2020). La cooperación favorece el aprendizaje basado en la resolución de problemas y retos, facilita la iniciativa personal y otorga al estudiantado un control sobre sus procesos de aprendizaje. En definitiva, habilidades metacognitivas ubicadas en las estrategias centradas en la gestión del propio aprendizaje por parte del estudiante que permite pasar de una comprensión individualizada del aprendizaje a un aprendizaje situado y distribuido (Cañabate y Colomer, 2020; Shpeizer, 2019).

En relación con los fundamentos teóricos de la eficacia del aprendizaje cooperativo, Anastasio Ovejero (2018) considera que el trabajo empírico en el aprendizaje cooperativo es mayor que el teórico, y pretende contribuir a este vacío. De esta manera, la organización de los aprendizajes en el contexto del sistema educativo ignora la relevancia de la cooperación como rasgo clave en la evolución humana y da como válidos normas y criterios propias de la cultura industrial (fragmentación de aprendizajes, su individualización y evaluación como control de 
objetivos prefijados y externos al alumnado) lo que origina hoy día todavía nos encontremos ante innovaciones marginales (Rué, 2020).

Entre las características que definen el aprendizaje cooperativo se encuentran interdependencia positiva, interacción directa cara a cara, responsabilidad individual, habilidades sociales e interpersonales, autoevaluación grupal, participación equitativa, igualdad de oportunidades para el éxito, heterogeneidad y liderazgo compartido (Iglesias, González y Fernández-Río, 2017; Ovejero, 2018; Pújolàs, 2009). Estos rasgos favorecen el aprendizaje tanto directamente a través del trabajo en equipo como indirectamente por medio de la creación de un clima de aula positivo, basado en el apoyo social y las relaciones constructivas entre las y los estudiantes (Gillies, 2016). Incluso se ha sugerido que el aprendizaje cooperativo no contribuye por sí solo al logro académico, sino que lo hace cuando va acompañado de actitudes cooperativas y conductas prosociales (Premo, Cabagnetto y Davis, 2018). Por ello, aunque el aprendizaje cooperativo en la Universidad es concebido como un proceso complejo (Smart, 2009), que requiere una planificación rigurosa (Cañabate y Colomer, 2020), constituye un valor formativo indispensable tanto a nivel de aula como en la formación de una ciudadanía del siglo XXI que no podemos dejar escapar.

Por otra parte, la literatura destaca que la internacionalización, como aspecto ineludible en la actual educación superior, junto a una mayor diversidad en las aulas universitarias brinda oportunidades para desarrollar habilidades y actitudes valiosas como son la comunicación y competencia intercultural y habilidades de colaboración y mentalidad global (De Hei et al., 2019; Poort et al., 2020). Asimismo, es una fuente de inclusión social mediante los aprendizajes que incluyen valores y formas de pensar. De esta forma, la cooperación supera un paradigma centrado en potenciar el pensamiento, el conocimiento, considerado volátil, para potenciar el razonamiento (Cañabate y Colomer, 2020), cuestión insoslayable en el ámbito de la Educación en la que nos situamos en la formación inicial docente. De hecho, la Asociación Americana de Colleges y Universidades (2011) ha identificado los proyectos cooperativos como una de las prácticas de alto impacto en la educación superior.

Por todo ello, Ovejero (2018) destaca que el aprendizaje cooperativo es "más que una técnica pedagógica" y cualquier docente que pretenda este fin debe incorporar a esta práctica 
docente los ingredientes de la pedagogía crítica siendo intelectuales transformadores (Giroux, 1990) dados los efectos dañinos de la hegemonía neoliberal.

\section{Objetivo/Descripción de la experiencia}

La experiencia profesional sobre aprendizaje cooperativo en el aula universitaria se ajustó a un objetivo general muy concreto: "Conocer en qué medida el uso de técnicas de aprendizaje cooperativo (TAC) contribuyen a la mejora del clima de aula, así como a un posicionamiento más favorable hacia la inclusión de la diversidad en la universidad".

Por tanto, y considerando el objetivo anterior, se diseñaron TAC para alcanzar metas más específicas. Además, en todo momento estas técnicas se acomodaron al contexto particular en el que tuvieron lugar y para el que fueron diseñadas (conocimientos y competencias de las asignaturas implicadas según sus respectivas guías docentes, posibles necesidades y ritmos del alumnado, y medidas sociosanitarias introducidas a consecuencia de la COVID-19).

Por un lado, y una vez formados los equipos de trabajo de entre 4 y 5 personas cada uno, se comenzó planteando técnicas que permitieran al alumnado conocerse entre sí. Al mismo tiempo, estas técnicas facilitaron la asignación de roles entre el alumnado (Véase Figura 1) y el diseño de normas de organización y funcionamiento, lo que supondría después una economía relativa de esfuerzos en el desarrollo del trabajo grupal. Todo esto quedó reflejado bajo un 'contrato de aprendizaje' por el que los integrantes del equipo se responsabilizaban de manera compartida y comprometían con el debido desarrollo del trabajo final de la asignatura.

Figura 1. Roles habituales en un grupo de trabajo (Barkley, Cross y Major, 2012, p.52). 


\begin{tabular}{||l|l|}
\hline Facilitador & $\begin{array}{l}\text { Modera todos los diálogos del equipo, manteniendo en cada trabajo la atención del grupo } \\
\text { centrada en la tarea y se ocupa de que todo el mundo lleve a cabo su parte del trabajo. } \\
\text { Los facilitadores tratan de garantizar que todos los miembros tengan oportunidad de } \\
\text { aprender, de participar y de ganarse el respeto de los demás miembros del grupo. }\end{array}$ \\
\hline Secretario & $\begin{array}{l}\text { Registra todas las actividades encargadas al equipo. Los secretarios toman notas que } \\
\text { resumen los diálogos, mantienen al dia todos los registros necesarios (incluyendo las } \\
\text { hojas de datos, como las de asistencia y las verificaciones de los trabajos para casa) y } \\
\text { cumplimentan las hojas de trabajo o redactan los trabajos escritos para su entrega al pro- } \\
\text { fesor. }\end{array}$ \\
\hline Portavoz & $\begin{array}{l}\text { Actúa como tal en nombre del grupo y resume oraimente las actividades o conclusiones } \\
\text { del grupo. El portavoz ayuda también al secretario en la preparación de informes y hojas } \\
\text { de trabajo. }\end{array}$ \\
\hline Cronometrador & $\begin{array}{l}\text { Indica al grupo las limitaciones de tiempo, trabaja con el facilitador para mantener el gru- } \\
\text { po centrado en la tarea y puede también asumir el rol de cualquier miembro del grupo } \\
\text { ausente. El cronometrador es responsable de la organización y de garantizar que el área } \\
\text { de trabajo del equipo quede en perfectas condiciones al acabar la sesión. }\end{array}$ \\
\hline $\begin{array}{l}\text { Supervisor } \\
\text { de carpetas }\end{array}$ & $\begin{array}{l}\text { Si el profesor ha creado carpetas de trabajo del grupo, el supervisor se encarga de la car- } \\
\text { peta del equipo, distribuye todo el material que no sean hojas de datos y traslada todos } \\
\text { los papeles, tareas o notas a los miembros del equipo. Los supervisores de carpetas } \\
\text { garantizan que todos los materiales de clase relevantes estén en la carpeta al final de } \\
\text { cada clase. }\end{array}$ \\
\hline Comodin & \begin{tabular}{l} 
Asume el rol de cualquier miembro ausente y ocupa su puesto siempre que sea preciso. \\
\hline
\end{tabular} \\
\hline
\end{tabular}

A continuación, se trabajaron técnicas que contribuyeron al acceso, a la búsqueda y a la discusión de información relacionada con las asignaturas haciendo uso del diálogo, el respeto y la escucha activa como herramientas principales. Asimismo, se sucedieron otras técnicas o actividades que buscaban poner a prueba al alumnado en lo relativo al proceso de toma de decisiones de manera democrática. Tras aportar cada miembro su idea libremente al equipo, este debatiría a continuación qué reflexión era la más acertada conforme a lo que se pedía.

Finalmente, se diseñaron técnicas cuya finalidad era mejorar la redacción del trabajo final, así como darle un enfoque de equipo. Por ejemplo, en parejas o el grupo en su conjunto, se revisaba detenidamente el texto final valorando el uso adecuado de las reglas gramaticales y ortográficas, así como comprobando que se respondiera críticamente a lo que se pedía en los diferentes apartados. Además, y a expensas de conocer cómo había resultado el trabajo de equipo y su repercusión sobre el clima social de aula, por un lado, se reflexionó en voz alta junto a todo el alumnado en torno a esta cuestión, y, por otro lado, el alumnado de manera individual respondió a dos preguntas abiertas (diseñadas ad hoc en Google Forms) sobre algo que hubiera aprendido del equipo que probablemente no lo hubiera hecho solo o sola y algo que los demás miembros del equipo hubieran aprendido de uno o una y que probablemente no lo hubieran aprendido en otro circunstancia. 


\section{Contexto}

La experiencia docente tuvo lugar en los Grados de Educación Infantil y Primaria de la Facultad de Ciencias de la Educación de la Universidad de Córdoba durante el primer cuatrimestre del curso académico 2020/2021. Concretamente, en la parte práctica presencial de las asignaturas Diversidad, Convivencia y Educación Inclusiva en Educación Infantil de segundo curso, y en Fundamentos Teóricos e Históricos de la Educación Primaria junto a alumnado de primer curso. En total, participaron 210 estudiantes, siendo el porcentaje de mujeres superior al de hombres, especialmente en el grupo de Educación Infantil, quienes conformaron entre sí pequeños grupos de trabajo (entre 4-5 personas).

Por otro lado, y teniendo en cuenta las medidas sociosanitarias introducidas como consecuencia de la COVID-19, en el diseño y puesta en marcha de las TAC en el contexto de las asignaturas, se introdujeron todas aquellas adaptaciones metodológicas pertinentes para evitar la pérdida de eficacia. Por ejemplo: uso de medios de comunicación digital como medios de comunicación y redacción del trabajo en grupo (Drive, Skype, Meet, Zoom, Discord u otros deliberados previamente por el alumnado), distancias mantenidas entre el alumnado (sistema de chequeo mediante código QR establecidos en cada mesa), ventilación de aulas y desinfección del área de trabajo. Además, cabe señalar el paso de la modalidad presencial a la virtual para el caso del grupo de Educación Primaria casi a finales del cuatrimestre, lo que supuso una adaptación añadida en la aplicación de algunas de las técnicas diseñadas.

\section{Aplicación y resultados}

Tras la aplicación de las TAC en la parte práctica de las asignaturas, y teniendo en cuenta los resultados derivados de la reflexión final grupal y la reflexión individual acerca del trabajo en grupo, encontramos las siguientes evidencias en relación con el clima de aula y su aportación al desarrollo de sociedades inclusivas en el marco de los Objetivos de Desarrollo Sostenible.

Por un lado, la reflexión final de grupo nos llevó a considerar la metodología basada en aprendizaje cooperativo una estrategia idónea para fomentar el clima social entre los miembros del 
equipo de trabajo, así como entre el resto de compañeros y compañeras del aula. Pues así lo expresaban algunas y algunos estudiantes:

Siempre a la hora de trabajar en grupo puede pasar, ocurrir dos cosas: que el grupo, que las relaciones interpersonales se hagan más fuertes o... o al revés. En este caso, pues... como todo ha estado muy bien organizado, yo creo que aunque hayamos tenido nuestros rocecillos, porque es verdad que todo el mundo pues trabaja a su ritmo y eso pues eh... tiene unas repercusiones, ¿no?, pero yo creo que de manera general, pues nos hemos unido un poco, nos conocemos mucho más el grupo y hemos unido un poco unos lazos que no creo que se nos olviden nunca, la verdad (Alumno Educación Primaria).

Así el alumnado manifiesta en dos circunstancias al trabajar con otras personas diferentes dentro de un grupo: el desarrollo de relaciones positivas o, por el contrario, relaciones que dificulten el ritmo y la armonía del trabajo. Además, relacionan el trabajo cooperativo con el clima social de aula mediante aspectos como son fomento del respeto, la escucha activa y la autorrealización personal junto al grupo. De este modo lo indicaba una estudiante:

Que yo en ese aspecto estoy totalmente de acuerdo con Antonio, porque yo antes hacía debates en mi colegio y eso, y ni siquiera hablaba, entonces gracias al clima y al buen ambiente que ha habido en la clase, pues he podido hablar mucho porque yo antes era un poco más tímida y entonces como que eso me ha ayudado a eso a poder hablar más en la clase y a poder desarrollar más mis habilidades con los compañeros y compañeras (Alumna Educación Primaria).

Por otro lado, la reflexión individual de grupo nos llevó a considerar que, mediante la metodología basada en aprendizaje cooperativo, el estudiantado había desarrollado paciencia, creatividad, había conocido nuevas formas de trabajar, había reflexionado con mayor profundidad sobre los temas de las asignaturas, había aprendido a ser resolutivo, entre otras cuestiones que no hubiera sido capaz de hacerlo sin el grupo.

Y, al final, al estar en grupo pues aprendes que no solo está tu manera de hacer las cosas, que hay muchas más maneras de hacerlas, y pues... te puedes enriquecer con muchas ideas, a la hora de expresarte también (Alumna Educación Infantil). 
Además, en cuanto a los posibles aspectos que el resto de miembros del grupo pudieran haber aprendido de algún compañero o compañera surgieron, por ejemplo, la capacidad de organización, la paciencia, el desarrollo de vocabulario, la mejora en la redacción de textos, la búsqueda y referenciación de la información, la mejora de aspectos formales y decorativos de los trabajos, la reflexión nuevamente sobre el contenido de las asignaturas, entre otros:

Por ejemplo, a quien se le dé muy bien redactar, es verdad que a Carmen se le da muy bien redactar y todo eso, pero a lo mejor el hecho de que lo hagamos más o menos todas juntas alivia a Lidia que le cuesta un poco más. Ahora sabe redactar un poco mejor que antes, eso porque está aprendiendo... (Alumna Educación Infantil).

Miriam también, pero Carmen habla técnica no, lo siguiente, y a mí esas palabras me parecen tan complicadas... que yo antes no podía; entonces, a mí, gracias a ellas, pues mi vocabulario ha aumentado (Alumna Educación Infantil).

A pesar de las dificultades introducidas por la COVID-19, la mayor parte de las respuestas abiertas han destacado los aspectos positivos de esta metodología en relación con el clima de aula ${ }^{1}$.

\section{Conclusiones}

Los beneficios evidenciados en esta experiencia basada en aprendizaje cooperativo contribuyen a la construcción de una sociedad solidaria y plenamente democrática. En este sentido, coincidimos con la propuesta que elaboran autores como Ovejero (2018) cuando señalan que esta metodología figure como columna vertebral del sistema educativo. Y, de esta manera, fomentar el desarrollo del pensamiento crítico y de un aprendizaje basado en la cooperación altruista que den lugar a nivel global a sociedades más justas e inclusivas.

En conclusión, como resaltan Torrego y Negro (2014, p.15):

El aprendizaje cooperativo no es solo una alternativa metodológica y potencialmente eficaz para enseñar, sino una estructura didáctica con capacidad para articular los procedimientos,

${ }^{1}$ Fue grabado un vídeo Aprendizaje Cooperativo y Clima de Aula en los Grados de Educación: https://www.youtube.com/watch?v=jacw2MaDY0Y\&t=5s 
las actitudes y los valores propios de una sociedad democrática que quiere reconocer y respetar la diversidad humana.

Financiación o apoyos: Este trabajo ha sido realizado tanto en el marco de un proyecto de investigación estatal (REF. EDU2017 82862-R) financiado por el Ministerio de Economía, Industria y Competitividad de España, como de un proyecto de innovación docente (REF. 20202-4001) financiado por la Universidad de Córdoba.

\section{Referencias}

Barkley, E. F., Cross, K. P., Major, C. H. (2012). Técnicas de Aprendizaje Cooperativo. Manual para el Profesorado Universitario. Ediciones Morata.

Cañabate, D. y Colomer, J. (2020). El aprendizaje cooperativo en la universidad del siglo XXI. Propuestas, estrategias y reflexiones. Graó.

Chiva, Ò., Gil, J., Corbatón, R. y Capella, C. (2016). El aprendizaje servicio como propuesta metodológica para una pedagogía crítica. RIDAS, Revista Iberoamericana de Aprendizaje Servicio, 2, 70-94.

Gaudet, A. D., Ramer, L. M., Nakonechny, J., Cragg, J. J., \& Ramer, M. S. (2010). Small-group learning in an upper-level university biology class enhances academic performance and student attitudes toward group work. PLoS One, 5(12), 1-10. https://doi.org/10.1371/journal.pone.0015821

Gillies, R. M. (2016). Cooperative learning: Review of research and practice. Australian Journal of Teacher Education, 41(3). http://dx.doi.org/10.14221/ajte.2016v41n3.3

Giroux, H. A. (1990). Los profesores como intelectuales. Paidós.

De Hei, M., Tabacaru, C., Sjoer, E., Rippe, R., \& Walenkamp, J. (2019). Developing intercultural competence through collaborative learning in international higher education. Journal of Studies in International Education, 24(2), 190-211. https://doi.org/10.1177/1028315319826226 
Iglesias, J. C. González, L. F. y Fernández-Río, J. (Coords.) (2017). Aprendizaje cooperativo: Teoría y práctica en las diferentes áreas y materias del currículum. Pirámide.

Johnson, D. W., Johnson, R. T., \& Smith, K. A. (2014). Cooperative learning: Improving university instruction by basing practice on validated theory. Journal on Excellence in College Teaching, 25(3-4), 85-118.

Ovejero, A. (2018). Aprendizaje cooperativo crítico. Mucho más que una eficaz técnica pedagógica. Pirámide.

Premo, J., Cabagnetto, A., \& Davis, W. B. (2018). Promoting collaborative classrooms: The impacts of interdependent cooperative learning on undergraduate interactions and achievement. CBE Life Sciences Education, 17(2). http://dx.doi.org/10.1187/cbe.17-08$\underline{0176}$

Tomasello (2010). ¿Por qué cooperamos? Katz Editores.

Poort, I., Jansen, E. \& Hofman, A. (2020). Does the group matter? Effects of trust, cultural diversity, and group formation on engagement in group work in higher education. Higher Education Research \& Development, $1-16$. https://doi.org/10.1080/07294360.2020.1839024

Pújolàs, P. (2009). 9 ideas clave. El aprendizaje cooperativo. Graó.

Shpeizer, R. (2019). Towards a successful integration of project-based learning in higher education: Challenges, technologies and methods of implementation. Universal Journal of Educational Research, 7(8), 1765-1771. https://doi.org/10.13189/ujer.2019.070815

Torrego, J. C., y Negro, A. (2014). Aprendizaje cooperativo en las aulas. Alianza Editorial.

Association of American Colleges and Universities. (2011). The LEAP vision for learning: Outcomes, practices, impact, and employers' views. https://www.aacu.org/sites/default/files/files/LEAP/HIP_tables.pdf 
Rué, J. (2020). Treinta años de aprendizaje cooperativo. Qué hemos aprendido y qué nos falta por aprender. En D. Cañabate y J. Colomer (Coords.), El aprendizaje cooperativo en la universidad del siglo XXI. Propuestas, estrategias y reflexiones. Graó. 


\title{
"Fármacos musicales": una solución a la docencia en pandemia
}

\author{
Ana Isabel Serrano
}

Roberto Anadón

Universidad de Zaragoza

Palabras clave: Píldora musical anti-COVID; píldora musical; píldora audiovisual; píldora didáctica.

\section{Introducción}

El aislamiento en los domicilios derivado de la COVID-19 durante los meses de marzo a mayo del pasado año supuso que el único desempeño docente factible fuera realizado en modalidad no presencial. Gracias a que, sobre todo en la década precedente, se habían consolidado numerosas formas de comunicación digital, se pudieron aplicar metodologías basadas en las nuevas tecnologías que estaban al alcance de toda la comunidad universitaria. Estas TIC fueron una herramienta que ya había contribuido a democratizar el proceso de comunicación (Anzano, Vázquez, Latorre y Liesa, 2020) y que permitió abrir horizontes de aprendizaje utilizando los recursos sin restringirlos a un tiempo y un espacio (Muñoz, Espiñeira y Rebollo, 2016). Desde hace algunos años hemos sido conscientes de la importancia de esa competencia digital y de que el profesorado trabajase de manera innovadora incorporando las TIC a la vida del aula, integrándolas en las actividades diarias de su alumnado, aprovechando todas las posibilidades que éstas brindan a la enseñanza y al aprendizaje (Liesa, Vázquez y Lloret, 2016).

La nueva situación debida a la pandemia despojó a los docentes de un día para otro de sus aulas y despachos, conduciendo su magisterio a un escenario en el que los recursos parecían demasiado limitados. Esto produjo un bloqueo inicial que pronto dio pasó a la búsqueda de soluciones, que vieron en la emisión de clases a través de Google Meet y en la elaboración de píldoras audiovisuales la combinación más idónea para su propósito. 
Estas píldoras musicales se graban con una cámara de vídeo, pudiendo editarse posteriormente a voluntad. Su duración suele ser breve, aportando exclusivamente la esencia del contenido a explicar, atendiendo a necesidades concretas, gracias a un mensaje sencillo y clarificador. En este sentido, Borrás Gené las define como "la unidad más pequeña de información dotada de significado y totalmente independiente, de tal manera que se pueda utilizar de forma autónoma. A su vez, también puede formar parte de un curso más extenso" (citado en Muñoz, Espiñeira y Rebollo, 2016, p. 158). Eines, Aranda y Amilivia añaden que "con las Píldoras de Aprendizaje asumimos el principio enunciado por Gardner y Boix: menos, es más” (2018, p. 17).

El uso de estas cápsulas de conocimiento ayuda a nuestra docencia por partida doble. En primer lugar, son de utilidad para mejorar la adquisición de competencias musicales, proporcionando recursos que atienden a la idiosincrasia de una materia eminentemente práctica y, en segundo lugar, promueven sinergias emocionales que emulan las se producen en la docencia presencial en el aula de música. Esta naturaleza bifronte nos permite, con una única acción, bifurcar la enseñanza atendiendo a estas necesidades específicas de contenido musical y ampliarla al trabajo de otras capacidades relacionadas con la motivación y la expresividad artística.

Que estos materiales se ubiquen en Internet mejora incluso la enseñanza exclusivamente presencial, ya que las posibilidades de una consulta ilimitada en la red proporcionan el refuerzo y la interiorización necesarios para atender a la diversidad y los ritmos personales de asimilación de cada uno de los discentes, permitiendo el estudio y feedback formativo fuera del aula, facilitando el repaso y dando cabida a mejorar el proceso de la práctica docente, lo que no sucede a veces en el efímero lapso de una clase. Como nos apuntaba Shinichi Suzuki, sin repetición no hay aprendizaje musical, ya que el talento no es innato, sino que hay que trabajarlo y exprimirlo al máximo para poder obtener logros que produzcan un aprendizaje significativo. Esto es posible gracias a la realización de vídeos "a la carta" que pueden ser visionados tantas veces como desee el usuario (Serrano y Anadón, 2020). Estas tabletas informativas permiten, además, ayudar en la evaluación final, ya que el alumnado realiza sus propias grageas de aprendizaje que envía como resultado de los conocimientos adquiridos.

Los recursos audiovisuales generados deben ser presentados en un formato atractivo que promueva su consumo, por lo que se tiene que acercar su diseño al mundo del estudiante con tareas motivadoras basadas en el uso de las TIC (Hernández, 2013) y que pueden tener en el ordenador 
o el teléfono un aliado indispensable. Y es que es un hecho constatable que el uso del teléfono móvil para recabar información se extiende cada vez más entre los estudiantes de los grados, convirtiéndose en un poderoso y atractivo instrumento complementario en nuestro día a día docente, ya que es considerado por los discentes como un medio cercano (Anadón y Serrano, 2018).

Este extra de estimulación también alcanza y alienta al profesorado, que encuentra en la preparación de los materiales un incentivo que les permite superar los obstáculos metodológicos aumentando su resiliencia para combatir las dificultades de la docencia a distancia. Su exposición semanal en Moodle genera, además, un incremento en el compromiso de ejecución y acentúa su prurito en la elaboración, impeliéndoles a dotar al producto de la mayor fundamentación y utilidad posible (Anadón y Serrano, 2017).

\section{Descripción de la experiencia/Objetivo}

Objetivos para el alumnado:

- Diseñar píldoras audiovisuales que permitan la adquisición de contenidos musicales de manera virtual.

- Motivar el estudio a través de las nuevas tecnologías.

- Mejorar el proceso de enseñanza-aprendizaje.

- Paliar la frustración y el miedo a una docencia exclusivamente online.

Objetivos para el profesorado:

- Aumentar la resiliencia para superar los obstáculos metodológicos de un magisterio totalmente telemático.

- Propiciar la innovación educativa y la actualización pedagógica.

- Implementar buenas prácticas docentes, la equidad educativa y la inclusión. 


\section{Contexto}

Los dos profesores integrantes de esta experiencia imparten asignaturas de música en dos titulaciones diferentes de la Universidad de Zaragoza: en el Grado en Historia de Arte (Facultad de Filosofía y Letras), en la asignatura "Historia de la Música"; y en el Grado de Magisterio en Educación Primaria e Infantil (Facultad de Ciencias Humanas y de la Educación de Huesca) en las asignaturas "Fundamentos de Educación Musical” y "Desarrollo de la Expresión Musical”. El proyecto, realizado durante el curso 2019-2020, ha contado con un total de 98 participantes y se ha llevado a cabo durante los meses de confinamiento por la COVID (marzo a mayo de 2020).

\section{Aplicación y resultados}

Las píldoras musicales se grabaron con la cámara vídeo del teléfono móvil de los profesores, que las trabajaron en el ordenador con diversos programas de edición. La aplicación Google Meet del correo electrónico de la Universidad sirvió de plataforma de difusión y contacto. Para su diseño y temporalización se concretó la información a introducir ajustándola a los contenidos estipulados en las guías docentes de las asignaturas, que fueron revisadas por el profesorado de cada área y adaptadas a la situación de la no presencialidad.

En la elaboración de estos materiales, necesarios para poder continuar con el desarrollo de las asignaturas, primó su solvencia/capacidad para acercar el conocimiento de manera eficaz, accesible y cercana. El alumnado pudo disponer de estos recursos on-line, complementando las clases y tutorías retransmitidas a tiempo real. De esta manera, a la par de obtener información de índole práctica, podía sentir más cercana la presencia del profesorado al verlo participando activamente en estos audiovisuales.

La edición de estas grabaciones se llevó a cabo con el software Windows Movie Maker. Una vez finalizado el diseño, se subía a una cuenta del profesorado del canal YouTube cuya URL era compartida en la plataforma universitaria Moodle. 
Figura 1. Píldoras musicales en YouTube.

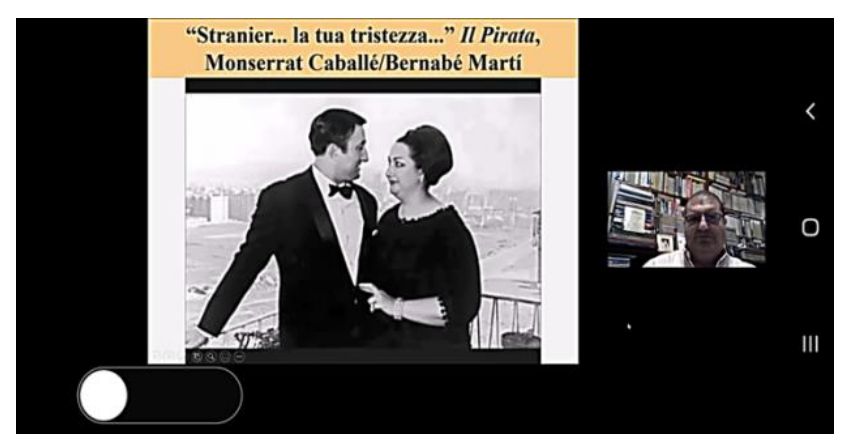

Estos vídeos se suben al canal de YouTube del profesorado para su posterior inserción en Moodle.

Los vídeos, una vez visualizados, eran trabajados en común en clase por videoconferencia a través de Google Meet, promoviéndose el debate y la discusión para su mejora, labor que favorecía a su vez una evaluación formativa. Todo ello implicaba también la puesta en marcha de trabajo colaborativo y de dinámicas activas, redundando en un acercamiento entre alumnado y enseñante cimentador de provechosos vínculos.

Figura 2. Ejemplo de píldora musical.

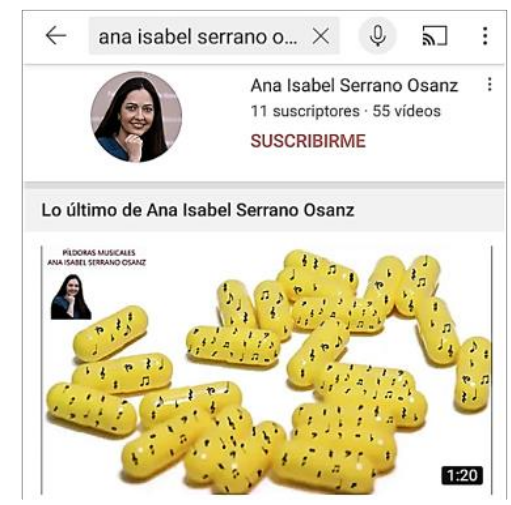

Estas píldoras fueron también un elemento para la mejora de la evaluación ya que, a su vez, se aprovecharon como medio para realizar parte de los exámenes del alumnado, que enviaba en este formato las actividades propuestas para examen. El estímulo en la preparación mejoró su trabajo autónomo y creatividad, sirviendo de instrumento de evaluación particular. El discente 
compartió estas elaboraciones personales con el profesorado a través de diversos tipos de herramientas como Dropbox, Google Drive, WeTransfer u otras aplicaciones gratuitas.

Figura 3. Más ejemplos de Píldoras musicales.

$\leftarrow$ PILDORAS CANCIONES MAGISTERIO

Nombre $\uparrow$

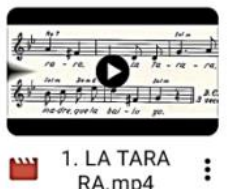

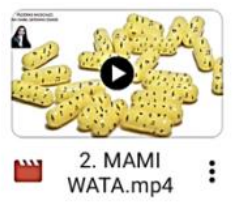

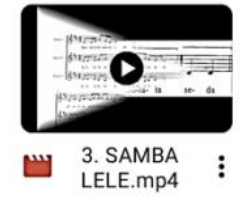

Q : :

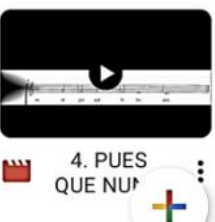

\section{Resultados}

Tras la experiencia, en el mes de junio se planteó un cuestionario con cinco preguntas para valorar el impacto de las píldoras musicales en el alumnado. Los resultados son positivamente reveladores: al menos el 80\% está muy de acuerdo en haber mejorado sus capacidades musicales; el $78 \%$ de que el proceso de enseñanza y aprendizaje ha sido motivador; el $75 \%$ que ha mitigado el miedo, la frustración y el vacío emocional de una docencia totalmente online; el $90 \%$ tiene la autopercepción de que la adquisición de información ha sido igualitaria e inclusiva y, finalmente, al $81 \%$ le gustaría seguir consumiendo este tipo de recursos para complementar su aprendizaje presencial.

Reflejamos la encuesta efectuada en la siguiente tabla:

Tabla 1. Impacto de las píldoras musicales en el alumnado

\begin{tabular}{llllll}
\hline $\begin{array}{l}\text { Variables } \\
\text { estudio }\end{array}$ & de & $\begin{array}{l}\text { 1. Muy de } \\
\text { acuerdo }\end{array}$ & 2. De & 3. No opino & 4. Discrepo \\
\hline 1. & $80 \%$ & $15 \%$ & $3 \%$ & $2 \%$ \\
2. & $78 \%$ & $17 \%$ & $4 \%$ & $1 \%$
\end{tabular}


$\begin{array}{lllll}3 . & 75 \% & 15 \% & 8 \% & 2 \%\end{array}$

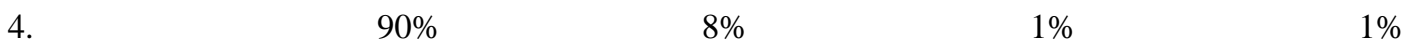

$\begin{array}{lllll}5 . & 81 \% & 16 \% & 2 \% & 1 \%\end{array}$

- $\quad 1=$ Se han mejorado las capacidades musicales.

- $\quad 2$ = Se ha ayudado al proceso de enseñanza y aprendizaje on-line de manera motivadora.

- 3 = Se ha mitigado el miedo, la frustración y el vacío emocional de una docencia totalmente online.

- $\quad 4$ = Autopercepción de que la adquisición de información ha sido igualitaria e inclusiva.

- 5 = Le gustaría seguir consumiendo este tipo de recursos para complementar su aprendizaje presencial.

Todos estos datos, en su conjunto, evidencian que gracias a un enfoque metodológico basado en las nuevas tecnologías la docencia exclusivamente a distancia es posible y, además, de manera eficaz, dinámica y motivadora. En consonancia con otros estudios como los de Casanova y Serrano, los estudiantes "han utilizado los recursos digitales con gran asiduidad y han optimizado el tiempo que tenían disponible fuera del aula para organizar su propio aprendizaje. Esto ha conllevado una mayor cantidad y calidad de estudio personal" (2016, p. 53). El uso de las píldoras educativas ha enriquecido también el proceso de la enseñanza y aprendizaje: "La utilización de estos recursos con fines educativos ha permitido fomentar un aprendizaje interactivo y significativo en los estudiantes" (Artal et al, 2019, p. 85). A tenor de los resultados de este proyecto, el profesorado ve validadas las ventajas en el campo de la innovación que suponen la edición de materiales multimedia y, por ende, el uso de las TIC, sin dejar de tener en cuenta, como ya apuntaba Álvarez Herrero (2015, p. 142) que "una buena metodología, asociada con una implementación de las TIC implica que la tecnología sea transparente y viva, que esté al servicio de la metodología”. Gracias a esta propuesta se facilita también la evaluación, obteniendo en el diseño de estos audiovisuales el modelo imprescindible para la mejora de la transferencia bidireccional del conocimiento.

Tanto alumnado como profesorado han diluido sus miedos y frustraciones iniciales ante la sobrevenida propuesta metodológica ejercitada exclusivamente on-line gracias a estos materiales diseñados ad hoc que atienden a necesidades específicas. La evaluación entre iguales practicada por los dos profesores intervinientes pone también de manifiesto que han acrecentado 
su resiliencia para superar los obstáculos metodológicos de un magisterio totalmente telemático y que han continuado con la labor iniciada en cursos anteriores de innovación y actualización pedagógica. Además, tienen la convicción de haber implementado buenas prácticas docentes, con especial atención a la equidad educativa y la inclusión.

En efecto, la preparación de las píldoras educativas ha promovido una educación igualitaria ya que el alumnado ha tenido los mismos materiales a su alcance y los ha podido aprovechar según su propia conveniencia y disponibilidad temporal. Asimismo, se ha favorecido la inclusión de los discentes que necesitan crear una metodología particular de estudio adecuada a sus diferentes capacidades o tiempos de aprendizaje, encontrando en esta posibilidad de estudio autónomo adaptado un salvoconducto óptimo para reforzar y mejorar su asimilación.

\section{Conclusiones}

El uso de píldoras musicales ha mitigado algunos de los efectos secundarios, o más precisamente, no deseados, derivados la docencia exclusivamente on-line debida a la COVID19. Refrendados por los resultados anteriormente expuestos extraídos del cuestionario propuesto al alumnado y por los derivados de nuestra evaluación, podemos afirmar que: se han generado unos recursos que han permitido aprender contenidos musicales de manera eficaz y motivadora; se ha mejorado el proceso de enseñanza y aprendizaje; se ha mitigado la falta de contacto físico entre los docentes y discentes pudiéndose reducir la ansiedad y frustración ante una docencia totalmente virtual; y se han podido consultar los materiales de manera equitativa e igualitaria.

Estas cápsulas formativas han ido creando, a su vez, un banco o repositorio en la red que puede ser consultado en cursos venideros. El coste económico es cero, ya que solo precisa de la motivación de profesorado y alumnado.

Debemos sumar un dato más derivado de la autoevaluación y heteroevaluación de las prácticas docentes: el profesorado también apreció las mejoras que produjeron las píldoras musicales ya que pudo concretar con éxito una información necesaria para implementar la 
asignatura. Además, la motivación emergente durante su misma realización y la buena acogida por parte de los alumnos, refrendada durante las clases telemáticas semanales, elevó su estado de ánimo, redujo su frustración y el estrés de tener que realizar una docencia virtual, lo que aumentó la su vez su resiliencia. Podemos concluir que, aun contando con unos recursos aparentemente insuficientes, ya que no se disponía del habitual espacio del aula y el contacto directo interpersonal, las nuevas tecnologías han permitido el logro de los objetivos docentes demostrando que, entre otras herramientas, las píldoras musicales son un aliado para el profesorado de estas disciplinas no solo poderoso y eficaz sino, vista su andadura, prácticamente irreemplazable.

\section{Referencias}

Álvarez Herrero, J. (2015). Tres propuestas prácticas para presentaciones y vídeos. En A. Giráldez (Ed.), De los ordenadores a los dispositivos móviles (pp. 141-161). Graó.

Anadón Mamés, R. y Serrano Osanz, A.I. (2017). Mejora de las prácticas docentes en el aula de música: creación de materiales multimedia. En J. L. Alejandre Marco (Ed.), Buenas prácticas en la docencia universitaria como apoyo de TIC. Experiencias en 2016 (pp. $253-$ 261). Prensas Universitarias.

Anadón Mamés, R. y Serrano Osanz, A.I. (2018). Elaboración de materiales multimedia: mejora de las metodologías activas en el aula de música. La difusión de la innovación docente: retos y reflexiones (pp. 253-259). Vicerrectorado de Política Académica y el Instituto de Ciencias de la Educación de la Universidad de Zaragoza.

Anzano Oto, S., Vázquez Toledo, S., Latorre Cosculluela, C., y Liesa Orús, M. (2020). Futuros docentes y redes sociales: usos e implicaciones según sexo y formación. Avances en Supervisión Educativa, 33, 1-25. https://doi.org/10.23824/ase.v0i33.670

Artal Sevil, J.S., Bernal Agustín, J. L. y Domínguez Navarro, J. A. (2019). Theory-Pills y contenidos enriquecidos. Recursos aliados del profesor en la docencia universitaria. En J. L. Alejandre Marco (Ed.), Buenas prácticas en la docencia universitaria como apoyo de TIC. Experiencias en 2018 (pp. 75-86). Prensas Universitarias. 
Casanova López, O. y Serrano Pastor, R. Ma . (2016). Flipped classroom en la educación musical. Eufonía, 68, 51-55.

Eines, M. E., Aranda, N. I. y Amilivia, L. A. (2018). Las Píldoras de Contenidos. Revista Iberoamericana de Tecnología en Educación y Educación en Tecnología, 21, 15-23. Recuperado de http://teyetrevista.info.unlp.edu.ar/TEyET/article/view/919/451

Hernández, D. M. (noviembre, 2013). La composición musical en el aula y las herramientas TIC, instrumentos motivadores para el aprendizaje cooperativo. II Congreso Internacional sobre Aprendizaje, Innovación y Competitividad (CINAIC). Recuperado de http://www.dmami.upm.es/dmami/documentos/liti/ACTAS_CINAIC_2013.pdf

Liesa Orús, M., Vázquez Toledo, S., Lloret Gazo, Jorge (2016). Identificación de las fortalezas y debilidades de la competencia digital en el uso de aplicaciones de internet del alumno de primer curso del Grado de Magisterio. Revista complutense de educación, 27(2), 845-862. http://dx.doi.org/10.5209/rev_RCED.2016.v27.n2.48409

Muñoz Cantero, J. M., Espiñeira Bellón, E. Ma. y Rebollo Quintela, N. (2016). Las píldoras formativas: diseño y desarrollo de un modelo de evaluación en el Espacio Europeo de Educación Superior. Revista de Investigación en Educación, 14(2), 156-169. Recuperado de http://webs.uvigo.es/reined/

Serrano Osanz, A.I. y Anadón Mamés, R. (marzo, 2020). Elaboración de píldoras audiovisuales para la mejora de la enseñanza-aprendizaje en el aula de música universitaria. VI Congreso CEIMUS. Zaragoza, España. 


\title{
Breakout Educativo Virtual como Buena Práctica en la Universidad para el Desarrollo de Objetivos de Desarrollo Sostenible durante la COVID-19
}

\author{
Carmen-María Hernández-Lloret \\ María-José Hernández-Lloret \\ Universidad de Córdoba
}

Palabras clave: Breakout educativo; gamificación; virtual; educación superior; COVID-19.

\section{Introducción}

Las universidades españolas se hallan sumergidas en un proceso de cambios incesantes como consecuencia de una serie de factores o condicionantes que se han ido sucediendo en el tiempo, y que actualmente nos comprometen. Estos factores se refieren a la entrada de nuestras instituciones en el Espacio Europeo de Educación Superior (EEES) y su misión fundamental de "formar a los estudiantes para que tengan éxito en un mundo complejo e interconectado que se enfrenta a rápidos cambios tecnológicos, culturales, económicos y demográficos" (Comisión Europea, 2021, https://ec.europa.eu/education/policies/innovation-in-education/about-innovationin-education_es) mediante la incorporación de las competencias en el proceso de enseñanzaaprendizaje (Moreno y Lopezosa, 2020; Moreno, 2019), la participación de una sociedad globalizada del conocimiento y de la información y, por si fuera poco, la situación socioeducativa ocasionada por la COVID-19 que requiere de la adopción de una modalidad dual de enseñanzaaprendizaje (presencial y virtual). En consecuencia, se sucede una sociedad que Bauman (2007) ha denominado líquida, donde se evidencian menos certezas y más inseguridades, y que pone a prueba a los profesionales de la educación quienes tienen que afrontar una serie de desafíos y retos globales para garantizar la calidad de las enseñanzas: la formación docente en competencias 
tecnológicas (Barrón, 2020) y la búsqueda de nuevas aplicaciones y metodologías activas en las enseñanzas que involucren al alumnado.

Así pues, y atendiendo a la era digital que permea de manera innegable en nuestros sistemas educativos y sociedades, aparecen experiencias docentes activas que integran el uso de las nuevas tecnologías. De hecho, informes recientes hablan acerca de la implicación de modelos y técnicas educacionales activas centradas en el alumnado y el uso de las TIC, que brindan capacidades como la resiliencia, la persistencia, la capacidad de adaptación y de resolución de problemas, y la capacidad para trabajar en equipo de manera asertiva (Alexander et al., 2019).

Por ejemplo, el modelo Technological Pedagogical Content Knowledge o TPACK (traducido del inglés como ‘Conocimiento Tecnológico y Pedagógico del Contenido') establece el marco de conocimientos que todo docente necesita para una práctica efectiva. En este sentido, integra el uso de la tecnología en ambientes de aprendizaje y apuesta por la interacción entre la tecnología, la pedagogía y el conocimiento del contenido (Mishra y Koehler, 2006).

Figura 1. Representación del modelo TPACK. Fuente: adaptado de Koehler y Mishra (2008) por MorenoCorrea (2020).

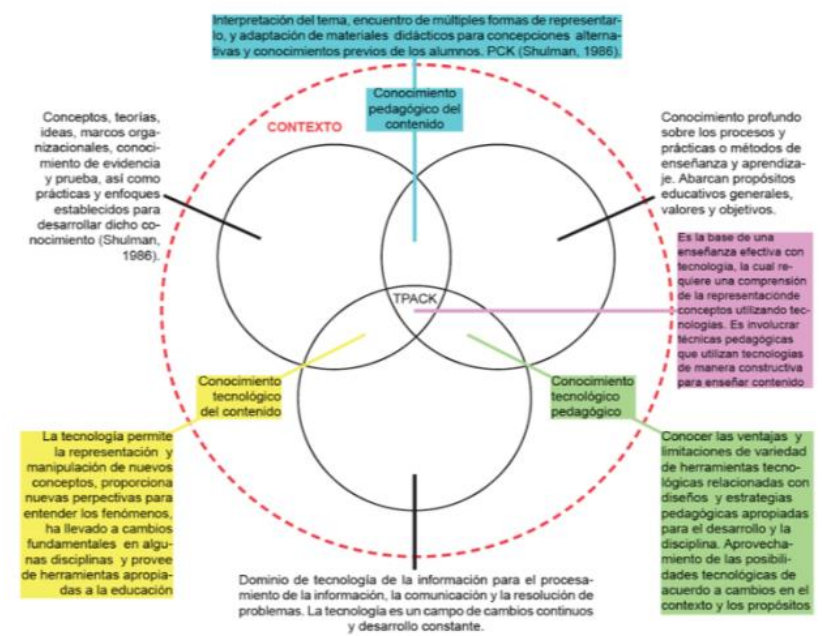

Teniendo en cuenta estos tres conocimientos que señala el TPACK, se pueden encontrar metodologías o técnicas activas de aprendizaje que integran la tecnología, la pedagogía y el dominio del contenido, tal como puede ser la gamificación o el aprendizaje basado en el juego (GBL- Game-based learning) por su capacidad para motivar, comprometer, garantizar una actitud favorable o mayor predisposición hacia el aprendizaje y un mayor rendimiento académico del 
alumnado. Sin embargo, hasta 2013, la gamificación no recibe la atención que requiere en el ámbito de la educación superior (Subhash y Cudney, 2018).

Con frecuencia, el término 'gamificación' es utilizado para referirse a la aplicación del juego o elementos del mismo en entornos de no juego (Subhash y Cudney, 2018; Deterding et al., 2011). De esta manera, persigue satisfacer las necesidades del alumnado, proporcionar feedback inmediato, permitirle cierto control sobre el material y generarle curiosidad por el aprendizaje (Kapp, 2012).

En este sentido, según Moreno y Lopezosa (2020) la gamificación educativa ha ido adquiriendo importancia en las instituciones universitarias, por ejemplo, mediante la aplicación de los Escape Rooms educativos, y más específicamente de los Breakout EDU (por su capacidad para adaptarse al entorno de trabajo), una manifestación real de la innovación docente en educación superior que, mediante la resolución de acertijos y pistas, y trabajando en equipo se busca satisfacer un objetivo común final. Mientras que el fin último de una Escape Room normalmente es escapar de una habitación en un tiempo limitado, en un Breakout se asocia con la apertura de una caja cerrada con uno o más candados de diferente tipo para lo que será necesario resolver problemas, cuestionarios, acertijos y enigmas (Negre, 2017). De acuerdo con este autor, el uso del breakout educativo resulta una estrategia metodológica interesante para el alumnado, pues permite que este sea capaz de adaptarse a cualquier contenido curricular, trabaje de manera cooperativa en la satisfacción de un objetivo común, desarrolle el pensamiento crítico y su aplicación en la resolución de problemas, mejore la capacidad comunicativa, plantee retos y se muestre perseverante con ellos, construya un pensamiento deductivo, aprenda a trabajar bajo presión, sea el protagonista del aprendizaje, y vea su motivación incrementada. Además, esta estrategia ha permitido enriquecer la experiencia educativa, y favorecer el desarrollo de habilidades esenciales propias del siglo XXI que preparan al alumnado para el alcance de su éxito en la universidad y en otros ámbitos de la vida (O’Brien y Pitera, 2019), y que así sean capaces de enfrentarse a situaciones de incertidumbre global de manera comprometida y sostenible. De ahí, la importancia de la experiencia 'Breakout educativo virtual' que se describe a continuación. 


\section{Descripción de la experiencia/Objetivo}

La experiencia docente 'Breakout Educativo virtual', titulada 'Pequeños pedagogos críticos', perseguía un objetivo doble. Por un lado, y teniendo en cuenta al alumnado, perseguía la aplicación, interiorización y reflexión acerca de un contenido teórico muy concreto 'la pedagogía crítica de Paulo Freire', previamente abordado durante la sesión teórica. Por otro lado, y desde el punto de vista del profesorado, la experiencia docente perseguía innovar mediante la aplicación de un modelo o estrategia metodológica diferente que incluyera herramientas tecnológicas y supusiera una mayor motivación del alumnado, así como un aumento en la captación de la atención del alumnado a través de la enseñanza virtual donde se pierde el contacto visual y la comunicación bidireccional.

Teniendo en cuenta los objetivos didácticos previamente descritos, el alumnado se sumergía en una aventura cuyo fin último era 'dar voz a la clase oprimida' a la que se refería la pedagogía crítica de Paulo Freire. Por tanto, y puesto que la experiencia tuvo lugar de manera virtual, el alumnado junto a la profesora tenía que ir superando una serie de pruebas (acertijos, visionado de vídeos y preguntas tipo test, descubrir personajes, entre otras) para conseguir diferentes dígitos que le permitirían abrir una caja fuerte y alcanzar el objetivo formulado al inicio. Además, tras el desarrollo de la actividad, el alumnado en sus diferentes grupos de trabajo tenía que reflexionar en torno a las siguientes cuestiones: ¿En qué medida la alfabetización (educación) contribuye a la libertad y a la justicia social (eliminar desigualdad) de quienes estaban siendo oprimidos? ¿Qué papel desempeña el 'diálogo', teniendo en cuenta su rol conforme a la pedagogía crítica de Paulo Freire?, e incorporarlas a su portafolios o trabajo final de prácticas grupal de la asignatura.

\section{Contexto}

Esta experiencia ha tenido lugar en la parte práctica (grupos reducidos de entre 19 y 22 personas) de la asignatura "Fundamentos Teóricos e Históricos de la Educación Primaria" del primer curso del Grado en Educación Primaria de la Facultad de Ciencias de la Educación, adscrita a la Universidad de Córdoba. Así pues, a lo largo del primer cuatrimestre del curso académico 2020/2021 se ha llevado a cabo una experiencia de gamificación donde el alumnado ha participado 
y tomado protagonismo en un breakout educativo virtual a través de la plataforma de videoconferencias 'Blackboard Collaborate Ultra'.

\section{Aplicación y resultados}

El 'Breakout educativo virtual' (https://view.genial.ly/5fa90c6f316b3b0cf52db834/gamebreakout-pequenos-pedagogos-criticos) fue diseñado con la herramienta 'Genially' en su versión gratuita e implementado durante tres sesiones prácticas de 50 minutos cada una haciendo uso de la herramienta de videoconferencias.

Primero, se planteaba la actividad al alumnado (en qué consistía y qué sentido tenía su aplicación), permitiendo de esta manera el vínculo directo con la parte teórica de la asignatura.

A continuación, se captaba la atención del alumnado planteando el contexto y el objetivo de la actividad. Para ello, se pasaba a la ventana de 'introducción' pulsando directamente sobre la palabra en la herramienta creada (Véase Figura 2).

Figura 2. Ventana inicial e introductoria 'Breakout Educativo Virtual'.

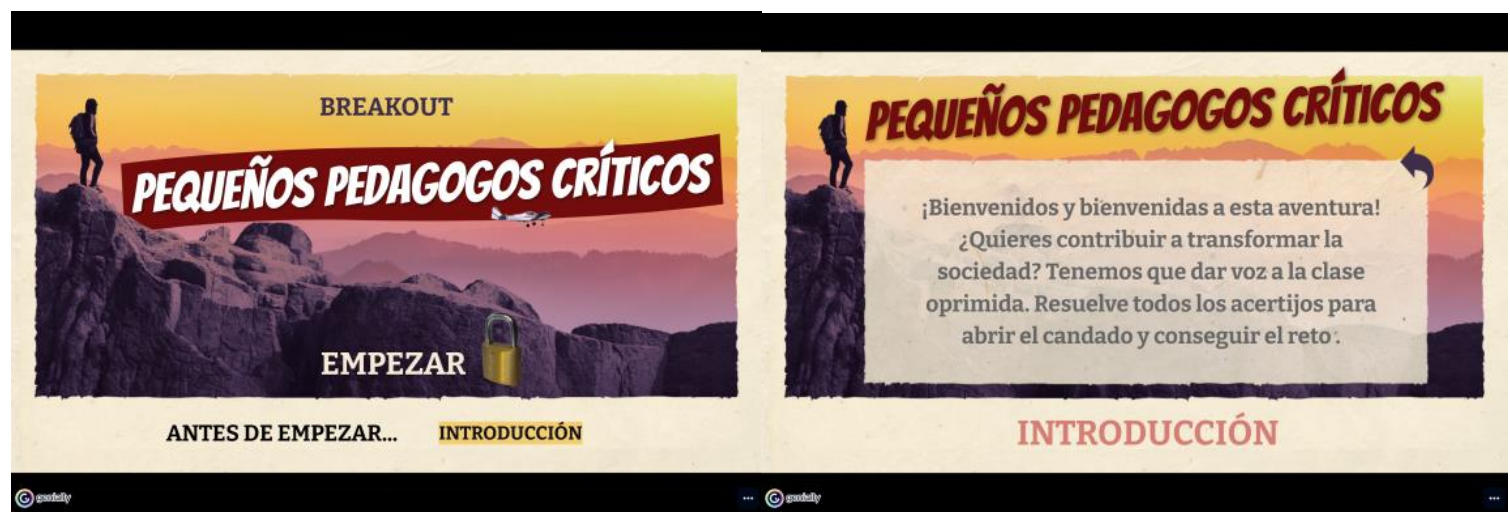

Después, tras captar la atención del alumnado y plantear el contexto de la actividad, se sucedían cinco misiones localizadas en un mapa (Véase Figura 3). Cada una de las misiones debían efectuarse en orden para descubrir la contraseña que abriría la caja fuerte, pues de lo contrario no se alcanzaría debidamente el objetivo ('dar voz a la clase oprimida'). 
Figura 3. Misiones Breakout Educativo Virtual distribuidas en el mapa.

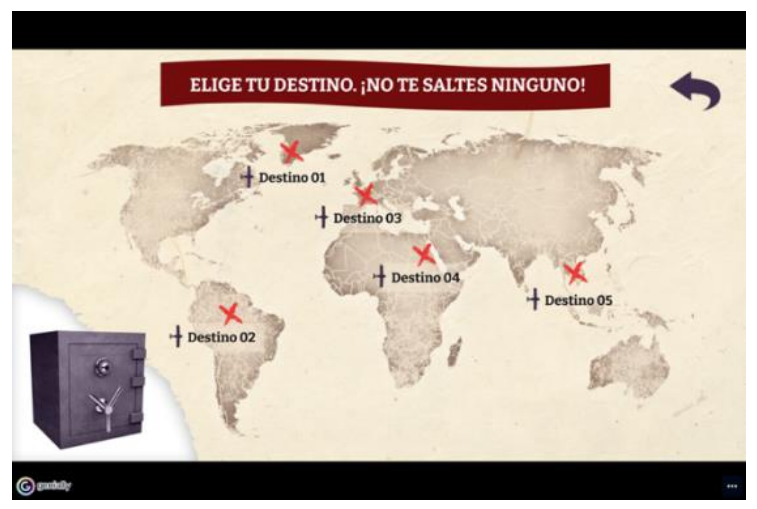

En las figuras 4, 5, 6, 7 y 8, respectivamente, se muestran de manera ilustrativa las diferentes misiones y su formato interactivo (visionado de vídeo, respuestas tipo test, descubrir personajes, vincular definiciones a conceptos, reflexionar en torno a una ilustración, etc.). En el primer destino, el alumnado tuvo que descubrir un vídeo como recurso adicional pasando con el cursor del ratón sobre una imagen. Tras el visionado del vídeo, se sucedieron una serie de cuestiones, y tras superarlas se consiguió el primer dígito de la contraseña que permitiría abrir la caja fuerte y alcanzar el objetivo.

Figura 4. Destino 1: La pedagogía del diálogo de Paulo Freire.

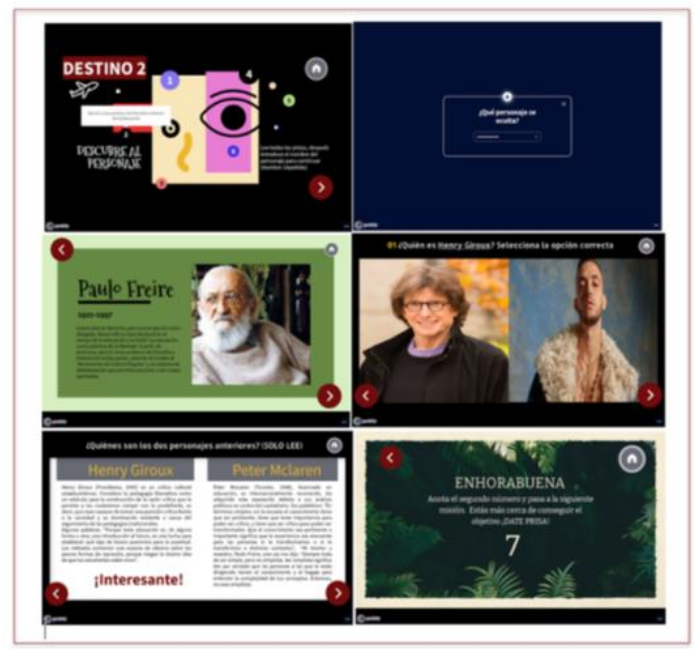

Después, en el destino dos, se ofrecían una serie de pistas con el fin de que el alumnado descubriera de que personajes se trataba (Paulo Freire, Henry Giroux y Peter Mclaren).

Figura 5. Destino 2: Descubre a personajes relevantes de la Pedagogía Crítica. 


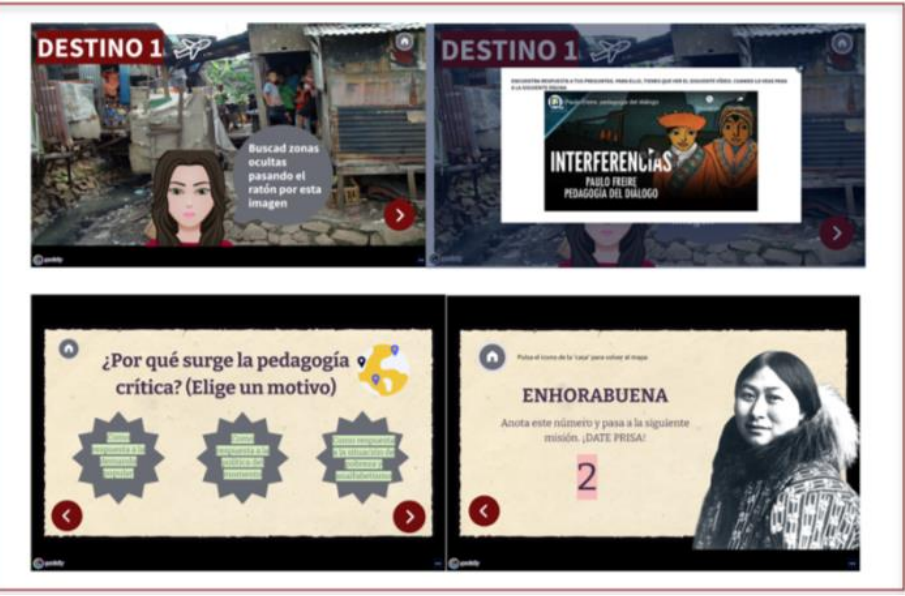

Tras superar este reto de manera conjunta y guiada por la profesora de la asignatura, se pasaba a la siguiente misión. En el destino tres, se pedía al alumnado que observara detenidamente una imagen denominada 'La máquina de la escuela' de Francesco Tonucci. Tras destinar tiempo a la observación, el alumnado tuvo que enfrentarse a una serie de cuestiones acerca de la imagen. Con esta actividad, el alumnado pudo reflexionar en torno a conceptos como el de 'educación bancaria' (depositar contenidos en la mente del estudiante, sin opción a crítica) más vinculado al neoliberalismo del que huía a través de su pedagogía Paulo Freire o el concepto de 'diversidad' y la necesaria atención que requiere este por parte del sistema educativo y de la sociedad.

Figura 6. Destino 3: Pedagogía crítica como reacción a la educación bancaria y como respuesta a la diversidad personal y social.

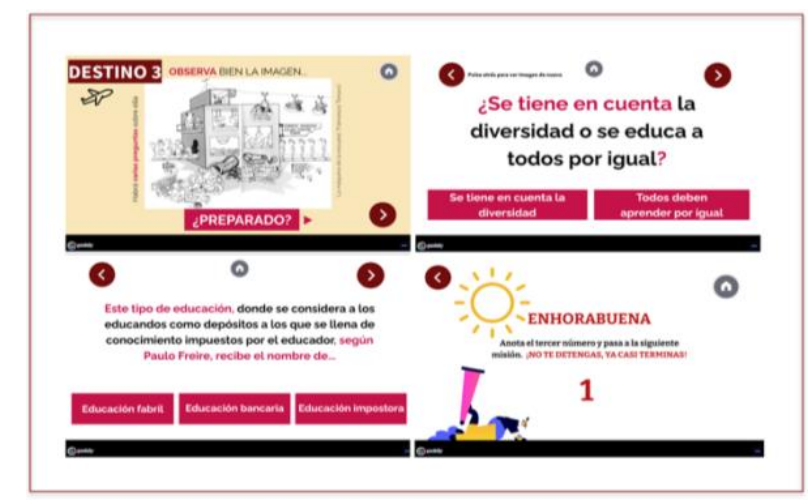

Como cuarto destino, el alumnado tuvo que intentar asociar conceptos relacionados con la pedagogía crítica a sus definiciones. Por ejemplo, se trabajaron conceptos como el de 'Educación liberadora o problematizadora' y el de ‘concientización', además de otros.

Figura 7. Destino 4: Conceptos relevantes en la pedagogía crítica que defendía Paulo Freire. 


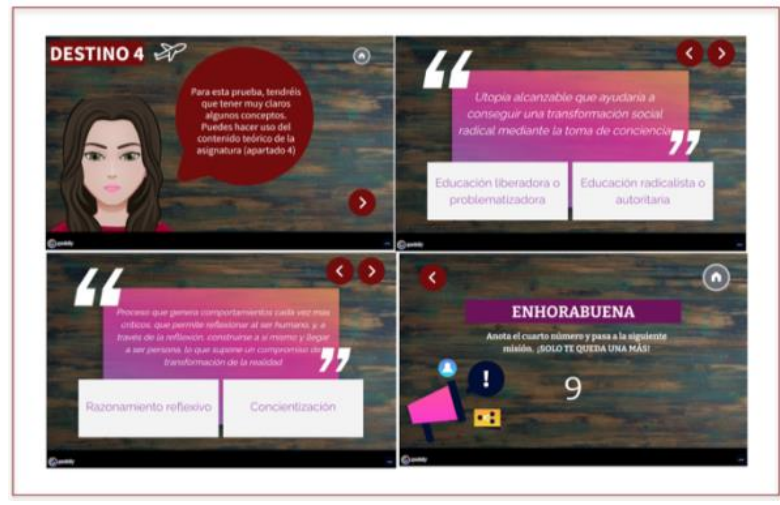

Finalmente, como última misión, en el quinto destino el alumnado tuvo que deslizar de nuevo el cursor sobre una imagen donde pudo encontrar un vídeo en el que Paulo Freire versaba acerca de su pedagogía y la importancia de escuchar y confiar en quien se educa. Tras ver el vídeo, el alumnado tuvo que resolver un acertijo, que fue extraído textualmente del vídeo (Respuesta: "Si el grupo me quiere escuchar, no puedo negarle mi voz, pero enseguida demuestro que necesito también de su voz. Mi voz no tiene sentido sin la del grupo"). Además, para conseguir el último dígito del código secreto, hacía falta descubrir un último acertijo (Respuesta: "Dar voz al oprimido").

Figura 8. Destino 5: La escucha entre educador y educando.

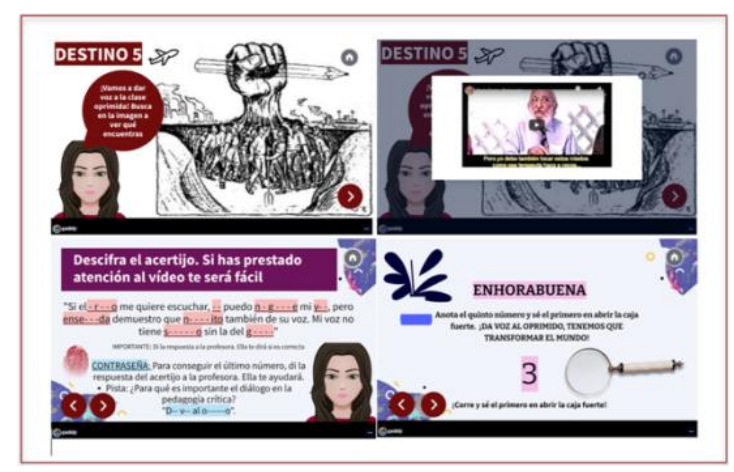

Definitivamente, y tras superar de manera ordenada y satisfactoria los cinco destinos, el alumnado pudo abrir la caja fuerte haciendo uso del código secreto (27193), y dar voz a la clase oprimida atendiendo al potencial del diálogo y la escucha activa (educación liberadora o problematizadora). De este modo, al abrir la caja fuerte y lograr el objetivo inicial, el alumnado recibió un certificado de superación satisfactoria del reto lo que suponía una motivación adicional (Véase figura 9). 
Figura 9.

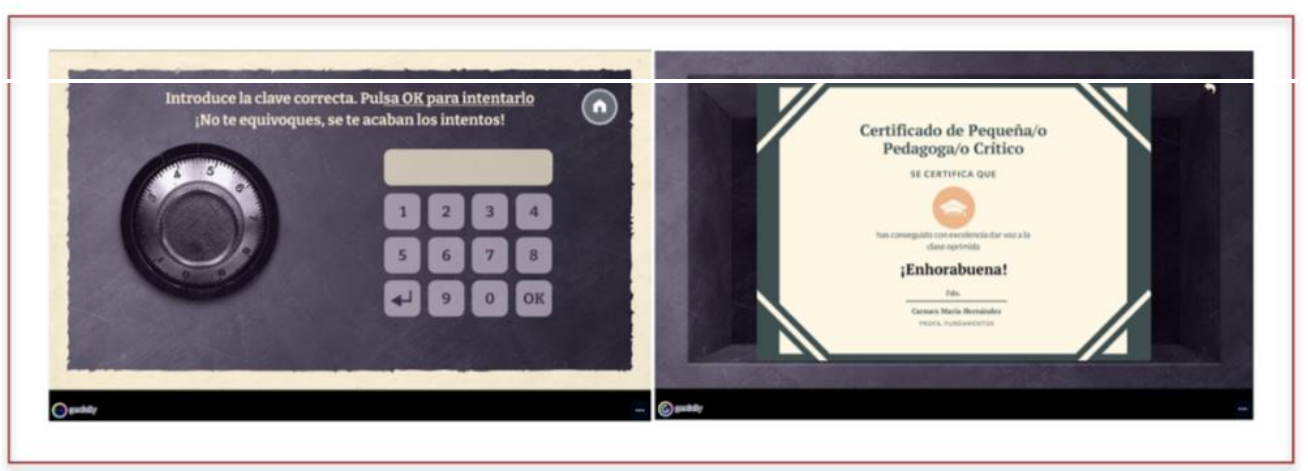

Conviene aclarar que, al tratarse de una herramienta interactiva el alumnado podía moverse por la aplicación fácilmente haciendo uso de flechas de continuación y retroceso, iconos de inicio (casa), entre otros. Además, recibían feedback inmediato de sus respuestas (Véanse Figuras 10 y $11)$.

Figura 10.

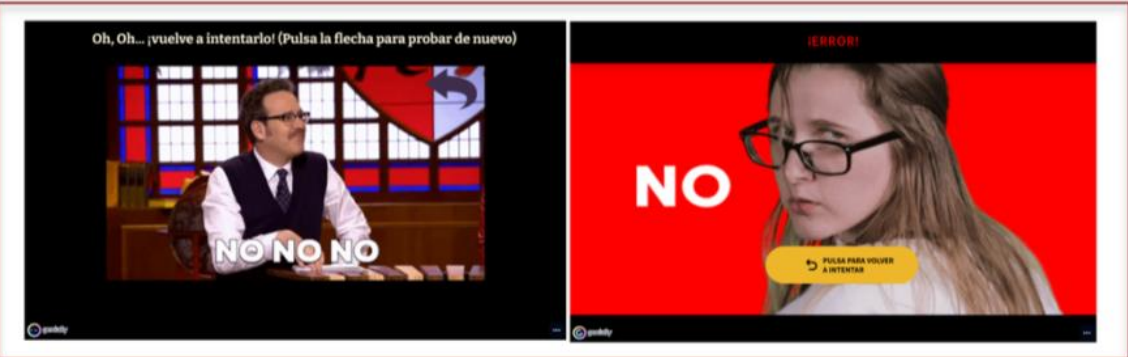

Figura 11.

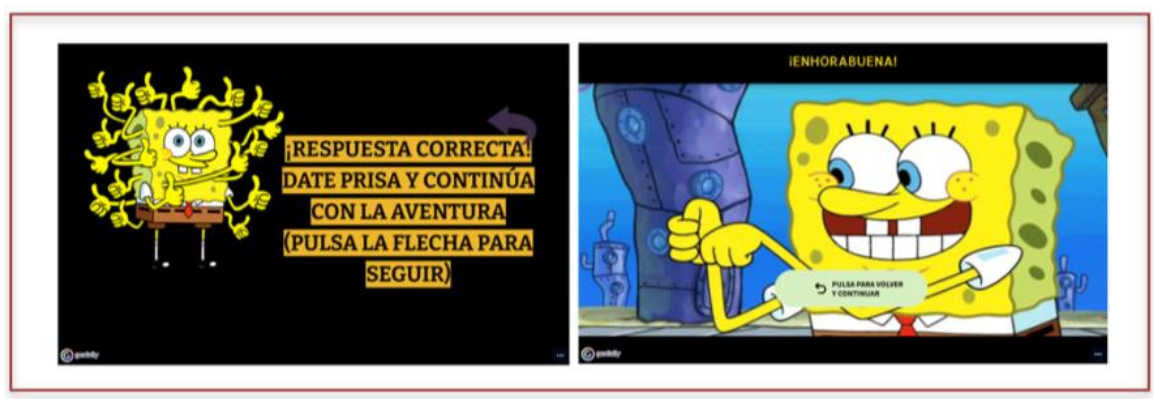

Tras desarrollar la actividad, algunos grupos de estudiantes manifestaron por escrito en sus portafolios de evaluación de las prácticas de la asignatura su satisfacción con la metodología: 
"Nos han parecido clases muy dinámicas con recursos muy atractivos y útiles para el desarrollo del proceso de enseñanza aprendizaje. Entre otras herramientas hemos trabajado con aplicaciones como Quizizz join y también el BreakOut realizado a través de genially. Estas técnicas utilizadas han favorecido a que nuestra motivación por la asignatura sea mayor y crecieran nuestras ganas de aprender, así como que viéramos la docencia de forma diferente a como mayormente la hemos experimentado en bachillerato, ciclos formativos, etc. Gracias al desarrollo de estas sesiones grupales hemos podido crecer como equipo, conocernos, motivarnos a trabajar conjuntamente, compartir conocimientos y adquirir habilidades que nos servirán en nuestro futuro como profesionales de la educación)" (G_N_3).

"También queremos destacar el desarrollo tan completo de las clases virtuales en las que las dinámicas nos querían llevar a la participación con métodos o proyectos que eran muy interactivos y te hacían sentir bastante integrado aún detrás de una pantalla" (G_E_3).

\section{Conclusiones}

Finalmente, y de acuerdo con Corchuelo-Rodríguez (2018) y Moreno (2019), la aplicación virtual de la gamificación en la docencia universitaria contribuyó satisfactoriamente al incremento de la motivación y la participación del alumnado, así como a una mejora en la adquisición de competencias clave y contenidos de la asignatura mediante el razonamiento crítico. Además, esta experiencia se aproxima a la satisfacción del Objetivo 4 de Desarrollo Sostenible de la Agenda 2030: Educación de calidad, asegurando la producción de un aprendizaje pertinente y efectivo donde la innovación metodológica, el uso de las nuevas tecnologías de la información y la implicación directa del alumnado en su aprendizaje juegan un papel esencial en la calidad de las enseñanzas.

\section{Referencias}

Alexander, B., Ashford-Rowe, K., Barajas-Murphy, N., Dobbin, G., Knott, J., McCormack, M., Pomerantz, J., Seilhamer, R., \& Weber, N. (2019). EDUCAUSE Horizon Report: 2019 Higher Education Edition. EDUCAUSE. https://linhadeleitura.files.wordpress.com/2019/05/2019horizonreport.pdf 
Barrón, M. C. (2020). La educación en línea. Transiciones y disrupciones. En IISUE, Educación y Pandemia. Una Visión Académica (pp. 66-74). UNAM.

Bauman, Z. (2007). Los retos de la educación en la modernidad líquida. Gedisa.

Corchuelo-Rodríguez, C. A. (2018). Gamificación en educación superior: experiencia innovadora para motivar estudiantes y dinamizar contenidos en el aula. EDUTEC, Revista Electrónica de Tecnología Educativa, 63. http://dx.doi.org/10.21556/edutec.2018.63.927

Deterding, S., Khaled, R., Nacke, L. E., \& Dixon, D. (mayo, 2011). Gamification: Toward a definition. In CHI 2011 gamification workshop proceedings (Vol. 12, pp. 12-15). Vancouver BC, Canada.

Kapp, K. (2012). The gamification of learning and instruction: game-based methods and strategies for training and education. Pfeiffer.

Koehler, M. J, y P. Mishra. (2008). Introducing TPCK. AACTE Committee on Innovation and Technology. En N. J. Mahwah (Ed.). The handbook of technological pedagogical content knowledge (TPCK) for educators. Routledge Taylor \& Francis Group.

Mishra, P., y Koehler, M. J. (2006). Technological Pedagogical Content Knowledge: A Framework for Teacher Knowledge. Teachers College Record, 108(6), 1017-1054.

Moreno, E. (2019). El "Breakout EDU" como herramienta clave para la gamificación en la formación inicial de maestros/as. EDUTEC. Revista Electrónica de Tecnología Educativa, 67, 66-79. https://doi.org/10.21556/edutec.2019.67.1247

Moreno, E., y Lopezosa, M. D. (2020). Gamificación a través de un proyecto de aprendizajeservicio. Diseñando un breakout educativo desde la universidad para el alumnado de primaria. Revista científica electrónica de Educación y Comunicación en la Sociedad del Conocimiento, 20(1). http://dx.doi.org/10.30827/eticanet.v20i1.15524

Moreno-Correa, S. M. (2020). La innovación educativa en los tiempos del Coronavirus. Salutem Scientia Spiritus, 6(1), 14-26. 
Negre, C. (2017). «BreakoutEdu», microgamificación y aprendizaje significativo. Educaweb. $\begin{array}{lllllll}\text { Recuperado } & \text { de } & (7 & \text { de } & \text { abril } & \text { de } & \text { 2021 })\end{array}$ https://www.educaweb.com/noticia/2017/07/26/breakoutedu-microgamificacionaprendizaje-significativo-15068/

O’Brien, K., y Pitera, J. (2019). Gamifying Instruction and Engaging Students With Breakout EDU. Journal of Educational Technology Systems, 48(2). https://doi.org/10.1177/0047239519877165

Subhash, S., y Cudney, E. A. (2018). Gamified learning in higher education: A systematic review of the literature. Computers in Human Behavior, 87, 192-206. doi: 10.16/j.chb.2018.05/028 


\title{
El aprendizaje cooperativo de la Historia en tiempos de pandemia: La Antigua Roma
}

\author{
Ismael Piazuelo Rodríguez \\ Colegio La Anunciata / Universidad de Zaragoza
}

Palabras clave: Geography and History, Aprendizaje Cooperativo, Protocolo COVID-19

\section{Introducción}

El Aprendizaje Cooperativo es una metodología que ofrece múltiples ventajas en el proceso enseñanza-aprendizaje y que, por tener como base la comunicación, es eficaz para el desarrollo de relaciones sociales sanas y de calidad. Permite que los educandos trabajen de manera autónoma, ejerzan responsabilidades en su propio proceso de aprendizaje y facilita la integración y participación de todos en contraposición a otras metodologías que solo permiten la participación de una parte del alumnado (Domingo, 2008).

La potencialidad de esta metodología activa se basa en principios ampliamente estudiados como la teoría de las inteligencias múltiples de Howard Gardner o las ideas sobre el aprendizaje entre iguales de Vygotski o Perret Clermont (Sánchez, 2015).

Cada vez más docentes se forman en esta metodología para aplicarla en sus aulas; no obstante, la pandemia ha ralentizado este proceso innovador debido a la llegada de los planes de contingencia a los centros. Estos protocolos exigen que se mantenga una cierta distancia entre los estudiantes, prohíben expresamente el uso compartido del material, contemplan el uso obligado de mascarilla en todo momento y la existencia de grupos "burbuja" que desaconsejan el movimiento de alumnos por diferentes aulas y limitan los contactos a los miembros de un mismo grupo clase.

Objetivos 
1. Adaptar la metodología del Aprendizaje Cooperativo a los protocolos COVID de los centros de ESO.

2. Llevar a cabo actividades que permitan a los alumnos adquirir los conceptos básicos sobre las primeras civilizaciones trabajando juntos y cooperando.

\section{Contexto}

Esta experiencia didáctica se ha llevado a cabo en $1^{\circ}$ de ESO, en la asignatura de Geografía e Historia durante el curso 2020/2021, cumpliendo con todos los protocolos establecidos con motivo de la situación sanitaria recogidos en la normativa.

Se trata de un grupo multicultural, bilingüe en inglés de un centro que se encuentra en el Gancho, una zona del Casco Histórico de la ciudad de Zaragoza. A diferencia de lo que ocurre en cursos anteriores y con el objetivo de reducir al máximo los contactos entre los estudiantes, no se producen desdobles en las materias que se imparten en otro idioma, sino que los estudiantes se dividen en función de si cursan o no el programa bilingüe.

Además, este curso se ha acogido al Programa de Integración de Materias, que permite que un mismo profesor imparta Lengua y literatura y Geografía e Historia y establece que el número de educandos por clase se limite a un máximo de 20. Estas dos condiciones, que se establecieron para mejorar la transición entre la etapa de Primaria y la de Secundaria, favorecen en gran medida la aplicación de la metodología del aprendizaje cooperativo: por un lado, hay más horas semanales disponibles y el profesor puede gestionarlas como mejor le convenga y, por otro; el número reducido de estudiantes permite al docente dedicarle más tiempo a cada alumno.

Debido a un cambio metodológico que el Colegio La Anunciata comenzó a llevar a cabo en el curso 2017/2018, la cantidad de libros de texto se ha ido reduciendo progresivamente y cada uno de los alumnos de la ESO cuenta con un dispositivo personal (Chromebook) para usar tanto en el centro como fuera de él.

En cuanto a las características del alumnado, se trata de una clase cohesionada, puesto que el grueso de los estudiantes lleva en el mismo centro desde la etapa de Infantil, razón por la cual todos se conocen. En cuanto a su nivel, es, en general, bastante bueno, todos los alumnos tienen 
un nivel de adquisición de competencias correcto o alto para su curso y edad, tienen una buena disposición al trabajo, están motivados y abiertos a realizar actividades de todo tipo. Con respecto a la convivencia, es destacable por buena; si bien surgen conflictos entre ellos, son perfectamente capaces de gestionarlos y solucionarlos de manera bastante autónoma.

En cuanto a su experiencia en el trabajo en grupo, están acostumbrados a hacerlo en las distintas materias y a sacar adelante proyectos de con una autonomía destacable. Su nivel de conocimientos informáticos es adecuado, pues han trabajado con equipos a lo largo de la etapa de primaria y muy especialmente durante el confinamiento de tercer trimestre de 2020 y, además, las primeras semanas del curso 2020/2021 los estudiantes de $1^{\circ}$ de ESO reciben por parte de los docentes de todas las materias una formación completa e intensiva de las aplicaciones del Google for education (Classroom, documentos, presentaciones, hojas de cálculo, Sites, Youtube, etc.) que utilizarán en todas las materias a lo largo de toda la etapa de Secundaria.

Al principio de cada curso, a todos los estudiantes se les realiza una sencilla prueba de inteligencias múltiples con el objetivo de obtener una cierta información acerca del distinto nivel de desarrollo de cada una de ellas. Esta primera prueba, sumada a la información proporcionada por los tutores del curso anterior a través de un informe individual, los resultados de las evaluaciones iniciales y la percepción del tutor a lo largo de las primeras semanas de curso ayuda a formar los equipos de trabajo (tanto para las actividades realizadas con la metodología del aprendizaje cooperativo como para el resto de los proyectos realizados en grupo). Si bien estos equipos están sujetos a modificaciones tras las primeras evaluaciones de su funcionamiento, son bastante estables en las distintas materias; no obstante, los grupos pueden cambiar una o dos veces al año con el objetivo de promover que todos los estudiantes de una clase sean capaces de trabajar unos con otros.

\section{Aplicación}

Es un proyecto enmarcado en la unidad didáctica de la Antigua Roma, adaptado a las circunstancias, y aprovechando las ventajas de las TIC para el trabajo en el aula.

El alumnado trabaja en grupos que reciben el nombre de un personaje célebre de la Antigua Roma de tres personas que asumen roles diferentes y que colaboran para completar el proyecto: 
cónsul (coordina y se comunica con el docente), censor (revisa el desarrollo del trabajo, controla que se cumpla con todos los requisitos y corrige los resultados) y edil (se encarga del material: fuentes de información, aplicaciones, webs, etc.) [Figura 1]. A cada equipo se le asigna una temática que coincide con una parte de los contenidos que se van a trabajar en la unidad; lo que les toca desarrollar a cada grupo aparece a su vez subdividido en los apartados esenciales que no deben faltar, todo ello, aparece reflejado en una ficha que se pone a disposición de cada grupo [Figura 2].

Figura 1. Ficha de rol. Elaboración propia.

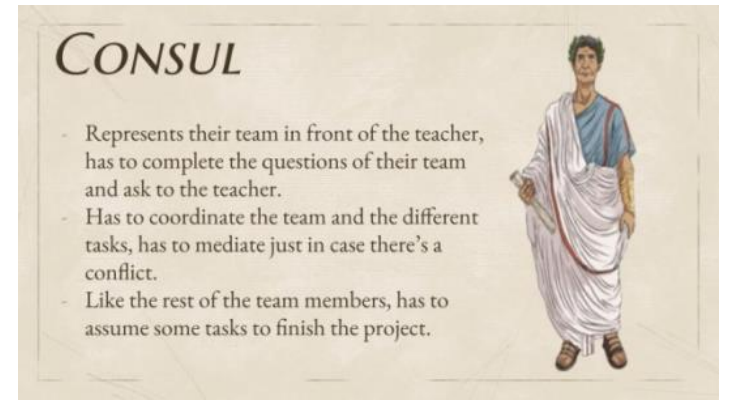

Figura 2. Ficha de equipo. Elaboración propia.

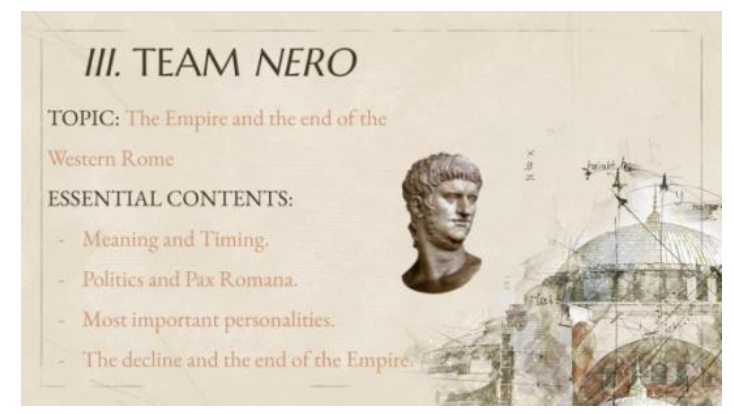

El estudiantado se agrupará en sus equipos manteniendo la distancia de seguridad exigida por el plan de contingencia, pero lo suficientemente cerca como para poder comunicarse con fluidez sin necesidad de alzar en exceso la voz [Figura 3]. Trabajarán de manera conjunta a través de diferentes aplicaciones y programas que permiten editar documentos, vídeos, imágenes o presentaciones desde distintos dispositivos al mismo tiempo.

Figura 3. Disposición de los equipos.

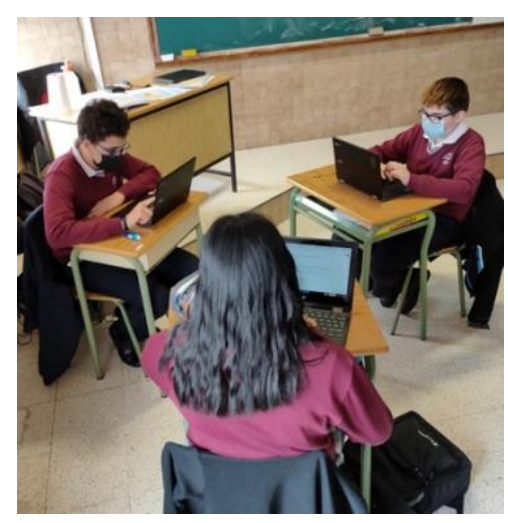

Si bien, los equipos deben organizarse con arreglo a las pautas marcadas desde un inicio, el docente supervisará todo el proceso continuamente a lo largo de todas las sesiones. 


\section{Contenidos, criterios, estándares y competencias}

Tabla 1. Contenidos, criterios, estándares y competencias. Elaboración propia.

\begin{tabular}{lllll}
\hline \multicolumn{1}{c}{ Contenidos } & \multicolumn{1}{c}{$\begin{array}{c}\text { Criterios de } \\
\text { evaluación }\end{array}$} & Estándares de aprendizaje & Competencias \\
\hline El Mundo clásico, Roma: & Crit.GH.2.1; 2.2; & 1. & Utiliza diversos tipos de fuentes & Se contribuye al \\
origen y etapas de la & $2.3 ; 2.4 ; 2.5 ; 2.8 ;$ & históricas. & desarrollo de todas \\
historia de Roma; la & $2.9 ; 2.15$ y 2.16 & 2. & Conoce los conceptos básicos de & las competencias, \\
república y el imperio: & & la política, sociedad, economía, & especialmente a: \\
organización política y & & cultura y religión de la Antigua & CCL, CD, CAA y \\
expansión colonial por el & & Roma. & CCEC. \\
Mediterráneo; el & & 3. & Conoce características y ejemplos & \\
cristianismo. & & del arte de la Antigua Roma. & \\
\hline
\end{tabular}

\section{Productos del aprendizaje}

Tabla 2. Productos del aprendizaje. Elaboración propia.

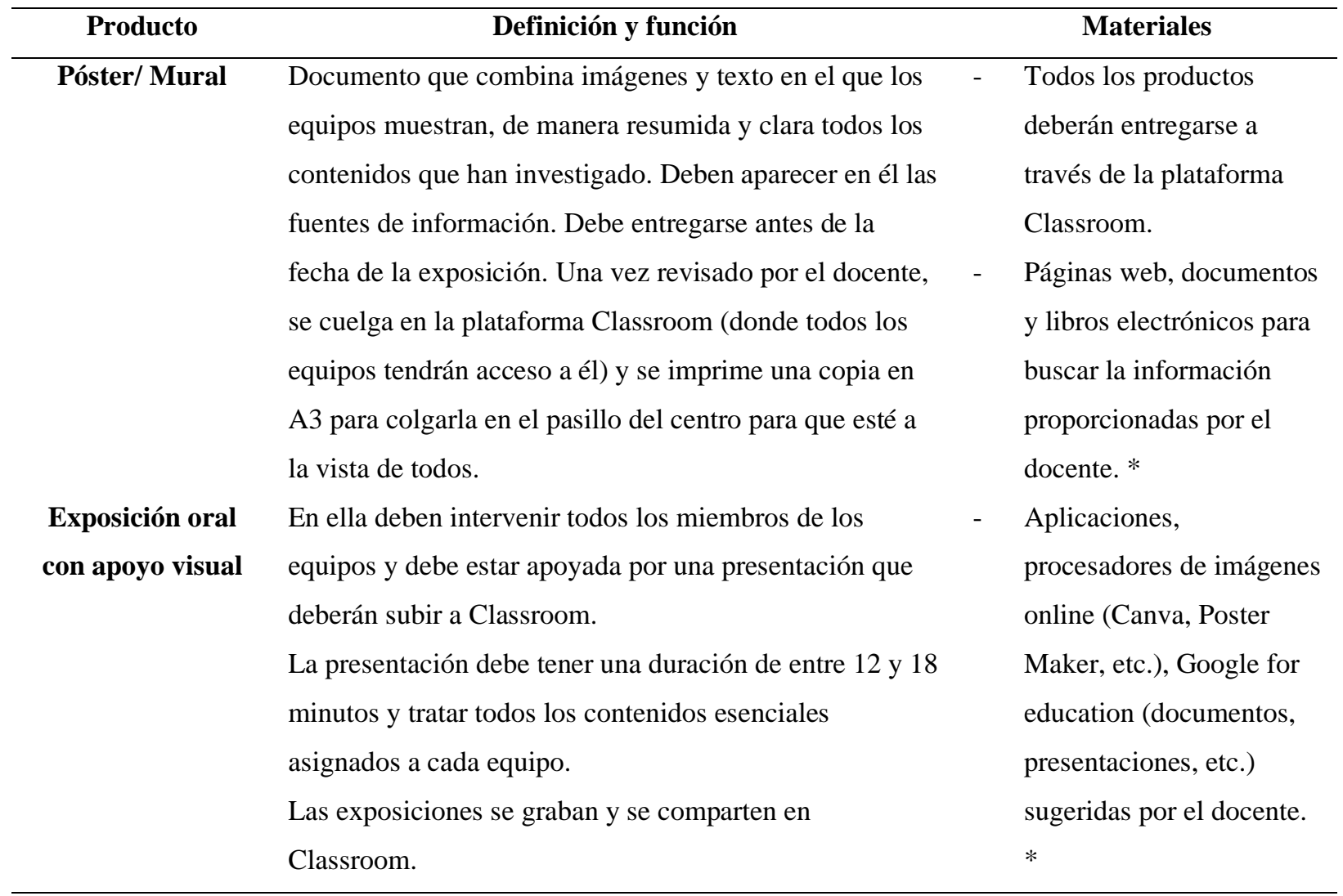




\begin{tabular}{|c|c|c|}
\hline $\begin{array}{c}\text { Preguntas y } \\
\text { respuestas tipo } \\
\text { test }\end{array}$ & $\begin{array}{l}\text { Cada equipo redacta } 10 \text { preguntas de tipo test con cuatro } \\
\text { opciones de respuesta. Deben ser adecuadas y deben } \\
\text { poderse responder con el contenido de la exposición oral } \\
\text { o a través del estudio de los pósteres. Deben ser lógicas, } \\
\text { estar correctamente redactadas y tener nivel de } \\
\text { complejidad adecuado para estudiantes de } 1^{\circ} \text { de ESO. }\end{array}$ & $\begin{array}{l}\text { El docente pone a } \\
\text { disposición de los } \\
\text { equipos una cantidad } \\
\text { suficiente de material, } \\
\text { pero se podrán proponer } \\
\text { otros materiales o }\end{array}$ \\
\hline $\begin{array}{l}\text { Autoevaluación y } \\
\text { coevaluación }\end{array}$ & $\begin{array}{l}\text { Los miembros de los equipos se evalúan a sí mismos, al } \\
\text { resto de su equipo y también los productos que han } \\
\text { presentado. Todas estas evaluaciones se realizan a través } \\
\text { de rúbricas que proporciona el docente; no obstante, } \\
\text { también hay espacio para que los estudiantes se expresen } \\
\text { o maticen sus evaluaciones. Incluirá también una breve } \\
\text { evaluación de la actividad. Se realiza a través de un } \\
\text { formulario de Google en el cual habrá preguntas } \\
\text { específicas para la evaluación del desempeño de cada rol. }\end{array}$ & $\begin{array}{l}\text { recursos que conozcan o } \\
\text { que hayan encontrado. }\end{array}$ \\
\hline $\begin{array}{l}\text { Prueba de } \\
\text { evaluación }\end{array}$ & $\begin{array}{l}\text { El docente selecciona } 24 \text { preguntas de entre las } \\
\text { presentadas por los equipos que se deberán responder de } \\
\text { manera individual, a través de un formulario de Google } \\
\text { que se corrige automáticamente. }\end{array}$ & \\
\hline
\end{tabular}

\section{Temporalización}

El proyecto requiere 11 sesiones, que se organizarán de la siguiente manera. En principio, no es necesario que los estudiantes avancen el trabajo en clase y, generalmente, no se llevarán tarea a sus casas, más allá de la revisión de los contenidos para la prueba de evaluación.

Tabla 3. Temporalización. Elaboración propia.

\begin{tabular}{|c|c|}
\hline Sesión & Actividad \\
\hline \multirow{5}{*}{1} & Evaluación inicial: “¿Qué conocéis de la Antigua Roma?” \\
\hline & Presentación del proyecto por parte del docente, explicación de los contenidos, del modo de \\
\hline & proceder, establecimiento de fechas de entrega, reparto de contenidos en los equipos y asignación de \\
\hline & roles. \\
\hline & $\begin{array}{l}\text { Revisión de contenidos por parte de los equipos, primera reunión organizativa y comienzo del } \\
\text { proyecto. }\end{array}$ \\
\hline 2 a 5 & Sesiones de trabajo de los equipos con apoyo por parte del docente. \\
\hline
\end{tabular}


Revisión del avance de todos los equipos en los productos finales del proyecto por parte del docente (unos 5' o 7' cada uno). Mientras se produce la revisión de cada equipo, el resto, puede continuar avanzando en su proyecto. Entrega del póster.

7 y 8

Sesiones de trabajo de los equipos con apoyo por parte del docente. Los estudiantes ultiman las tareas y las entregan.

9 Exposiciones orales.

10

10 ’ para realizar la autoevaluación y la coevaluación del proyecto.

1120 ' para revisar los contenidos, pudiéndolo hacer en sus equipos si así lo desean.

20 ' para realizar la prueba de evaluación.

\section{Evaluación y calificación}

La evaluación es un proceso complejo de recopilación de información por parte del docente acerca de la evolución y el desarrollo de sus alumnos. Se analizan los aprendizajes logrados por parte del alumno y se identifican las carencias para poder subsanarlas. Consta de tres partes.

Tabla 4. Evaluación. Elaboración propia.

\begin{tabular}{lll}
\hline \multicolumn{1}{c}{ Evaluación inicial } & \multicolumn{1}{c}{ Evaluación de seguimiento } & Evaluación final \\
\hline Además de la información & En la sexta sesión, el docente se dirige a & La exposición oral, la autoevaluación, \\
extraída de la evaluación & los equipos para conocer los avances en & coevaluación y el cuestionario final \\
inicial de principios de curso, & su proceso de aprendizaje y evaluar los & serán los instrumentos que se \\
se realiza al inicio de la & avances del proyecto con el objetivo de & utilizarán para conocer el nivel de \\
primera sesión de esta & tomar las medidas necesarias en caso de & conocimientos y competencias \\
evaluación un cuestionario & existir algún problema o dificultad. & adquiridas por parte de los \\
básico a través de Kahoot. & & educandos. \\
\hline
\end{tabular}

La calificación es una medición cuantitativa de la adquisición de las competencias, la superación de los criterios y el aprendizaje de los contenidos. Para que este dato numérico sea lo más justo y adecuado en relación con el trabajo de cada educando, establecemos una serie de porcentajes a cada una de las actividades realizadas a lo largo de las sesiones. Se utilizan diversas rúbricas, que se introducirán en Classroom para facilitar y agilizar la calificación. La no realización de alguna de las actividades o la observación de alguna conducta contraria a la convivencia influirá 
negativamente en la calificación, pudiendo llegar incluso a considerarse nula la participación en de un estudiante en esta actividad.

Tabla 5. Calificación. Elaboración propia.

\begin{tabular}{|c|c|c|c|}
\hline Actividad o producto & $\begin{array}{l}\text { Individual o } \\
\text { colectiva }\end{array}$ & Cómo se califca & Porcentaje \\
\hline Actitud/Esfuerzo diario/ & I & Rúbrica de observación $\rightarrow 60 \%$ & \\
\hline Cumplimiento de su rol & & $\begin{array}{l}\text { Autoevaluación } \rightarrow 20 \% \\
\text { Coevaluación } \rightarrow 20 \%\end{array}$ & $25 \%$ \\
\hline Póster/ Mural & $\mathrm{C}$ & $\begin{array}{l}\text { Rúbrica que tendrá en cuenta la } \\
\text { presentación, redacción, gestión de } \\
\text { información, uso correcto de las } \\
\text { fuentes, originalidad y estética. }\end{array}$ & $20 \%$ \\
\hline $\begin{array}{l}\text { Redacción de preguntas y } \\
\text { respuestas tipo test }\end{array}$ & $\mathrm{C}$ & $\begin{array}{l}\text { Rúbrica que tendrá en cuenta la } \\
\text { redacción y adecuación de las } \\
\text { preguntas y las respuestas. }\end{array}$ & $10 \%$ \\
\hline Exposición oral & I & $\begin{array}{l}\text { Rúbrica que tendrá en cuenta la } \\
\text { adecuación, los conocimientos, la } \\
\text { expresión oral, el lenguaje no verbal } \\
\text { y el nivel de preparación. }\end{array}$ & $25 \%$ \\
\hline Prueba de evaluación & $\mathrm{I}$ & $\begin{array}{l}\text { Calificación obtenida en la prueba de } \\
\text { evaluación. }\end{array}$ & $20 \%$ \\
\hline
\end{tabular}

\section{Resultados/ "Lecciones" aprendidas}

Se considera una experiencia muy positiva en la que los alumnos han tenido la oportunidad de volver a trabajar con esta metodología, colaborar para lograr objetivos y aprender de una manera diferente y más autónoma. Ha sido un éxito tanto en conocimientos adquiridos como en el interés que ha suscitado en una buena parte del alumnado.

Como elementos positivos, podemos destacar la motivación que les suscita a los alumnos volver a trabajar por grupos, el hecho de que sea de manera autónoma y con unos roles definidos también ha sido valorado muy positivamente. En general, la temática les ha entusiasmado y la temporalización les parece adecuada. 
Los pequeños conflictos que han surgido en los grupos han podido resolverse sin mayor problema y los distintos roles han sido asumidos con responsabilidad e ilusión por todo el alumnado.

Los elementos menos valorados en la evaluación por parte de los alumnos y que les han producido más dificultades son el hecho de tener que exponer oralmente el trabajo y, sobre todo tener que hacerlo en inglés; si bien su nivel es el adecuado para el curso en el que se encuentran y para realizar las actividades propuestas, algunos alumnos no se sienten cómodos teniéndose que expresar en público en una lengua diferente al español.

\section{Conclusiones}

Hemos superado las dificultades con éxito y, aunque consideramos que la cercanía física es insustituible, hemos encontrado una manera de poder seguir aplicando metodologías activas, sin dejar de ser responsables.

En cuanto a su replicabilidad, podría realizarse sin dificultad en cualquier otro grupo que tuviera acceso, o bien a un dispositivo personal, o bien a un aula de informática en la que los estudiantes puedan trabajar manteniendo las distancias adecuadas. Consideramos que sería incluso mejor si se realizase en una clase en la que la asignatura de Geografía e Historia no fuera impartida en inglés, pues hemos podido observar que en el idioma es donde radican la mayor parte de las dificultades o reservas por parte del alumnado. Pese a que el estudiantado encuentre más complejos los proyectos en las asignaturas impartidas en inglés, coincidimos con Elena del Pozo (2011) en que la asignatura de Geography and History se presta a reducir la clase magistral y trabajar con metodologías activas mejorando de esta manera la competencia lingüística en inglés.

Si bien recomendamos la puesta en práctica de actividades o incluso unidades didácticas enteras con la metodología del aprendizaje cooperativo, podemos entender que existan ciertas reticencias por parte de algunos profesionales de la educación que pueden sentirse inseguros por su falta de formación específica o por la existencia de ciertos prejuicios con respecto a estas metodologías (Caballero, 2014). Cabe apuntar que la labor del docente no termina en el diseño y la explicación del proyecto, pues este tipo de actividades, si bien fomentan la responsabilidad individual, las autonomías de tantos estudiantes desarrollándose al mismo tiempo requieren de un 
asesoramiento y una autoafirmación constante por parte del profesorado. Lejos de poder sentarse a observar la puesta en práctica de su diseño, tiene que poner toda su atención durante todas y cada una de las sesiones en gestionar los aprendizajes de la clase y dinamizar la actividad.

\section{Referencias}

Caballero, N. (2014). Actitud del profesorado hacia el aprendizaje cooperativo. Investigación e innovación en formación del profesorado (pp. 455-465). Ediciones de la Universidad de Murcia.

Domingo, J. (2008). El aprendizaje cooperativo. Cuadernos de Trabajo Social, 21, 231-246.

Pozo, Elena del (2011). La enseñanza de Ciencias Sociales en inglés: matando dos pájaros de un tiro. Retos de la Educación Bilingüe (pp.234-259). IFIIE, Conocimiento Educativo.

Roig, J. y Araya, J. (2014). El aprendizaje entre iguales: Una experiencia didáctica para la construcción del conocimiento en la educación superior. Revista Comunicación, 23(1), 54-64.

Sánchez, G. (2015). Aprendizaje entre Iguales y Aprendizaje Cooperativo: Principios Psicopedagógicos y Métodos de enseñanza. Revista Ensayos Pedagógicos, X(1), 103-123. 


\title{
Juego del Buen Comportamiento en Educación Primaria como Estrategia para el Control del Aula durante la Pandemia de COVID-19
}

\author{
María José Hernández-Lloret \\ Carmen María Hernández-Lloret \\ Universidad de Córdoba
}

Palabras clave: Comportamiento; juego; COVID-19; refuerzo positivo; refuerzo negativo.

\section{Introducción}

El inicio de un nuevo curso académico durante la pandemia de la COVID-19 ha requerido la adaptación continua de toda la comunidad educativa a la situación mediante nuevos protocolos de actuación, formas de interacción y prácticas educativas, entre otros. En el caso de la educación primaria, esto ha conllevado repercusiones notables en el comportamiento y el bienestar emocional del alumnado, que mostraba descontento y rechazo ante la ausencia de interacción entre grupos y el desarrollo de nuevas prácticas educativas. Además, transcurridos varios meses sin asistir al centro educativo, las disrupciones, faltas de atención y de disciplina resultaron notables. En consecuencia, surgió la experiencia educativa 'El Juego del Buen Comportamiento', contribuyendo a la consecución del cuarto Objetivo de Desarrollo Sostenible: Educación de calidad.

El Juego del Buen Comportamiento (JBC) está basado en el estudio descrito por primera vez por Barrish, Saunders y Wolf (1969) titulado Good Behaviour Game: Effects on individual contingencies for group consequences on disruptive behavior in a classroom. En este estudio una serie de observadores identificaron con ayuda de la maestra y del director cuáles eran las conductas disruptivas que más se daban y debían ser mejoradas en un grupo de cuarto de educación primaria. En la fase de aplicación del juego se dividió la clase en dos grupos y se identificó al alumnado con 
colgantes de lana de dos colores distintos para facilitar la anotación de la puntuación y la entrega de recompensas. Además, se añadía una puntuación semanal extra y las recompensas no solo se daban en la clase en la que se llevaba a cabo el estudio, sino que podían posponerse. Los resultados fueron positivos y los comportamientos disruptivos analizados disminuyeron notablemente.

Por otra parte, en el estudio realizado por Lannie y Mccurdy (2007), además del resultado positivo de la aplicación del JBC demostró que las respuestas neutras y negativas por parte del docente disminuían a medida que el comportamiento disruptivo lo hacía (p. 94).

Estos son solo algunos ejemplos de los resultados del JBC como estrategia de manejo conductual en la sala de clase que se consideraron para su implementación en el caso que nos ocupa. No obstante, existen diversas variaciones de la implementación del juego y se realizó la más conveniente. Por último, Ruiz Olivares, Pino Osuna y Herruzo Cabrera (2006) realizaron una revisión bibliográfica de los estudios y trabajos dedicados a la generalización y al mantenimiento de esta técnica para todos los docentes interesados en implantarla.

\section{Descripción de la experiencia/Objetivo}

La experiencia del Juego del Buen Comportamiento la llevé a cabo como maestra especialista de Inglés en el Colegio FUHEM Montserrat en Madrid durante el primer trimestre en dos cursos de tercero de educación primaria. En clase lo llamábamos The Good Behaviour Game (GBG) y comenzamos a trabajar de esta forma a principios de octubre de 2020.

La implantación de esta experiencia se vio condicionada por la detección de conductas disruptivas en clase provocadas por una serie de factores, entre ellos el sentimiento de caos general que se vivía en todo el mundo provocado por la crisis sociosanitaria de la COVID-19; la continua transformación de la situación y las medidas protocolarias en los centros educativos; la frustración y el estrés a la que se enfrentaban el alumnado y el profesorado; la vuelta al colegio tras más de seis meses de cuarentenas; y el escaso número de horas dedicadas a la asignatura de Inglés.

De este modo, los objetivos del JBC pretendían hacer frente a las necesidades detectadas en ambos grupos y eran los siguientes: 
- Reducir los comportamientos disruptivos en clase

- Mantener el control de la clase

- Hacer que el alumnado comprenda las normas de clase y las respete

- Fomentar el trabajo en equipo

- Impulsar el uso del refuerzo positivo

- Disminuir las prácticas de refuerzo negativo

- Centrar la atención del alumnado durante períodos cortos de tiempo

- Establecer una rutina de comportamiento

- Motivar al alumnado

- Aprovechar los recursos materiales del aula

\section{Contexto}

Como decía en el apartado anterior, la experiencia tuvo lugar en el Colegio FUHEM Montserrat en Madrid durante el primer trimestre del curso escolar 2020/2021. Mi ocupación en el mismo era la de especialista de Inglés en los cursos de tercero y cuarto de educación primaria. Se trata de un centro laico concertado que cubre las etapas de educación infantil, primaria (bilingüe), ESO y bachillerato. Pertenece a FUHEM (Fundación Hogar del Empleado), que es una "institución independiente de carácter laico que desarrolla y promueve un proyecto educativo de calidad basado en la innovación, el rigor académico, el desarrollo integral de la persona y la promoción de los valores" (Colegio Montserrat FUHEM, 2017, párr. 1). El centro consta de dos edificios cercanos entre ellos, uno para las etapas de infantil y primaria y otro para el resto de etapas. Se encuentra situado en un barrio de nivel socio-económico medio, cerca de El Retiro, al lado del Parque de Roma (que utiliza como recurso para llevar a cabo actividades formativas de forma continua) y cuenta con el compromiso y la participación de las familias. Tiene comedor y cocina dentro del edificio y el horario partido: de 9 a 12:30 h y de 14:30 a 16:00 h.

La etapa de educación primaria es bilingüe y antes de la COVID-19 se trabajaba "sin muros", es decir, las tres clases de un mismo nivel eran contiguas y no tenían separaciones fijas, sino que estaban conectadas por puertas correderas, que se abrían o se cerraban en función de los objetivos específicos y la actividad concreta que se iba a desarrollar. Este proyecto permitía que los tres tutores y el docente de Inglés estuvieran presentes de forma simultánea (Colegio 
Montserrat FUHEM, 2017) y conllevaba una metodología activa y transformadora nada parecida a la que se tuvo que dar durante la pandemia.

Como todos sabemos, en septiembre de 2020 era la primera vez que se abrían los colegios en España desde la pandemia de la COVID-19 y tanto los protocolos de seguridad como las restricciones no dejaban de cambiar. Todo era nuevo para el alumnado, el profesorado y el resto de equipos de servicio. Por todo esto, había una sensación de caos constante que se transmitía al alumnado de forma inconsciente y estaba más alborotado de lo común.

Por otra parte, algunas de mis clases eran poco disciplinadas, había alumnos disruptivos y con problemas de comportamiento, y otros con otro tipo de necesidades que debían ser atendidas. A ello se le sumaba que solo nos veíamos unas horas a la semana y que era nueva en el centro, por lo que el alumnado estaba menos acostumbrado a mí como figura de autoridad. Durante las primeras semanas observé que no respondía bien al refuerzo negativo, sino que mostraba interés en las recompensas que les ofrecían algunos de mis compañeros tutores. Además, observé que había clases en las que se segregaban en mini grupos y eran excesivamente competitivos entre ellos.

\section{Aplicación y resultados}

Como explicábamos anteriormente, el Juego del Buen Comportamiento se implementó únicamente en las clases de tercero, ya que no se detectó la necesidad de implementarlo en las de cuarto. Su aplicación se produjo de la misma forma en ambos grupos. Para ello, se formaron los equipos de antemano (team rabbit, team spider y team ant) y se creó un cartel con el nombre de todos los alumnos y alumnas que pertenecían a cada equipo para colgarlo en un lugar visible en clase. Además, se creó un PowerPoint para explicar su funcionamiento al alumnado, un cartel plastificado con la hoja de puntos por equipo y un cartel tamaño A3 con las normas de clase básicas en inglés y con dibujos que las ilustraran.

El JBC consiste en respetar las normas de clase durante un período de tiempo marcado por el profesor con el fin de obtener refuerzo positivo en forma de recompensas. Se juega una vez al día todos los días que se tenga la asignatura en cuestión, en este caso Inglés como Lengua Extranjera. La duración del mismo va variando a lo largo de su aplicación y a medida que el 
comportamiento del alumnado va evolucionando, en este caso comenzamos por 10 minutos, ya que en ambas clases las disrupciones eran constantes. Las normas han de ser claras, concisas y reducidas. El inicio del juego se marca con el sonido de un instrumento musical, aunque nosotros lo marcábamos con ritmos de palmas, y con la presencia de un cronómetro que proyectábamos en la pantalla digital. El alumnado jugaba formando parte de pequeños grupos y de gran grupo, es decir, su objetivo final era que todos los pequeños grupos ganaran. El incumplimiento de las normas de clase a nivel individual suponía una marca en el panel de puntos por grupos, de tal forma que si un grupo tenía más de un determinado número de marcas en el tiempo de juego no obtendría ninguna recompensa. Era necesario marcar también el final del juego y repartir las recompensas al final de clase para evitar más distracciones.

Durante la primera sesión, se explicó en clase y en inglés la dinámica del JBC con el apoyo del PowerPoint, se introdujeron las normas de clase, los materiales que utilizaríamos e hicimos un simulacro. La motivación y las recompensas de forma verbal son imprescindibles para el desarrollo de esta práctica educativa.

Comenzamos a principios de la semana y a finales de la misma ya se podían apreciar resultados. Los primeros días había algunas confusiones y era necesario recordar las normas del juego, además, el alumnado creía que era una competición. Las recompensas eran más tangibles: pegatinas, diplomas hechos a mano, etc. La meta era lograr un premio de clase que consistiera en recompensas menos tangibles y que exigieran la participación grupal como, por ejemplo: escuchar y cantar canciones, realizar bailes con distanciamiento social, tiempo libre, etc. El número máximo de marcas empezó en cuatro, de modo que el equipo que obtuviera cuatro o más marcas no obtendría la recompensa.

Los alumnos y alumnas más disruptivos comenzaron a mejorar su comportamiento debido a la presión ejercida por el grupo, interesado en obtener la recompensa, y a respetar las normas de clase durante la duración del JBC incluso cuando a nivel individual no estuvieran interesados en ganar. Al final de la semana, el alumnado trabajaba en silencio y obedecía siguiendo las normas durante, no solo los diez minutos de duración del juego, sino durante el resto de la clase por dos motivos principales: 1) pensaban que su comportamiento posterior podría afectar a la obtención de las recompensas; y 2) ya estaban tranquilos y tranquilas y no salían de su estado de concentración aún después de haber sonado la alarma de fin de juego. 
Seguimos implementado el juego hasta finales del trimestre y era el alumnado el que mostraba interés en llevarlo a cabo, sin embargo, fui yo, como maestra, a la que le costaba más seguir con él debido a la falta continua de tiempo. El alumnado, incluyendo alumnos y alumnas disruptivos y disruptivas, expresó que les había gustado el juego y hacían comentarios semejantes a los del estudio inicial de Barrish, Saunders y Wolf (1969): “me gusta jugar porque la clase está más callada"; "me gustan mucho los premios, ya llevo muchos sellos"; "no es justo que $\mathrm{X}^{2}$ esté en nuestro equipo, porque así nunca ganamos"; "X dice que le dan igual los premios y que quiere tener más marcas".

Además, tuvimos que añadir novedades para seguir progresando y adaptarnos a la situación: a) pasamos de diez a quince minutos de duración; b) los equipos que tuvieran más de seis marcas obtendrían un castigo, que sería tarea extra. Este último elemento no funcionó muy bien porque los alumnos más disruptivos mostraban apatía y pocos de ellos realizaban el castigo, mientras que el resto de sus compañeros de pequeño grupo, que se comportaban bien, sí que las hacían. Una alternativa podría haber sido la llevada a cabo en el estudio de Barrish et al. (1969), en el que el alumno disruptivo se saca del grupo y cuenta como una unidad independiente a la que también se le ponen marcas con el propósito de no penalizar siempre al resto del equipo.

El número de sesiones de JBC fue de cuatro por diez semanas, es decir, de cuarenta aproximadamente. La aproximación se debe a cuarentenas y otras situaciones provocadas por la COVID-19. Los comportamientos que se detectaron que el alumnado debía mejorar se expusieron en clase en forma de normas y son los presentes en la Figura 3:1) trabajar en silencio; 2) ser amable con el resto de personas; 3) levantarse solo con permiso; y 4) seguir instrucciones. Durante la aplicación del JBC mejoraron muy notablemente los comportamientos 1 y 3 , y en menor medida $\operatorname{los} 2$ y 4 , porque parecía que olvidaban que existían esas normas.

\section{Recursos materiales}

Uno de los objetivos de la implantación del JBC era "aprovechar los recursos materiales del aula”, por lo que se utilizaron únicamente materiales sencillos presentes en casi todos los colegios:

- Ficha impresa con los equipos y el nombre de todos los participantes (Figura 1)

\footnotetext{
${ }^{2}$ Nombre de algún alumno disruptivo.
} 
- PowerPoint con la explicación del JBC para el alumnado

- Cartel plastificado con la hoja de puntos por equipo (Figura 2)

- Rotulador borrable

- Cartel tamaño A3 con las normas de clase en inglés y con ilustraciones (Figura 3)

- Cronómetro de cualquier tipo, pero visible al alumnado

- Instrumento musical (opcional)

- Recompensas

Figura 1. Ficha de equipos y participantes.

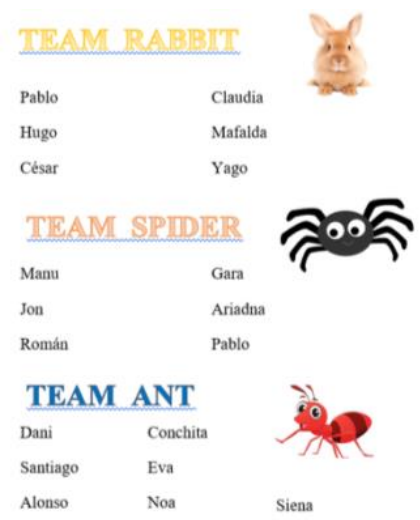

Figura 2. Ficha de puntos.

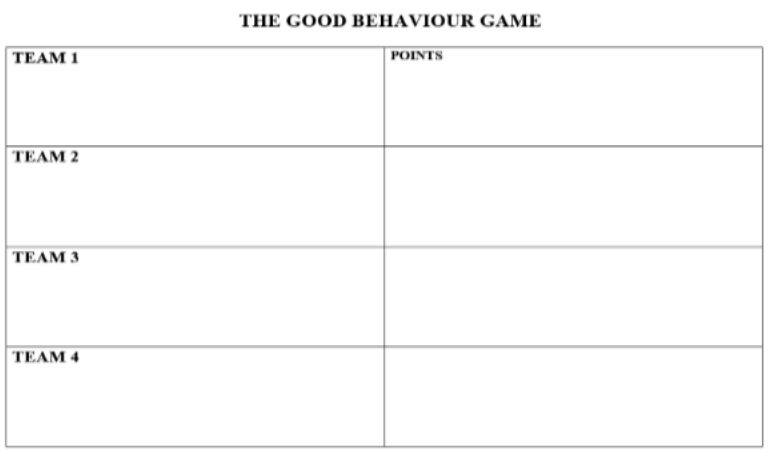

Figura 3. Normas de clase. 


\section{OUR C ASSROOM RULES}

1. We will work in silence.

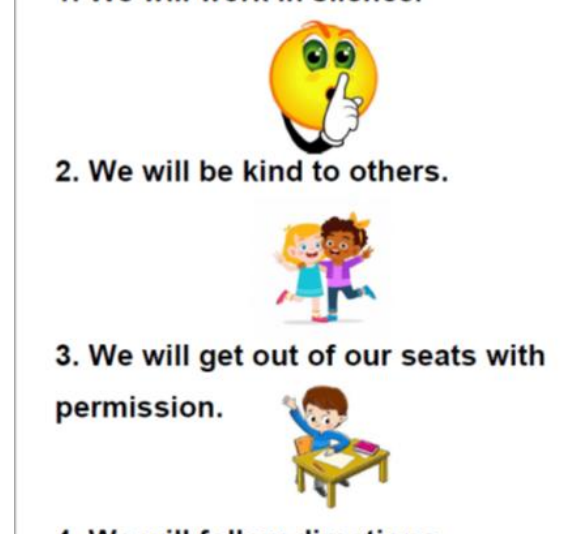

4. We will follow directions.

\section{Conclusiones}

El Juego del Buen Comportamiento es una intervención de manejo del comportamiento disruptivo en clase de fácil implementación que requiere de escasos recursos materiales, es asequible para todo tipo de centro, y que muestra resultados muy positivos a corto y largo plazo. Esta intervención constituye una buena práctica educativa para la gestión de la clase en tiempos caóticos y difíciles como el de la pandemia de la COVID-19 y contribuye a una educación de calidad.

La aplicación estricta del Juego del Buen Comportamiento daba muy buenos resultados, no obstante, su puesta en marcha requiere de gran organización y tiempo, sobre todo para repartir las recompensas. El retraso en el reparto de recompensas, la falta de tiempo y desorganización provoca en el alumnado la sensación de poca formalidad y el efecto del mismo puede decaer. Por este motivo, se necesita un compromiso pleno y constante con esta práctica educativa. 


\section{Referencias}

Barrish, H. H., Saunders, M., y Wolf, M. M. (1969). Good behavior game: effects of individual contingencies for group consequences on disruptive behavior in a classroom. Journal of Applied Behavior Analysis, 2(2), 119-124. http://doi.org/10.1901/jaba.1969.2-119

Colegio Montserrat FUHEM. (2017). Colegio FUHEM Montserrat [Primaria]. Recuperado de: https://colegiomontserrat.fuhem.es/

Lannie, A. L., y Mccurdy, B. L. (2007). Preventing Disruptive Behavior in the Urban Classroom: Effects of the Good Behavior Game on Student and Teacher Behavior. Education and Treatment of Children, 30(1), 85-98. http://doi.org/10.1353/etc.2007.0002

Ruiz Olivares, M. ${ }^{\text {a }}$ D. R., Pino Osuna, M. ${ }^{a}$ J., y Herruzo Cabrera, J. (2006). Revisión de la técnica "El juego del buen comportamiento". Análisis y modificación de conducta, 32(144). http://doi.org/10.33776/amc.v32i144.1727 


\title{
Inclusión educativa saludable mediante proyectos multidisciplinares: Deportes de raqueta con material reciclado
}

\author{
Nora Ramos Vallecillo \\ Francisco López Irache \\ Víctor Guillén Marín \\ Facultad de Educación, Universidad de Zaragoza
}

\begin{abstract}
Palabras clave: Educación Física; deportes de raqueta; material reciclado; Aprendizaje Basado en Proyectos; responsabilidad social.
\end{abstract}

\section{Introducción}

El proyecto multidisciplinar titulado "Smash al covid" es una experiencia desarrollada mediante la metodología del Aprendizaje Basado en Proyecto (ABP) en el colegio Escuelas Pías de Zaragoza, con alumnado de segunda etapa de Educación Secundaria Obligatoria (ESO). Desde el centro promulgamos un proyecto educativo que cree en la escuela y en su carácter socializador, en el que surgen experiencias de crecimiento en lo intelectual, lo emocional y lo espiritual yb se igualan posibilidades. Por ello, el eje metodológico implantado en nuestro colegio corresponde al desarrollo de Proyectos Multidisciplinares (Ramos, 2019).

Dar prioridad a una enseñanza en la que prevalezca el aprendizaje competencial es la base de la enseñanza actual (Mateo y Vlachopoulos, 2010). Uno de esos enfoques de aprendizaje es el ABP (Aprendizaje Basado en Proyectos) que, sin dejar de ser un modelo metodológico, implica un aprendizaje centrado en crear experiencias. El trabajo por proyectos nos permite desplegar un modelo que se dirige al desarrollo total del alumnado (Tamim y Grant, 2013). Para que el ABP sea eficaz, los estudiantes deben hacerse responsables de su aprendizaje y participar en los procesos de construcción del conocimiento y de creación de significados (Carbonell, Essomba y Valero, 2010; Sánchez, Brahim y López, 2013; Tamim y Grant, 2013). 
Por medio de los proyectos multidisciplinares se logra una organización de los contenidos didácticos con un enfoque globalizador, en la que el punto de partida es una situación de necesidad y los contenidos son necesarios para su solución y comprensión (Zabala, 1995). Las situaciones reales son complejas, las relaciones que se establecen entre las experiencias anteriores y el nuevo contenido son muchas y, por tanto, la significación del aprendizaje es mayor (Pareja, 2011). La singularidad del escenario real desencadena diferentes formas de razonamiento que los estudiantes deben tener en cuenta (Morales, 2018). Así, se genera un aprendizaje contextualizado y auténtico que se comprende mediante el desarrollo de la actividad.

\section{Descripción de la experiencia/Objetivo}

La situación de la COVID-19 nos ha planteado un escenario sin precedentes. En el ámbito educativo ha supuesto un reto a superar siendo necesaria una adaptación de las metodologías y formas de afrontar las clases. Durante el estado de alarma, cada centro educativo, siguiendo las instrucciones y normativas de los organismos competentes, ha actuado de manera diferente.

La línea estratégica que mantiene el colegio Escuelas Pías tiene como meta desarrollar una educación integradora que convierta a nuestro alumnado en ciudadanos comprometidos y coherentes con la situación actual. Por ello, desde el departamento de Educación Física y dado el complejo contexto que rodea a la materia (espacios, actividades, movimiento, interacción, materiales y equipamientos...), hemos querido generar procesos y procedimientos específicos que aseguraran el bienestar de los estudiantes y del personal docente, minimizando los riesgos derivados de la situación epidemiológica.

Creemos que los discentes tienen la capacidad de adaptarse a la situación actual y pueden utilizar la Educación Física para desarrollar una conciencia cívica, de hábitos de higiene, autonomía personal. Todo ello, para construir su identidad y confianza en sí mismo (Abós, Servil, Sanz, Aibar y García-González, 2016). Siguiendo la dinámica del centro el departamento de Educación Física se ha planteado realizar una adaptación de las unidades didácticas acorde a las medidas sanitarias, así como al plan de contingencia del centro (Colef, 2020). Todo ello, nos ha llevado al planteamiento de un proceso de enseñanza aprendizaje que se relata a continuación junto a sus objetivos educativos. 
El objetivo principal del proyecto se concreta en hacer de los deportes de raqueta el eje vertebrador de desarrollo de la asignatura en el segundo ciclo de ESO durante la primera y segunda evaluación (Aznar y González, 2001), como prácticas deportivas seguras y que minimicen el riesgo de contagio por la COVID-19.

Para alcanzar este objetivo se han trabajado los siguientes aspectos:

- Convertir al alumnado en protagonista principal de la unidad didáctica.

- Fomentar el uso sostenible de los materiales: uso compartido de mesas polivalentes, recuperación de material del centro.

- Impulsar a los estudiantes para que sean autónomos y comprometidos con el entorno ambiental y el contexto social y económico que le rodea: construcción de material deportivo a partir de material reciclado.

- Conseguir una dinámica multidisciplinar en cooperación a otras asignaturas derivado del aprendizaje basado en proyectos.

- Transferir las enseñanzas de la práctica deportiva al ámbito general del centro: organización de recreos deportivos.

- Generar e innovar en las estructuras y espacios del centro con la visión proactiva de crear recursos nuevos ante situaciones complicadas.

La experiencia educativa ha comenzado con la creación de raquetas de tenis de mesa propias de cada discente. Estas raquetas se han fabricado a partir de materiales reciclados y han servido como instrumentos personales e intransferibles para que los estudiantes no estuvieran en contacto con varias raquetas y así limitar contactos interpersonales.

Figura 1. Raquetas realizadas con material reciclado. Fuente propia.

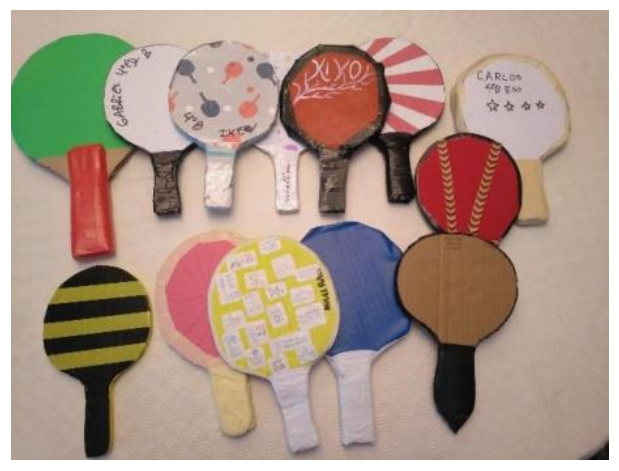


Durante las sesiones de Educación Física, el alumnado de tercero de Educación Secundaria en la primera evaluación y los estudiantes de cuarto de Educación Secundaria en la segunda evaluación, han realizado las tareas y contenidos propuestas por el docente siempre siguiendo las siguientes normas sanitarias:

- Uso de mascarilla obligatoria.

- Desinfección de manos antes y después de la actividad con gel hidroalcohólico.

- Desinfección de mesa, raquetas y pelota.

- Uso individualizado y exclusivo de las raquetas fabricadas por cada alumno.

- Respeto a la distancia de seguridad (2m).

- Uso de botella de agua individual.

- Espacios reservados para la actividad, repartiendo el espacio para que no confluyan participantes y no participantes.

- Ventilación cruzada en la sala.

Mención especial merece la organización e implementación de una serie de recreos activos basados en lo aprendido en clase. Dado el complejo contexto que rodea a la materia, ha pretendido generar procesos y procedimientos específicos que aseguren el confort de los estudiantes y del personal docente, mermando los riesgos derivados de la situación sanitaria actual. Esta actividad ha permitido al alumnado disfrutar del deporte incluso en espacios y horarios diferentes, siendo la educaión física una vía de entretenimiento y organización lúdica en los recreos que tengan que pasar dentro del centro. Todo ello, buscando el bienestar físico y psicológico del discente (GodoyIzquierdo y Pradas, 2007; Méndez-Giménez y Pallasá-Manteca, 2018).

\section{Contexto}

El colegio Escuelas Pías de Zaragoza fue fundado en 1733 por los Padres Escolapios. A lo largo de esta dilatada historia, han sido muchos los alumnos que se han educado en este colegio. Nuestro colegio pertenece a la Orden de los Escolapios manteniendo su carisma y preocupación por la formación integral de los alumnos que su fundador, San José de Calasanz, recogió bajo el lema: "Piedad y Letras". El colegio Escuelas Pías se encuentra en un enclave histórico dentro de la ciudad de Zaragoza, en la Calle Conde Aranda. En la actualidad cuenta con 931 alumnos, 
cursando infantil, educación primaria, educación secundaria obligatoria, así como Bachiller (Bachillerato Montal-Calasanz).

En lo que respecta a las instalaciones deportivas, el centro cuenta con dos patios exteriores y un pabellón polideportivo que son utilizados para la asignatura de Educación Física por los estudiantes de educación infantil, educación primaria y bachillerato. Para la correcta organización, el alumnado de ESO realiza la clase de Educación Física en los campos deportivos de Escuelas Pías situados en Camino de Los Molinos.

Ante el reto que suponía la situación epidémica, desde el departamento de Educación Física se ha buscado un escenario novedoso y diferente para realizar la unidad didáctica de deportes de raqueta, un espacio polivalente que se adecuara a las necesidades de la actividad física y el deporte a realizar y que cumpliera los requisitos y protocolo de actuación establecido por las autoridades y el plan de contingencia del centro en lo referente a medidas sanitarias frente al COVID-19.

Tanto las sesiones de la unidad didáctica como los recreos activos se han desarrollado en el espacio multiusos "MEJOR JUNTOS" un espacio en el que el alumnado de tercero y cuarto de ESO podían desarrollar la unidad didáctica de deportes de raqueta sin perjuicio alguno para su salud y creando valor para el centro. El departamento de Educación Física ha acondicionado el espacio, señalizando campos y espacios. También se han reciclado mesas que, hasta el momento no se utilizaban. Todo ello, para crear un entorno sostenible y seguro donde los estudiantes pudieran crecer y aprender.

Cabe destacar que, hasta el mes de enero, los discentes del segundo ciclo de ESO estaban en un régimen de semipresencialidad. Eso no fue obstáculo para el correcto desarrollo de las sesiones y del proyecto, así como tampoco lo fue la vuelta a la presencialidad de todo el alumnado.

Figura 2. Alumnado practicando en el espacio habilitado (Fuente propia). 


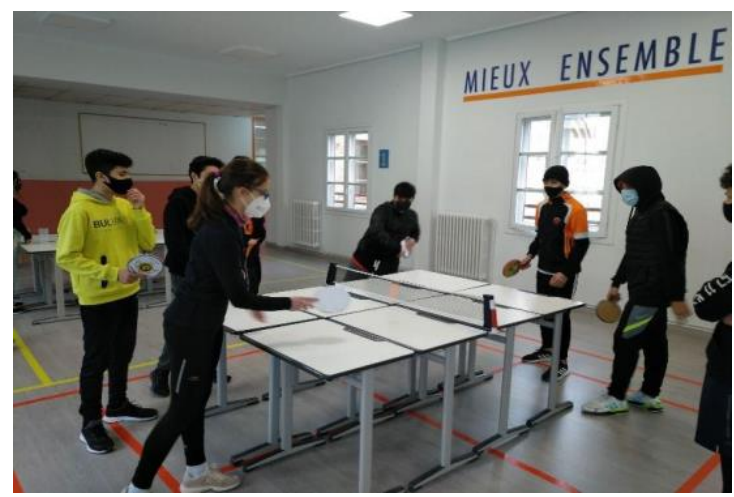

\section{Aplicación y resultados}

A continuación, pasamos a detallar los contenidos, según bloque y los criterios de evaluación alcanzados con el desarrollo del proyecto.

Tanto en tercero como en cuarto de ESO, se han trabajado los contenidos del bloque 2: “Acciones motrices de oposición”. Se ha desarrollado a través de ejercicios de aprendizaje de las diferentes técnicas del golpeo y saque en tenis de mesa. Además, se han llevado a cabo juegos y actividades en las que los discentes han interpretado el juego de sus oponentes. Para ello, han tenido que observar, anticipar y ajustar sus movimientos para ganar los puntos. La táctica se ha ido desarrollando a la vez que han adquirido las habilidades técnicas, a través de situaciones jugadas y los encuentros llevados a cabo tanto en las clases como en los recreos deportivos.

Además, se han trabajado los contenidos del bloque 6: "Gestión de la vida activa y valores". Los criterios de evaluación que hemos alcanzado con este bloque de contenidos han sido reconocer las posibilidades de las actividades físico-deportivas y artístico-expresivas como formas de inclusión social, facilitando la eliminación de obstáculos a la participación de otras personas independientemente de sus características, colaborando con los demás, aceptando sus aportaciones y respetando las normas establecidas. A su vez, han aprendido a controlar las dificultades y los riesgos durante su participación en actividades deportivas y expresivas, analizando las características de las mismas y las interacciones motrices que conllevan, y adoptando medidas preventivas y de seguridad en su desarrollo. Sobre todo, en lo que se refiere a evitar situaciones de contagio al montar y desmontar las mesas de tenis de mesa. 


\section{Conclusiones}

El desarrollo de este proyecto ha sido laborioso debido a la complejidad de la situación sanitaria actual. Es importante destacar que el alumnado ha sido consciente de la importancia de su compromiso para su puesta en práctica. Una de las claves del proyecto ha sido el logro de un desarrollo autónomo de los estudiantes y la adquisición de nuevas responsabilidades. Al utilizar estrategias de trabajo cooperativo, los docentes han sido los mediadores para el fomento de las estrategias de aprendizaje. Tanto alumnado como el equipo docente han adquirido nuevas responsabilidades.

Mediante esta experiencia se ha logrado que los estudiantes sean protagonistas de su proceso de aprendizaje. Los docentes han acompañado, guiado y evaluado su evolución siempre que ha sido necesario. De esta forma, el alumnado ha desarrollado la capacidad de adaptarse a la situación actual y poder utilizar la Educación Física para el desarrollo de una conciencia cívica, hábitos de higiene y autonomía personal, construyendo así su identidad y mejorando la confianza en sí mismo.

La realización de este proyecto nos ha permitido desarrollar los siguientes aspectos:

- Proporcionar a los estudiantes los mecanismos para organizar y disfrute del deporte en su tiempo libre.

- Generar un entorno seguro de práctica deportiva: Medidas de prevención y desinfección para minimizar el riesgo de contagio por COVID-19.

- Transferir las enseñanzas de la práctica deportiva al ámbito general del centro: Unidad didáctica deportes de raqueta.

- Fomentar que el alumnado sea autónomo y comprometido con el entorno ambiental y el contexto social y económico que le rodea: construcción de material deportivo a partir de material reciclado.

- Conseguir un uso responsable y sostenible del material del centro.

Los estudiantes se han sentido durante su desarrollo muy motivados, ya sea por el disfrute del entorno de aprendizaje grupal, el contenido específico del proyecto o por su aplicabilidad práctica final. Por medio de este trabajo los estudiantes han vivenciado como las diversas 
disciplinas no tienen por qué desarrollarse de manera individual, sino que poseen relación y puntos de encuentro. Gracias al enfoque multidisciplinar los discentes han experimentado una oportunidad para ampliar su aprendizaje.

El Plan de contingencia del colegio, debido a la situación de pandemia, nos ha obligado a prescindir de unidades didácticas que funcionaban muy bien como la natación en $1^{\circ}$ y $4^{\circ}$ de ESO. La práctica del tenis de mesa, uso de nuevos espacios y actividades como la de los recreos deportivos nos ha permitido realizar una práctica deportiva segura ante el COVID-19.

\section{Referencias}

Abós, A., Sevil, J., Sanz, M., Aibar, A., y García-González, L. (2016). El soporte de autonomía en Educación Física como medio de prevención de la oposiciónde prevención de la oposición. RICYDE. Revista Internacional de Ciencias del Deporte, XII(43), 66-78. Obtenido de https://www.redalyc.org/pdf/710/71043216005.pdf

Aznar, R., y González, M. (2001). Los juegos y deportes de raqueta en educación primaria: estudio de las consideraciones de las ventajas e inconvenientes por parte de los maestros-as en la provincia de Alicante. C.O.L.E.F, 6-13. Obtenido de http://colefcafecv.com/wpcontent/uploads/2013/04/Revista-colef-5.pdf

Carbonell, L., Essomba, M., y Valero, J. (2010). Los proyectos de trabajo: una herramienta al alcance. En VV.AA., Los proyectos de trabajo en el aula. Reflexiones y experiencias prácticas (pp. 23-28). Graó.

Colef, C. (2020). Recomendaciones docentes para una educación física escolar segura y responsable ante la "nueva normalidad". Minimización de riesgos de contagio de la COVID-19 en las clases de EF para el curso 2020-2021. Revista española de educación física $y$ deportes $-R E E F D, \quad 429, \quad 81-93 . \quad$ Obtenido de https://www.reefd.es/index.php/reefd/article/view/902/748

Godoy-Izquierdo, D. V., y Pradas, F. (2007). Nivel de dominio de las habilidades psicológicas en jóvenes jugadores de deportes de raqueta y pala: tenis de mesa y bádminton. Cuadernos de 
Psicología del Deporte, 7(1), 45-60. Obtenido de https://revistas.um.es/cpd/article/view/54651

Mateo, J., y Vlachopoulos, D. (2010). La nueva naturaleza del aprendizaje y de la evaluación en el contexto del desarrollo competencial, retos europeos en la educación del siglo XXI. Revista Iberoamericana de Evaluación Educativa, 3(3), 45-61. Obtenido de http://www.rinace.net/riee/numeros/vol3-num3/art3.pdf

Méndez-Giménez, A., y Pallasá-Manteca, M. (2018). Disfrute y motivación en un programa de recreos activos. Actividad Física y Salud, 134, 55-68. Obtenido de https://www.raco.cat/index.php/ApuntsEFD/article/view/341995/433056

Morales, P. (2018). Aprendizaje Basado en Problemas (ABP) y habilidades de pensamiento crítico, ¿Una relación vinculante? Revista Electrónica Interuniversitaria de Formación del Profesorado, 21(2), 91-108. doi: http://dx.doi.org/10.6018/reifop.21.2.323371

Pareja, J. (2011). Modelos globalizadores y técnicas didácticas interdisciplinares. En L. Delgado, Didáctica para la educación infantil, primaria y secundaria (pp. 167-198). Universitas.

Ramos, N. (2019). Suma y sigue. En VV.AA., VII Buenas prácticas de innovación docente en el espacio Europeo de Educaión Superior (pp. 309-320). Universidad San Jorge.

Sánchez, S., Brahim, C., y López, V. (2013). El proceso de aprendizaje a través de un pensamiento complejo. En VV.AA., Innovation in Engineering, Technology and Education for Competitiveness and Prosperity (pp. 1-8). Eleventh LACCEI Latin American and Caribb.

Tamim, S., y Grant, M. (2013). Definitions and Uses: Case Study of Teachers Implementing Project-Based Learning. Interdisciplinary Journal of Problem-Based Learning, 7(2), $72-$ 101. Obtenido de https://docs.lib.purdue.edu/ijpbl/vol7/iss2/3/

Zabala, A. (1995). Los enfoques didácticos. En VV.AA, El constructivismo en el aula (pp. 125162). Graó. 


\title{
Contextualización escolar de la enseñanza musical del Maestro de Educación Infantil en tiempos de Covid-19
}

\author{
Luis del Barrio Aranda \\ Ma Belén López Casanova \\ $M^{a}$ Rosa Serrano Pastor \\ Universidad de Zaragoza
}

Palabras clave: expresión musical; educación infantil; formación docente; Covid-19; prácticas contextualizadas

\section{Introducción}

La música y su contribución al desarrollo cognitivo (Dalla Bella, 2015; Herrera, Hernández, Lorenzo y Ropp, 2014), motor (Pica, 1995; Supartini, Weismann, Wijaya y Helaluddin, 2020), lingüístico (Herrera et al., 2014), afectivo (Di Maggio, Zappulla y Pace, 2016; Lacárcel Moreno, 2003) y social (Öztürk y Can, 2020) del niño en la etapa de Educación Infantil es un tema de estudio, cuya evidencia científica argumenta su trascendencia educativa, tanto desde la perspectiva del alumnado en cuanto a su contribución al desarrollo educativo integral, como desde la perspectiva docente, respecto a la formación que implica el conocimiento y desarrollo de la técnica musical y su didáctica.

La experiencia sensorial de la música estimula y satisface las necesidades primarias del niño en sus primeros años de vida, con la exploración del sonido, el ritmo y el movimiento concebida como una práctica natural y cotidiana que le lleva a tomar contacto con el mundo desde la que accede al conocimiento. Desde una dimensión curricular, la enseñanza de la música se establece en el currículo de la etapa de Educación Infantil en el área denominada Lenguajes: 
Comunicación y representación dentro del bloque 3: Lenguaje artístico ${ }^{3}$. Dado que no existe un maestro especialista de Música que imparta la materia en esta etapa, corresponde al maestro tutor la responsabilidad de su docencia.

El conocimiento del alumnado en la etapa de Educación Infantil es un factor esencial para la orientación y el ajuste de todo proceso educativo musical, de acuerdo con las características y las necesidades específicas individuales, que permite hacer efectivos los principios educativos de inclusión y equidad. El maestro tutor dedica más del $80 \%$ de la carga lectiva semanal a la educación del alumnado de su grupo-clase, por lo que adquiere un gran conocimiento individual y del modo de relacionarse en el grupo. Sus funciones incluyen las relacionadas con la acción tutorial y con la educación interdisciplinar que requiere el ejercicio docente en esta etapa. La relación de ambas funciones procura responder a las necesidades educativas del alumnado desde una dimensión preventiva y educativa (Lázaro, Casarrubios y Manzano, 1997). De acuerdo con la orientación musical de este estudio, la atención a estas necesidades puede estar relacionada con la mejora de la coordinación perceptivo-motora, mediante la adaptación de la respuesta corporal del alumnado en interacción con el espacio, con el docente y con sus iguales en diferentes entornos musicales; necesidades vinculadas con el desarrollo emocional y socio-afectivo orientadas desde el trabajo de la autonomía, la autoestima y la empatía, mediante la interpretación de canciones o actividades de música y movimiento que favorezcan la estimulación de la verbalización emocional; necesidades relacionadas con el desarrollo expresivo del lenguaje y la comunicación abordadas con la propuesta de oportunidades, espacios y tiempos para la adquisición del lenguaje, la comunicación y la expresión artística (plástica, corporal y musical) y necesidades relacionadas con las interacciones sociales trabajadas desde la estimulación de la autonomía social y personal con la participación en actividades musicales grupales en las que se promueve la escucha y el diálogo.

La formación interdisciplinar que debe adquirir el profesorado de Educación Infantil suscita una interpretación de la formación inicial, orientada al refuerzo de la significatividad de la didáctica, la actividad reflexiva y, de acuerdo con Santos-González y Sarceda-Gorgoso (2017) al incremento de la intervención docente en el desarrollo profesional, que le lleve a convertirse en un

\footnotetext{
${ }^{3}$ Real Decreto1630/2006, de 29 de diciembre, por el que se establecen las enseñanzas mínimas del segundo ciclo de Educación Infantil.
} 
agente activo del proceso, capaz de adaptar sus funciones a los tiempos, las necesidades y las personas.

La educación musical del futuro maestro en Educación Infantil requiere una adecuada formación inicial y didáctica en la comprensión y orientación del ejercicio profesional con el diseño y conducción de procesos didácticos musicales que aproximen al niño al mundo sonoro, al conocimiento musical, cultural y al desarrollo de las principales destrezas musicales desde las que relacionar la escucha, la interpretación y la creación musical en los distintos medios de expresión corporal, vocal e instrumental.

\section{Descripción de la experiencia/Objetivo}

Este trabajo se basa en una experiencia profesional que procura la mejora de la didáctica musical en la formación inicial del estudiante de Grado de Maestro en Educación Infantil de la Universidad de Zaragoza, mediante el diseño, la aplicación y la evaluación de materiales didácticos musicales audiovisuales originales elaborados por los estudiantes con recursos tecnológicos. La experiencia pretende relacionar los aprendizajes musicales y didácticos adquiridos en la asignatura de Desarrollo de la Expresión Musical durante el $3^{\circ}$ curso de Educación Infantil y su aplicación en contextos escolares de estudio como medio de evaluación.

El estudio se encuadra dentro de una experiencia de Aprendizaje-Servicio (ApS), ya que combina el trabajo académico de la asignatura con un Centro de Educación Infantil y Primaria que nos abre sus puertas de forma voluntaria. De acuerdo con Deleey (2016) el ApS difiere de la enseñanza tradicional en tanto que es aprendizaje activo a través de la experiencia. Además, se establece un diálogo entre la teoría y la práctica, e implica una experiencia personal que favorece y configura el aprendizaje del propio alumno.

El origen de este trabajo se encuentra en una experiencia de ApS por la que 6 maestras de Educación Infantil plantean unas necesidades didácticas, que son reformuladas e integradas por los estudiantes universitarios como objetivos didácticos en el diseño de propuestas educativas creadas en grupos colaborativos de 4 ó 5 miembros. Las propuestas son recogidas como materiales didácticos musicales audiovisuales. Su elaboración integra el desarrollo de destrezas musicales, el 
trabajo de contenidos, así como el conocimiento y el manejo de diferentes recursos tecnológicos que favorecen la grabación, la edición, el registro y la difusión.

La experiencia se enmarca en el proceso del Objetivo de Desarrollo Sostenible número 4: Educación de Calidad, con la que se pretende mejorar la formación didáctica y musical inicial del estudiante de Grado en Educación Infantil.

Aunque el planteamiento inicial procuraba emprender el desarrollo y la evaluación presencial de los procesos didácticos musicales elaborados por los estudiantes en contextos escolares de estudio, la situación de aislamiento derivada de la pandemia COVID-19 determina la adaptación de la experiencia a la elaboración de videos de materiales didácticos musicales, aplicados por las maestras tutoras participantes en sus respectivas aulas de Educación Infantil. La evaluación de los aprendizajes mediante la aplicación de una rúbrica involucra la coevaluación, la autoevaluación y la evaluación de las docentes.

La formación musical inicial del docente comprende el trabajo de competencias técnicas asociadas a destrezas musicales relacionadas con la escucha, la interpretación y la creación; didácticas y metodológicas referidas al modo de diseñar el proceso didáctico y facilitar el aprendizaje; y tecnológicas que implican el uso de diferentes recursos tecnológicos. Por ello, este trabajo pretende estimular la reflexión del estudiante sobre las posibilidades didácticas de la música y las exigencias formativas que requiere el ejercicio docente musical en esta etapa.

El objetivo de esta experiencia es promover la mejora de la formación musical, didáctica y de praxis docente del estudiante de $3^{\circ}$ curso de Educación Infantil a través de prácticas contextualizadas de estudio en entornos escolares mediante la elaboración de materiales didácticos audiovisuales.

\section{Contexto}

El desarrollo de este trabajo conlleva una colaboración interinstitucional entre el departamento de Expresión Musical, Plástica y Corporal de la Universidad de Zaragoza y un colegio público de Educación Infantil y Primaria de Zaragoza, centro destinatario y facilitador de la práctica contextualizada del estudio en el que se llevan a cabo la aplicación y la evaluación de 
los materiales audiovisuales elaborados por los estudiantes universitarios. En el estudio participan 98 estudiantes de 2 grupos-clase de $3^{\circ}$ curso de Grado de Maestro en Educación Infantil, 6 maestras tutoras de los tres niveles de Segundo Ciclo de Educación Infantil y 1 maestra de apoyo de un centro público de Educación Infantil y Primaria y 3 profesores de la Universidad.

\section{Aplicación y resultados}

La temporalización del estudio comprende un período de cuatro meses (febrero-mayo) y su desarrollo consta de cuatro fases: elaboración de los materiales didácticos audiovisuales; presentación en el grupo-clase, coevaluación y evaluación docente; aplicación y evaluación en las aulas de Infantil; grupo de discusión final y autoevaluación.

$1^{a}$ fase. Elaboración de materiales didácticos. Los 98 participantes que configuran el alumnado del estudio de 2 grupos es distribuido en 23 grupos colaborativos de 4 ó 5 miembros. Seleccionan el nivel de Educación de Infantil en el que piensan desarrollar su trabajo. Se les proporciona la pauta de trabajo con los objetivos didácticos y diseñan los materiales audiovisuales, supervisados por las profesoras. Para la elaboración de los videos se les sugiere algunas herramientas que pueden utilizar ya trabajadas en la asignatura como: imovie, ed-puzzle entre otras.

$2^{\mathrm{a}}$ fase. Presentación de materiales. Coevaluación y evaluación docente. La presentación de los materiales audiovisuales elaborados por los grupos en clase es una modalidad de aprendizaje coeducativo. Su visionado permite conocer la organización del trabajo, la distribución de roles, la expresión oral, las dificultades, los aprendizajes y las propuestas de mejora. Se realiza la autoevaluación, la coevaluación y la evaluación docente con una rúbrica de evaluación en la que se utiliza la aplicación Co-Rubrics. Los estudiantes ponen en común los aprendizajes y las dificultades y se discuten propuestas de mejora.

$3^{a}$ fase. Aplicación y evaluación en las aulas de Infantil. Las maestras disponen de un período para aplicar los materiales en sus aulas y valorar mediante una rúbrica de evaluación aspectos relacionados con: la adecuación de los materiales a los objetivos didácticos, la claridad en la expresión oral, la metodología trabajada, la originalidad y la calidad de los recursos. 
$4^{a}$ fase. Grupo de discusión y Autoevaluación. Se propone un grupo de discusión final en el que los estudiantes debaten sobre aspectos didácticos a partir de las aportaciones y valoraciones de las maestras tutoras derivadas de la aplicación de los materiales en el aula. La discusión que genera el intercambio de opiniones pretende motivar la construcción de conocimiento grupal como una forma de aprendizaje profesional en esta experiencia de $\mathrm{ApS}$ y de formación didáctica inicial del profesorado. La autoevaluación en el momento final se corresponde con un tipo de evaluación sumativa en la que el estudiante ha adquirido un conjunto de aprendizajes y reflexiones derivadas de la elaboración de recursos, la observación de los materiales de sus compañeros, el análisis sobre las evaluaciones realizadas (compañeros, maestras del colegio y docentes de la universidad) y la discusión. La autoevaluación pretende la verbalización de los aprendizajes, de las dificultades encontradas a nivel individual o en el grupo de trabajo, de las medidas adoptadas para su resolución y de las propuestas de mejora.

Los resultados registran la evaluación docente, coevaluación y autoevaluación de los aprendizajes según las categorías de estudio de la rúbrica de evaluación: adecuación didáctica, expresión oral, metodología y recursos, con la correspondiente asignación de porcentajes (evaluación docente $=60 \%$, coevaluación $=30 \%$ y autoevaluación $=10 \%$ ).

Figura 1. Evaluación media de las categorías del estudio (n=98)

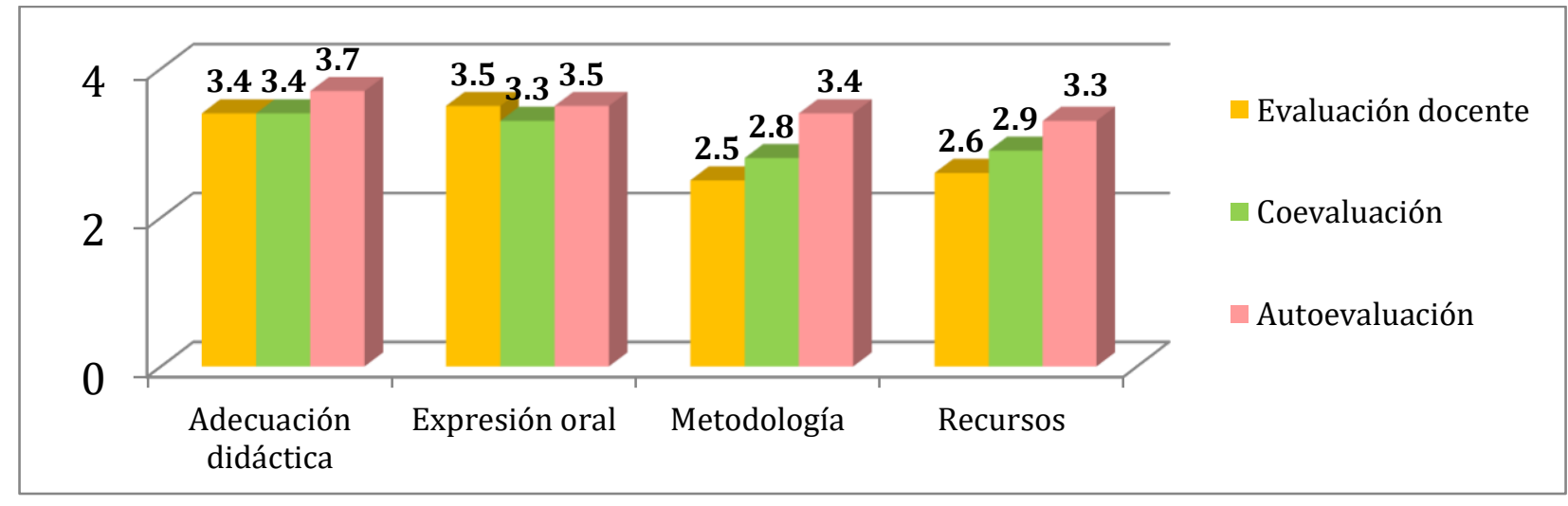

Nota: Niveles de evaluación: (1= novel; $2=$ aprendiz; $3=$ avanzado; $4=$ experto)

Respecto a la adecuación a la finalidad didáctica de los materiales elaborados, la media de la evaluación es nivel 3,5 (avanzado). Las actividades se han ajustado a los propósitos para cada nivel y a la edad del alumnado. Cuando se han incluido varias actividades en el video, ha proporcionado mayor riqueza tanto al proceso didáctico como al conjunto de aprendizajes. 
La expresión oral adquiere especial atención en Educación Infantil. Este aspecto es cuidado por los participantes, cuya evaluación media es: nivel 3,43 (avanzado). Es un recurso fundamental para captar y mantener la atención y lograr la comprensión de cada consigna por lo que su buen uso ha sido fundamental para el éxito del aprendizaje. En la expresión oral, la repetición y la entonación han sido recursos fundamentales. El lenguaje corporal, el uso de muñecos, disfraces, objetos y pictogramas ha facilitado la expresión y la adecuación a la edad del alumnado.

La metodología didáctica tiene una evaluación media: nivel 2,9 (aprendiz). Los procesos didácticos han sido dinámicos e inclusivos desde los que se ha facilitado la participación del conjunto del alumnado. La evaluación de actividades planteadas como básicas para la edad del alumnado ha requerido la propuesta de actividades secuenciadas. Los estudiantes y el profesorado han valorado la actitud, el esfuerzo, la dimensión colaborativa y la combinación de recursos (analógicos y digitales) como aspectos relevantes en la metodología.

Los recursos tecnológicos y su calidad adquieren una valoración de 2,9 (aprendizavanzado). La dimensión audiovisual, el planteamiento dinámico y el uso de diferentes aplicaciones han favorecido la atención y el aprendizaje. La calidad de los recursos ha estado determinada por el tipo de dispositivos, la familiarización en el manejo de las herramientas, el esfuerzo y la creatividad. Las maestras del colegio han valorado de manera muy positiva la utilidad de los materiales que han sido incorporados en la programación de aula.

\section{Conclusiones}

La promoción de una didáctica musical significativa durante la formación inicial constituye una de las principales metas de la enseñanza en la formación del estudiante de Grado de Maestro en Educación Infantil. La práctica contextualizada facilita la relación, aplicación y reflexión de los aprendizajes y conocimientos aplicados en contextos escolares de estudio, cuya contribución influye en la construcción de la praxis docente. La elaboración de recursos didácticos audiovisuales facilita la repetición como un modo de adecuación del proceso didáctico para mejorar la comprensión. Los materiales elaborados pueden presentar o consolidar contenidos trabajados y se incorporan como actividades de la rutina. 
El trabajo colaborativo en el diseño de procesos didácticos motiva la iniciativa, el compromiso, la construcción del conocimiento social a partir de una necesidad real de un contexto escolar. El trabajo colaborativo facilita la reflexión del estudiante en entornos de aprendizaje colaborativos tanto en la construcción, aplicación y evaluación de sus productos como en la evaluación de los procesos didácticos de los compañeros en prácticas de coevaluación. La evaluación de los materiales desde una triple dimensión: autoevaluación, coevaluación y evaluación docente enriquece la dimensión didáctica desde la reflexión, la aplicación y el pensamiento crítico.

La creación y grabación audiovisual de productos didácticos musicales permite integrar en el trabajo de contenidos, los principios metodológicos de las principales corrientes pedagógicas musicales activas, las potencialidades de las herramientas tecnológicas como soporte didáctico y la creatividad en el diseño de los mismos.

Proporcionar significatividad a la formación didáctica musical requiere prácticas próximas a la realidad escolar. La práctica didáctica contextualizada implica una colaboración entre instituciones docentes (universidad-colegio) que resulta significativa y enriquecedora para ambas partes: para la maestra del colegio al enriquecer su trabajo cotidiano de aula con la adquisición y aplicación de recursos musicales de interés que puedan complementar los suyos, y para el estudiante universitario al adquirir el feedback de la aplicación didáctica en un contexto educativo real y evaluar la utilidad y efectividad de los materiales evaluados por maestras en ejercicio.

\section{Referencias}

Dalla Bella, S. (2015). Music and Brain Plasticity. In Hallam, S., Cross, I., and Thaut, M. The Oxford Handbook of Music Psychology, Second Edition, (pp.1-16). Oxford University Press. http://doi.org/10.1093/oxfordhb/9780198722946.013.23

Deleey, S. J. (2016). El Aprendizaje-Servicio en educación superior. Teoría, Práctica y perspectiva crítica. Narcea Ediciones. 
Di Maggio, R.; Zappulla, C. y Pace, U. (2016). The Relationship Between Emotion Knowledge, Emotion Regulation and Adjustment in Preschoolers: A Mediation Mode. Journal of Child and Family Studie, 25(8), 2626-2635. https://doi.org/10.1007/s10826-016-0409-6

Herrera, L., Hernández, M., Lorenzo, O. y Ropp, C. (2014). Influencia del entrenamiento musical en el desarrollo cognitivo y lingüístico de niños de 3 a 4 años. Revista de Psicodidáctica, 19(2), 367-386. http://doi.org/10.1387/RevPsicodidact.9761

Lacárcel Moreno, J. (2003). Psicología de la música y emoción musical. Educatio Siglo XXI, 20, 213-226. https://revistas.um.es/educatio/article/view/138

Lázaro, A.; Casarrubios, R. y Manzano, N. (1997). La Tutoría y la orientación educativa en la Educación Infantil y Primaria. En Álvarez y Bisquerra, Manual de Orientación y Tutoría. Praxis.

Öztürk, E., y Can, A. A. (2020). The effect of music education on the social values of preschool children. Cypriot Journal of Educational Sciences, 15(5), 1053-1064. https://doi.org/10.18844/cjes.v15i5.5150

Pica, R. (1995). Experiences in Movement with Music, Activities, and Theory. Delmar Publishers.

Real Decreto 1630/2006, de 29 de diciembre, por el que se establecen las enseñanzas mínimas del segundo ciclo de Educación Infantil. (BOE $\mathrm{n}^{\mathbf{0}} 4$, de 4 de enero de 2007) https://www.boe.es/eli/es/rd/2006/12/29/1630

Santos-González, C. y Sarceda-Gorgoso, C. (2017). Desarrollo de competencias docentes en Educación Infantil. Una experiencia interdisciplinar en la formación inicial de profesores. Formación Universitaria, 10(6), 39-50. http://dx.doi.org/10.4067/S0718$\underline{50062017000600005}$

Supartini, T., Weismann, I., Wijaya, H., y Helaluddin (2020). Development of learning methods through songs and movements to improve children's cognitive and psychomotor aspects. European Journal of Educational Research, 9(4), 1615-1633. https://doi.org/10.12973/eujer.9.4.1615 


\title{
Análisis, estrategias y acciones de mejora emprendidas con el alumnado con discapacidad ante la pandemia por COVID19
}

\author{
Amalia Aguilar Bail \\ Facultad Ciencias Humanas y de la Educación, Universidad Zaragoza
}

Palabras clave: digitalización, accesibilidad, derecho universal, inclusión, atención multidisciplinar

\section{Introducción}

El nuevo escenario generado por la pandemia del COVID19 supuso para las personas que son atendidas en ASPACE HUESCA y sus entornos familiares una situación sobrevenida que les hacía especialmente vulnerables ante las dificultades añadidas que trajo asumir la distancia social como medida preventiva.

Con la perspectiva de una crisis sanitaria que iba a necesitar tiempo para su remisión, y como efecto colateral colocaba a las personas con parálisis cerebral de la Entidad ante el panorama de un periodo de tiempo dilatado para volver a tener un día a día igual al de antes de que llegara, era prioritario poner en marcha mecanismos que permitieran acortar distancias, y que el colectivo que se atiende desde ASPACE HUESCA y sus familias siguieran estando acompañadas, y sintieran cerca, aunque fuera de forma virtual, a todo el equipo de profesionales y al resto de personas que forman parte del colectivo.

Y desde un enfoque de globalidad se apostó a la vez por poner en marcha estrategias que permitieran dar continuidad a los programas de la Entidad, todos de vital importancia para el bienestar personal (Colegio Educación Especial, Habilitación Física, Logopedia, Terapia Ocupacional...), siendo una prioridad dar con las fórmulas que permitieran seguir adelante con el 
trabajo a desarrollar y la atención profesional, entendidas como una de las bases para el mantenimiento y mejora de su calidad de vida.

Tal como afirma Verdugo (2.016) a partir de la propuesta de la calidad de vida de las personas con discapacidad su grado de dependencia no dependen tanto de la propia persona y sí de los recursos y estrategias que se movilizan para la cobertura de sus necesidades, siendo fundamentales, entre otros, aquellos que garantizan una atención especializada para su cuidado.

\section{Descripción de la experiencia/Objetivo}

La experiencia que ASPACE HUESCA ha vivido desde que comenzó la pandemia por COVID19 hasta hoy, en todos los servicios, desde lo que se atienden a las personas que forman parte de la Entidad, y por ende, el alumnado del Colegio de Educación Especial San Jorge, es la crónica de la consolidación de nuevas líneas de trabajo.

En lo que se refiere a la atención y acompañamiento de los niños y niñas, y adolescentes escolarizados en el Colegio de ASPACE HUESCA, fueron varios los retos a abordar: el establecimiento de vías de comunicación que permitieran mantener las relaciones establecidas entres todos ellos, puesta en marcha de iniciativas que facilitaran seguir con su atención por parte de especialistas, garantizar la adquisición de nuevos aprendizajes y consolidación de los adquiridos hasta ese momento del curso y acompañamiento de los entornos más próximos, fundamentalmente sus familias.

Todo ello se gestó a partir del compromiso de alcanzar el objetivo de consolidar estrategias para mantener la atención profesional y el acompañamiento personal, además de proteger los entornos próximos habituales cuando factores sobrevenidos implican el distanciamiento social, el asilamiento preventivo o el confinamiento domiciliario, como mecanismos de protección (ya sea por una crisis sanitaria, o por protección personal por complicación de salud).

Su consecución en el caso del Colegio de ASPACE HUESCA fue estructurada en tres objetivos específicos: mantener las dinámicas habituales de trabajo de los equipos profesionales durante el periodo de no presencialidad en el Centro, fortalecer los vínculos afectivos de las personas del colectivo para que la distancia física no supusiera una merma minimizando así el 
riesgo de exclusión social del colectivo y dar contenido a los tiempos de descanso y ocio de los niños y niñas y adolescentes sin poder disfrutar de espacios abiertos junto a otras personas (estudiando posibilidades como es el caso del ocio virtual).

Y en la búsqueda de alternativas para abordar el gran reto que se manifestó ante todas las personas que trabajan en la Entidad de la mano del COVID19, no tardó en abrirse camino la idoneidad de fomentar el manejo que las personas con discapacidad pueden hacer de la tecnología, perfectamente viable desde los primeros años de vida, y por lo tanto abordable desde el Colegio, con los apoyos necesarios, apostando por encontrar en ella una gran aliada para paliar las limitaciones de la distancia social que impuso la pandemia.

\section{La consecución de los objetivos de desarrollo sostenible (ODS) como guía}

La razón de ser de ASPACE HUESCA es la mejora de la calidad de vida de las personas que se atienden, y sus entornos familiares, dando respuesta a sus necesidades, entre ellas todos los aspectos relacionados con su Salud y su Bienestar en diferentes áreas (entornos accesibles, oferta de actividades estimulantes, atención de personal especializado...), como es el caso de sus escolares.

Junto a la salud, desde la Entidad se apuesta por la Educación entendida como proceso de aprendizaje, de las personas con parálisis cerebral desde los primeros años de vida, poniendo en marcha los mecanismos necesarios para protegerla de cualquier situación sobrevenida que pueda ponerla en peligro, garantizando así que sea un derecho universal para todos los niños y niñas.

Y el compromiso hacia la educación responde a la defensa de los derechos del colectivo, entre ellos los niños, niñas y adolescentes, uno de los ejes del Plan Estratégico de la Entidad, y uno de los pilares hacia los que apunta el trabajo que se desarrolla a diario, siendo la accesibilidad y la igualdad de oportunidades dos de sus sustentos fundamentales. 


\section{Contexto}

El Centro de Educación Especial San Jorge, de ASPACE HUESCA, atiende a niños, niñas y adolescentes con pluridiscapacidad entre los 3 y los 21 años, con una escolaridad a tiempo completo o en modalidad de combinada. En él se trabaja desde los ámbitos de calidad de vida y bajo los principios de atención y educación integral, normalización e integración social, desde el respecto a la individualidad y a la diversidad.

La ejecución de las acciones que se desarrollaron se apoyó en la intervención de los profesionales de la Entidad, tanto en el caso de dinamizar las actividades, como en la elaboración de materiales de trabajo para difundir, y en la labor de acompañamiento y seguimiento de los entornos familiares, encontrando en estos últimos un gran apoyo a la hora de realizar todas las tareas vinculadas a la atención de su familiar en los domicilios.

Como señala la Confederación Aspace (2021) en su Informe de resultados, conclusiones y propuestas sobre el Impacto y Sobrecoste económico del COVID-19 en las Entidades Aspace en 2020 la llegada de la pandemia supuso un gran reto para todos sus servicios, entre ellos sus Colegios, en cuanto a adopción de medidas preventivas, buscando combinarlas con fórmulas de trabajo que permitieran seguir ofreciendo una atención especializada a su alumnado, desde diferentes áreas complementarias entre sí (la fisioterapia, la logopedia y la terapia ocupacional), esenciales para ralentizar lo máximo posible su deterioro y mantener los aprendizajes y habilidades adquiridas, con una repercusión directa en su calidad de vida.

La búsqueda de soluciones llevó a la Entidad a innovar con iniciativas a partir de la priorización de acciones inclusivas, con las oportunidades que nos ofrecía la digitalización creciente, buscando fórmulas para establecer lazos de contacto virtual y trabajo on-line.

\section{Aplicación y resultados}

El trabajo que se ha venido desarrollando desde marzo del pasado año 2.020 hasta hoy, y el que queda por realizar hasta el final de la pandemia, dentro de los posibles escenarios que se puedan dar, contempla mecanismos para que los profesionales de diferentes áreas de ASPACE HUESCA sigan trabajando con las personas y sus entornos familiares. 
Con esta máxima como referencia el Blog de Escolar se ha convertido en una de las plataformas fundamentales para seguir trabajando con el alumnado, especialmente para el caso del equipo de Maestros y Maestras. De forma periódica preparaban y subían contenidos de tipo pedagógico con un enfoque de diversión utilizando las estrategias necesarias para fomentar la atención y participación del alumnado (actividades, retos a resolver, juegos,...para realizar en casa) y facilitar la labor de apoyo y acompañamiento de sus entornos familiares.

A lo largo de los meses que el Blog se convirtió en el canal fundamental de comunicación e interacción entre Maestros y Maestras y alumnado se prepararon materiales de forma periódica, que eran seguidos con interés por el alumnado, y consultados y resueltos con la ayuda de las familias. En aquellos domicilios en los que no contaban con los recursos técnicos necesarios jugó un papel fundamental la colaboración de Protección Civil, que se hizo cargo de llevar los materiales de trabajo en papel.

Para que esta línea de trabajo haya funcionado ha sido fundamental la colaboración de las familias. La respuesta obtenida por todas las familias del Colegio ha sido de un gran interés e implicación para realizar las actividades con sus hijos e hijas desde casa, y de agradecimiento por el acompañamiento que se ha realizado desde el Colegio, haberles ayudado a dar contenido al día a día durante el confinamiento domiciliario y velar por la continuidad en el proceso de su aprendizaje.

Tal como indican Patiño y Jaúdenes (2004) es fundamental la colaboración entre los entornos profesionales y la familia, en la medida en que hablamos de una institución socializadora primaria con gran peso en los aprendizajes y la estabilidad emocional, especialmente en las edades tempranas, pero que acompaña toda la vida, teniendo gran relevancia en la inserción social y el desarrollo personal, con gran repercusión en el caso de las personas con discapacidad.

Además de poder continuar con el trabajo a nivel académico era relevante desde un primer momento buscar herramientas que permitieran el mantenimiento de sus marcos relacionales, facilitando el contacto entre las personas que forman parte de su entorno escolar, especialmente sus compañeros y compañeras de aula. Con tal fin se realizaban de forma periódica videollamadas en las que participaba el alumnado. Desde un primer momento se reveló como una actividad con gran aceptación, porque les ha dado la oportunidad de seguir manteniendo el contacto con sus 
compañeros de Colegio, y amigos, personas que forman parte de otros de sus entornos más próximos.

La Confederación Aspace (2017) en su estudio Un modelo de ASPACE para fomentar la autodeterminación de la Infancia y la Adolescencia con Parálisis Cerebral se reafirma en la idea de que el alumnado está formado por niños, niñas y adolescentes con gustos, preferencias, habilidades, fortalezas y capacidades, que deben salir a la luz con la intervención de profesionales especializados y el manejo de los productos de apoyo ajustados a sus afectaciones. Este hecho supone para las personas que se forman en el Colegio de Educación Especial San Jorge de ASPACE HUESCA la superación de retos vinculados a su proceso de aprendizaje personal y su participación como ciudadano o ciudadana de pleno derecho.

Por lo tanto es crucial la intervención continuada de profesionales especializados en diferentes áreas complementarias para su crecimiento personal, lo que se convirtió en otra de las prioridades tras el estallido de la pandemia por COVID-19. Una vez más la tecnología sería una gran aliada, facilitando plataformas para poder realizar sesiones de trabajo y continuar con las terapias, de forma on-line.

Las familias mostraron también un gran interés y aceptación a estas sesiones on-line de contacto y trabajo conjunto realizado con sus hijos e hijas con el acompañamiento de sus especialistas de referencia.

Sabiendo que la estabilidad en los entornos familiares es fundamental para la estabilidad personal de los niños, niñas y adolescentes del Colegio de ASPACE HUESCA, y teniendo en cuanta que en la propia Misión de la Entidad se recoge la atención de las familias de las personas del colectivo, desde un primer momento las acciones a desarrollar con las familias fue otro de los ejes en torno al cual hacer trabajo on-line, con la realización de videollamadas periódicas, que eran acogidas con mucho agrado.

Con las diferentes acciones emprendidas en el intento de dar una respuesta lo más completa posible ante la situación generada por la pandemia del COVID19 se buscaba generar oportunidades para que las personas con discapacidad participaran en, y fueran destinatarias de acciones que superan barreras físicas y sociales. 
La experiencia profesional que está suponiendo afrontar las medidas restrictivas para hacer frente a la pandemia, y el efecto que tiene en el colectivo de personas con parálisis cerebral, se sustenta en una firme apuesta por la innovación tecnológica, lo que implica un ejercicio continuo de reflexión, puesta en práctica y valoración, en un proceso constante como base para el avance a partir de los aciertos y aprendizajes, sobre metodología de trabajo on-line, apostando por ella para reforzar lazos de comunicación, y proteger la estabilidad emocional y el bienestar de las personas de la Entidad, y por lo tanto del alumnado de su Colegio.

Con la evolución de las acciones desarrolladas se va produciendo el retorno de resultados a las personas destinatarias, en un avance claro hacia la reducción de la brecha digital, al consolidar su uso como herramienta para afrontar posibles escenarios en los que no es posible trabajar de forma presencial con las personas.

\section{Conclusiones}

La llegada de la pandemia del COVID19 supuso una ruptura abrupta de la cotidianeidad de la vida de las personas con parálisis cerebral, y por lo tanto de los niños, niñas y adolescentes escolarizados en el Colegio de Educación Especial de ASPACE HUESCA. Esto supuso tener que buscar opciones para intentar sostener en el tiempo la atención especializada y el mantenimiento y estabilidad de sus entornos próximos con un recurso hasta entonces apenas explorado, como es la tecnología y la comunicación on-line. Se ha revelado con fuerza para la sociedad en general, y para el colectivo en particular.

Desde un principio la Entidad entendió que debía pensar en un conjunto de acciones para tener capacidad rápida de respuesta y adaptación cuando, por una circunstancia sobrevenida como ha sido la pandemia, no fue posible trabajar por un tiempo de forma presencial con las personas que se atienden. Porque mantener el contacto diario con ellas para que siguieran recibiendo la atención profesional interdisciplinar y activar los mecanismos necesarios para que siguieran teniendo contacto con sus compañeros era básico para su bienestar, sin dejar de lado la atención y acompañamiento de sus familias. Además así ASPACE HUESCA seguiría avanzando en la igualdad de oportunidades que el resto de la sociedad para superar dificultades. 
Como señala Rodríguez (2.012) la crónica de la evolución de la discapacidad es el resultado de dos aspectos complementarios entre sí como son la capacidad de respuesta de los centros de atención al contexto de cada momento y la capacidad de respuesta de la sociedad a lo que a defensa de derechos de las personas se refiere.

El trabajo que se ha venido desarrollando desde el inicio de la pandemia por COVID19 contempla mecanismos para que los profesionales de diferentes áreas de ASPACE HUESCA sigan trabajando con las personas que ya están volviendo presencialmente y con aquellas que siguen en sus casas, además de sentar las bases para poder continuar con su labor en cualquier escenario que se pueda dar a futuro.

Además es crucial mantener los círculos de apoyo personal de los niños, niñas y adolescentes del Colegio, fundamentalmente con las personas de sus entornos más próximos. Y también hay que consolidar como línea de trabajo el acompañamiento a sus familias, garantizando las bases que permitan el mantenimiento de la conciliación familiar y personal.

La llegada de la pandemia por COVID19 ha colocado a la Entidad ante un gran reto de innovación tecnológica, en la medida en que hay que consolidar la planificación de actividades que tengan viabilidad presencial, pero también, y sobretodo online. Y este reto, que ASPACE HUESCA ya se planteaba con anterioridad a la pandemia, por el avance de la sociedad general, creció en exigencia con el COVID19 por el compromiso hacia las personas que se atienden, y la mejora de su calidad de vida. Por lo tanto se tiene la certeza de que es un reto que ha llegado para quedarse, y al que se está dando respuesta de forma progresiva, planteada como una acción de mejora.

Financiación o apoyos: Abordar la situación descrita, generada por la pandemia del COVID19, poniendo en marcha los mecanismos necesarios para minimizar el gran efecto limitante que podría haber tenido sobre el colectivo, ha sido posible gracias al Gobierno de Aragón al mantener el Convenio de Educación con el Colegio de Educación Especial San Jorge de ASPACE HUESCA, y a la colaboración de Protección Civil. 


\section{Referencias}

Confederación Aspace (2017). Un modelo de ASPACE para fomentar la autodeterminación de la infancia y adolescencia con parálisis cerebral. Confederación Aspace

Confederación Aspace (2021). Impacto y sobrecoste económico del COVID-19 en las Entidades Aspace en 2020. Confederación Aspace

Patiño,I., y Jaúdenes,C. (2004). Familia y Discapacidad. En A. S. Adroher (Coord.), Discapcidad e integración: familia, trabajo y sociedad (pp. 25-29). Universidad Pontificia Comillas de Madrid

Rodríguez, G. (2012). El sector de la discapacidad: realidades, necesidades y retos futuros. Grupo Editorial Cinca

Verdugo, M.A. (2016). Calidad de vida: manual para profesionales de la educación, salud y servicios sociales. Alianza 


\title{
Tendiendo redes para la inclusión educativa en la Universidad Nacional de Córdoba
}

\author{
Vanina Elizabeth Zurita \\ Ricardo Matías Hernández \\ Carmen Gloria Clark \\ Oficina de Inclusión Educativa para Personas en Situación de Discapacidad \\ Departamento de Acompañamiento a las Trayectorias Académicas Estudiantiles \\ Universidad Nacional de Córdoba
}

Palabras clave: Accesibilidad, Educación Superior, Tutorías, Discapacidad.

\section{Introducción}

La inclusión está relacionada con el acceso, la participación y los logros de todos los/as estudiantes, con especial énfasis en quienes están en riesgo de ser excluidos por diferentes razones. Concebida así, se convierte en responsabilidad del Estado y del Ministerio de Educación o dependencia relacionada, y no de alguna subdivisión asignada exclusivamente a la educación especial (Blanco, 2006; UNESCO, 2005, citado en Brito, Basualto Porra y Reyes Ochoa, 2019).

Por tanto, la educación inclusiva, tiene como propósito ampliar la mirada respecto del sistema educativo, reconociendo el derecho innegable a la educación y el valor de la diversidad de estudiantes, como derecho humano universal, según se enuncia en la Declaración de Salamanca (UNESCO, 1994, citado en Brito et al., 2019).

En este sentido, numerosos trabajos documentan avances en materia de inclusión educativa en el nivel primario y secundario (Blanco, 2014). Sin embargo, en el nivel superior, la inclusión educativa es un campo de estudio reciente, donde metodológicamente, se acrecientan los esfuerzos por dotar de rigor científico los análisis y prácticas en la materia; y en relación al punto de vista 
epistemológico, requerirá situar a la inclusión educativa en otros campos semánticos, rescatándolo de los análisis parametrales (Brito et al., 2019).

En tal sentido, un hito significativo es la firma en las Naciones Unidas de la Convención sobre los Derechos de las Personas Con Discapacidad (CDPCD) en 2006, donde se asume el compromiso de ampliar el alcance de la educación inclusiva a todos los niveles educativos.

Asimismo, se entiende que la discapacidad es considerada una categoría social y política, una condición producto de la interrelación de estructuras económica, social y cultural, una forma de opresión social que impone limitaciones (Angelino, 2009 citado en Castignani, 2017) y tal como se acuña en CDPCD, se adopta el modelo social de la discapacidad. Por ende, para que las personas con discapacidad puedan vivir en forma independiente y participar plenamente en todos los aspectos de la vida, se considera necesario garantizar la accesibilidad, Artículo $9^{\circ}$ CDPCD (2006).

En tal sentido, resulta clave focalizarse en las barreras que imposibilitan la plena participación de las personas con discapacidad en la comunidad (Palacios, 2008). Las barreras, pueden definirse como obstáculos que impiden el desarrollo personal, la libre elección y el pleno disfrute de la vida social y en comunidad; existen cuando entornos, productos o servicios no permiten que todas las personas se beneficien o disfruten de ellos (Cermi, 2016). En el ámbito educativo, Booth y Ainscow (2002) hacen referencia a barreras para el aprendizaje y la participación, las cuales surgen no solo de la interacción entre estudiantes y sus contextos; sino también producto de personas, políticas, instituciones, culturas, circunstancias sociales y económicas que afectan a sus vidas.

De esta manera, para De Asis Roig (2005, citado en Corrales Huenul, Soto Hernández y Vallafañe Hormazabal, 2016) las barreras determinan "ámbitos de accesibilidad, entre los que destacan: movilidad, comunicación e información, acceso a bienes y servicios, y actitudes negativas hacia la discapacidad" (p. 4). Enuncia que existe una "relación dinámica entre accesibilidad universal y barreras" (p. 4) como un proceso recíproco, el estudio de uno nutre al otro y viceversa (De Asis Roig (2005, citado en Corrales Huenul et al., 2016).

Además de las barreras, otro punto que se presenta como problemática en las universidades de Argentina y países latinoamericanos, es el acceso a la universidad, aspecto que se refleja en los 
aplazos masivos en el ingreso a universidades públicas (Capelari, 2016). En este punto, Misischia (2018) expresa que estudiantes con discapacidad solo representan $0.8 \%$ de la población ingresante a las universidades públicas y no hay datos sobre el egreso, lo cual refleja que se invisibiliza a las personas con discapacidad en Argentina. Actualmente, las universidades desarrollan estrategias y programas destinadas a promover el acceso y la permanencia de estudiantes con discapacidad, los cuales pueden subdividirse en diferentes momentos temporales: previo al acceso, estrategias de retención durante el trayecto académico, el egreso y de manera global (Fernández, Barrera y Díaz, 2013, citado en Corrales Huenul et al., 2016).

Por tanto, hay que tener presente la promesa que se hizo en la Agenda 2030 para el Desarrollo Sostenible de no dejar a nadie atrás; en 2019, se pone en marcha la Estrategia de las Naciones Unidas para la Inclusión de la Discapacidad, un compromiso de apoyar a los Estados Miembros y en 2020 se presenta el primer informe, conforme con la resolución 74/144 de la Asamblea General, sobre las medidas adoptadas por el sistema de las Naciones Unidas para transversalizar la inclusión de la discapacidad.

Entendiendo, que no debe reducirse a un problema individual y del sujeto, sino como un asunto social, colectivo y desde la concepción del modelo social, se deben revisar las prácticas docentes e institucionales vinculadas a la educación superior (Castignani, 2017)

Por lo mencionado, se propone recuperar una experiencia de trabajo en red, acerca de buenas prácticas en inclusión educativa, realizadas en la Universidad Nacional de Córdoba (UNC) Argentina durante el COVID-19, año 2020. Que mediante acciones colaborativas y participativas de diferentes actores de la comunidad educativa se buscó fortalecer la inclusión educativa universitaria y avanzar en la construcción de una universidad que garantice una educación inclusiva, equitativa, de calidad y promueva oportunidades de aprendizaje.

\section{Objetivos}

- Promover acciones colaborativas y participativas de diferentes actores de la comunidad educativa para fomentar la inclusión educativa universitaria.

- Reflexionar sobre las estrategias de acompañamiento y accesibilidad para estudiantes con discapacidad en un cursado virtual. 


\section{Descripción de la experiencia}

La experiencia vivenciada, surge de la propuesta del equipo de reforzar las redes de acompañamiento y apoyo, para fortalecer las trayectorias educativas de estudiantes con discapacidad en el cursado virtual, medida implementada ante la pandemia Covid-19, año 2020. Se enmarca en las acciones que se desarrollan desde la Secretaría de Asuntos Estudiantiles, Dirección de Inclusión Social, Departamento de Acompañamiento a las Trayectorias Académicas Estudiantiles (DATAE), en sus dos áreas Oficina de Inclusión Educativa de Personas en Situación de Discapacidad y Sistema de Tutorías y Acompañamiento a estudiantes. En articulación con las diferentes unidades académicas, y con la participación de docentes, tutores, estudiantes y personal técnico.

\section{Contexto}

La Universidad Nacional de Córdoba, desde hace más de 10 años desarrolla acciones institucionales en materia de inclusión educativa, con la misión de transversalizar la perspectiva de la accesibilidad. Entre los hitos a destacar debe mencionarse la creación de la Oficina de Inclusión Educativa de Personas en Situación de Discapacidad (Resolución Rectoral $\mathrm{N}^{\mathrm{o}}$ 3398/2008), área institucional dependiente de la Secretaría de Asuntos Estudiantiles, destinada al tratamiento integral de las temáticas de la accesibilidad y la discapacidad. Su misión consiste en transversalizar la perspectiva de la accesibilidad y la diferencia en las políticas, planes, programas y proyectos que se adoptaran en las funciones de docencia, investigación y extensión de la UNC.

Durante 2010, 2011 y 2014, se aprobó por el Honorable Consejo Superior UNC una serie de recomendaciones y pautas, nominados Protocolos de Actuación sobre Accesibilidad, para favorecer que la población estudiantil en situación de discapacidad pueda participar y cursar una carrera universitaria en condiciones de equidad. La elaboración de estos documentos tuvo un carácter participativo y multiactoral.

Este conjunto de protocolos constituye el Marco regulatorio de la accesibilidad en la UNC:

- Protocolo de Actuación sobre Estrategias Pedagógicas Inclusivas. 1386/2010 describe una serie de estrategias pedagógicas a aplicarse en el desarrollo de actividades académicas, 
para promover prácticas docentes inclusivas y que estudiantes ciegos/as o con baja visión transiten su formación académica en equidad de condiciones.

- Protocolo de Actuación para las Situaciones de Evaluación. 1389/2010 Especifica algunas modalidades de evaluación a implementar en situaciones en las que un/a estudiante no pueda o presente dificultades para realizar un examen, ya sea parcial o final, según las modalidades oral o escrita.

- Protocolo de Actuación sobre la Accesibilidad Comunicacional en Actividades Académicas. 1390/2010 Específica condiciones de accesibilidad comunicacional que deben considerarse en el desarrollo de actividades académicas, para que la población estudiantil sorda pueda participar y transitar en condiciones de equidad.

- Protocolo de pautas para la supresión de barreras culturales que condicionan el uso de los espacios comunes. 1605/2011 Recomendaciones que tienen como objetivo suprimir barreras culturales que vulneran la utilización de los espacios de uso común, como el uso de aulas comunes y su mobiliario, sanitarios, mobiliario urbano y módulos de estacionamiento de automóviles.

- Protocolo de Pautas de Accesibilidad en Espacios Urbanos y Edificios. 1389/2014 tiene como objetivo orientar el diseño y construcción del espacio urbano y edilicio, para que sea utilizable por todas las personas de manera autónoma, segura y sin restricciones.

Finalmente, desde 2017, la Oficina de Inclusión Educativa para Personas en Situación de Discapacidad forma parte de DATAE, espacio institucional que tiene por objetivo fortalecer los trayectos estudiantiles en el ingreso, permanencia y egreso. Para tal fin, se consolidó un sistema de apoyo atendiendo a la diversidad de necesidades estudiantiles en su conjunto, desde un enfoque de educación inclusiva, que se complementa con estrategias y programas para garantizar los apoyos necesarios, para promover el acceso y la permanencia de estudiantes con discapacidad en la universidad.

Desde estos espacios, se viene trabajando con 15 Unidades Académicas y 2 colegios preuniversitarios UNC. Tal trabajo colaborativo posibilita la implementación de acciones institucionales, con el objetivo de garantizar la inclusión educativa de las personas con discapacidad. Esta red de trabajo, involucra a autoridades, docentes, profesionales de gabinetes y/u espacios de acompañamiento de las Facultades, a los fines de compartir la situación de los/as 
estudiantes con discapacidad y delinear un dispositivo compartido de acompañamiento que garantice la accesibilidad del cursado.

En 2020, ante el contexto de pandemia Covid-19, se acordó adherir a las medidas sanitarias nacionales, lo cual implico adecuar el cursado de todas sus carreras a la virtualidad en el menor tiempo posible, dando continuidad al ciclo lectivo.

Esta decisión impacto al interior de las unidades académicas, que históricamente sus carreras son mayoritariamente presenciales, con escaso o nulo uso de la plataforma virtual, y con énfasis en la asistencia a clases $(60 \%$ a $80 \%)$ para obtener la regularidad o promoción de una materia. El panorama inicial resulto incierto, sobre cómo se iba sostener la exigencia de asistencia, cuando un gran porcentaje de estudiantes carecía de internet, computadora, celular y los medios necesarios para la virtualidad.

Asimismo, con la prolongación de las medidas sanitarias, comenzó a evidenciarse desbordes en las tareas docentes; licencias de personal; desconcierto, estrés y frustración por no manejar adecuadamente las TIC, etc. También, cobro relevancia la desinformación sobre la accesibilidad en la virtualidad, como de plataforma Moodle, PDF, Word, PPT, páginas web, entre otros. Todo lo mencionado, más el desconocimiento y dudas de los/as estudiantes produjo acceso a información errónea y confusa, a no sentirse cómodos/as con la propuesta virtual e incluso a estar des-conectados de compañeros/as, docentes, etc.

\section{Aplicación y resultados}

En primer lugar, se procedió como cada año a contactar desde nuestras oficinas a cada estudiante, para que informen materias, docentes, horarios y días de cursado.

Para esa tarea contamos con colaboración del equipo de tutores/as docentes, que en sus espacios de tutoría aclaraban dudas sobre las inscripciones, ampliaban información sobre el enfoque de las materias, explicaban uso del sistema guaraní y/o plataforma Moodle, recordaban plazos de inscripciones y otros asuntos relacionados a la vida universitaria. Asimismo, se realizaron comunicaciones telefónicas y/o mensajería para conocer la situación de conectividad para afrontar un cursado virtual. 
Es así, que se logró contacto con más de 100 estudiantes, para empezar las articulaciones con espacios claves y construir redes sólidas para encarar un año lectivo muy diferente.

Con dicha información, se contactó a las unidades académicas y se solicitó que notifiquen a las/os docentes y se les brinde las recomendaciones de accesibilidad y protocolos de actuación con especificaciones propias de la singularidad de la situación de cada estudiante.

Posteriormente, se dio apertura a reuniones de asesoramiento e intercambio con docentes y referentes de cada facultad, ya que se buscaba familiarizarlos con las accesibilidades requeridas y darles a conocer cuáles son las barreras a las que se expone a estudiantes.

$\mathrm{Al}$ respecto, ante el desconcierto del escenario a futuro y falta de experiencia previa de gran parte de la comunidad educativa en relación al uso de plataformas virtuales y acerca de la accesibilidad, se acrecentó la demanda de consultas y solicitudes de asesoramiento.

Ante tal escenario, se procedió a confeccionar una guía de recomendaciones. Tal propuesta se enfocó en la supresión de barreras de acceso al conocimiento, dirigida a docentes, adscriptos/as, ayudantes alumnos/as y/o profesionales de los equipos técnicos, que estuvieran acompañando en el armado y adaptación de las materias para un cursado virtual.

La "guía de recomendaciones para un cursado virtual accesible" tiene un carácter eminentemente práctico y buscaba que el cursado virtual no se volviera un obstáculo más para la trayectoria estudiantil. Asimismo, para darle mayor alcance, fue enviada a las Secretarías de Asuntos Estudiantiles de cada unidad académica, junto a los mencionados protocolos de actuación, para que formalmente sea extendida a los equipos de cátedra.

En relación a la participación activa de estudiantes, se destaca la realización de aportes significativos a estas redes de trabajo colaborativo, al enriquecer con sus observaciones, experiencias y conocimientos el lente de la inclusión educativa en el ámbito universitario y el cursado virtual.

Entre ello, se recupera una de las intervenciones realizadas junto a un grupo de estudiantes, quienes propusieron sumarse a reuniones junto a docentes, por lo cual resignificamos dicho 
espacio para convertirlo en un encuentro de socialización, donde se pudiera reflexionar entre los actores involucrados las estrategias, herramientas y la accesibilidad que se estaba brindando.

En tal espacio, se identificaron barreras de acceso al conocimiento, desinformación respecto de la accesibilidad y normativas vigentes; se de-construyeron mitos y prejuicios; se revalido la figura de docente tutor/a como andamiaje y lazo fundamental en el vínculo entre estudiantes, facultad y equipos técnicos; posibilitando la voz y participación a estudiantes y en palabras de las estudiantes, sentirse oídas.

Este intercambió de saberes, aprendizajes e ideas, nos encamino a la co-construcción de estrategias, soluciones y acciones anudadas desde el trabajo colectivo. Al generarse acuerdos y compromisos para por ejemplo, hacer envíos anticipados de apuntes y diapositivas al equipo de bibliografía accesible SAE, para que se adapten a letra ampliada y/o para lectores. A estar en contacto fluido con estudiantes, visibilizar los canales de comunicación y referentes de cada espacio para que consulten cuando fuese necesario.

De este espacio de intercambios, quedó abierta la solicitud de replicarlo en años posteriores y que se extienda a otras unidades académicas.

Por otro lado, de la labor realizada en conjunto con todos los actores implicados, se logró involucrar a docentes y personal que anteriormente no participaba, ya que, hasta entonces no consideraban urgente interiorizarse dado que "no tenían estudiantes con discapacidad en sus aulas y/o carreras". Asimismo, se reforzaron los canales oficiales para contactar y solicitar los apoyos que se brindan (LSA, digitalización, tutorías, talleres complementarios) y se familiarizaran en qué consistían dichas acciones y porque eran fundamentales para garantizar la inclusión educativa.

Finalmente, puso en primera plana el valor de construir redes y fortalecerlas, dado que resulta inviable realizar abordajes individuales, aislados y fragmentados, cuando además los/as estudiantes nos interpelan a una verdadera inclusión integral. 


\section{Conclusiones}

Con la presentación de esta experiencia nos propusimos compartir el avance que paulatinamente se está dando en la transversalización de la perspectiva discapacidad y accesibilidad en el contexto de la UNC.

El sistema de educación superior, debe asumir estrategias concretas que posibiliten esta meta de manera más eficiente, que las diversas acciones individuales queden plasmadas en políticas institucionales en materias de inclusión para que efectivamente se genere un cambio. Asimismo, es necesario repensar las condiciones políticas, institucionales, académicas y pedagógicas en las que sería posible no sólo acercar la universidad a un sector socialmente excluido, favorecer el ingreso de las personas con discapacidad, sino brindar acciones para su permanencia y egreso (Castignani, Hanlon, Lujan, Katz y Peiro, 2014).

Este tipo de experiencias nos revelan la importancia de trabajar colectivamente y en redes, desde el respeto de la diversidad, el compromiso por la inclusión educativa y el desafío de fortalecer las trayectorias educativas de estudiantes con discapacidad en la universidad pública.

Avanzar en esta línea, que promueve la accesibilidad e involucra a toda la comunidad educativa, va a permitir a futuro reconocer estrategias enfocadas en el acceso a la educación superior, destinadas a los y las futuros aspirantes con discapacidad que deseen ingresar a la Universidad.

Resulta entonces fundamental, entender el enfoque de Derechos Humanos de la discapacidad para pensar y actuar diferente, comprendiendo que las barreras que imposibilitan la participación plena de estudiantes con discapacidad también son una decisión nuestra. Por lo tanto, las perspectivas, respuestas y desafíos en torno de la accesibilidad se vinculan con la concepción que tengamos acerca de la discapacidad quienes formamos parte de la Universidad.

Será entonces necesario continuar trabajando por la transversalización de la perspectiva de discapacidad y accesibilidad en el ámbito de la educación superior. 
Este presente, sin duda nos sigue planteando numerosos desafíos, a sabiendas que todavía queda un largo camino por recorrer en la accesibilidad universal, el diseño para todos y todas, los ajustes razonables y la efectiva igualdad de oportunidades en la Educación Superior para que pueda hablarse de Universidad inclusiva.

\section{Referencias}

Blanco, R. (2014). Inclusión educativa en América Latina: caminos recorridos y por recorrer. En A. Marchesi, R. Blanco \& L. Hernández (Eds.), Avances y desafíos de la educación inclusiva en Iberoamérica (pp. 11-36). Organización Estados Iberoamericanos.

Booth, T. \& Ainscow, M. (2002). Index for Inclusion. Developing learning and participation in schools. UNESCO.

Brito, S., Basualto Porra, L., \& Reyes Ochoa, L. (2019). Inclusión Social/Educativa, en Clave de Educación Superior. Revista Latinoamericana de Educación Inclusiva, 13(2), 157-172. http://dx.doi.org/10.4067/S0718-73782019000200157

Capelari, M. I. (2016). El rol del tutor en la Universidad. Configuraciones, significados y prácticas. Sb Editorial.

Castignani, M., Hanlon, P., Lujan, M., Katz, S., \& Peiro, M. (2014). Comisión universitaria sobre Discapacidad: una experiencia de gestión en la Universidad Nacional de La Plata. Revista Latinoamericana de Educación Inclusiva, 8(1), 51-61.

Castignani, M. L. (2017). Estrategias favorecedoras que inciden en las elecciones educativas y ocupacionales de los adolescentes con discapacidad visual. Revista Orientación y Sociedad, 17(1), 49-68.

CERMI. (2016). Activando la accesibilidad universal. Guía práctica. Comité Español de Representantes de Personas con Discapacidad.

Corrales Huenul, A., Soto Hernández, V., \& Villafañe Hormazabal, G. (2016). Barreras de aprendizaje para estudiantes con discapacidad en una universidad chilena. Demandas 
estudiantiles - desafíos institucionales. Actualidades Investigativas en Educación, 16(3), 129.

Ley N ${ }^{\circ}$ 26378. (2006). Convención sobre los Derechos de las personas con discapacidad. Naciones Unidas.

Misischia, B. S. (2018). The University - Disability relationship. ¿An excluding inclusion? Educación, Lenguaje y Sociedad, 15(15), 1-18. http://dx.doi.org/10.19137/els-2018$\underline{151506}$

Palacios, A. (2008) El modelo social de la discapacidad: orígenes, caracterización y plasmación en la convención internacional sobre los derechos de las personas con discapacidad. Grupo editorial CINCA. Colección No 36 CERMI

Universidad Nacional de Córdoba, (2008) Oficina de Inclusión Educativa de Personas en Situación de Discapacidad. Resolución Rectoral Nº 3398.

Universidad Nacional de Córdoba, (2010) Protocolos de Actuación sobre Estrategias Pedagógicas Inclusivas. Honorable Consejo Superior Resolución $\mathrm{N}^{\circ} 1386$.

Universidad Nacional de Córdoba, (2010) Protocolo de Actuación para las Situaciones de Evaluación. Honorable Consejo Superior Resolución № 1389.

Universidad Nacional de Córdoba, (2010) Protocolo de Actuación sobre la Accesibilidad Comunicacional en Actividades Académicas. Honorable Consejo Superior Resolución $\mathrm{N}^{\circ}$ 1390.

Universidad Nacional de Córdoba, (2011) Protocolo de pautas para la supresión de barreras culturales que condicionan el uso de los espacios comunes. Honorable Consejo Superior Resolución $\mathrm{N}^{\circ} 1605$.

Universidad Nacional de Córdoba, (2014) Protocolo de Pautas de Accesibilidad en Espacios Urbanos y Edificios. Honorable Consejo Superior Resolución № 1389. 


\title{
Bienestar emocional a través de la educación musical en tiempos de pandemia. Una revisión teórica
}

\author{
Carmen M. Zavala Arnal \\ Jorge Ramón Salinas \\ Universidad de Zaragoza
}

Palabras clave: Educación musical; buenas prácticas; bienestar emocional; Covid-19.

\section{Introducción}

Desde marzo de 2020, estamos inmersos en una situación de pandemia mundial generada por la Covid-19 que ha modificado sustancialmente nuestro modo de vida debido a su gran impacto psicosocial (Chamorro, 2020). Durante este último año, se ha puesto de relieve el importante papel de la música y de las artes en general para el bienestar emocional desde el contexto de la resiliencia tanto individual como social (Signes, 2020). Sabemos además, que en diferentes contextos, la música es el arte más utilizado para generar bienestar personal y grupal, y que las personas con formación artística y musical recurren a sus formas de expresión para conseguir estados emocionales positivos (Gustems y Calderón, 2013; Calderón, Martín, Gustems y Portela, 2018; Zavala, 2020). En el contexto pandémico, no sólo en el actual sino en otros acaecidos en el pasado (Ezquerro, 2020; González, 2020), la expresión artística ha surge como una estrategia para paliar los efectos sobre la salud mental de la reducción de la libertad que padecemos, así como las consecuencias de las pérdidas humanas y materiales (Claro y Lapa, 2020). Además, la música ha sido una de las grandes protagonistas en internet y en las redes sociales. Los estímulos ambientales que proporciona el disfrute de la música promueven la comunicación y la empatía a nivel colectivo, favoreciendo a su vez el bienestar personal, la autoestima y la autoconfianza (Santacana, Llonch y Martínez, 2015). Como consecuencia, se ha evidenciado la importancia de la educación musical. 
Por otro lado, en el contexto del confinamiento ha habido más oferta y demanda de enseñanza musical online. Si bien la docencia virtual en el ámbito musical lleva décadas desarrollándose, sus profesionales hemos tenido que adaptar los diferentes contenidos y metodologías práctico-musicales (audición, expresión vocal, instrumental y corporal) a las nuevas circunstancias de la pandemia. En este sentido, se pretende realizar una revisión teórica sobre algunos trabajos científicos que se han publicado en los últimos meses en los que se recogen reflexiones, experiencias docentes y buenas prácticas sobre educación musical en tiempos de Covid-19.

\section{Objetivos}

A través de la presente revisión teórica se pretende destacar aquellos aspectos que han contribuido a través de la educación musical a la mejora de la salud emocional durante la pandemia. Para ello, se quiere poner también en relieve la importancia de adquirir una formación musical para fomentar la actitud de escuchar, interpretar, crear y experimentar con la música tanto en contextos formales como no formales (Calderón et al., 2018), y así poder crear espacios de bienestar en situaciones como las que nos acontece. Para ello, en los distintos contextos educativos se han tenido que adaptar los procesos de enseñanza-aprendizaje a modalidades virtuales o mixtas, con metodologías y herramientas ya existentes o recientemente actualizadas (Diez-Gutiérrez y Gajardo-Espinoza, 2020).

Además, se objetiva la necesidad de educar la mirada hacia la contemplación de la belleza en su dimensión estética y trascedente (Signes, 2020), tan importante para sobrellevar circunstancias adversas.

En definitiva, tras la revisión planteada, se presente demostrar cómo la educación musical en sus múltiples facetas se ha postulado en tiempos de pandemia como una excelente vía de bienestar psicológico y emocional para quien la recibe, ya sea a través de la audición o la práctica y que, gracias al esfuerzo de los profesionales implicados, se ha abierto una nueva vía de enseñanza híbrida, presencial y online, que ha de tenerse en cuenta en el futuro. 


\section{Revisión Teórica}

Siguiendo la metodología empleada por Chiva, Salvador, Ferrando y Cabedo (2019) en su revisión teórica sobre publicaciones de Aprendizaje-servicio en educación musical, se ha realizado en primer lugar una búsqueda de artículos con una relevante indexación en las plataformas web de Scopus-Elvesier (SCOPUS) y DIALNET, a través de los términos "Covid-19" y "pandemia", asociados a los términos “educación musical” y "bienestar", tanto en español como en inglés.

Los criterios de inclusión y exclusión utilizados una vez recopilados los artículos se han basado, en primer lugar, en la vinculación del contenido con los objetivos del presente estudio. Posteriormente, se ha tenido en cuenta la rigurosidad de los mismos. Finalmente, se han excluido aquellos trabajos que tenían un enfoque exclusivamente terapéutico, alejado del educativo, y aquellos que se basaban en metodologías de educación musical, eludiendo contenidos relacionados con el bienestar. Sin embargo, hay un gran número de publicaciones concluidas sobre metodología de educación musical online por un lado, y por otro de los efectos psicológicos positivos de la música durante la pandemia en contextos no educativos (Cabedo-Mas, Arriaga-Sanz y MolinerMiravet 2021; Centeno, Ortega-Sánchez, Nieto y Gil, 2021; Martínez-Castilla, Gutiérrez-Blasco, Spitz y Granot, 2021). Con los criterios antes expuestos no se ha encontrado numerosa literatura, si bien se han revisado más de 40 publicaciones, entendiendo que se trata de un tema de investigación de actualidad, con multitud de estudios en curso no finalizados o en proceso de publicación. A través de los criterios señalados, finalmente, se han seleccionado seis publicaciones, tres ambientadas en España, y otras tres en otros países, que se han analizado desde determinados ejes descriptivos. Son las siguientes:

1- Arús Leita, E., Pujol i Subirà, M. A. y Palau Franco, N. (2021). La educación musical en movimiento en línea. Tres etapas, tres docentes, tres procesos. Eufonía, 87, 22-28.

2- García Gil, D., Bonastre Vallés, C., y Cuervo Calvo, L. (2020). Educación musical en tiempos del COVID: Una mirada en femenino. Desafíos de investigación educativa durante la pandemia COVID19, 578-590.

https://repositorio.ipv.pt/bitstream/10400.19/6697/1/9788413771724\%20(1).pdf

3- Habe, K., Biasutti, M. y Kajtna, T. (2021). Wellbeing and flow in sports and music students during the COVID-19 pandemic. Thinking Skills and Creativity, 39, 1-9. https://doi.org/10.1016/j.tsc.2021.100798 
4- Liddiard, E., y Rose, D. (2021). A Pilot Study of an Intervention for Children Using Music Listening and Music Making to Explore Core Emotions and Support Wellbeing. Open Journal of Social Sciences, 9, 329-364. https://doi.org/10.4236/jss.2021.93022

5- Rosset, M., Baumann1, E. y Altenmüller, E. (2021). Studying Music During the Coronavirus Pandemic: Conditions of Studying and Health-Related Challenges. Frontiers in Psychology, 12(651393), 1-11. doi: 10.3389/fpsyg.2021.651393

6- Vernia Carrasco, A. M. (2021). Música y tecnología contra el Covid-19: un caso en personas mayores. Prisma Social: revista de investigación social, 32, 244-261. https://revistaprismasocial.es/article/view/4050

A continuación, se exponen los resultados del análisis de las publicaciones ordenadas alfabéticamente desde los siguientes ejes descriptivos: método de investigación, instrumentos de investigación, etapa educativa y contenido curricular trabajado, así como el impacto en el alumnado. Estos se muestran a través de la siguiente tabla y de una reflexión específica de cada eje:

Tabla 1. Ejes descriptivos sobre las publicaciones seleccionadas sobre Covi-19, educación musical y bienestar.

\begin{tabular}{|c|c|c|c|c|}
\hline Artículo & Método & Instrumentos & Etapa/Contenido & Impacto \\
\hline 1. Arús et al. (2021) & Cualitativo & $\begin{array}{l}\text { Observación y } \\
\text { reflexión }\end{array}$ & $\begin{array}{l}\text { Infantil, Primaria y } \\
\text { Universidad/ } \\
\text { Música }\end{array}$ & $\begin{array}{l}\text { Aprendizaje } \\
\text { musical, visual y } \\
\text { corporal }\end{array}$ \\
\hline $\begin{array}{l}\text { 2. García et al. } \\
(2020)\end{array}$ & Cualitativo & $\begin{array}{l}\text { Cuestionario } \\
\text { abierto, análisis y } \\
\text { reflexión }\end{array}$ & $\begin{array}{l}\text { Universidad/ } \\
\text { Música }\end{array}$ & $\begin{array}{l}\text { Aprendizaje } \\
\text { musical, digital y } \\
\text { social }\end{array}$ \\
\hline $\begin{array}{l}\text { 3. Habe et al. } \\
(2021)\end{array}$ & Cuantitativo & $\begin{array}{l}\text { Cuestionario y } \\
\text { análisis cuantitativo }\end{array}$ & $\begin{array}{l}\text { Universidad/Música } \\
\text { y Educación Física }\end{array}$ & $\begin{array}{l}\text { Aprendizaje } \\
\text { musical, deportivo } \\
\text { y social }\end{array}$ \\
\hline $\begin{array}{l}\text { 4. Liddiard y Rose } \\
\text { (2021) }\end{array}$ & Cuantitativo & $\begin{array}{l}\text { Cuestionario y } \\
\text { análisis cuantitativo }\end{array}$ & Primaria / Música & $\begin{array}{l}\text { Aprendizaje } \\
\text { musical }\end{array}$ \\
\hline $\begin{array}{l}\text { 5. Rosset et al. } \\
\text { (2021) }\end{array}$ & Cuantitativo & $\begin{array}{l}\text { Cuestionario y } \\
\text { análisis cuantitativo }\end{array}$ & $\begin{array}{l}\text { Universidad/ } \\
\text { Música }\end{array}$ & $\begin{array}{l}\text { Aprendizaje } \\
\text { musical }\end{array}$ \\
\hline 6. Vernia (2021) & Cualitativo & $\begin{array}{l}\text { Entrevista, análisis } \\
\text { y reflexión }\end{array}$ & $\begin{array}{l}\text { Otro contexto / } \\
\text { Música }\end{array}$ & $\begin{array}{l}\text { Aprendizaje } \\
\text { musical, digital y } \\
\text { social. }\end{array}$ \\
\hline
\end{tabular}

Al tratarse de un tema de investigación de actualidad, todos los estudios se han desarrollado y publicado en el año 2020 y en el presente 2021, y se han ambientado en los siguientes países: 
España (3), dos de ellos publicados en lengua española y uno en lengua inglesa; Eslovenia, Reino Unido y Alemania, los tres en lengua inglesa.

En relación al eje de "método de investigación", tres de las investigaciones se han llevado a cabo a través de métodos cuantitativos (Habe et al., 2021; Liddiard y Rose, 2021; Rosset et al., 2021), y las otras tres siguiendo métodos cualitativos (Arús et al., 2021; García et al., 2020; Vernia, 2021).

Respecto a los instrumentos de investigación, el cuestionario ha sido el instrumento de investigación cuantitativa empleado, mientras que los cualitativos han sido variados: cuestionario abierto, entrevista y observación de los grupos focales. Todos han utilizado una metodología online de obtención de datos a excepción de Habe et al. (2021), de manera híbrida.

En relación a las etapas educativas en las que se han ambientado los estudios, Rosset et al. (2021), García et al. (2020), y Habe et al. (2021) lo han hecho exclusivamente en estudios universitarios, mientras que Liddiard y Rose (2021) lo han llevado a cabo en la Educación Primaria y Arús et al. (2021) de manera transversal en tres etapas diferentes: Educación Infantil, Educación Primaria y Universidad. Vernia (2021) ha realizado su investigación en un contexto educativo no formal, en el de la educación musical de personas mayores. Todas las investigaciones se han realizado en contextos educativos musicales, y la publicación de Habe et al. (2021), además, lo ha hecho en el ámbito de la educación física. Los grupos educativos seleccionados han estado formados en todos los casos por estudiantado excepto en los casos de García et al. (2020) que ha implicado también a profesorado universitario, y Liddiard y Rose (2021) a padres y madres del alumnado de Primaria.

El impacto generado sobre los grupos receptores ha sido más variado. Arús et al. (2021), presenta tres experiencias educativas diferentes en tres grupos focales de distintas etapas educativas con aprendizajes significativos en educación musical a partir de la expresión musical, corporal y artística en su vinculación con lo visual. García et al. (2020) reflexionan sobre el aprendizaje-enseñanza musical online en el ámbito exclusivo de alumnas y profesoras, con un impacto social en relación al género. Habe et al. (2021) exploran aspectos relacionados con el flow desde la educación musical y la educación física, incidiendo también en las diferencias entre géneros y entre las dos áreas de conocimiento señalas. Liddiard y Rose (2021), Rosset et al. (2021) 
y Vernia (2021), por su parte, inciden en la obtención de beneficios emocionales desde diversas formas de expresión musical: práctica musical, audición musical activa y la creatividad.

\section{Conclusiones}

En la actualidad, existe un creciente corpus de investigaciones dedicadas a estudiar, por un lado, los efectos positivos de la educación musical durante la pandemia de la Covid-19 en contextos educativos formales y no formales, en sus diferentes etapas; y por otro lado, los beneficios de la música desde el punto de vista de la neurociencia y psicología sobre la población general. Sin embargo, son aún escasos, aunque incipientes, aquellos dedicados a investigar sobre la utilidad educativa de la música en circunstancias tan desfavorables para el bienestar individual y colectivo como los ocasionados por la pandemia.

En este sentido, los seis estudios seleccionados, además de la variedad encontrada respecto a los resultados de los ejes descriptivos, a pesar de tratarse de una muestra escasa, vienen a avalar la importancia de la educación musical, no sólo en sus aspectos estrictamente formativos, sino a la hora de expresar sentimientos y emociones positivas y negativas, y comunicar y desarrollar ideas y significados.

Por otro lado, se incide en el beneficio del contacto entre los distintos agentes educativos, especialmente en un contexto de parcial reclusión de tanto impacto, y del refuerzo del sentimiento de grupo y socialización a través de la educación musical. También se evidencia la importancia de estimular la formación digital y reducir esta brecha en alumnado procedente de contextos sociales más desfavorecidos así como en población de personas mayores.

Por último, estos estudios ofrecen implicaciones prácticas para situaciones similares futuras que pudieran acaecer mostrando su valor transferible.

En relación a la revisión teórica realizada, esta puede completarse en el futuro con el análisis de nuevas publicaciones que exploren el bienestar a través de las distintas formas de percepción y expresión en el ámbito de la educación musical en sus diferentes contextos. 


\section{Referencias}

Arús Leita, E., Pujol i Subirà, M. A. y Palau Franco, N. (2021). La educación musical en movimiento en línea. Tres etapas, tres docentes, tres procesos. Eufonía, 87, 22-28.

Cabedo-Mas A., Arriaga-Sanz C. y Moliner-Miravet L. (2021). Uses and Perceptions of Music in Times of COVID-19: A Spanish Population Survey. Frontiers in Psychology, 11(606180), 1-13. https://doi.org/10.3389/fpsyg.2020.606180

Calderón Garrido, D., Martín Piñol, C., Gustems Carnicer, J. y Portela Fontán, A. (2018). La influencia de las Artes como motor de bienestar: un estudio exploratorio. Arte, Individuo y Sociedad, 30(1), 77-93. https://doi.org/10.5209/ARIS.56350

Centeno Martín, J., Ortega-Sánchez, D., Nieto Miguel, I. y Gil Martín G. M. (2021). Music as a factor associated with emotional self-regulation: A study on its relationship to age during COVID-19 lockdown in Spain. Heliyon, 7, 1-5. https://doi.org/10.1016/j.heliyon.2021.e06274

Chamarro, A. (2020). Impacto psicosocial del COVID-19: algunas evidencias, muchas dudas por resolver. Aloma, revista de psicologia, ciències de l'educació i de l'esport, 38(1), 9-12. https://doi.org/10.51698/aloma.2020.38.1.9-10

Chiva Bartoll, O., Salvador García, C., Ferrando Félix, S., y Cabedo Más, A. (2019). Aprendizajeservicio en educación musical: revisión de la literatura y recomendaciones para la práctica. Revista Electrónica Complutense de Investigación en Educación Musical, 16, 57-74. https://doi.org/10.5209/reciem.62409

Claro, C. y Lapa Esteves, M. (2020). A música na lupa da psicologia face à pandemia: Covid19! International Journal of Developmental and Educational Psychology: INFAD. Revista de Psicología, 1(1), 143-154.

Diez-Gutiérrez, E. y Gajardo-Espinoza, K. (2020). Educar y Evaluar en Tiempos de Coronavirus: la Situación en España. Multidisciplinary Journal of Educational Research, 10(2), 102134. https://doi.org/10.17583/remie.2020.5604 
Ezquerro Esteban, A. (2020). Vanidad de vanidades. Del rey Salomón a la aflicción medieval hispana en tiempo de desolación. Vitamina H(umanidades), 1-5. https://www.imf.csic.es/files/ficheros/VitH/VitH-EZQ-2020.pdf

García Gil, D., Bonastre Vallés, C., y Cuervo Calvo, L. (2020). Educación musical en tiempos del COVID: Una mirada en femenino. Desafios de investigación educativa durante la pandemia COVID19 (pp. 578-590). Dykinson. https://repositorio.ipv.pt/bitstream/10400.19/6697/1/9788413771724\%20(1).pdf

González Marín, L. A. (2020). "Música contra la epidemia", Vitamina H(umanidades), 1-3. https://digital.csic.es/bitstream/10261/221512/1/VitH-LAGM-2020M\%c3\%basica\%20contra\%201a\%20epidemia.pdf

Gustems Carnicer, J., Calderón Garrido, C. (2013). Arte y bienestar. Investigación aplicada (ed. Josep Gustems), Universitat de Barcelona, 19-28.

Habe, K., Biasutti, M. y Kajtna, T. (2021). Wellbeing and flow in sports and music students during the COVID-19 pandemic. Thinking Skills and Creativity, 39, 1-9. https://doi.org/10.1016/j.tsc.2021.100798

Liddiard, E., y Rose, D. (2021). A Pilot Study of an Intervention for Children Using Music Listening and Music Making to Explore Core Emotions and Support Wellbeing. Open Journal of Social Sciences, 9, 329-364. https://doi.org/10.4236/jss.2021.93022

Martínez-Castilla, P., Gutiérrez-Blasco I. M., Spitz D. H. y Granot R. (2021). The Efficacy of Music for Emotional Wellbeing During the COVID-19. Lockdown in Spain: An Analysis of Personal and Context-Related Variables. Frontiers in Psychology, 12(647837), 1-15. https://doi.org/10.3389/fpsyg.2021.647837

Rosset, M., Baumann1, E. y Altenmüller, E. (2021). Studying Music During the Coronavirus Pandemic: Conditions of Studying and Health-Related Challenges. Frontiers in Psychology, 12(651393), 1-11. https://doi.org/10.3389/fpsyg.2021.651393 
Signes, M. T. (2020). El poder de la belleza en tiempos de pandemia. Pandemia y resiliencia: aportaciones académicas en tiempos de crisis (pp. 59-77). Ediciones Universidad de Navarra. EUNSA.

Vernia Carrasco, A. M. (2021). Música y tecnología contra el Covid-19: un caso en personas mayores. Prisma Social: revista de investigación social, 32, 244-261. https://revistaprismasocial.es/article/view/4050

Zavala Arnal, C. M. (2021). Patrimonio cultural y bienestar: una reflexión acerca de su integración en el currículo a través de la música y las artes. En E.M. Lira Rodríguez (Coord.), Bienestar Social: Organizaciones Saludables (pp. 393-402). Tirant Humanidades. 


\title{
El estilo motivacional docente en Educación Física: una oportunidad para la mejora de la calidad de la docencia y los procesos motivacionales del alumnado
}

\author{
Luis García-González \\ Javier Sevil-Serrano \\ Sergio Diloy-Peña \\ Javier García-Cazorla \\ Ángel Abós \\ Universidad de Zaragoza
}

Palabras clave: Modelo circular, necesidades psicológicas básicas, teoría de la autodeterminación, motivación, objetivo de desarrollo sostenible.

\section{Introducción}

Los centros educativos son un escenario privilegiado para desarrollar hábitos saludables en los jóvenes (Sevil, García-González, Abós, Generelo y Aibar, 2019). Concretamente, el docente de Educación Física (EF), en sus clases, tiene la posibilidad de generar experiencias positivas que fomenten, entre otras consecuencias, la práctica de actividad física en la adolescencia y en la vida adulta (Ladwig, Vazou y Ekkekakis, 2018). Para ello, según la teoría de la autodeterminación (Ryan y Deci, 2017), el denominado estilo interpersonal o estilo motivacional del docente de EF, puede influir notablemente en la satisfacción o frustración de las necesidades psicológicas básicas (NPB; i.e., autonomía, competencia y relaciones sociales), a través de distintas estrategias didácticas y motivacionales (Haerens, Aelterman, Vansteenkiste, Soenens, y Van Petegem, 2015).

El estilo motivacional docente, siguiendo los postulados del modelo circular (ver Figura 1; Aelterman, Vansteenkiste, Haerens, Soenens, Fontaine y Reeve, 2019; Delrue et al., 2019), puede articularse en cuatro estilos principalmente. El estilo de apoyo la autonomía y el estilo estructurado 
conforman los dos estilos que apoyan las NPB, generando satisfacción de las NPB del alumnado en las clases de EF, tal y como apunta la secuencia del lado claro de la motivación (Sánchez-Oliva, Sánchez-Miguel, Leo, Kinnafick, y García-Calvo, 2014). Por otro lado, el estilo controlador y el estilo caótico se configuran como los dos estilos que conllevan conductas docentes que favorecen la frustración de las NPB del alumnado, tal y como se establece en el lado oscuro de la motivación en las clases de EF (Haerens, Vansteenkiste, Aelterman, y Van den Berghe, 2016). Sin embargo, esta aproximación multidimensional de los estilos motivacionales que puede adoptar un docente, no solo se centra en las diferencias entre estilos motivacionales, sino también en distintas conductas que pueden estar próximas entre sí, a pesar de ser conceptualmente contrarias o diferentes, lo que lleva a desarrollar una perspectiva circular de esta intervención docente (ver Figura 1). Además, debe tenerse en cuenta que estas conductas de apoyo y frustración pueden adoptarse simultáneamente en la misma tarea o sesión (Haerens et al., 2018).

Según el modelo circular, con relación a conductas que conforman el estilo de apoyo a la autonomía, podemos encontrar conductas docentes que son más cercanas a un comportamiento participativo (i.e., ofrecer diferentes opciones y posibilidad de elección al alumnado) y otras más cercanas a un perfil adaptativo o empático (i.e., ponerse en el lugar del alumnado, teniendo en cuenta sus opiniones o sugerencias). Respecto al estilo controlador, en el modelo circular se identifican dos tipos de conductas diferenciadas: conductas demandantes, que desarrollan control externo, como puede ser amenazar al alumnado con castigos, gritar, etc.; y conductas de tipo dominador, que desarrollan control interno, enfocadas a que el alumnado se vea obligado a realizar lo que el docente le exija para evitar sentimientos de culpa, vergüenza, inferioridad y desilusión (e.g., emitir una mirada de decepción) (Aelterman et al., 2019).

Figura 1. Representación gráfica de los estilos y conductas motivacionales docentes en el modelo circular. Traducido de Aelterman et al. (2019). 


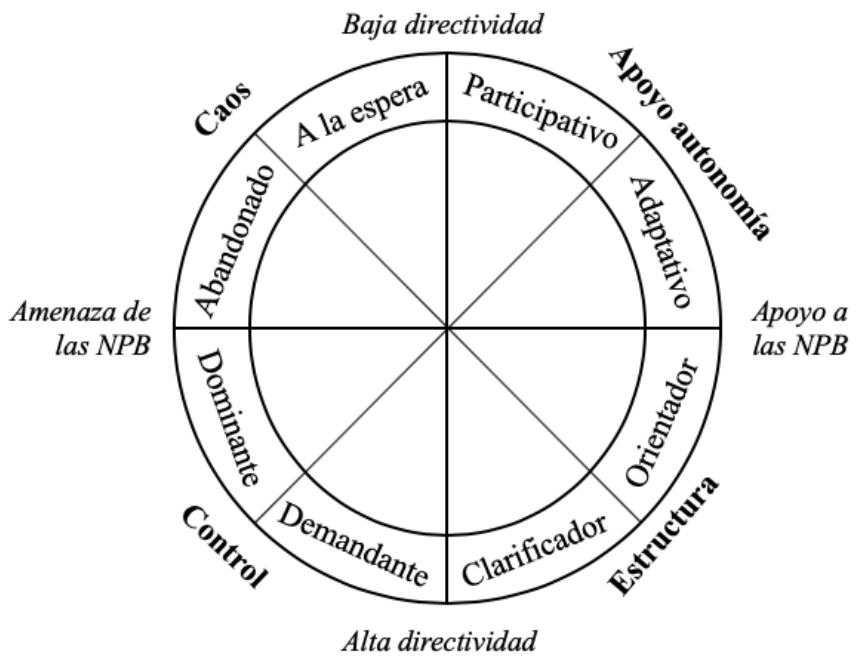

Nota: $N P B=$ Necesidades psicológicas básicas. En la parte exterior del círculo se establecen los cuatro estilos motivacionales. En la parte interior del círculo aparecen las ocho conductas motivacionales, apareciendo dos conductas en cada estilo motivacional. En el eje vertical se indica el nivel de directividad asociado a las conductas y en el eje horizontal el nivel de apoyo o amenaza a las NPB de las conductas.

Los dos tipos de conductas del estilo estructurado son: conductas clarificadoras, donde el docente establece las expectativas y la forma de conseguirlas, y supervisa estos pasos con el objetivo de que el alumnado se sienta más eficaz; $y$, por otro lado, conductas orientadoras, a través de las cuales se intenta guiar al alumnado aportándoles ayuda en función de sus necesidades, o ajustando la dificultad de las tareas al nivel de habilidad los alumnos para que las puedan acometer. La parte contraria al apoyo a la competencia o estructura se identifica con un perfil caótico. Se puede desarrollar un perfil caótico caracterizado por estar "a la espera", cuando el docente no es claro o incluso contradictorio en las expectativas que declara o en los requisitos que plantea de la tarea, de forma que los alumnos lo perciben de forma confusa o no saben muy bien cómo afrontar la actividad. Por otro lado, dentro del perfil caótico, existe un perfil de desinterés o abandono por parte del docente, donde se le deja al alumnado hacer lo que quieran, existe demasiada permisividad o no les aporta la ayuda que necesitan (Aelterman et al., 2019; Delrue et al., 2019).

En base a esta enumeración de estilos y conductas propuestas por el modelo circular, se considera que las conductas docentes dejan de tener una ordenación categórica y pasan a tener una clasificación más gradual. Las conductas "orientadoras" y "adaptativas" son las que más claramente generan apoyo de las NPB del alumnado, ya que se alinean claramente a la derecha del 
eje vertical de la Figura 1, mientras que las conductas "participativas" y "clarificadoras" están más vinculadas a activar únicamente las NPB, pero no garantizan su satisfacción. En el otro lado, encontraremos conductas docentes como la "dominadora" o la de "abandono" que generan una frustración activa de las NPB (i.e., a la izquierda del eje vertical en la Figura 1), con consecuencias nefastas sobre la motivación e implicación en las tareas, mientras que las conductas "demandantes" y "a la espera", aunque también pueden frustrar las NPB, puede que se queden solo en una privación o carencia de satisfacción de las NPB. Esta evidencia de aproximación gradual ha sido identificada en correlaciones realizadas por estudios previos (Vansteenkiste, Aelterman, Haerens, y Soenens, 2019). En este sentido, los resultados aportados por Aelterman et al. (2019) en un estudio realizado en el contexto educativo, muestran cómo las distintas conductas docentes tienen un reflejo en las percepciones de los estudiantes, donde las conductas "adaptativas", "orientadoras" y "clarificadoras" son las que mejor evaluación reciben por parte de éstos, correlacionando con la motivación autónoma o la persistencia en la tarea, mientras que las conductas "demandantes", “dominadoras" y "de abandono" son las que producen más despersonalización el alumnado, asociándose positivamente con la desmotivación y la oposición desafiante.

Este nuevo modelo, aplicado a la EF, podría garantizar una educación de calidad (i.e., Objetivo de Desarrollo Sostenible $\mathrm{n}^{\circ} 4$ ) en diferentes etapas educativas, dado que estudios realizados en diferentes contextos (e.g., educativo, deportivo, sanitario, etc.) han demostrado la asociación entre los cuatro estilos y las ocho conductas docentes con diferentes consecuencias motivacionales en el alumnado o en deportistas (e.g., satisfacción y frustración de las NPB y motivación autodeterminada) (Aelterman et al., 2019; Delrue et al., 2019; Vermote et al., 2020). Es necesario seguir avanzando en el conocimiento del efecto de los estilos y conductas motivacionales de los docentes de EF sobre distintas variables que pueden afectar a la calidad de la docencia. Estas pueden ser variables afectivas (e.g., diversión y aburrimiento en las clases de $\mathrm{EF}$ ), cognitivas (e.g., predisposición hacia las clases de EF) o comportamentales (e.g., conductas de oposición desafiante del alumnado hacia el profesorado).

\section{Objetivos}

En este capítulo se van a plasmar algunos resultados preliminares de la aplicación de este modelo teórico en la evaluación de las conductas docentes en EF y se discutirán las implicaciones 
que pueden tener para la docencia, así como para la motivación y el aprendizaje del alumnado. De forma específica, se analizará la percepción del alumnado de las conductas motivacionales docentes y su relación con la satisfacción y frustración de las NPB, con la diversión, el aburrimiento, la oposición desafiante y la predisposición hacia la EF.

\section{Método}

\section{Participantes}

En este estudio participaron dos submuestras de estudiantes de EF de Educación Secundaria Obligatoria (ESO) de cuatro centros educativos aragoneses. Una primera submuestra estuvo compuesta por 255 estudiantes entre $1^{\circ}$ de ESO y $1^{\circ}$ de Bachillerato (Medad=15.10; $\mathrm{DT}=1.29$ ) que cumplimentaros los instrumentos relacionados con las conductas motivacionales de sus docentes de EF y la valoración del propio docente. Una segunda submuestra estuvo compuesta por 170 estudiantes de los mismos cursos (Medad=14.89; DT=1.36) que cumplimentaron las medidas sobre las conductas motivacionales de sus docentes de EF, satisfacción y frustración de sus NPB en las clases de EF y distintas consecuencias afectivas (i.e., diversión y aburrimiento), cognitivas (i.e., predisposición hacia la EF) y comportamentales (i.e., oposición desafiante).

\section{Variables e instrumentos}

Para la evaluación de las ocho conductas motivacionales docentes (i.e., participativas, adaptativas, orientadoras, clarificadoras, demandantes, dominadoras, abandonadas y a la espera) se utilizó una versión adaptada a la EF en castellano del Situations in School Questionnaire (SIS; Aelterman et al., 2019). Este cuestionario consta de 17 situaciones docentes, con cuatro posibles formas de actuar en cada una de ellas, las cuales son respondidas a través de una escala Likert del 1 ("No describe en absoluto a mi profesor") al 7 ("Describe perfectamente a mi profesor"),

El resto de variables también fueron evaluadas a través de distintos cuestionarios validados al contexto de la EF en castellano. La satisfacción y frustración de las NPB se evaluó a través del Cuestionario de Satisfacción y Frustración de las NPB en EF (Zamarripa, Rodríguez-Medellín, Pérez-García, Otero-Saborido, y Delgado, 2020). La diversión y aburrimiento se evaluaron a través del cuestionario de Diversión de Baena, Granero-Gallegos, Bracho-Amador, y Pérez-Quero, (2012), mientras que la oposición desafiante se evaluó mediante un cuestionario elaborado por Haerens et al. (2015). La predisposición hacia la EF se evaluó a través de la Physical Education 
Predisposition Scale (PEPS) (Hilland, Stratton, Vinson, y Fairclough, 2009). Por último, se evaluó la valoración que cada alumno hace de su docente a través de ocho ítems en los que el alumnado valoraba su satisfacción con su docente (Aelterman et al., 2019).

\section{Procedimiento}

Tras un primer contacto con los equipos directivos de los centros educativos participantes, se presentaron los objetivos del estudio y se recabaron las pertinentes autorizaciones y consentimientos informados a padres y tutores. La cumplimentación de los distintos cuestionarios se realizó en un aula, por el investigador principal, y sin la presencia del docente de EF para no condicionar las respuestas del alumnado, con una duración aproximada de 30 minutos. Se siguieron los procedimientos éticos recogidos en la Declaración de Helsinki (2013).

\section{Análisis estadísticos}

Para la evaluación de las relaciones entre variables se utilizaron correlaciones bivariadas de Pearson, que fueron calculadas con el paquete estadístico SPSS 25.0.

\section{Resultados}

Las correlaciones entre la percepción del alumnado de las conductas motivacionales docentes, la satisfacción y frustración de las NPB y las distintas consecuencias evaluadas son reportadas en la Tabla 1. Los valores de las correlaciones siguen de forma clara un patrón gradual, donde se identifican algunas conductas que se relacionan significativamente con variables positivas y otras con variables más negativas. En general, se observa que las conductas docentes adaptativas y orientadoras tienen relaciones positivas, significativas y fuertes con variables positivas (i.e., valoración docente, satisfacción de las NPB, diversión y predisposición hacia la $\mathrm{EF}$ ), así como relaciones negativas, significativas, y fuertes con variables desadaptativas (i.e., frustración de las NPB, aburrimiento y oposición desafiante). Siguiendo esta aproximación gradual, las conductas participativas y clarificadoras muestran el mismo signo de correlación, pero, en este caso, la fuerza de dichas asociaciones es ligeramente menor.

En el lado opuesto, las conductas dominadoras y abandonadas son las que se relacionan negativa y significativamente, de forma más pronunciada, con las variables positivas (i.e., valoración docente, satisfacción de las NPB, diversión y predisposición hacia la EF) y positiva y 
significativamente con las variables desadaptativas (i.e., frustración de las NPB, aburrimiento y oposición desafiante). Las conductas demandantes y a la espera reproducen este mismo patrón de correlaciones, pero con valores menores.

Tabla 1. Correlaciones bivariadas entre las conductas docentes y distintas variables motivacionales

\begin{tabular}{lcccccccc}
\hline Variables & Particip. & Adapt. & Orient. & Clarif. & Deman. & Domin. & Aband. & Espera \\
\hline Valoración docente (n=255) & $.468^{* *}$ & $.699^{* *}$ & $.757^{* *}$ & $.565^{* *}$ & $-.246^{* *}$ & $-.596^{* *}$ & $-.513^{* *}$ & $-.289^{* *}$ \\
Satisfacción de las NPB (n=170) & & & & & & & & \\
Sat. Autonomía & $.528^{* *}$ & $.488^{* *}$ & $.479^{* *}$ & .342 & .125 & -.060 & -.138 & -.078 \\
Sat. Competencia & $.314^{* *}$ & $.255^{* *}$ & $.287^{* *}$ & $.161^{*}$ & .073 & .028 & -.025 & -.103 \\
Sat. Relaciones sociales & .068 & .105 & .143 & .149 & .099 & -.026 & $-.168^{*}$ & $-.179^{*}$ \\
Frustración de las NPB (n=170) & & & & & & & & \\
Frust. Autonomía & $-.387^{* *}$ & $-.490^{* *}$ & $-.509^{* *}$ & $-.385^{* *}$ & -.025 & $.163^{*}$ & $.398^{* *}$ & $.290^{* *}$ \\
Frust. Competencia & -.125 & -.142 & $-.194^{*}$ & -.138 & .012 & .044 & $.252^{* *}$ & $.281^{* *}$ \\
Frust. Relaciones sociales & -.023 & -.071 & $-.177^{*}$ & -.133 & .054 & .096 & $.357^{* *}$ & $.414^{* *}$ \\
Consecuencias (n=170) & & & & & & & & \\
Diversión & $.346^{* *}$ & $.421^{* *}$ & $.492^{* *}$ & $.366^{* *}$ & .081 & -.122 & $-.255^{* *}$ & $-.180^{* *}$ \\
Aburrimiento & -.033 & $-.204^{* *}$ & $-.320^{* *}$ & $-.204^{* *}$ & .114 & $.234^{* *}$ & $.413^{* *}$ & $.318^{* *}$ \\
Oposición desafiante & -.037 & $-.224^{* *}$ & $-.334^{* *}$ & $-.264^{* *}$ & $.201^{* *}$ & $.327^{* *}$ & $.580^{* *}$ & $.411^{* *}$ \\
Predisposición hacia la EF & $.494^{* *}$ & $.646^{* *}$ & $.629^{* *}$ & $.530^{* *}$ & $.157^{*}$ & -.085 & $-.332^{* *}$ & $-.250^{* *}$ \\
\hline
\end{tabular}

Nota: Sat. $=$ Satisfacción $;$ Frust.$=$ Frustración $; N P B=$ Necesidades psicológicas básicas $; * \mathrm{p}<.01 ; * * \mathrm{p}<.001 ;$

Figura 2. Representación gráfica de las relaciones entre las conductas motivacionales y la oposición desafiante y la valoración docente por parte del alumnado. Fuente: elaboración propia. 


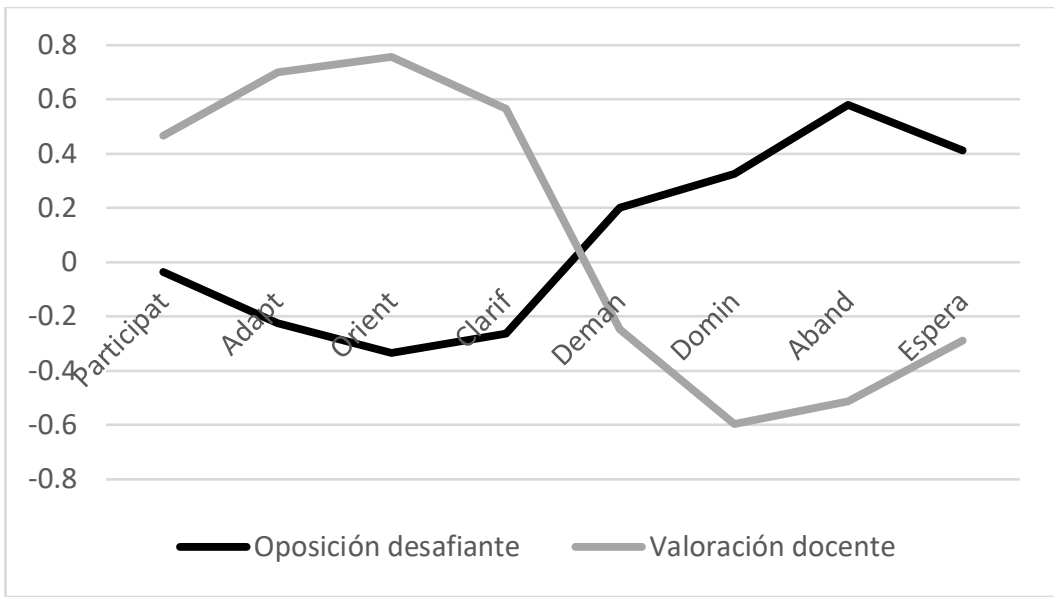

Nota: Correlaciones entre conductas motivacionales y oposición desafiante $(N=170)$; Correlaciones entre conductas motivacionales y valoración docente $(N=255)$.

De forma gráfica, en la Figura 2, podemos observar cómo estas conductas reproducen una relación sinusoidal con la valoración del docente y la oposición desafiante, representando esta clasificación gradual mencionada anteriormente.

\section{Discusión y conclusiones}

El presente capítulo de investigación, de carácter preliminar, trata de presentar un marco teórico para el estudio detallado de las conductas motivacionales docentes en EF, siendo este el primer trabajo que examina el modelo circular de Aelterman et al. (2019) en EF en el contexto español. En primer lugar, es necesario destacar la necesidad de realizar un análisis detallado de las conductas motivacionales docentes en EF, ya que de esta forma se representa con mayor fidelidad el amplio abanico de conductas docentes que existe en la realidad (Vermote et al., 2020). Los resultados muestran la validez de establecer hasta ocho tipologías de conductas docentes diferentes, que pueden ser desarrolladas simultáneamente por los docentes de EF, y que van a provocar consecuencias diferenciadas en los procesos motivacionales de los estudiantes, así como en distintas consecuencias afectivas (e.g., diversión y aburrimiento), comportamentales (e.g., conductas de oposición desafiante) y cognitivas (e.g., predisoposición hacia la EF). El aumento de la diversión y la predisposición hacia la EF y la disminución del aburrimiento y la oposición desafiante a través de la optimización de las conductas motivacionales docentes contribuirá a la consecución del ODS4 relacionado con la educación de calidad. 
Uno de los resultados principales de este capítulo es la confirmación de que las ocho conductas motivacionales docentes estudiadas tienen un efecto gradual sobre distintas consecuencias examinadas en el alumnado (Aelterman et al., 2019; Vansteenkiste et al., 2019). Las conductas que mejores efectos producen son las orientadoras, adaptativas y clarificadoras, ya que maximizan su efecto sobre distintas consecuencias motivacionales. En el polo opuesto, las conductas que deben ser evitadas mayoritariamente son las dominadoras y abandonadas, coincidiendo con estudios anteriores en contexto educativo general (Aelterman et al., 2019) o en docentes de educación superior (Vermote et al., 2020).

Además, esta evaluación detallada de las conductas motivacionales docentes va a permitir un conocimiento detallado a los propios docentes, lo que puede redundar en una adopción de un estilo de mayor apoyo a las NPB que beneficie tanto a los alumnos como a los propios docentes (Reeve, 2016). Igualmente, la evaluación de las conductas docentes permitirá establecer distintos perfiles de docentes con objeto de que cada docente pueda tener un feedback personalizado sobre sus conductas, siendo más conscientes de las mismas (Vermote et al., 2020).

Como conclusiones de este capítulo podemos establecer: 1) es necesario desarrollar un estudio detallado de las conductas motivacionales docentes, siendo el modelo circular un marco teórico válido para ello; 2) las distintas conductas motivacionales van a tener distintos efectos sobre variables cognitivas, afectivas y comportamentales del alumnado de EF, por lo que es necesario seguir evaluando estas conductas y los efectos que producen. Esto, permitirá en el futuro desarrollar estudios de intervención que busquen la formación de los docentes de EF para mejorar su estilo motivacional docente, con el objetivo de mejorar los procesos motivacionales en el alumnado de EF y generar consecuencias adaptativas. Todo ello redundará en una mejora de la EF, ayudando a cumplir el ODS 4, garantizando una educación de calidad.

\section{Referencias}

Abós, Á., Sevil, J., Julián, J. A., Abarca-Sos, A., y García-González, L. (2017). Improving students' predisposition towards physical education by optimizing their motivational processes in an acrosport unit. European Physical Education Review, 23(4), 444-460. https://doi.org/10.1177/1356336X16654390 
Aelterman, N., Vansteenkiste, M., Haerens, L., Soenens, B., Fontaine, J. R. J., y Reeve, J. (2019). Toward an integrative and fine-grained insight in motivating and demotivating teaching styles: The merits of a circumplex approach. Journal of Educational Psychology, 111(3), 497-521. https://doi.org/10.1037/edu0000293

Baena, A., Granero-Gallegos, A., Bracho-Amador, C., y Pérez-Quero, F. J. (2012). Spanish version of the sport satisfaction instrument (SSI) adapted to physical education. Journal of Psychodidactics, 17(2), 377-395. https://doi.org/10.1387/RevPsicodidact.4037

Delrue, J., Reynders, B., Broek, G. V., Aelterman, N., De Backer, M., Decroos, S., ... Vansteenkiste, M. (2019). Adopting a helicopter-perspective towards motivating and demotivating coaching: A circumplex approach. Psychology of Sport y Exercise, 40, 110-126. https://doi.org/10.1016/j.psychsport.2018.08.008

Haerens, L., Aelterman, N., Vansteenkiste, M., Soenens, B., y Van Petegem, S. (2015). Do perceived autonomy-supportive and controlling teaching relate to physical education students' motivational experiences through unique pathways? Distinguishing between the bright and dark side of motivation. Psychology of Sport and Exercise, 16, 26-36. https://doi.org/10.1016/j.psychsport.2014.08.013

Haerens, L., Vansteenkiste, M., Aelterman, N., y Van den Berghe, L. (2016). Toward a systematic study of the dark side of student motivation: Antecedents and consequences of teachers' controlling behaviors. En W.C. Liu, J.C.K. Wang y R.M. Ryan (Eds.), Building autonomous learners Perspectives from Research and Practice using Self-Determination Theory (pp. 5981). Springer.

Haerens, L., Vansteenkiste, M., De Meester, A., Delrue, J., Tallir, I., Vande Broek, G., ... \& Aelterman, N. (2018). Different combinations of perceived autonomy support and control: Identifying the most optimal motivating style. Physical Education and Sport Pedagogy, 23(1), 16-36. https://doi.org/10.1080/17408989.2017.1346070 
Hilland, T. A., Stratton, G., Vinson, D., y Fairclough, S. (2009). The physical education predisposition scale: Preliminary development and validation. Journal of Sports Sciences, 27(14), 1555-1563. https://doi.org/10.1080/02640410903147513

Ladwig, M. A., Vazou, S., y Ekkekakis, P. (2018). "My best memory is when I was done with it": PE memories are associated with adult sedentary behavior. Translational Journal of the American College of Sports Medicine, 3(16), 119-129. https://doi.org/10.1249/TJX.0000000000000067

Reeve, J. (2016). Autonomy-supportive teaching: What it is, how to do it. En J. C. K. Wang, W. C. Liu, y R. M. Ryan (Eds.), Motivation in educational research: Translating theory into classroom practice (pp. 129-152). Springer.

Ryan, R. M., y Deci, E. L. (2017). Self-determination theory: Basic psychological needs in motivation, development, and wellness. Guilford Publications.

Sánchez-Oliva, D., Sánchez-Miguel, P. A., Leo, F. M., Kinnafick, F., y García-Calvo, T. (2014). Physical education lessons and physical activity intentions within Spanish secondary schools: A self-determination perspective. Journal of Teaching in Physical Education, 33(2), 232-249. https://doi.org/10.1123/jtpe.2013-0043

Sevil, J., García-González, L., Abós, Á., Generelo, E., y Aibar, A. (2019). Can high schools be an effective setting to promote healthy lifestyles? effects of a multiple behavior change intervention in adolescents. Journal of Adolescent Health, 64(4), 478-486. https://doi.org/10.1016/j.jadohealth.2018.09.027

Vansteenkiste, M., Aelterman, N., Haerens, L., y Soenens, B. (2019). Seeking stability in stormy educational times: A need-based perspective on (de) motivating teaching grounded in selfdetermination theory. En E.N. Gonida y M.S. Lemos (Eds.). Motivation in Education at a Time of Global Change: Tehory, Research, and Implications for Practice. Emerald Publishing Limited.

Vermote, B., Aelterman, N., Beyers, W., Aper, L., Buysschaert, F., y Vansteenkiste, M. (2020). The role of teachers' motivation and mindsets in predicting a (de)motivating teaching style in 
higher education: A circumplex approach. Motivation and Emotion, 44(2), 270-294. https://doi.org/10.1007/s11031-020-09827-5

Zamarripa, J., Rodríguez-Medellín, R., Pérez-Garcia, J. A., Otero-Saborido, F., y Delgado, M. (2020). Mexican basic psychological need satisfaction and frustration scale in physical education. Frontiers in Psychology, 11, 253. https://doi.org/10.3389/fpsyg.2020.00253 


\title{
Principios pedagógicos del juego digital activo como material educativo
}

\author{
Alejandro Quintas \\ Universidad de Zaragoza
}

Palabras clave: videojuego; recurso; magisterio; didáctica; tecnología.

\section{Introducción}

Hay gran cantidad de léxico educativo en torno a los materiales: medios, recursos, materiales, instrumentos, tecnologías, etc., complementados con los apellidos didácticos o curriculares indistintamente. Fue a partir de la LOGSE (1990) cuando se revalorizó el peso de los materiales didácticos en el currículum (Heredia, 2007, p. 141). Podríamos entender que un material didáctico es «todo tipo de medio, soporte o vía que facilita la presentación y tratamiento de los contenidos objeto de enseñanza-aprendizaje» (Escamilla, 2009, p. 134). Es decir, son per se un medio para conseguir un fin, que en el caso educativo puede ser el aprendizaje, la equidad, los objetivos de desarrollo sostenible, la autonomía, la competencia, etc. El gran aumento actual de aplicación de materiales y recursos en cualquier etapa educativa pudiera dar a pensar que hemos cambiado los medios y los fines, olvidando aquellos objetivos que, a nivel social y educativo, son los realmente importantes; los objetivos no son sustituibles (aunque son cambiables, según los tiempos), pero los medios son prescindibles e intercambiables. Así, se está extendiendo cada vez más falacias como que la mera introducción de un material novedoso es en sí mismo motivante (cuando realmente puede producir un elemento efímero de interés y curiosidad por lo nuevo, pero no motivación como característica psicológica); igualmente, se justifica que las metodologías activas o la tecnología digital son buenas y virtuosas por el propio hecho de ser aplicadas. Quizá tenga que ver con la rapidez, el consumismo y la mercadotecnia actual, que pueden promover, también en educación, prácticas de aplicación e introducción automáticas y constantemente 
nuevas. Por ello, la reflexión sobre los materiales educativos en educación debe mantener una postura sosegada y escéptica, pensando muy bien cuáles pueden ser los efectos positivos y negativos de su introducción en un ámbito educativo, así como el sentido de hacerlo. De esta forma, quizá se deba empezar a pensar cuáles son los materiales y recursos que realmente son compatibles con los objetivos de desarrollo sostenible y tantos otros valores socialmente deseables (virtud, justicia, equidad, igualdad, belleza, bien, etc.) (Quintas, 2020).

Un principio didáctico establece que el mejor método de aprendizaje es aquel que proporciona una experiencia directa del estudiante con la realidad; cuando esta experiencia directa no se puede dar, entonces el profesorado debe hacer uso de los materiales didácticos, de forma que estos median entre la realidad y el aprendiz (Heredia, 2007, p. 143). Lo juegos digitales son un buen ejemplo de materiales con esta capacidad: facilitar al estudiante unas experiencias que, de otro modo (por la distancia, el nivel socioeconómico, la situación social, la época histórica...), no podría acceder (Gee, 2003).

Los juegos digitales, concretamente los videojuegos, han adquirido una posición más allá del entretenimiento; son un fenómeno social que últimamente se ha convertido en un recurso educativo. Según el Instituto Nacional de Estadística (INE) de España, entre aquellos que suelen utilizar videojuegos es mucho más frecuente la asistencia al cine y la afición por la música o la lectura (INE, 2019). ¿Qué pueden tener los juegos digitales para que tantos jóvenes (y no tan jóvenes) los usen y se mantengan largo tiempo en ellos? ¿qué podría aprender la didáctica y la pedagogía de los videojuegos para imitar aquellos aspectos que sí funcionan y son compatibles con la enseñanza-aprendizaje y los valores considerados educativos? Tener una actitud a priori reacia hacia el mundo del juego digital y su tratamiento educativo podría suponer una exposición al alumnado de primaria a un mundo en el cual estaría rodeado de juegos digitales, pero sin recursos para afrontarlos con autonomía, competencia y crítica. Por ello, como mínimo, el juego digital como fenómeno social debe tratarse a nivel educativo aunque sea a nivel teórico-dialógico, para debatir y reflexionar con el alumnado sobre el mismo (Rivoltella, 2017).

Las tecnologías han permitido la aparición de juegos más dinámicos, con mayor aceptación y con diferentes niveles de interacción, en el que gran cantidad de datos, información, procedimientos y valores están íntimamente vinculadas a la didáctica (Morales, 2014). Los videojuegos están teniendo un crecimiento exponencial en cuanto a su generación y su uso. El 
interés por el fenómeno gaming, medida en tendencias de búsqueda en Google (Google Trends), ha crecido desde enero de 2004 con 43 puntos porcentuales hasta los 100 puntos porcentuales en diciembre de 2019, es decir, en los últimos 15 años ha crecido de forma progresiva el interés por los videojuegos a nivel mundial. En el ámbito social, cada vez están más asentados en diferentes esferas de la población, y no sólo la adolescente y joven (Hernández-Pérez, 2015). Por ello, en el presente estudio se plantean como objetivos desarrollar cómo se pueden concebir los juegos digitales activos, y explicar los principios pedagógicos asociados, para poder dirimir si son compatibles con los objetivos de desarrollo sostenible.

\section{Comprendiendo el juego digital}

Un juego digital activo es más conocido en la literatura específica como exergame. No obstante, no existe un mínimo consenso de uso, utilizándose una gran variedad de términos: exergame, exertion game, gamercising, exertainment, active video game, interactive video game, physical gaming, aesthetic video games, entre otros (Vaghetti, Monteiro-Junior, Finco, Reategui, \& Botelho, 2018). Los estudios pioneros en definir teóricamente el exergame fue como Active Gaming o Exergaming, entendidos como una forma más de realizar actividad física, definiéndolo como «videojuegos que aportan actividad física o ejercicio a través del juego interactivo» (Mears \& Hansen, 2009, p. 27). Posteriormente, ampliaron el término considerando que «requieren que los jugadores participen en juegos digitales y juegos basados en otra tecnología donde ellos se involucran con movimiento físico para jugar al juego» (Witherspoon-Hansen \& Sanders, 2011, p. 124).

En la misma línea, De Medeiros et al. (2017, p. 465) entendieron los videojuegos activos o exergames como «tecnologías que requieren de todo el cuerpo para moverse, combinando ejercicios físicos con videojuegos», siendo por tanto la diferencia entre los exergames y los videojuegos sedentarios el «esfuerzo físico y las habilidades motrices y las capacidades requeridas durante el juego». Por último, se considera necesario utilizar una definición lógico-pragmática de exergame con una base teórica más solida: juego motriz digital orientado a estimular la motricidad del jugador (Quintas, 2019a). 


\section{Los principios pedagógicos de los juegos digitales}

A nivel educativo, Paul Gee (2003, pp. 207-212) en su obra Lo que enseñan los videojuegos sobre el aprendizaje y el alfabetismo desarrolla 36 principios pedagógicos que analizan qué y cómo permiten aprender los juegos digitales — que él denomina de forma más encorsetada como videojuegos - . De igual forma, como un tipo de juegos digitales que son, los juegos digitales activos también incluyen estos principios pedagógicos, a los cuales se les puede añadir las virtudes de la corporalidad (embodyment), la motricidad, y el pragmatismo (learning by doing). A continuación, se explicarán cada uno de ellos, relacionándolos con diversas teorías sociopsicológicas más asentadas científicamente:

1. Principio del aprendizaje activo y crítico: los elementos del entorno de aprendizaje promueven un aprendizaje activo y crítico, es decir, no pasivo por parte del juegadoralumno. Se asociarían a la mayoría de los planteamientos metódicos de la Escuela Nueva.

2. Principio de diseño: aprender y valorar el diseño virtual, así como los principios del diseño estético audiovisual. Se asemeja al principio de la estética en educación de Malaguzzi (Hoyuelos, 2006).

3. Principio semiótico: aprender y llegar a valorar las interrelaciones entre, y a través de, múltiples sistemas de signos (imágenes, palabras, acciones, símbolos, artefactos, etc.). Aspecto asociado a la competencia digital particularmente.

4. Principio del dominio semiótico: el aprendizaje implica maestría sobre un dominio semiótico y ser capaz de participar en un grupo de afinidad o en grupos conectados con él. Aspecto asociado a la competencia digital, y la comunicativa.

5. Principio del pensamiento metanivel acerca del dominio semiótico: el aprendizaje implica el pensamiento activo y crítico sobre las relaciones entre el dominio semiótico en el que se logró el aprendizaje y otros dominios semióticos.

6. Principio de «moratoria psicológica»: los aprendices-jugadores se atreven a correr riesgos cuando las consecuencias reales de sus actos son leves o de bajo impacto. Esto es, dentro del círculo mágico (Huizinga, 1972), no hay consecuencias en la vida real, por ello el videojuego es un juego - al contrario que la gamificación-

7. Principio de compromiso con el aprendizaje: los aprendices participan comprometiéndose plenamente dado que sienten inmersión y se identifican con las acciones que suceden 
dentro del videojuego. Se correspondería con el concepto de estado de Flow de Csíkszentmihályi (1990).

8. Principio de identidad: el jugador siente que su identidad real se ha extendido en una identidad virtual que le compromete. El aprendizaje implica tomar o jugar con diversas identidades, pudiendo reflexionar sobre las relaciones entre las nuevas identidades y las anteriores, así como entre las identidades en el mundo real y en el mundo virtual. Correspondería al juego simbólico (Piaget, 1984).

9. Principio de autoaprendizaje: el mundo virtual ha sido construido de tal manera que los aprendices pueden aprender no solo acerca del dominio del juego, sino también acerca de sí mismos y de su actuales y potenciales capacidades. El videojuego promueve la autonomía del alumnado, esencial según la teoría de las necesidades psicológicas básicas (Ryan \& Deci, 2017).

10. Principio de amplificación de los inputs: para un pequeño input —entrada de información—, los aprendices proporcionan muchos outputs — productos o información de salida-.

11. Principio del logro: existen recompensas desde el inicio del videojuego, diferenciados según el nivel de aprendizaje y el esfuerzo requerido, así como un reconocimiento continuo de los logros alcanzados. Sería similar a la técnica de los refuerzos positivos de Skinner (1953)

12. Principio de la práctica: los aprendices tienen muchas oportunidades de practicar, pero en un contexto en el que practicar no es aburrido, por lo que emplean gran cantidad de tiempo probando, según el principio educativo del pragmatismo de John Dewey.

13. Principio del aprendizaje en proceso: la diferencia entre el aprendiz y el experto no es clara, ya que los aprendices, gracias al principio de régimen de competencia, deben deshacerse de la rutina que los hizo expertos para adaptarse a unas nuevas o modificadas condiciones. Sería similar a la diferencia entre asimilación y acomodación en Piaget (1984), es decir, cuando el jugador ya ha automatizado las respuestas a las dificultades del videojuego, las dificultades y condiciones cambian.

14. Principio del régimen de competencia: el aprendiz tiene muchas oportunidades para usar sus propios recursos, más allá de sus límites actuales, pero de manera que no siente que el reto es imposible. Sería similar al principio de zona de desarrollo próximo de Vygotski (1978). 
15. Principio de exploración: el juego digital permite aprender mediante un ciclo de exploración-descubrimiento del mundo virtual: (1) exploración inicial del mundo virtual, (2) reflexión sobre el mundo y sobre la exploración que se está realizando, a partir de lo cual se formulan hipótesis, (3) re-exploración del mundo para verificar dicha hipótesis, (4) aceptar o rechazar finalmente la hipótesis. Estaría asociado al principio de aprendizaje por descubrimiento (Bruner, 1963), así como al perfil de explorador según la clasificación de Bartle (2003).

16. Principio de múltiples caminos: el videojuego permite varios caminos para avanzar, progresar y aprender. Se permite a los aprendices tomar decisiones, confiar en sus propias fortalezas y en sus estilos para aprender y para solucionar problemas, así como explorar estilos alternativos. Sería un principio que promovería la autonomía del videojuego, de nuevo una de las tres necesidades psicológicas básicas (Ryan \& Deci, 2017).

17. Principio del significado situado: los significados de los signos (palabras, acciones, objetos, artefactos, símbolos, textos, etc.) se sitúan siempre desde y en la experiencia personal. No hay significados generales o descontextualizados. Detrás de toda generalidad en los significados se descubre siempre una experiencia personal desde la que ha partido. Estaría asociado a la didáctica del episodio de aprendizaje situado (Rivoltella, 2016), así como a cualquier acercamiento educativo desde el enfoque del situacionismo explicado por Lave.

18. Principio del texto: los textos no se comprenden solo verbalmente sino que son comprendidos en términos de experiencias personales. Los aprendices se mueven, de un lado al otro, entre los textos y sus experiencias personales. Se asociarían con el principio de aprendizaje enactivo (Bruner, 1963).

19. Principio intertextual: comprender un grupo de textos como un género de textos es en gran medida lo que ayuda al aprendiz a construir el sentido de tales textos, es decir, de manera relacional y conectada.

20. Principio multimodal: el aprendizaje mediante videojuegos es multimodal (imágenes, textos, símbolos, interacciones, abstracciones, sonidos, etc.), y no solo textual.

21. Principio de la inteligencia material: los conocimientos, las decisiones y la solución de problemas son guardados en objetos materiales y en el entorno. Esto libera a los aprendices para que se puedan focalizar en otras tareas, pudiendo así lograr efectos más potentes. Podría estar asociado a un currículum en espiral (Bruner, 1963), en lugar de lineal. 
22. Principio del conocimiento intuitivo: se tiene en cuenta el conocimiento intuitivo o tácito, construido en la práctica repetida y en la experiencia, no solo el conocimiento verbal.

23. Principio del subconjunto: el aprendizaje, incluso en sus inicios, se desarrolla en un (simplificado) subconjunto del dominio real.

24. Principio de incremento: las situaciones de aprendizaje son ordenadas, inicialmente, para que los primeros casos puedan conducir a generalizaciones que sean provechosas para la comprensión de los casos posteriores. Se ajustaría al principio de nivelación en la teoría de la gamificación Mecánica-Dinámica-Estética (Quintas, 2019b, p. 261)

25. Principio del ejemplo concentrado: signos y acciones fundamentales se concentran, en los estadios iniciales, para que los aprendices los usen frecuentemente y los aprendan bien.

26. Principio de habilidades básicas de abajo a arriba: las habilidades básicas no se aprenden aisladas o fuera de contexto, sino, más bien, lo que realmente se considera habilidad básica es desarrollada, desde abajo, enganchando más y más en el dominio de un juego o en los dominios de juegos similares. Las habilidades básicas son elementos comunes de un dominio dado.

27. Principio de la información explícita, bajo demanda y oportuna: el aprendiz recibe información explícita cuando él la demanda y en el momento oportuno, cuando él la necesita, o el momento adecuado, es cuando puede comprenderla y usarla en la práctica. Este principio estaría asociado a la ontología del affordance u ofrecimiento (Gaver, 1991).

28. Principio de descubrimiento: un buen juego digital da explicaciones iniciales muy bien pensadas, cortas y concisas, para dar la mayor oportunidad a los aprendices a experimentar y descubrir por sí mismos. Estaría asociado con el aprendizaje por descubrimiento (Bruner, 1963).

29. Principio de transferencia: los aprendices pueden transferir lo que aprendieron en un momento previo hacia nuevos problemas, incluyendo casos que exijan adaptación y cambios en los primeros aprendizajes.

30. Principio de los modelos culturales sobre el mundo: el aprendizaje se establece teniendo en cuanto la existencia de diferentes identidades y culturas en el mundo virtual. Será necesario tener en cuenta un gran abanico de recursos de videojuegos que sean realmente representativos de las diferentes culturas e identidades humanas — solo de aquellas respetables, se entiende- 
31. Principio de los modelos culturales sobre el aprendizaje: el aprendizaje se establece teniendo en cuanto la existencia de diferentes métodos y maneras de aprender. Aunque no es una teórica sólida sobre cómo se aprende, la teoría de las inteligencias múltiples de Gardner (1994) se acerca a este principio.

32. Principio de los modelos culturales acerca de los dominios semióticos: el aprendizaje se establece teniendo en cuanto la existencia de diferentes métodos y técnicas que sean sensibles a los diferentes modelos semióticos.

33. Principio de distribución: el conocimiento se halla distribuido entre el aprendiz, los objetos, las herramientas, los símbolos, las tecnologías y el entorno. Se basa en un modelo ecológico de la educación.

34. Principio de dispersión: el conocimiento se encuentra disperso en el sentido en el que el aprendiz lo comparte con otros fuera del dominio del videojuego. En este sentido, los aprendizajes trascienden el videojuego, saliendo del círculo mágico (Huizinga, 1972).

35. Principio de grupo de afinidad: los estudiantes-jugadores constituyen un grupo de afinidad que está unido por compromisos, objetivos y prácticas y que no comparten etnia, género, edad, nacionalidad o cultura. Correspondería a una de las necesidades psicológicas básicas (Ryan \& Deci, 2017): la percepción de relaciones sociales.

36. Principio de insider o iniciado: el aprendiz es un productor, profesor e insider, y no solo un consumidor, capaz de personalizar la experiencia de aprendizaje y el dominio/juego desde el inicio y durante toda la experiencia.

Estos 36 principios pedagógicos no deben entenderse como una razón más para aplicar los juegos digitales activos en un ámbito educativo, sino como pilares o bases desde las cuales reflexionar y poder tomar decisiones sobre la incorporación de los videojuegos en educación; y en caso afirmativo, decidir sobre cómo, cuándo, cuánto, para qué, etc. No se deben olvidar tantos otros límites o desventajas de los juegos digitales, especialmente los efectos de su abuso, como son la hiperestimulación, la continua exposición a la red ya las pantallas, el estrés y la ansiedad, el límite de acceso material de todo el mundo a ellos, o la adicción a ciertas sensaciones que producen (cortisol, dopamina, serotonina, etc.), entre otros muchos. 


\section{Conclusiones}

La investigación e innovación educativas sobre materiales y recursos educativos es una perspectiva de la didáctica que debe acompañarse de otras: el estudio de las finalidades, de los métodos, de las técnicas, de las organizaciones y disposiciones materiales, de la evaluación, etc. Especialmente, la investigación axiológica de los materiales. De esta forma, evitaremos una aplicación casi automática de nuevos materiales al ámbito educativo, cayendo quizá en cierto tecnicismo. Las prácticas educativas deben tener referentes teóricos, y en el presente estudio se han definido 36 principios pedagógicos desde los cuales pensar los juegos educativos, al mismo tiempo que se han expuesto la incardinación de estos principios con otros conceptos e ideas sociopsicológicos más asentadas en educación. Los exergames o juegos digitales en general pueden ofrecer ciertas virtudes de las cuales el ámbito educativo se puede aprovechar, especialmente la consecución de más y mejor aprendizaje en el alumnado.

\section{Referencias}

Bartle, R. (2003). Designing virtual worlds. New Riders.

Bruner, J. S. (1963). El proceso de la educación. Unión Tipográfica Editorial Hispano Americana.

Csíkszentmihályi, M. (1990). Flow: The Psychology of Optimal Experience. Harper \& Row.

De Medeiros, P., Capistrano, R., Zequinão, M. A., Da Silva, S. A., Beltrame, T. S., \& Cardoso, F. L. (2017). Exergames as a tool for the acquisition and development of motor skills and abilities: a systematic review. Revista Paulista de Pediatria, 35(4), 464-471. http://dx.doi.org/10.1590/1984-0462/;2017;35;4;00013

Escamilla, A. (2009). Las competencias en la programación de aula. Infantil y primaria (3-12 años). Graó.

Gardner, H. (1994). Estructura de la mente: la teoría de las inteligencias múltiples. Fondo de Cultura Económica.

Gaver, W. W. (1991). Technology affordances. Paper presented at the CHI'91, Nueva Orleans. 
Gee, J. P. (2003). What video games have to teach us about learning and literacy. Palgrave Macmillan.

Heredia, A. (2007). Curso de didáctica general. Prensas Universitarias, Universidad de Zaragoza.

Hernández-Pérez, J. F. (2015). La influencia de los videojuegos en el proceso de adopción tecnológica: un estudio empírico en la región de Murcia. Universidad Católica de San Antonio, Murcia.

Hoyuelos, A. (2006). La estética en el pensamiento y obra pedagógica de Loris Malaguzzi. Octaedro.

Huizinga, J. (1972). Homo ludens: Esencia y significación del juego como fenómeno cultural. Alianza Editorial.

INE. (2019). Encuesta de hábitos y prácticas culturales en España, 2018-2019. Ministerio de Cultura y Deporte Retrieved from https://bit.ly/3djSUkQ.

Mears, D., \& Hansen, L. (2009). Active Gaming: Definitions, Options and Implementation. Article \#5 in a 6-Part Series. Strategies, 23(2), 26-29.

Morales, E. (2014). La nueva cultura multimedia en la era digital: el caso de los videojuegos. Universidad Complutense de Madrid.

Piaget, J. (1984). La formación del símbolo en el niño: imitación, juego y sueño, imagen y representación. Fondo de Cultura Económica.

Quintas, A. (2019a). Análisis del potencial didáctico de los exergames: reconceptualización y enfoque pedagógico. Scholè. Rivista di educazione e studi culturali, 3(1), 97-116.

Quintas, A. (2019b). The benefits of incorporating exergames and gamification in physical and musical education: a proposal from didactics and science. Paper presented at the II World Congress on Education, Santiago de Compostela (Spain). 
Quintas, A. (2020). Teoría educativa sobre tecnología, juego y recursos en didáctica de la educación infantil. Prensas de la Universidad de Zaragoza.

Rivoltella, P. C. (2016). Che cos'è un EAS. L'idea, il metodo, la didattica. Editrice La Scuola.

Rivoltella, P. C. (2017). Media Education. Idea, metodo, ricerca. ELS La Scuola.

Ryan, R. M., \& Deci, E. L. (2017). Self-determination theory: Basic psychological needs in motivation, development, and wellness. Guilford Press.

Skinner, B. F. (1953). Science and human behavior. Macmillan.

Vaghetti, C., Monteiro-Junior, R., Finco, M., Reategui, E., \& Botelho, S. (2018). Exergames Experience in Physical Education: A Review. Physical Culture and Sport. Studies and Research, 78(1), 23-32. https://doi.org/10.2478/pcssr-2018-0010

Vygotski, L. (1978). El desarrollo de los procesos psicológicos superiores. Crítica.

Witherspoon-Hansen, L., \& Sanders, S. (2011). Active gaming: a new paradigm in childhood physical activity. Digital Culture \& Education, 3(2), 123-139. 


\title{
La evaluación en tiempos de pandemia: análisis de una experiencia en la formación del grado de magisterio en Educación Infantil
}

\author{
Esther Laín Sancho
}

Lucía Forcadell Aznar

Facultad de Ciencias Humanas y de la Educación, Universidad de Zaragoza

Palabras clave: covid-19; evaluación; equidad

\section{Introducción}

El covid-19 ha generado una situación de crisis en la sociedad, transformando temporalmente nuestros contextos de trabajo, de ocio y de vida. Durante el confinamiento experimentado en la primavera de 2020 se transformó el contexto habitual de la relación educativa en el que la presencialidad era lo más común. Este texto parte de preguntarse qué cambios ha generado esta situación de crisis en las relaciones educativas, y más concretamente en los procesos de evaluación. Quizás ha pasado poco tiempo para saber si realmente la crisis causa cambios que cristalicen en el tiempo y provoca prácticas alternativas más allá de los momentos puntuales de cambios que impusieron las circunstancias de confinamiento o semipresencialidad. Pero sí está en nuestra mano documentar o recoger experiencias y esfuerzos realizados por los agentes educativos para mantener la relación educativa en una situación de excepcionalidad. Según Inés Dussel,

se hace cada vez más imperioso si tenemos en cuenta el surgimiento de discursos que plantean «el año perdido» o descalifican por completo los duros esfuerzos que realizaron miles de educadores para conservar, en las condiciones posibles, los procesos de vínculo y transmisión con sus estudiantes (2020, p. 12).

En palabras de Skliar (2020, p. 32), "hubo pretensión de una cierta continuidad pedagógica -al menos en lo que se refiere a la gestión estatal y a la instalación de una trilogía básica: envío de 
tareas, realización y evaluación del aprendizaje- también existieron fenómenos concretos de discontinuidad, interrupción, ruptura y vacío, todo a la vez, o en fragmentos distintos de formas, tiempos y espacios", sin embargo, tal como se pregunta el mismo autor, ¿supuso que hubiera aprendizaje en la misma dirección, es decir, en el sentido de lo planificado, lo registrado, lo evaluable? (Ibíd.). Esta pregunta nos conduce a reflexionar sobre cómo se desarrolló la evaluación en el contexto de no presencialidad. Se abre el debate de replantearse cuál es la mejor forma de evaluar si las clases no son presenciales, dado que se hizo indispensable adaptar las programaciones didácticas al nuevo contexto y, por tanto, la forma de evaluación.

Empecemos por la etimología de la palabra evaluación. Su raíz procede de la palabra en latín "valere", que significa la acción de tasar, valorar, justipreciar, es decir, atribuir cierto valor a una cosa. La dificultad que encierra esta disyuntiva es saber a qué le damos nosotros ese valor. Santos Guerra (2018) ha explorado ampliamente la evaluación. Como muestra en sus textos, la evaluación pone de manifiesto nuestras concepciones docentes. La evaluación implica sobre todo un juicio de valor, y detrás de este juicio puede haber formas de control, de clasificación o de dominación, pero también de mejora o de regulación del aprendizaje. Sanmartí (2007) considera que la evaluación actualmente se puede concebir como un proceso caracterizado por: recoger información, analizar esa información y emitir un juicio de valor y tomar decisiones de acuerdo al juicio emitido (para la mejora). Estas decisiones pueden estar orientadas a constatar el nivel de conocimientos (sumativa) o a regular el proceso de aprendizaje y tomar decisiones para la mejora (formativa).

\section{Objetivo}

Desde estas aproximaciones nos hemos preguntado cómo se resolvía la cuestión de la evaluación en aquellos momentos excepcionales que fueron los meses de confinamiento domiciliario durante la primavera de 2020, para analizar en qué medida en el contexto de la formación universitaria se brindaron experiencias de evaluación formativa o sumativa que contribuyeran a consolidar los aprendizajes del alumnado. Así, el objetivo del texto es reflexionar sobre cómo fueron los procesos de evaluación en las asignaturas del grado de magisterio de educación infantil. Para ello se analizará el proceso de evaluación a partir del relato biográfico elaborado por una alumna a modo de diario sobre cómo se desarrolló la docencia y la evaluación 
que cursaba en dicho momento, con la finalidad de conducirnos hacia un proceso de reflexión que nos ayude a repensar los fundamentos de los procesos de evaluación, descubriendo posibles mejoras personales e institucionales de cara al posterior desarrollo de la función docente.

\section{Metodología}

Para reflexionar sobre cómo se adaptaron las formas de evaluación y en qué medida la situación condujo a procesos de evaluación formativa, vamos a situarnos en una aproximación cualitativa en la que no buscamos tanto "la verdad o la moralidad sino una comprensión detallada de las perspectivas de otras personas" (Taylor y Bogdan, 2010, p. 21). También pretendemos dar voz a los estudiantes, objeto de los procesos de evaluación. Para ello elaboraremos un relato en forma de "documento personal" (Taylor y Bogdan, p. 140) presentando las reflexiones sobre el acontecimiento de la evaluación desarrollado durante el citado periodo en la formación universitaria. En concreto recogemos la experiencia de una estudiante de magisterio de educación infantil en forma de diario autobiográfico. El diario se ha elaborado describiendo los procesos de evaluación que experimentó en las asignaturas que cursó en la alumna en aquel periodo en el contexto de la formación de grado. Posteriormente analizaremos desde las concepciones de evaluación explicitadas la experiencia de la evaluación en el citado periodo a partir del relato.

\section{Resultados}

Vamos a narrar la experiencia vivida en situación de confinamiento, en relación a cómo se evaluaron los procesos de enseñanza-aprendizaje que se desarrollaron en el contexto de un curso de magisterio de educación infantil. A continuación presentamos el relato en primera persona:

Gracias a los diferentes enfoques que ofrecieron los diferentes docentes en la evaluación, pude observar las variadas direcciones que tomaron, lo que me permitió valorar en qué medida las decisiones tomadas apoyaron el proceso individual de aprendizaje. Aunque en muchas de ellas, por motivos personales no resultaron positivas, quiero poner en valor y agradecer el esfuerzo acometido de todos los maestros para sacar adelante la docencia aquellos momentos tan complejos. A continuación, haré una descripción detallada de la evolución que tuvo cada una de las asignaturas que cursé: 
En la asignatura A, continúo la docencia por medio de la plataforma google meet. Este recurso telemático nos permitió conectarnos periódicamente manteniendo una continuidad y seguimiento en el trabajo, entablando puentes de comunicación muy necesarios en ese momento.

A lo largo del cuatrimestre realizamos muchos casos prácticos acompañados de un seguimiento y atención por parte de los docentes, dedicando tiempo a la corrección de las tareas. Existió mucho interés porque lleváramos la asignatura al día. Sin embargo, a la hora de evaluar, las condiciones que presentaban generaban desventaja aquellas personas con mayores dificultades. El examen constaba de 10 preguntas cortas a las que teníamos que responder en la mitad de tiempo, nos pidieron mantener los micrófonos abiertos en todo momento y la cámara del móvil enfocando la pantalla del ordenador, justificando estas medidas para evitar la posibilidad de que copiáramos, ya que el examen se realizaba desde casa. Las continuas intervenciones que hubo entre profesores y alumnos ocasionaron que no hubiera un ambiente propicio para la concentración, la interrupción de la conexión por unos minutos en mitad del examen provocada por problemas técnicos, sumado a la reducción del tiempo, generaron una tensión que me impidió terminar la prueba, quedándome en la pregunta 6 de 10. El resultado fue el suspenso de la asignatura. En mi caso, desde pequeña sobrellevé un aprendizaje lleno de dificultades y obstáculos, los cuales me han llevado a estudiar magisterio, para evitar precisamente, las desventajas que sufrí en la escuela. Como alumna de la universidad sigo experimentando dichos contratiempos, ya que requiero de mayor tiempo para leer y comprender un texto.

En este caso la evaluación se centró en el control de las condiciones de realización de una prueba puntual, más que en la formación, aunque la metodología durante el desarrollo de la asignatura sí acompañara en todo momento al estudiante.

Otra de la problemática con la que me topé fue la conectividad. No dispongo de una fuente de ingresos suficiente como para contar con el acceso a internet desde mi casa, esta circunstancia supuso gran tensión e incertidumbre, puesto que no sabía si podría realizar la prueba sin interrupciones. Gracias al apoyo del vecindario, logre tener acceso a wifi para llevar a cabo el examen sin ningún contratiempo.

En la asignatura B, comenzamos el cuatrimestre con un docente que a los pocos días tuvo que marcharse por motivos laborales, y al que le siguieron dos más hasta tener el definitivo. El 
último acabó dando el grueso de la asignatura pero nunca lo conocí presencialmente, ya que a los pocos días de empezar a impartir la asignatura nos confinaron. La docencia consistió en que el docente grababa clases magistrales en audios y los colgaba en la plataforma de moodle. Los alumnos teníamos que hacer entregas regulares de trabajos con fecha límite para cada uno. Hubo uno en concreto que me costó esfuerzo afrontarlo, ya que se nos preguntaba sobre situaciones personales, por lo que me retrasé en la entrega. Emocionalmente durante la situación de confinamiento y soledad (vivo sola en un piso) el trabajo se me hizo cuesta arriba. Por ese motivo perdí la opción de asistir al examen de junio. Le envié un correo explicándole mi situación pero no hubo negociación posible. No conocía al docente ni él a mí, yo era un número más dentro de unos parámetros que, de nuevo, no apoyaban el proceso de aprendizaje del alumno. En la segunda convocatoria a la que ya me pude presentar, fue un examen tipo test en el que también redujeron el tiempo, pero que en este caso, pude superar sin problema. De nuevo, la evaluación se insertó eminentemente en dinámicas de control, sin tener en cuenta la evolución del alumno.

En otra de las asignaturas, (C), el docente colgaba moodle una serie de vídeos explicativos y los alumnos debíamos realizar tareas. A diferencia de otras nos permitió administrarnos el tiempo, por lo que pude entregar todas las tareas sin ningún problema. El examen fueron preguntas cortas, duró alrededor de dos horas y pudimos realizarlo con los apuntes y el manual de referencia. Estas preguntas estaban formuladas de tal manera que no era posible contestarlas copiando un apartado del libro, sino que debíamos construir la respuesta a partir de los contenidos impartidos. Este formato me llevó a aprender a partir de la construcción de significados, y aunque la interacción con el docente era solo vía e-mail con clases magistrales, el tipo de examen invitaba a la reflexión y buscaba la comprensión de la asignatura y no tanto la memorística.

Por último, en la asignatura D, el docente colgó el contenido teórico en la plataforma de moodle sin ningún vídeo explicativo. Llevamos a cabo una serie de prácticas tutorizadas. En la evaluación realizamos un ensayo en el que teníamos que reflexionar y analizar noticias actuales sobre la situación de crisis por la que estaban pasando las escuelas durante el confinamiento, aplicando los contenidos de la asignatura. También realizamos una autoevaluación sobre nuestra implicación en la asignatura. Me pareció muy buena idea aprovechar el momento que estábamos viviendo para aplicarlo en la asignatura e indagar sobre ello. 
A continuación realizaremos una síntesis de las categorías que han emergido en la construcción del relato, tratando de analizar los procesos de evaluación adaptados, desde el marco explicitado.

A partir de diferentes experiencias evaluativas, podemos comprobar en qué medida la evaluación ha apoyado el aprendizaje. En las asignaturas A y B la evaluación sólo valoró el resultado final, siendo fundamentalmente sumativa. Las condiciones a las que se vio sometida la evaluación en estas asignaturas a causa de la situación de confinamiento contribuyeron a dificultar la reflexión y el razonamiento. Es cierto que el examen media con la nota de las prácticas realizadas durante el curso, y por tanto hay un componente de proceso, pero cuando las condiciones de control priman sobre otras cuestiones, las posibilidades de demostrar los conocimientos sobre el tema se ven condicionadas.

Tal y como reflexiona Martín Pinos (2020), en esta situación excepcional de confinamiento domiciliario, debemos tener en cuenta las necesidades de nuestros alumnos, intentando ajustar la carga de trabajo y flexibilizando los plazos para que estos no deriven en una congestión y abandono, en lugar de un aprendizaje. También teniendo en cuenta que dicha situación provoca un afloramiento de las emociones que debemos respetar para que el cerebro esté en condiciones favorables para el aprendizaje. En este sentido, en la asignatura B no se tuvieron en cuenta estas circunstancias, la falta de flexibilidad dificultó la realización de tareas diseñadas para el aprendizaje.

En cambio, en las asignaturas C y D la evaluación resultó más formativa, en tanto que invitó al alumnado a la reflexión, considerando los conocimientos de los alumnos y posibilitando la aplicación de los conocimientos teóricos.

Por otra parte, en la asignatura D, la evaluación invitó a la introspección y al análisis de la situación que estábamos experimentando. Al no tener un tiempo limitado, como ocurre en las pruebas escritas, que midiera nuestro saber, se posibilitó la elaboración y construcción de un proceso de reflexión que condujo al aprendizaje.

Tal y como describe Sanmartí (2007), la evaluación por competencias radica en comprobar si nuestros alumnos son capaces resolver problemas aplicando de forma coherente los 
conocimientos y demostrando la capacidad de saber interpretar teniendo en cuenta diferentes variables y puntos de vista.

En general, se produjo un distanciamiento físico entre el alumnado y el profesor ocasionado por la obligación de impartir las clases on-line, junto con la necesidad que en esos momentos había de establecer una calificación que determinara la promoción de curso, quizás fueron condiciones que mediaron en los procesos de evaluación. Y aunque hubo esfuerzo por parte de algunos profesores en establecer nexos de unión, este hecho ocasionó que la evaluación quedara alejada del contexto personal.

\section{Conclusiones}

El cambio de ambiente en el aprendizaje que supuso la situación de confinamiento, provocó una desigualdad educativa (Larrosa, 2020), implicando también a los procesos de evaluación. Como lleva años defendiendo Miguel Ángel Santos Guerra (2018) la evaluación debe acompañar al proceso de aprendizaje teniendo en cuenta las condiciones en las que se genera dicha formación. Dado que si esta se reduce a un solo acto aislado, resulta poco exacta debido a que puede verse afectada por las variables existentes del momento, desacreditando su validez. Como este autor ha planteado la evaluación desvela las concepciones sobre la enseñanza que tiene el evaluador. A partir del relato hemos podido observar cómo las respuestas fueron tan diversas con docentes y asignaturas, pudiendo brindar al estudiante tanto experiencias de evaluación sumativa y formativa. Quizás en una situación excepcional, el profesorado también se encuentra constreñido por las demandas de la institución, o la urgencia de la situación. Como plantean Sadovsky y Castorina, (2020,) "las inquietudes de las y los docentes tuvieron más que ver con los modos de transmitir qué actividades proponer, cómo brindar explicaciones, cómo ligarlas con las tareas-que con las adquisiciones de los alumnos, sus dificultades, sus dudas, sus logros, sus progresos" dado a que en parte, al haberse interrumpido en contexto de aprendizaje (la presencialidad que permite ver y observar las respuestas de los estudiantes en los procesos de enseñanza-aprendizaje), se hace difícil seguir las elaboraciones y progresos de los estudiantes.

Y aunque resultó un momento crítico tanto para estudiantes, como para profesorado, podemos aprovechar este dilema para hacer una lectura que nos ayude a descubrir los aciertos y errores que tuvieron lugar, y que estos sirvan como un proceso de mejora personal e institucional. 
Toda experiencia que vivimos nos ofrece una oportunidad de aprendizaje que nos enfrenta a nuevos desafíos. La mirada humilde y abierta, nos permite contemplar diferentes puntos de vista desde el respeto a nosotros mismos y a los demás. Es de esta manera como más se aprende. Tal y como define Paulo Freire (2018), el aprendizaje del educador no se limita únicamente a la corrección de los errores de sus alumnos, sino a la apertura para repensar y revisar sus posiciones involucrándose en la curiosidad de sus alumnos. Desde una mirada inocente, como quien descubre algo nuevo, el educador aprende enseñando construyendo caminos de la mano del alumno.

Como señala Daniel Pennac (2007, p. 245) "Es preciso que quienes pretenden enseñar tengan una visión de su escolaridad, que sientan un poco el estado de ignorancia, si quieren tener la menor posibilidad de sacarnos de ahí". El trabajo realizado en este texto ha implicado procesos de reflexión sobre la práctica que nos permiten repensar sobre los alumnos que fuimos, para convertirnos en los docentes que nos hubiera gustado tener. Y de no haber sido por esto, no hubiéramos podido llegar a las preguntas planteadas y las respuestas que buscamos en este camino de aprendizaje que implica a todo maestro para poder acompañar a otros niños en sus procesos de vida.

\section{Referencias}

Dussel, I., Ferrante, P. y Pulfer, D. (2020). Pensar la educación en tiempos de pandemia II. UNIPE y CLACSO

Freire, P. (2018). Cartas a quien pretende enseñar. Siglo Veintiuno Editores.

Larrosa J. (2020). Una vez más la igualdad. En Dussel, I., Ferrante, P. y Pulfer, D. (Coords.), Pensar la educación en tiempos de pandemia II (pp.17-31). UNIPE y CLACSO.

Pennac, D. (2018). Mal de escuela. Debolsillo contemporánea.

Pinos, M. (2021): Aprendizaje basado en la neurociencia, la emoción y el pensamiento. Consultado el día 20 de marzo de 2021. Recuperado de https://martinpinos.com/category/blog/ 
Sadosky, P. y Castorina, J.A (2020): Enseñar en tiempos de excepción, nuevos desafíos pedagógicos, incertidumbre y nuevo reconocimiento social. En Dussel, I., Ferrante, P. y Pulfer, D. (Coords.), Pensar la educación en tiempos de pandemia II (pp. 211-225). UNIPE y CLACSO.

Santos guerra, M.A. (2018). La evaluación como aprendizaje: cuando la flecha impacta en la diana. Narcea

Sanmartí, N. (2007). 10 claves. Evaluar para aprender. Graó.

Skliar, C. (2020). Sobre la incertidumbre educativa. Continuidades, discontinuidades, interrupciones y vacíos. En Dussel, I., Ferrante, P. y Pulfer, D. (Coords.), Pensar la educación en tiempos de pandemia II (pp. 31-45). UNIPE y CLACSO.

Taylor, S.J. y Bogdan, R. (2010). Introducción a los métodos cualitativos de investigación. Paidós. 
".".". Universidad Congreso internacional sobre buenas prácticas ODS durante el COVID: Aprendizaje Servicio, calidad y equidad

\section{CAPÍTULO 3}

\section{RESPONSABILIDAD SOCIAL E}

\section{INCLUSIÓN}




\title{
Twitter una nueva ventana a la sociedad, una apuesta de las universidades españolas y francesas
}

\author{
Mercedes Gil Lamata \\ Raquel Lozano Blasco \\ Universidad de Zaragoza
}

Palabras clave: Universidad; Twitter; comunicación; Covid-19; redes sociales.

\section{Introducción}

En los últimos años las redes sociales han cambiado la manera de comunicar, de relacionarse, de trabajo, de entretenimiento, entre otros. Han traído consigo un nuevo panorama donde intervienen nuevos roles sociales. Los más conocidos son los influencers (Trainor, Andzulis, Rapp y Agnihotri, 2014). Adicionalmente, las redes sociales han sido las responsables de la generación de grandes volúmenes de datos (Katz y González, 2016). De esta manera, se ha construido un nuevo ecosistema social, en el que la imagen, el marketing, la publicidad y los valores sociales han cambiado (González-Bailón y Wang, 2016; Kim y Hastak, 2018).

No pueden entenderse las redes sociales sin los influencers, estos tienen un papel fundamental en el área de marketing de las empresas, es decir tienen un cometido como imagen de empresas. Estos influencers debido a su interacción con su comunidad o seguidores son capaces de empatizar con los futuros consumidores de los productos que las marcas les pagan por publicitar. Es fundamental la interacción y expresión de gustos, sentimientos y opiniones que ejercen, siendo cercanos con sus seguidores y yendo un paso más allá de la llamada publicidad de información. Por lo tanto, la manera en la que se expresan los influencers tiene un rol clave en la interacción o respuesta que provocan los mensajes o sugerencias que lanzan. 
Este tipo de comunicación a través de las redes sociales es todavía más notoria si es realizada mediante las instituciones académicas. Debido a que tienen una mayor autoridad científica (Ruz, 2020), más aún si se considera la actual coyuntura en la que se encuentra toda la sociedad debido a la Covid-19. Y es que la universidad es una institución no solo académica sino también social y que tiene una responsabilidad para y con la sociedad. Por ello, resulta relevante analizar el sentimiento generado para entender los mensajes y la percepción de los destinatarios (Yu, Duan y Cao, 2013; Ceron, Curini, Iacus y Porro, 2014). Este análisis de sentimiento se respalda en los datos obtenidos a través de FanPage Karma y el análisis de reconocimiento de algoritmo. En suma, mediante la aplicación del modelo ECCD se podrá profundizar en estos aspectos, clasificando las cuentas y tweets de acuerdo con su sentimiento y polaridad. Ya que este modelo posibilita la categorización de la información compartida de Twitter según su intencionalidad, pudiendo ser este educativo, cooperativo, corporativo o divulgativo (FerrerSerrano, Latorre-Martínez y Lozano-Blasco, 2020).

\section{Objetivos}

Se plantea el objetivo de estudiar el rol de las cuentas institucionales del sur de Francia y Norte de España, estableciendo diferencias entre la fase pre-covid y enseñanza presencial y durante el confinamiento estricto y enseñanza online. Concretamente, este trabajo tiene los siguientes subobjetivos:

a. Estudiar el comportamiento de las universidades transfronterizas de los países de España y Francia en la red social Twitter, así como las respuestas obtenidas.

b. Examinar la comunicación institucional de estas universidades durante las clases teniendo en cuenta las medidas a causa de la pandemia Covid-19.

c. Realizar una comparación entre la comunicación a través de Twitter de dichas universidades

A fin de lograr estos objetivos, se toma como punto de partida la hipótesis de que la comunicación realizada por las universidades en Twitter ha sufrido una influencia debido a la Covid-19. 


\section{Metodología}

La metodología de estudio versa sobre "social media análisis" de forma que se monitorizaron las cuentas corporativas de Twitter de 36 universidades de España y Francia mediante el software de análisis de mercado Fanpage Karma. Por otra parte, se realiza sobre las publicaciones de mayor impacto un análisis de sentimiento mediante el software de Meaning cloud para determinar las diferencias en polaridad de ambas fases. En último lugar, se efectúa un análisis semántico atendiendo a los principios del modelo ECCD, que categoriza los tweets de acuerdo con cuatro temas según su significado e intencionalidad: educativos, cooperativos, corporativos y divulgativos.

\section{Muestra}

La muestra seleccionada está constituida por las cuentas corporativas de Twitter de 36 universidades tanto públicas como privadas. De las cuales 14 son pertenecientes al sur de Francia y 22 al norte de España, ya que se pretende realizar una comparación de comportamientos institucionales y respuestas entre las universidades más cercanas de ambos países. Se recogen un total de 5.000 tweets, los que más likes han obtenido de entre todas las cuentas objeto de estudio mediante la herramienta FanPage Karma, que es capaz de monitorizar tweets y también indicadores clave de rendimiento o también llamados medidores de desempeño, de ahora en adelante "KPIs".

A continuación, en la Tabla 1 se presenta la procedencia de las cuentas de Twitter de la muestra seleccionada, haciendo una diferenciación entre los dos países vecinos.

Tabla 1. Listado de Universidades de la muestra de estudio monitorizadas. Fuente: Elaboración propia a partir de las Universidades de la muestra de estudio.

\begin{tabular}{ll}
\hline Sur de Francia & Norte de España \\
\hline Aix-Marseille Université & Universidad de Mondragón \\
Avignon Université & Universidad Abad Oliva CEU \\
Toulouse INP & Universidad de Lleida \\
Université Bordeaux Montaigne & Universidad Internacional de Cataluña \\
Université Côte d'Azur & Universidad de Cantabria \\
\hline
\end{tabular}




\begin{tabular}{ll}
\hline Université de Montpellier & Universidad de La Rioja \\
Université de Nîmes & Universidad de Navarra \\
Université de Pau et des Pays de l'Adour & Universidad Deusto \\
Université Perpignan & Universidad Oviedo \\
Université Toulouse - Jean Jaurès & Universidad San Jorge \\
Université de Toulouse I Capitole & Universidad Zaragoza \\
Université Toulouse III - Paul Sabatier & Universidad de La Coruña \\
U Bordeaux & Universidad de Vigo \\
Université Paul-Valéry Montpellier & Universidad Autònoma de Barcelona \\
& Universidad de Barcelona \\
& Universidad de Girona \\
& Universidad Politécnica de Cataluña \\
& Universidad Rovira i Virgili \\
& Universidad Abierta de Cataluña \\
& Universidad Pompeu Fabra \\
& Universidad Pública de Navarra \\
& Universidad del País Vasco \\
& Universidad de Santiago de Compostela \\
Universidad de Vic- UCC
\end{tabular}

\section{Diseño y procedimiento}

El periodo de tiempo seleccionado para el análisis es desde el 1 de enero de 2020, hasta el 30 de marzo del 2020, es decir, tres meses. Con ello se pretende establecer diferencias entre la fase pre-covid y enseñanza presencial y durante el confinamiento estricto y enseñanza online, y comparando al mismo tiempo este paradigma entre los dos países fronterizos.

El procedimiento fue el siguiente, en primer lugar, con la herramienta Fanpage Karma, se monitorizan las cuentas de Twitter, obteniéndose los 5.000 mejores tweets y los KPIs de las cuentas de la muestra objeto de estudio. Tras ello, se lleva a cabo un análisis mediante Meaning Cloud, que se realiza mediante reconocimiento de algoritmo para estudiar la polaridad de los tweets emitidos. El estudio de las emociones se deriva de la rueda de Robert Plutchik (2001). 
Figura 1. Procedimiento abordado para el análisis. Fuente: Elaboración propia.

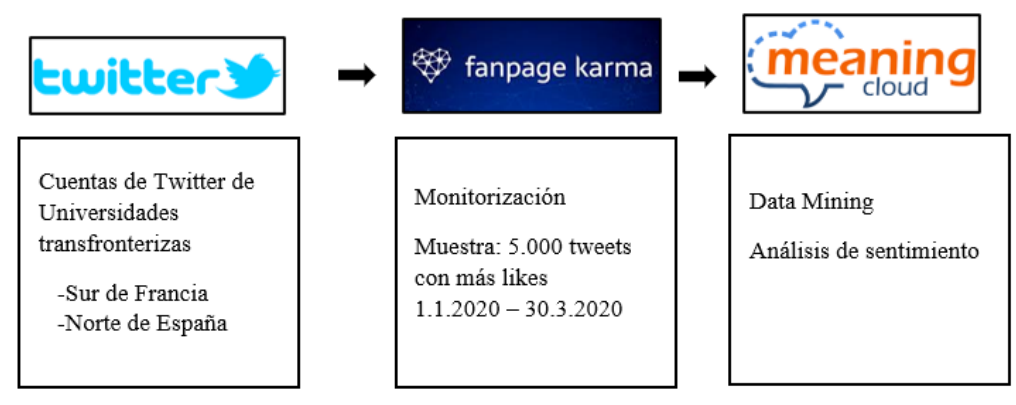

De la Figura 1 se extrae la manera en la que se ha procedido para la realización del análisis objeto de estudio, de manera ordenada y con las tres principales herramientas utilizadas.

\subsection{Instrumentos y variables}

Con objeto de realizar el análisis de los datos se utilizaron los siguientes instrumentos que se describen a continuación.

a. FanPage Karma, instrumento de análisis con la que se pueden estudiar las actividades de las redes sociales. Se estudian los siguientes KPIs:

- Número de seguidores (fans).

- Número de publicaciones.

- Número de me gusta.

- Compromiso.

- Crecimiento de seguidores media semanal.

- Índice de rendimiento de la página.

- Interacción de las publicaciones (número de interacciones dividido por el número de impresiones).

- Total de reacciones, comentarios, compartidos.

- Tweets al día.

b. Flourish, utilizada con objeto de fomentar una mejor visualización de los resultados obtenidos mediante figuras.

c. Meaning Cloud, en concreto su paquete analítico Emotion Recognition. Se trata de un software de análisis de sentimiento por algoritmo empleado para profundizar en las 
expresiones emocionales presentadas. Se analizaron las variables: polaridad, emotividad, subjetividad, ironía y emociones según rueda de Plutchik (2001). Éstas se aplicaron sobre los posts más significativos de las cuentas seleccionadas, de acuerdo con sus KPIs.

Figura 2: Gráfico de dispersión de los KPIs Número de me gusta y Total de reacciones. Fuente: Elaboración propia a través de los datos obtenidos en Fanpage Karma.

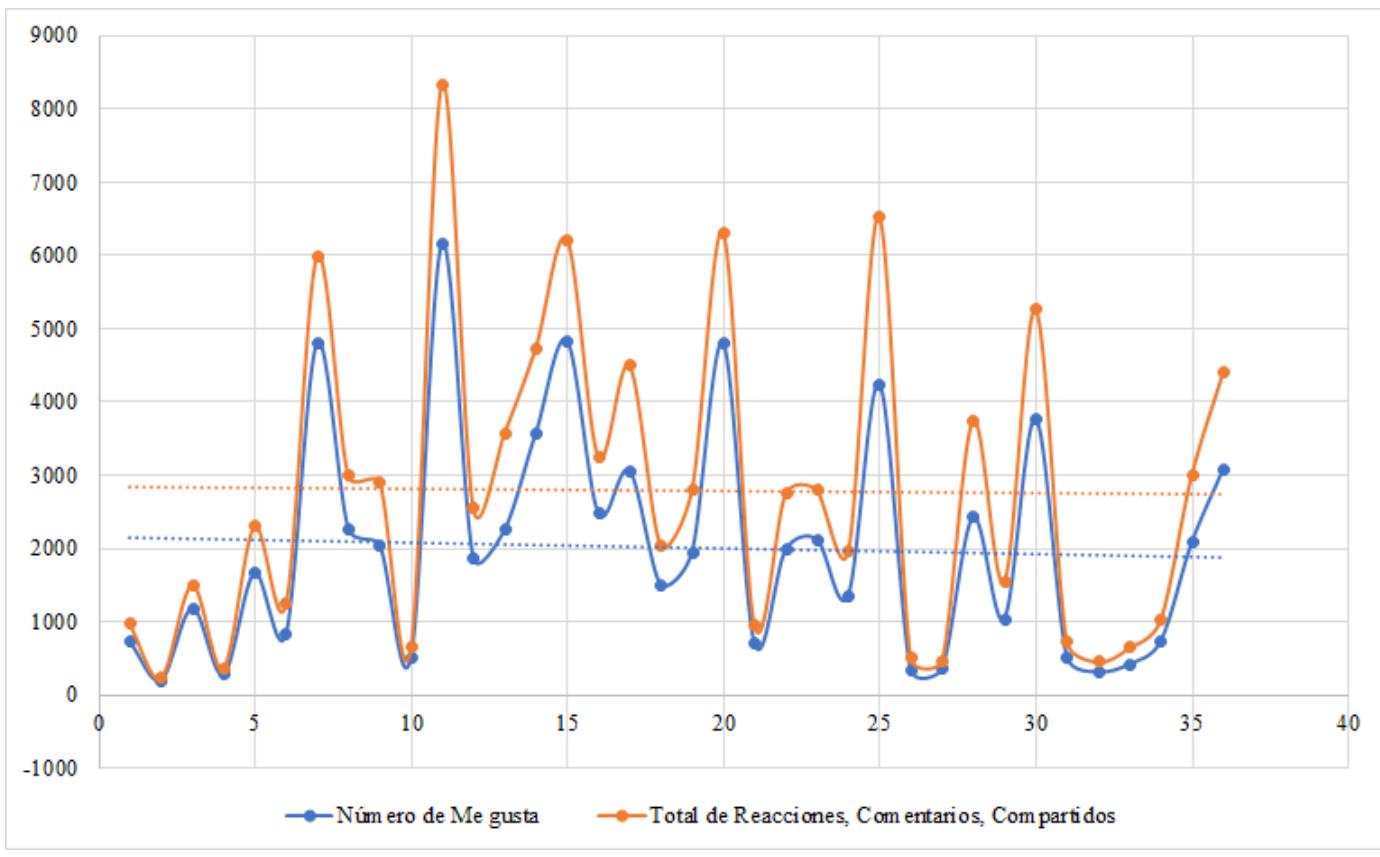

En la Figura 2 y con el objetivo de ver que la tendencia de los KPIs de número de me gusta y total de reacciones es muy parecida, teniendo una dispersión en la misma dirección y donde el número de me gusta es acumulativo dentro del total de reacciones. También pueden verse con líneas de puntos las líneas de tendencia de ambos KPIs, siendo superior, como es lógico el total de reacciones. El ranking de las cuentas de las universidades con mayor número de me gusta y de reacciones son: Universidad de Zaragoza con 8336 reacciones y 6161 me gustas, Aix-Marseille Université con 6525 reacciones y 4245 "me gustas" y Universidad Pompeu Fabra con 6305 reacciones y 4798 "me gustas". 


\section{Resultados}

\section{Análisis de KPIs}

En el presente subapartado se procede a la muestra de los KPIs obtenidos una vez analizada la muestra de estudio de las 36 universidades.

En primer lugar, se analiza el total de la interacción de las publicaciones de las respectivas cuentas de Twitter y se obtiene que las universidades que tienen una mayor interacción en sus cuentas cada vez que comparten su contenido son las siguientes: Université Perpignan, Université Côte d’Azur, Université de Nîmes, Université de Montpellier, Aix-Marseille Université, Université Toulouse- Jean Jaurès. Por lo tanto, las 6 universidades con una mayor interacción de sus publicaciones con una notable diferencia respecto al resto son francesas. En el otro extremo se encuentran las universidades españolas, ya que son las cuentas con una menor interacción, siendo estas de menor a mayor: Universidad de La Rioja, Universidad Abierta de Cataluña, Universidad de Girona y Universidad de Vigo.

Figura 3. Análisis de KPI de interacción de las publicaciones del total de las cuentas de Twitter de las universidades. Fuente: Elaboración propia a partir de Flourish.

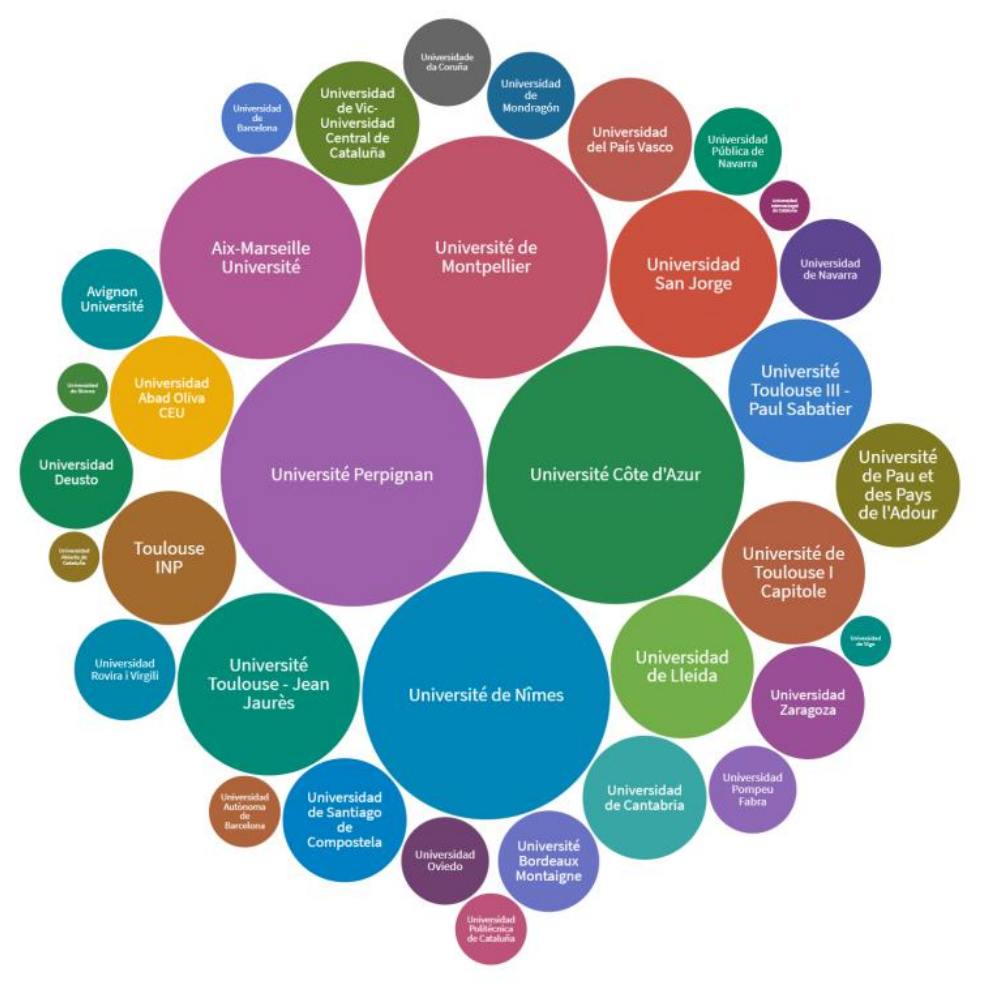


En segundo lugar, se realiza una comparación de dos KPIs fundamentales: el índice de rendimiento de la cuenta de Twitter y los fans de las misma, ya que en ocasiones pueden darse casos en los que una cuenta con muchos seguidores o fans no tenga un rendimiento tan alto como se espera, o viceversa. Para llevar a cabo esta comprobación, en la Figura 4 vemos cómo hay universidades con un número escaso de seguidores pero que tienen un índice de rendimiento muy elevado (en orden descendente de índice de rendimiento: Aix-Marseille Université, Université de Montpellier, Université de Toulouse I Capitole y Université Toulouse III- Paul Sabatier). Se observa que esta situación es más común en las universidades francesas, a excepción de la Universidad de Lleida donde también se da esta circunstancia, que es española. Por el contrario, como la Universidad de Autónoma de Barcelona, la Universidad de Girona, la Universidad de Vigo, la Universidad de La Rioja y la Universidad de Navarra tienen un número de seguidores muy superior al índice de rendimiento. Llama la atención la comparación de la Figura 4 con la Figura 2 se puede ver claramente que en esta última la tendencia que siguen los KPIs de número de me gusta y total de reacciones es totalmente similar con una dispersión muy parecida y donde el total de reacciones engloba al número de me gusta. Sin embargo, en la Figura 4 que se encuentra a continuación, no ocurre así, teniendo tendencias totalmente diferentes.

Figura 4. Comparación de KPIs del índice de rendimiento de la página y los fans de las cuentas de la muestra. Fuente: Elaboración propia.

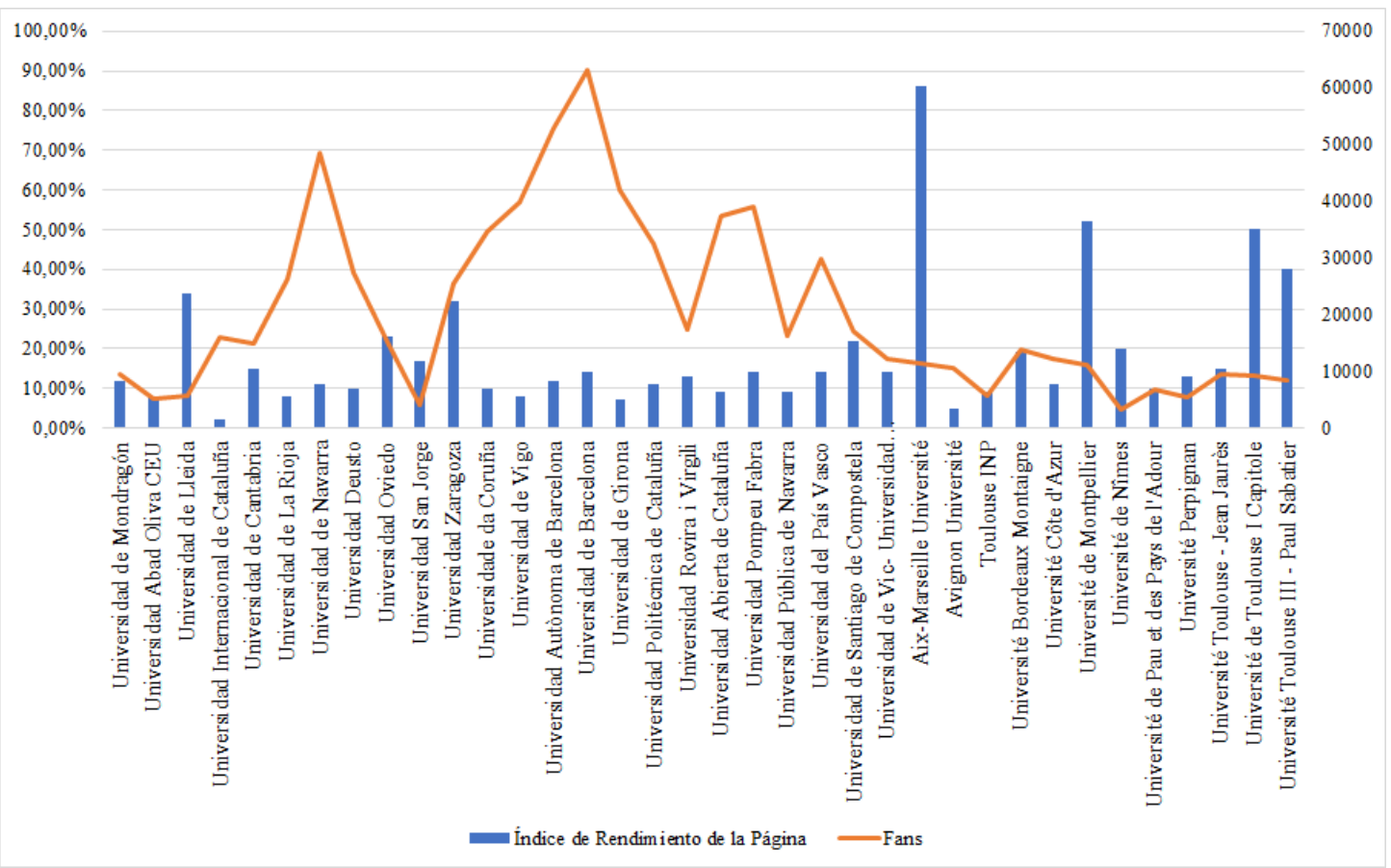


En tercer lugar, se analiza un KPI que es fundamental para analizar el impacto que las cuentas de Twitter de las universidades tienen: el llamado engagement o compromiso. Y se calcula dividiendo la cantidad diaria de retweets y favoritos entre el número de seguidores que tiene la cuenta.

Para ver cuáles son las universidades que gozan de un mayor compromiso se muestra en la Figura 5, donde queda patente cómo las 10 universidades más importantes en este sentido y ordenadas de manera descendente son: Aix-Marseille Université, Universidad de Zaragoza, Université Toulouse III - Paul Sabatier, Université de Montpellier, Universidad de Lleida, Université de Toulouse I Capitole, Universidad Oviedo, Universidad Pompeu Fabra, Universidad de Santiago de Compostela y Universidad de Vic- Universidad Central de Cataluña. Se observa por lo tanto un mayor equilibrio respecto al país de origen de las mismas, habiendo 6 españolas y 4 francesas.

Figura 5. Análisis de KPI del compromiso de las cuentas de Twitter de las universidades. Fuente: Elaboración propia a partir de Flourish.

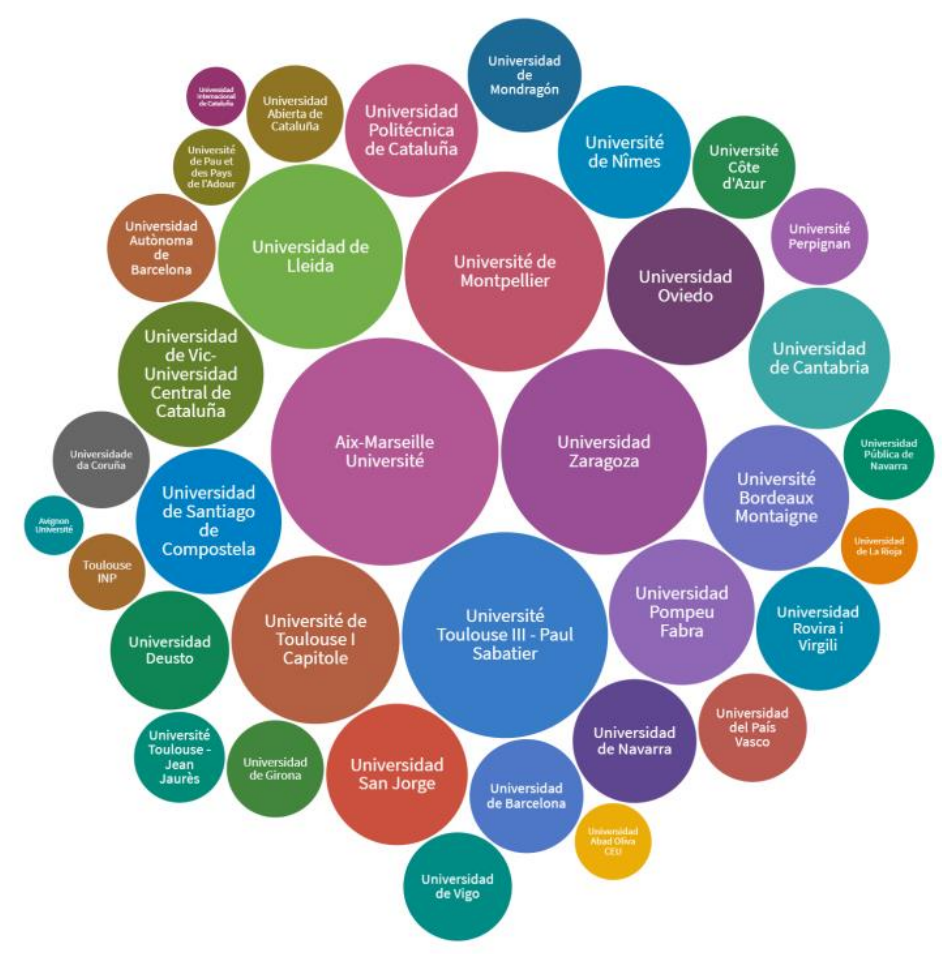




\section{Análisis de polaridad y emociones}

Primero se examina la polaridad de los tweets, esto es de positividad o negatividad de estos mensajes (Hu y Liu, 2004). En la Figura 6 se observa que la polaridad es mayoritariamente positiva, siendo residuales las publicaciones con una connotación negativa. Por ello, queda latente que predomina la positividad en los mensajes de las cuentas corporativas de las universidades en los dos países. Otra cuestión común que queda reflejada es que apenas son significativos los mensajes muy positivos $(\mathrm{P}+)$ ni los muy negativos $(\mathrm{N}+)$. Sin embargo, abundan los mensajes que no tienen polaridad (NONE).

Figura 6. Polaridad presentada en la muestra total. Fuente: Elaboración propia a partir de los datos obtenidos en Meaning Cloud.

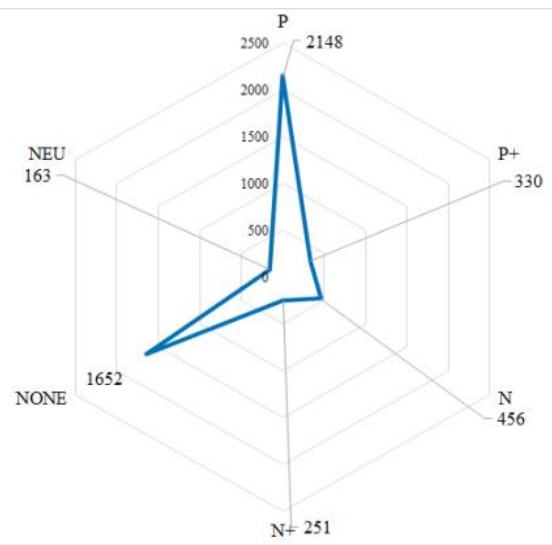

Tras analizarse a nivel general, se analiza también para cada uno de los países del estudio, para así poder observar diferencias entre los mismos:

Figura 7. Polaridad francesa. Fuente: Elaboración propia a partir de los datos obtenidos en Meaning Cloud.

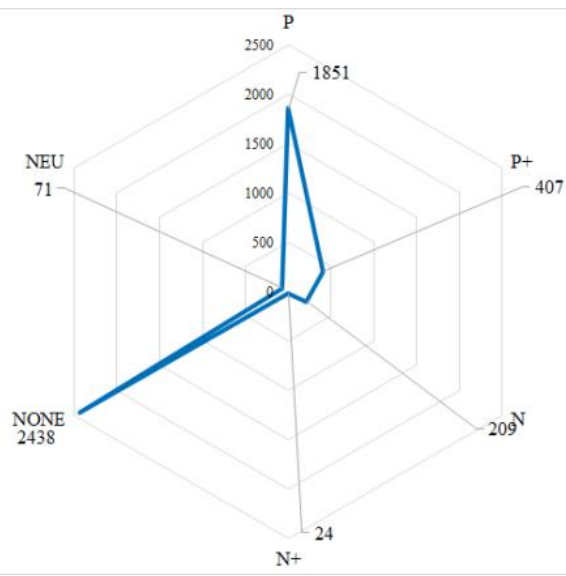


En la comparación a nivel transfronterizo, que puede verse en las Figuras 7 y 8, se denota un mayor número de mensajes negativos $(\mathrm{N})$ en las cuentas españolas con 446 frente a 209 que poseen las francesas. No obstante, son mayores los mensajes positivos (P) aunque en menor proporción, con 1949 frente a los 1851 de las universidades francesas. Otra cuestión a tener en cuenta es que el modelo español es el que más se asemeja a la polaridad presentada en el total de la muestra presente en la Figura 6. Para finalizar quedan patentes las diferencias en el modo de comunicación de las instituciones universitarias a nivel transfronterizo, siendo más positivo Francia y más neutral España.

Figura 8. Polaridad española. Fuente: Elaboración propia a partir de los datos obtenidos en Meaning Cloud.

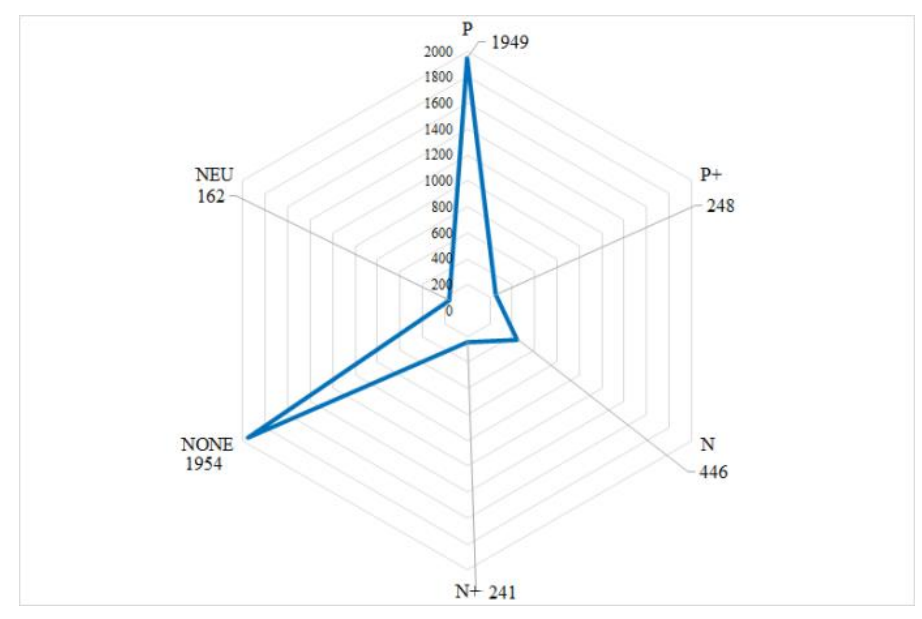

Tras analizar la polaridad a nivel general y diferenciada por países, se procede al examen de las emociones encontradas en los tweets de las universidades y mostrada en la Figura 9.

Figura 9. Emociones de los mensajes. Fuente: Elaboración propia a partir de los datos obtenidos en Meaning Cloud.

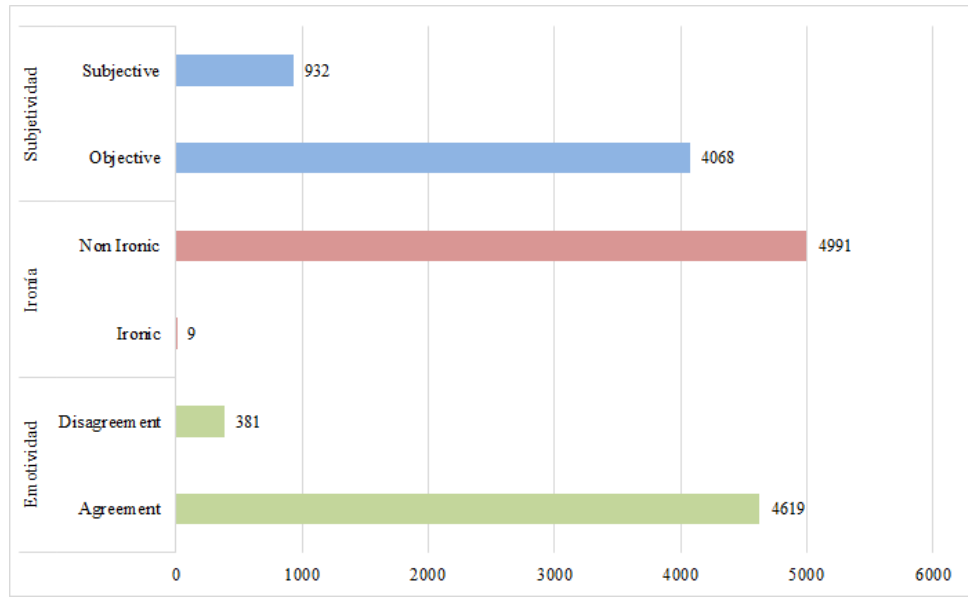


Tras analizar los datos obtenidos puede decirse que la mayoría de los mensajes emitidos por las universidades son objetivos, no irónicos y mostrar acuerdo con 4068, 4991 y 4619 respectivamente sobre 5.000 tweets analizados, lo que significa que de media el $91,19 \%$ de los mensajes de estas cuentas de Twitter son de tal manera. Con lo cual, tras la obtención de los resultados de polaridad en primer lugar y seguidamente de emociones puede formularse la siguiente afirmación, y es que estas instituciones tienen preferencia por comunicarse con menor carga emocional. Esta situación se da de manera general para toda la muestra estudiada, pero si se analizan en función del país de origen se pueden encontrar algunas diferencias. Destaca que existe una mayor subjetividad y desacuerdo en España, lo cual podría relacionarse con la mayor neutralidad de sus mensajes antes mencionada en lo referente a la polaridad.

En cuanto al análisis de la intencionalidad educativa según el modelo ECCD basado en una intencionalidad de tipo: educativo, cooperativo, corporativo o divulgativo (Ferrer-Serrano, Latorre-Martínez y Lozano-Blasco, 2020), se observan importantes diferencias entre ambas fases, mostrando una intencionalidad dispar entre antes de la pandemia (01-01-2020 al 14-03-2020) a después de la irrupción de la pandemia (15-03-2020 al 30-05-2020). De este modo antes de declararse la pandemia encontramos cómo los mensajes tenían una finalidad corporativa y divulgativa, en la que la universidad presenta sus logros. Sin embargo, cuando se inicia la pandemia, la universidad cobra un sentido más profundo en el cual sus mensajes están más orientados a contenidos de tipo educativo (formas de mantener la evaluación, becas para acceso a internet y a ordenadores, apoyo socio-emocional al estudiante) y de tipo cooperativo, en el cual la universidad como organización social muestra su apoyo en la lucha contra el Covid-19.

Figura 10. Intencionalidad comunicativa según el modelo ECCD. Fuente: Elaboración propia.

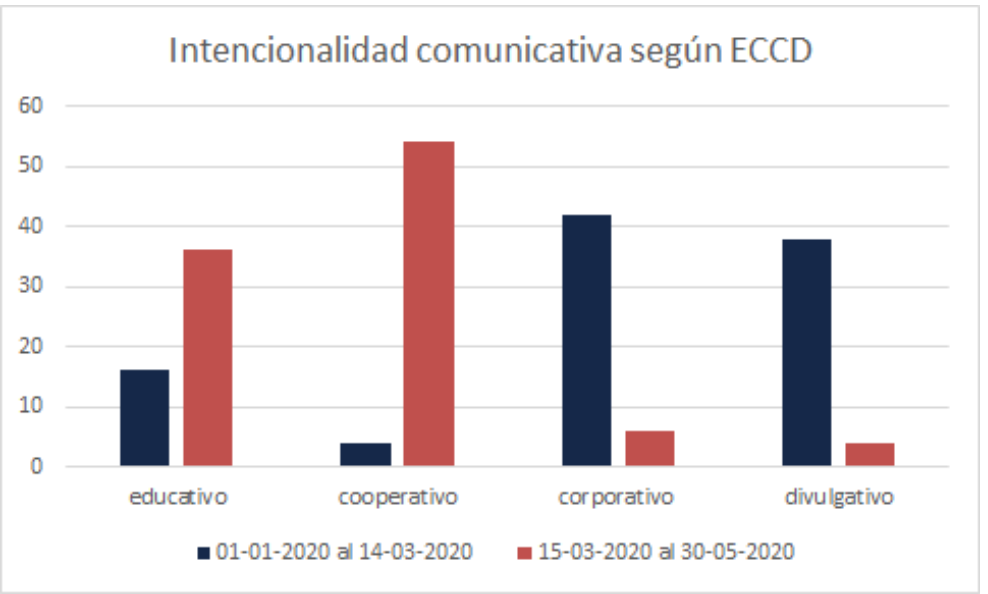




\section{Discusión y conclusiones}

La comunicación en las redes sociales de las universidades españolas y francesas muestra no solo una gran generación de datos (Katz y González, 2016) sino un nuevo ecosistema en el que las instituciones académicas se comunican con su comunidad de forma que ejecutan una estrategia comunicativa encaminada a generar seguridad y confianza, tal y como muestran los datos del estudio siendo coincidentes con investigaciones previas como González-Bailón y Wang, (2016) y Kim y Hastak (2018). Esta visión es coherente a los datos encontrados, en los cuales observamos cómo los Kpi muestran un crecimiento continuo, mejorando su capacidad de atraer a seguidores a la vez que mantienen el contacto estrecho. Al igual que los influencers, las cuentas corporativas de las universidades logran establecer una comunicación efectiva mediante el uso de mensajes con elevada carga positiva a la vez que logran transmitir información de manera descriptiva y clara, al igual que ocurre en investigaciones previas como Trainor, Andzulis, Rapp y Agnihotri, (2014). De esta forma, logran los niveles de interacción y respuesta expresados en los diferentes Kpi. No obstante, no se debe obviar cómo la universidad es un ente social con responsabilidad, en consecuencia, es lógico encontrar diferencias entre las fases pre-pandemia y pandemia, estando de acuerdo con estudios previos (Ferrer-Serrano, Latorre-Martínez y Lozano-Blasco, 2020). En este sentido, se encuentra cómo las emociones positivas y la expresión de tipo realista son permanentes en las estrategias de comunicación, sin embargo, la intencionalidad del mensaje cambia. Ante una situación habitual, la universidad presenta más interés por mostrar mensajes cargados de información de tipo corporativo en el cual se hace presencia de los logros de la institución, también le dan importancia a la divulgación, cumpliendo con su función de transferencia a la sociedad. Si bien, cuando se inicia un estado de crisis humanitaria, la universidad se vuelca en apoyar a sus estudiantes y a dar una visión cooperativa, basada en el humanismo, la empatía hacia la sociedad, mostrando un compromiso social. Se concluye cómo las universidades del norte de España y del sur de Francia realizan estrategias comunicativas de tipo social que buscan generar empatía en su comunidad, a la vez que ante una situación de emergencia social se muestran empáticas y humanas, dejando de lado visiones más estratégicas y corporativas. 


\section{Referencias}

Ceron, A., Curini, L., Iacus, S.M., y Porro, G. (2014). Every tweet counts? How sentiment analysis of social media can improve our knowledge of citizens' political preferences with an application to Italy and France. New media and society, 16 (2), 340-358. https://doi.org/10.1177/1461444813480466

Ferrer-Serrano, M., Latorre-Martínez, M.P., y Lozano-Blasco, R. (2020). Universidades y comunicación. Papel de Twitter durante el inicio de la crisis sanitaria de la Covid-19. Profesional de la información, 29 (6), e290612. https://doi.org/10.3145/epi.2020.nov.12

González-Bailón, S., y Wang, N. (2016). Networked discontent: The anatomy of protest campaigns in social media. Social networks, 44, 95-104. https://doi.org/10.1016/j.socnet.2015.07.003

Hu, M., y Liu, B. (2004). Mining and summarizing customer reviews. Proceedings of the 10th ACM Sigkdd International conference on knowledge discovery and data mining, 168-177. https://doi.org/10.1145/1014052.1014073

Katz, V.S., y González, C. (2016). Toward meaningful connectivity: Using multilevel communication research to reframe digital inequality. Journal of communication, 66 (2), 236-249. https://doi.org/10.1111/jcom.12214

Kim, J., y Hastak, M. (2018). Social network analysis: Characteristics of online social networks after a disaster. International journal of information management, 38 (1), 86-96. https://doi.org/10.1016/j.ijinfomgt.2017.08.003

Ruz, G. A., Henríquez, P. A., y Mascareño, A. (2020). Sentiment analysis of Twitter data during critical events through Bayesian networks classifiers. Future generation computer systems, 106, 92-104. https://doi.org/10.1016/j.future.2020.01.005

Trainor, K.J., Andzulis, J. M., Rapp, A., y Agnihotri, R. (2014). Social media technology usage and customer relationship performance: A capabilities-based examination of social CRM. 
Journal of business research, $67 \quad$ (6), 1201-1208. https://doi.org/10.1016/j.jbusres.2013.05.002

Plutchik, R. (2001). The Nature of Emotions: Human emotions have deep evolutionary roots, a fact that may explain their complexity and provide tools for clinical practice. American Scientist, 89 (4), 344-350. https://doi.org/10.1511/2001.4.344

Yu, Y., Duan, W., y Cao, Q. (2013). The impact of social and conventional media on firm equity value: A sentiment analysis approach. Decision support systems, 55 (4), 919-926. https://doi.org/10.1016/j.dss.2012.12.028 


\title{
Educación de adultos de las personas con síndrome de Down o con otras discapacidades intelectuales en entornos inclusivos
}

\author{
Elías Vived Conte \\ Jorge Arbués Salazar \\ Asociación Down y Universidad de Zaragoza
}

Palabras clave: educación inclusiva; síndrome de Down; educación de adultos; inclusión social

\section{Introducción}

Este proyecto se ubica en el ámbito de la educación de personas adultas con síndrome de Down o con otras discapacidades intelectuales (SD/DI) en escenarios inclusivos y en el medio rural, y se desarrolla dentro de la convocatoria Erasmus+ (experiencias innovadoras). La finalidad del proyecto consiste en impulsar, innovar e indagar acciones formativas en el medio rural que permitan a las personas adultas con SD/DI la posibilidad de adquirir, actualizar, o ampliar sus competencias para su desarrollo personal, social y profesional en contextos inclusivos de enseñanza y aprendizaje. Un contexto formativo prioritario son los Centros de Educación de Adultos, con los que colaboran las Asociaciones participantes en este proyecto y los Ayuntamientos de las localidades respectivas, para desarrollar talleres y cursos formativos y acciones de proyección y divulgación de los resultados y productos obtenidos en dichos talleres.

Las entidades que forman este proyecto Erasmus+ son: Asociación Down Huesca (España), Association Trisomie 21 Pyrénées-Atlantiques (Francia), "Primavera" Società Cooperativa Sociale (Italia) y la Asociación Las Cañas de Alcañiz (España).

El grupo objetivo fundamental de este proyecto lo constituyen las personas con síndrome de Down o con otras discapacidades intelectuales. Pero también hay otros grupos a los que se dirigen algunas de las acciones planteadas en el proyecto: educadores (profesores de los centros 
de educación de adultos y profesionales de las asociaciones) y familiares; contextos de aprendizaje inclusivos, fundamentalmente, los centros de educación de adultos en el medio rural; administraciones educativas; sociedad en general. Muchas de las acciones de proyección (recitales, exposiciones, charlas, etc.) van dirigidas a toda la sociedad, al objeto de colaborar y contribuir a una mayor sensibilización de la sociedad hacia la diversidad.

La investigación se refleja en la indagación continua en nuevos modelos de formación de personas adultas en escenarios inclusivos, con metodologías activas de investigación-acción, que nos hace reflexionar en todo el proceso y cambiar la práctica pedagógica en relación a lo que observemos y registremos. También en el cambio de mirada hacia la educación, no solo poner la importancia en el contenido, sino en cómo aprendemos (conjuntamente, con unas relaciones estrechas entre los diferentes participantes) y como enseñamos.

El carácter innovador también se manifiesta en la definición, el diseño y el desarrollo de cursos, talleres formativos, programas, etc., vinculados a la formación permanente de adultos con $\mathrm{SD} / \mathrm{DI}$, centrados en nuevos conceptos y visiones sobre la discapacidad intelectual y en enfoques metodológicos de gran potencia pedagógica, que responden a sus necesidades formativas actuales. Estos enfoques metodológicos son los siguientes: aprendizaje cooperativo, aprendizaje basado en proyectos, modelo de apoyos, enfoque didáctico mediacional y aprendizaje servicio.

La inclusión es el resultado de la transferencia de los talleres de las entidades a los centros de educación de adultos de cada localidad. Se realizarán esos mismos talleres para personas con y sin discapacidad, donde todos puedan compartir un espacio, participar y aprender juntos.

\section{Objetivos}

El objetivo básico de este proyecto es el impulso de acciones formativas en el medio rural que permitan a las personas adultas con SD/DI la posibilidad de adquirir, actualizar, o ampliar sus competencias para su desarrollo personal, social y profesional en contextos inclusivos de enseñanza y aprendizaje.

Entre los objetivos específicos podemos señalar los siguientes: a) promover acciones de diseño y planificación de cursos y/o talleres formativos en contextos inclusivos, b) divulgar la 
experiencia y los productos (intelectuales, didácticos,..) desarrollados; c) promover medidas de colaboración dentro de un contexto de trabajo en red cooperativa; d) promover acciones de formación y coordinación de los apoyos incluidos en la formación; e) Promover acciones de investigación e innovación; f) elaborar los materiales didácticos precisos y g) definir estrategias que permitan transferir la experiencia realizada en otros territorios.

Una de las prioridades que no debemos dejar de citar es apoyar el establecimiento y el acceso a itinerarios de mejora de las capacidades y desarrollar mecanismos para supervisar la eficacia de las políticas de formación de adultos o para controlar y supervisar el progreso de los estudiantes adultos.

\section{Acciones a desarrollar}

\section{Talleres educativos}

Una de las acciones a desarrollar en el proyecto son los talleres realizados en cada entidad por las personas con síndrome de Down o con otras discapacidades intelectuales. A continuación se reflejan las características de uno de ellos, el taller de relatos. Otros que se realizarán son el taller de poesía, el taller de teatro u otros que puedan surgir y se adecuen a las personas y plan formativo de cada territorio.

\section{Objetivos:}

- Desarrollar en los participantes en el taller el interés por los diferentes formatos literarios, especialmente por los relatos.

- Desarrollar competencias de habilidades lectoras y de comprensión lectora.

- Promover una actitud favorable hacia la conversación sobre los relatos y los temas que se abordan en ellos.

- Potenciar la creatividad literaria en jóvenes con síndrome de Down o con otras discapacidades intelectuales (SD/DI), así como su afición para la lectura de relatos y la comprensión de los mismos.

- Contribuir a desarrollar la memorización y otras funciones cognitivas. 
- Potenciar la creatividad de todos los participantes a partir del fomento del sentimiento de competencia.

- Promover el gusto y el uso de los textos de relatos (lectura, escritura, conversación) en el tiempo libre de los participantes, especialmente los relatos escritos por jóvenes con SD/DI y los versionados en lectura fácil.

- Participar en acciones de divulgación y de proyección que se impulsan en el taller (cuentacuentos, elaboración de textos de relatos, talleres colaborativos en centros escolares, etc.), potenciando el compromiso y la motivación de los participantes en el taller.

\section{Contenido:}

El texto que utilizaremos en el taller es un libro de relatos titulado Cómo trato de llevar mi vida, cuyo autor es un joven con síndrome de Down de la Asociación Down Huesca. Este texto va acompañado de un cuaderno de trabajo grupal y un cuaderno de trabajo personal. Asimismo, contamos con un libro de orientaciones didácticas. Estas orientaciones didácticas se proponen a partir de los enfoques metodológicos utilizados en la propuesta pedagógica vinculada a las creaciones literarias de los jóvenes: modelo didáctico mediacional, aprendizaje cooperativo, aprendizaje basado en proyectos, aprendizaje servicio y modelo de apoyos. Estos enfoques metodológicos se han investigado y se siguen investigando en el contexto de las organizaciones vinculadas a Down España (Down España, 2017, 2019; Down Huesca, 2020)

\section{Desarrollo metodológico de las actividades:}

Las orientaciones didácticas que van a guiar la aplicación de los talleres están basadas en los enfoques metodológicos planteados anteriormente. A continuación, se analiza la secuencia didáctica utilizada en el taller de relatos con los diferentes capítulos en los que se estructura el programa.

Para cada uno de los capítulos (o tema, o relato, o unidad didáctica) se proponen una serie de actividades que ordenamos en una secuencia didáctica. Evidentemente será cada profesor quien determine la secuencia concreta para cada grupo de alumnos, que podrá coincidir con la que 
presentamos o modificar en parte, en función de las características del grupo y de los objetivos que persiga.

Las actividades se plantean para trabajar en tres situaciones de aprendizaje: grupo clase, pequeño grupo y situación individual. La mayor parte de las tareas recae en la situación de pequeño grupo.

\section{Actividades con todo el grupo:}

1. Presentación de objetivos y de las actividades que se van a realizar

2. Evaluación de los conocimientos previos

3. Explicación y debate colectivo sobre determinados contenidos vinculados al funcionamiento de los grupos, al aprendizaje cooperativo y al aprendizaje por proyectos.

\section{$\underline{\text { Actividades en grupo colaborativo: }}$}

1. Lectura del texto

2. Valoración y comentarios sobre el capítulo leído

3. Responder a las siguientes preguntas sobre el contenido del relato

4. Resumen

5. Completar las siguientes frases con una o dos palabras

6. Inventar una frase con las siguientes palabras

7. Continuar la frase con otra frase

8. Seguir con el relato

9. Trabajo personal: inventar un relato inspirado en el que has leído

Actividades individuales:

1. Lectura del texto

2. Responde a las siguientes preguntas sobre el contenido del relato

3. Completa las siguientes frases con una o dos palabras

4. Resumen

5. Trata de seguir con el relato 
Actuaciones de divulgación y proyección:

El formato metodológico de los talleres, además de una labor interna de formación, también plantea el desarrollo de acciones de proyección, con una intencionalidad de divulgación y de sensibilización social (a partir de las metodologías del aprendizaje basado en proyectos y del aprendizaje servicio). La participación de los jóvenes con SD en mesas redondas, talleres colaborativos en centros escolares, recitales, etc. son algunas estrategias de difusión y proyección de lo que se aprende y se realiza en los talleres del proyecto ERASMUS+. Estas acciones de proyección dan protagonismo a los jóvenes, y vincula la formación con la participación en la comunidad y la sensibilización social, avanzando en el desarrollo de sociedades más inclusivas.

\section{Resultados intelectuales}

Una de las acciones propuesta en el proyecto es la elaboración de un texto sobre la experiencia desarrollada. Se trata de una Guía de buenas prácticas en Educación de adultos de personas con síndrome de Down o con otras discapacidades intelectuales en entornos inclusivos

Este texto se realizará conjuntamente por las entidades socias del proyecto, y en él se plantearán una revisión de temas prioritarios vinculados a la educación de adultos de personas con discapacidad intelectual en contextos inclusivos: Universidades y centros de educación de adultos como contextos de aprendizaje, antecedentes, objetivos y planteamientos generales de nuestra propuesta, marcos conceptuales, marco normativo, enfoques metodológicos, talleres educativos, acciones de proyección, etc.

Con respecto a los marcos conceptuales se detallará la evolución del concepto de discapacidad intelectual, el modelo de apoyos como referente metodológico en discapacidad intelectual, el concepto de calidad de vida, autodeterminación y autonomía personal, la accesibilidad y adaptación de los contextos, la vida independiente como referente y el modelo social de la discapacidad. Estos contextos conceptuales suponen un cambio de visión ante el modelo de déficit o clínico. En esta visión, las características de la persona con discapacidad no son el foco en el que nos tenemos que centrar, sino que es el contexto el que condiciona la actuación de cualquier persona y por ello nos centramos en las oportunidades y apoyos que debemos definir, orientar e impulsar. 


\section{Encuentro transnacional sobre educación de adultos de personas con síndrome de Down o} con otras discapacidades intelectuales

En este encuentro en el Albergue la Sabina de la Asociación Down Huesca - Fonz (Huesca), participarán 9 adultos con síndrome de Down o con otras discapacidades intelectuales de cada territorio, con 3 acompañantes de apoyo.

Los objetivos son los siguientes:

- Facilitar oportunidades de convivencia y comunicación entre personas con síndrome de Down o con otras discapacidades intelectuales que experimentan situaciones similares en distintos países.

- Fomentar la autonomía personal y la independencia y promover la participación activa de las personas con discapacidad intelectual, mediante intercambios y actividades no formales, reforzando su condición de ciudadanos europeos.

- Desarrollar enfoques innovadores de aprendizaje con el fin de fomentar la inclusión de las personas con síndrome de Down o con otras discapacidades intelectuales en escenarios de educación permanente.

- Intercambiar ideas y experiencias que permitan el enriquecimiento personal (de las personas con discapacidad, sus familiares y sus educadores) y organizativo.

- Conocer otras realidades socioculturales y otras organizaciones que desarrollan su actividad con personas con discapacidad intelectual.

- Promover situaciones y experiencias con los participantes del programa que contribuyan a su desarrollo como ciudadanos activos en procesos de inclusión social.

- Dar visibilidad y sensibilizar sobre la situación de los derechos de las personas con discapacidad intelectual al resto de ciudadanos y a las Administraciones Públicas, así como sobre los proyectos de vida independiente, la autodeterminación y los proyectos más innovadores e inclusivos que actualmente se están desarrollando con estas personas

- Promover los valores fundamentales de la UE, en especial el respeto de la dignidad humana, la igualdad, los derechos humanos, la tolerancia y la no discriminación.

Seminario de educación de adultos de las personas con síndrome de Down o con otras discapacidades intelectuales: innovación, investigación e inclusión 
Dentro de las acciones que se desarrollan en el proyecto ERASMUS + están los eventos multiplicadores; en este proyecto se expuso la organización de seminarios de proyección y divulgación. Este seminario de innovación, investigación e inclusión quiere ser el primer seminario organizado en este ámbito de actuación. Será realizado en Fonz (Centro Cultural y Albergue La Sabina)

Este seminario se plantea como una propuesta de multiplicación de efectos, como una reflexión desde las prácticas innovadoras y como un lugar para debatir las aportaciones de la investigación. Pero sobre todo, este seminario quiere ser un lugar de encuentro de todos los agentes implicados en la educación adultos de las personas con síndrome de Down o con otras discapacidades intelectuales: las propias personas, sus familiares, los profesores de los centros de educación de adultos, los profesionales de las asociaciones y los investigadores. Cada colectivo dispondrá de un tiempo para exponer sus preocupaciones, sus anhelos y sus perspectivas. Cada mesa redonda contará con cuatro participantes.

En definitiva, lo que pretende este seminario es promover la innovación e indagar prácticas y estrategias nuevas para responder a las necesidades de las personas con síndrome de Down o con otra discapacidad intelectual en la etapa adulta, grupo con el que pretendemos incrementar sus oportunidades formativas y plantear estrategias que reduzcan la tendencia a la despoblación del medio rural.

\section{Objetivos:}

1. Analizar la situación actual de la educación de adultos de las personas con síndrome de Down o con otras discapacidades intelectuales (SD/DI).

2. Impulsar un encuentro de debate y reflexión en torno a la educación de adultos, que integre a todos los agentes implicados: personas con SD/DI, familiares, profesionales de las asociaciones, profesores de centros de educación de adultos e investigadores.

3. Promover medidas y estrategias de innovación vinculadas a la educación adultos.

4. Promover medidas y estrategias de investigación vinculadas a la educación de adultos.

5. Crear una red de cooperación para impulsar la innovación, la investigación y la inclusión en la educación de adultos, dentro del contexto europeo. 
6. Fomentar una cultura colaborativa entre personas y entidades que participen en el diseño y desarrollo de procesos educación de adultos en entornos inclusivos.

\section{Asociación europea de apoyo a la innovación en la educación de adultos con síndrome de Down o con otras discapacidades intelectuales}

Las organizaciones que inicialmente impulsan la creación de la Asociación Europea de apoyo a la innovación en la educación de adultos de personas con síndrome de Down o con otras discapacidades intelectuales son las que participan en el proyecto ERASMUS +. Ahora bien, se pretende seguir construyendo dicha asociación con organizaciones de otros países, para dar cumplida respuesta al objetivo principal del proyecto, que consiste en el desarrollo de la innovación en educación de adultos para personas con síndrome de Down o con otras discapacidades intelectuales (SD/DI) en escenarios inclusivos.

Una de las acciones programadas en el proyecto es la creación de una Asociación Estratégica de apoyo a la innovación en materia de educación de adultos para personas con SD/DI en el medio rural.

Para el desarrollo del proyecto ERASMUS + se ha configurado, por tanto, una red de apoyo en cada territorio y una Asociación Estratégica entre organizaciones pertenecientes a distintos países, para facilitar la presencia y la participación de las personas con SD/DI en la educación de adultos, en contextos educativos inclusivos. Se trata de redes colaborativas para fomentar la innovación, la inclusión y la investigación en materia de educación de adultos para personas con SD/DI.

Estas redes colaborativas (Asociación Estratégica y red interna de apoyo) pretenden el desarrollo de sistemas y productos innovadores en materia de educación de adultos para personas con SD/DI. Esta diversificación de los socios permitirá beneficiarse de diferentes experiencias y conocimientos especializados y obtener resultados pertinentes y de gran calidad.

Los objetivos de la Asociación Estratégica son los siguientes:

- Apoyar el desarrollo de prácticas y experiencias innovadoras en torno a la educación de adultos para las personas con SD/DI en contextos inclusivos. 
- Apoyar la ejecución de iniciativas conjuntas y en cooperación de los diferentes socios de la red de apoyo.

- Promover acciones formativas conjuntas para los adultos con SD/DI, en el contexto de la autodeterminación de las personas y de los proyectos de vida independiente, del marco educativo de la CDPD y de las nuevas visiones sobre la discapacidad intelectual.

- Plantear propuestas pedagógicas fundamentadas en enfoques didácticos contrastados y experimentados con personas con SD/DI: aprendizaje colaborativo, enfoque didáctico mediacional, aprendizaje basado en proyectos, modelo de apoyo, aprendizaje servicio

- Promover acciones formativas para los apoyos profesionales (profesores de los centros de educación de adultos, profesionales vinculados a las distintas organizaciones de discapacidad) y los apoyos naturales (familiares, voluntarios, estudiantes en prácticas, etc.) en el contexto de la educación de adultos.

- Colaborar en las acciones de investigación en materia de educación de adultos.

- Fomentar el intercambio de experiencias y conocimientos entre los socios colaboradores y participantes en el proyecto ERASMUS +.

- Fomentar la divulgación y difusión de las experiencias desarrolladas y de los productos elaborados en los talleres educativos a través de acciones de proyección a la comunidad, colaborando en estrategias de sensibilización social hacia la inclusión y la diversidad.

\section{Conclusiones}

Este proyecto va a desarrollarse durante todo el año 2021 y pretende continuar en años sucesivos tratando de desplegar a lo largo del itinerario políticas, culturas y prácticas inclusivas en educación de adultos de personas con síndrome de SD/DI en contextos inclusivos.

Con este proyecto pretendemos adquirir experiencia y conocimientos que posibiliten la vinculación del aprendizaje a lo largo de la vida y la educación permanente de las personas adultas con síndrome de Down con escenarios formativos inclusivos, ligando estrategias de enseñanzaaprendizaje con estrategias de inclusión social, su participación social y el desarrollo del rol de adulto. Estos entornos formativos deben crear oportunidades y sistemas de apoyos para el aprendizaje compartido y la convivencia entre estudiantes adultos con y sin discapacidad, en una cultura inclusiva y de reconocimiento de la diversidad. 
La propuesta pedagógica de la educación de adultos en entornos inclusivos está basada en los nuevos marcos conceptuales de la discapacidad, en el marco normativo de la CDPD, en donde hay que recalcar que la educación inclusiva es un derecho a lo largo de toda la vida, en los enfoques metodológicos innovadores, en las acciones de proyección y difusión de resultados y todo ello centrado en el protagonismo de las personas con síndrome de Down o con otras discapacidades intelectuales (SD/DI).

Los términos innovación, investigación e inclusión son referentes de este camino que comenzamos para el desarrollo de una asociación estratégica europea para la educación de adultos personas con síndrome de Down o con otras discapacidades intelectuales en entornos inclusivos.

\section{Referencias}

Down España (2017). Campus oportunidades para la inclusión. Down España y MECD.

Down España (2019). Educación y formación permanente: diversidad e inclusión. Down España y MECD.

Down Huesca (2020). Proyecto Erasmus+: Educación permanente de las personas con síndrome de Down o con otras discapacidades intelectuales: innovación e inclusión en el medio rural. Asociación Down Huesca (proyecto presentado a convocatoria, no publicado). 


\title{
Recursos educativos abiertos en la educación superior: la implementación de software no privativo para una enseñanza inclusiva
}

\author{
Javier Rodríguez Árbol \\ María Eva Martín-Puga \\ Universidad de Jaén
}

Palabras clave: JASP; LIBRE Office; alternativa SPSS.

\section{Introducción}

El desarrollo en los últimos años de los equipos informáticos y de comunicación digital, la posibilidad de acceso a internet desde los domicilios particulares, así como la adquisición masiva de dispositivos personales por parte de la población, ha facilitado el rápido crecimiento y expansión de la educación a distancia. La situación provocada por la pandemia de COVID-19, sin embargo, ha convertido en la única modalidad posible lo que hasta entonces era una opción, por lo menos mientras duren las restricciones y medidas de seguridad sanitarias. Aunque la amplia disponibilidad de tecnologías ejecutables en dispositivos domésticos ha facilitado el desarrollo de la docencia en remoto, también ha puesto en evidencia las desigualdades en oportunidades educativas que conlleva la disparidad de recursos económicos; señalando, entre otros aspectos, las diferencias individuales en cuanto a posibilidad de acceso a las herramientas informáticas y a una conexión a internet de calidad, fundamentales para el correcto seguimiento del curso académico en formato telemático.

Una de las cuestiones más salientes con respecto a este asunto ha sido la brecha digital que se abre en el estudiantado cuando no pueden acceder a las instalaciones y recursos físicos de sus respectivas universidades, lo que a su vez resalta la función de reducción de desigualdades estructurales que cumplen la enseñanza presencial y las instalaciones de las universidades públicas. 
En este apartado se pueden incluir las salas de estudio que proporcionan condiciones ambientales adecuadas para la actividad intelectual, el libre acceso a material de consulta que ofrecen las bibliotecas de las universidades (incluyendo las suscripciones a revistas y bases de datos digitales), el acceso a la red de internet de alta velocidad de los campus o, en el caso que vamos a desarrollar en el presente texto, el acceso a equipos informáticos con software privativo o de licencia restrictiva.

El término software privativo hace referencia a aquellos programas informáticos desarrollados por empresas privadas que requieren del pago de una suscripción por parte del usuario para poder ejecutarlo. Es una práctica habitual el que las universidades adquieran una número importante de licencias en suscripción de determinados programas para su instalación en los equipos utilizados en sus instalaciones docentes, lo que conlleva una inversión económica considerable, pero que garantiza poder usar dichos recursos en la formación del estudiantado. Este es el caso de IBM SPSS, uno de los programas de análisis estadístico más extendidos en el ámbito académico (Okagbue, Oguntunde, Obasi, \& Akhmetshin, 2021). Inicialmente conocido como Statistical Package for the Social Sciences, este programa incluye una serie de módulos estadísticos que permiten realizar los análisis más habituales en ciencias sociales y de la salud. La interfaz de usuario está basada en menús contextuales y no requiere conocimientos de programación para construir los modelos de análisis y ejecutarlos. Quizás por estas características de accesibilidad, el software SPSS se ha considerado tradicionalmente la opción de referencia para la parte práctica de las asignaturas de estadística en los currículos de distintos grados, como es el caso del Grado en Psicología de la Universidad de Jaén. Sin embargo, a pesar de las mencionadas ventajas, este paquete estadístico lleva aparejado un importante coste económico por su característica de software privativo. Por ejemplo, en abril de 2021 el precio de una suscripción personal de IBM SPSS ascendía a 95.53€ por mes (IBM, 2021) y, aunque la empresa ofrece suscripciones tipo campus (la posibilidad de contratar por curso académico un número determinado y relativamente elevado de suscripciones para ser instaladas y ejecutadas únicamente desde las instalaciones de la institución educativa superior que contrate dicha licencia) y descuentos para estudiantes universitarios, la adquisición de una licencia particular para la utilización del programa continúa suponiendo una inversión significativa de recursos económicos. 
Como se puede ver, la utilización de software privativo de suscripción en la enseñanza superior implica ciertas restricciones y dificultades de acceso, establece una barrera económica para su uso y, aunque las universidades públicas tienen en cuenta en sus políticas de gestión la importancia de facilitar al alumnado igualdad de oportunidades para la utilización de dicho software, lo hacen asumiendo una importante inversión de recursos económicos y técnicos. El hecho de que las instituciones de educación superior asuman este coste no debería atenuar la responsabilidad de la Comunidad Universitaria, especialmente del Personal Docente e Investigador (PDI), en buscar alternativas que impliquen menos restricciones y que favorezcan la equidad, siempre que no comprometan la calidad de la experiencia de aprendizaje.

El debate sobre la importancia de facilitar la accesibilidad de los recursos educativos para reducir la desigualdad de oportunidades que imponen las diferencias económicas no es nuevo, pero tradicionalmente se ha centrado en analizar e intentar solventar las diferencias en oportunidades educativas que se observaban en los países en vías de desarrollo en comparación con aquellas zonas geográficas económicamente más desarrolladas (UNESCO, 2002). Sin embargo, las circunstancias derivadas de las restricciones por la pandemia COVID-19 han puesto también de manifiesto las desigualdades existentes dentro de las zonas geográficas consideradas más desarrolladas económicamente y las diferencias individuales que se observan entre el estudiantado en cuanto a disponibilidad de recursos particulares que facilitan el seguimiento de la educación a distancia cuando no se pueden hacer uso de los recursos que proporcionan las instalaciones universitarias. Esta situación, con la llamada a la reflexión que implica, puede potenciar la expansión de una línea de acción derivada del mencionado debate y que va tomando cada vez más fuerza: la corriente internacional que aboga por el desarrollo de Recursos Educativos Abiertos (REA) u Open Educational Resources (OER), en inglés. Aunque existen diversas definiciones de REA, quizás una de las más completas sea la de Atkins, Brown y Hammond (2007):

Recursos para la enseñanza, el aprendizaje y la investigación que son de dominio público o que han sido publicados bajo licencias de propiedad intelectual que permiten su libre uso y reutilización por terceros. Este concepto incluye desde cursos completos a material audiovisual de apoyo a la docencia, libros de texto, videos educativos, cuestionarios, software libre y de código abierto y cualquier otra herramienta, material o técnica usadas para facilitar el acceso al conocimiento. (p. 4) 
Las posibilidades que ofrecen los medios digitales en la reproducción de contenido y la consecuente reducción de la inversión necesaria para su distribución facilita que algunos autores remarquen el formato digital que caracteriza a los REA (p.e. Hylen \& Schuller, 2007). Sin embargo, más allá de identificar los productos intelectuales o ítems derivados que ya se han especificado, y debido al hondo calado social que tiene la propuesta, el concepto de REA implica también en lo más amplio de su significado una postura ética y de compromiso social, una forma de entender la educación y el derecho de acceso a la misma, por lo que algunos autores proponen hacer referencia también a prácticas educativas abiertas (Murphy, 2013) y no exclusivamente a recursos. El énfasis en el concepto de prácticas generalizadas tiene, entre otros, el objetivo de involucrar a las instituciones educativas, trascendiendo el efecto limitado de las iniciativas individuales, para fomentar el diseño e implementación de políticas que favorezcan la inclusión de REA en los programas de estudios oficiales, así como conseguir el compromiso de la Comunidad Universitaria en el desarrollo y difusión de los mismos (Murphy, 2013). Estas iniciativas en busca del compromiso colectivo e institucional son fundamentales para el crecimiento y consolidación de estas prácticas inclusivas; puesto que, aunque las ventajas de esta perspectiva son evidentes tanto en términos económicos como sociales, tampoco hay que pasar por alto las dificultades y obstáculos que pueden surgir en su implementación. El informe publicado en 2011 por la Open Educational Quality Initiative (Andrade et al., 2011) identifica por lo menos cinco barreras con las que se puede encontrar cualquier individuo dispuesto a implementar o desarrollar algún tipo de REA: falta de apoyo institucional, falta de herramientas tecnológicas para compartir y adaptar los recursos generados, falta de tiempo y de conocimiento técnico para desarrollar e implementar los recursos, falta de un sistema normalizado y contrastado que ofrezca información verificada acerca de la calidad de los REA y, por último, factores personales como la desconfianza en todo material educativo que no haya sido desarrollado o aprobado por empresas y editoriales consolidadas. Todos estos aspectos, por tanto, deberían ser valorados a la hora de poner en marcha cualquier iniciativa de prácticas educativas abiertas.

\section{Descripción de la experiencia/Objetivo}

Ante las restricciones de acceso y uso de las instalaciones universitarias implementadas en la UJA durante el curso 2020/2021 por razones sanitarias, en el caso de la asignatura Análisis de Datos II surgía la dificultad añadida de que la parte práctica estaba diseñada para ser realizada 
empleando el software privativo IBM SPSS. Con el objetivo de proporcionar una enseñanza de carácter inclusivo y facilitar el seguimiento de la asignatura por parte del estudiantado independientemente de sus recursos económicos y en línea con la filosofía de las prácticas educativas abiertas, el equipo docente de la asignatura llegó al acuerdo de realizar una adaptación de las actividades utilizando REA siempre que fuera posible, pero priorizando ante todo la calidad de la experiencia de aprendizaje y manteniendo la fidelidad a los contenidos didácticos especificados en la guía docente de la asignatura.

\section{Software libre de análisis estadístico}

La primera necesidad claramente identificada fue la de poder disponer de un software no privativo (ya fuera libre o de código abierto) y gratuito de análisis estadístico que pudiera ser empleado para realizar las actividades que tradicionalmente se hacían utilizando IBM SPSS (principalmente relacionadas con inferencia estadística, especialmente con el contraste de hipótesis siguiendo el modelo lineal general). En septiembre de 2020 existían por lo menos tres programas gratuitos y de código abierto que cumplían con los requisitos especificados: R, jamovi y JASP. Así que el siguiente paso consistió en analizar las características de cada uno de ellos en función de los objetivos didácticos a cubrir.

El programa R (www.r-project.org) goza de gran prestigio entre la comunidad académica, es una herramienta de referencia para investigadores de diversas áreas de conocimiento y es sin duda el más completo de los tres. Sin embargo, requiere de conocimientos de programación para su uso, lo que añadiría una dificultad añadida para la implementación como herramienta introductoria al análisis estadístico formal en cursos de grado.

Los dos programas restantes: jamovi (The jamovi project, 2021) y JASP (JASP Team, 2019), tienen una interfaz casi idéntica, la cual está basada en menús contextuales similares a los de IBM SPSS e incluyen todas las funciones requeridas para cubrir satisfactoriamente los contenidos didácticos de la asignatura. Una de las diferencias más salientes entre JASP y jamovi, sin embargo, es la disparidad de posibilidades a la hora de editar conjuntos de datos: mientras que jamovi incluye la función de crear, introducir y modificar datos directamente en la aplicación (de forma similar a IBM SPSS), JASP no dispone de las dos primeras funciones, permitiendo únicamente modificar ciertas características del conjunto de datos una vez que esté cargado en la 
aplicación. Es decir, JASP permite realizar operaciones y analizar conjuntos de datos creados previamente con otras aplicaciones, ya sean hojas de cálculo u otros programas estadísticos (soporta los archivos con extensión .csv, .sav, .ods, .dta, .por, .txt, .sas7bcat y .sas7bdat). Aunque, atendiendo a razones ergonómicas y de practicidad, esta diferencia en cuanto a funciones de gestión de datos pudiera ser una razón para decantarse por jamovi, la idiosincrasia de las circunstancias en las que se impartiría la docencia añadían una dificultad extra a ser salvada: no todo el alumnado matriculado en la asignatura disponía de ordenador personal. Al comienzo de la pandemia el Vicerrectorado de Estudiantes de la Universidad puso en marcha un plan de acción social dirigido a abordar la brecha digital en el alumnado mediante el préstamo de equipos informáticos y routers inalámbricos a aquellas personas que lo necesitaran. Sin embargo, parte de la demanda de equipos se cubrió con tabletas digitales con sistema operativo Android. Los tres programas de análisis estadístico mencionados son compatibles con los sistemas operativos Windows, iOS y Linux, pero no con Android, por lo que existía el riesgo de que el alumnado que estaba utilizando las tabletas proporcionadas por el Vicerrectorado de Estudiantes no pudiera seguir las actividades prácticas de la asignatura desde sus domicilios. Tras buscar varias alternativas de compatibilidad, se descubrió la posibilidad de ejecutar la aplicación JASP a través de rollApp (www.rollapp.com): una página web que permite la ejecución a través del navegador web (y por tanto independientemente del sistema operativo del dispositivo) de aquellas aplicaciones de escritorio que tiene en catálogo. Debido a esta ventaja añadida y priorizando la dimensión inclusiva, se optó por adaptar las prácticas de la asignatura a este software, aunque eso conllevara emplear una aplicación adicional para la gestión de los datos a analizar.

\section{Gestión de datos mediante software libre}

Al igual que con el software de análisis estadístico, se procedió a realizar una valoración y selección de aquellos programas gratuitos y no privativos que permitieran realizar una gestión adecuada de conjuntos de datos cuantitativos para los objetivos de la asignatura. Se añadían además dos requisitos: que el tipo de archivo generado fuera compatible con JASP y que se pudiera ejecutar en sistemas Android. Finalmente, el equipo docente se decantó por LibreOffice (www.libreoffice.org): un paquete de ofimática de código abierto similar a Microsoft Office. Entre sus aplicaciones se incluye LibreCalc, una hoja de cálculo que contiene todas las funciones de 
cálculo y gestión de datos que se requieren para los objetivos de la asignatura. Además, se puede ejecutar a través de rollApp.

\section{Contexto}

La adaptación docente basada en prácticas educativas abiertas se realizó en la asignatura Análisis de Datos II, correspondiente al segundo curso del Grado en Psicología, durante el primer cuatrimestre del curso 2020/21. La población objetivo estaba compuesta por las 223 personas matriculadas en la asignatura para dicho periodo. La comunicación con el estudiantado y la facilitación de los REA se realizó a través de la plataforma de docencia virtual ILIAS de la Universidad de Jaén.

\section{Aplicación y resultados}

A comienzo de curso se realizó una encuesta al estudiantado matriculado en la asignatura Análisis de Datos II para recabar información acerca de los recursos informáticos de los que disponían. El 100\% disponían de dispositivos digitales y conexión a internet, si bien existían diferencias en la calidad y velocidad de esta última. Cinco de las personas matriculadas únicamente disponían de dispositivos con sistema operativo Android (tabletas digitales o smartphones) para realizar el seguimiento de la docencia telemática. Esta información fue fundamental para el proceso de toma de decisiones con respecto las adaptaciones a implementar. Tras la adaptación de las actividades didácticas mediante el uso de REA, el 100\% del alumnado pudo seguir las actividades propuestas desde sus domicilios, independientemente del dispositivo al que tuvieran acceso, sin tener que incurrir en ninguna inversión económica adicional. El rendimiento académico de las personas matriculadas, medido en función de las calificaciones obtenidas en la convocatoria ordinaria del primer cuatrimestre, fue similar al de otros cursos académicos. La supresión de la necesidad de contar con licencias de software privativo para el correcto seguimiento de la asignatura podría suponer asimismo un ahorro considerable para la Universidad de Jaén. Como ventaja adicional, el alumnado aprendió a utilizar una herramienta de análisis estadístico a la que tienen acceso desde sus equipos personales y para cuyo uso no dependen de las licencias suscritas por la institución educativa, ganando por tanto autonomía e independencia al respecto. 


\section{"Lecciones" aprendidas}

A pesar de los obstáculos que se pueden presentar a la hora de implementar cualquier iniciativa basada en prácticas educativas abiertas, los resultados obtenidos compensan con creces el tiempo y recursos que necesitan ser invertidos en un primer momento. El estudiantado valoró positivamente la autonomía que proporcionaba el tener libre acceso a los recursos, sin barreras económicas ni de distribución que lo limiten. Esa libertad de acceso, además, facilitó el desarrollo de una experiencia de aprendizaje más fluida y una mejor integración de las destrezas prácticas con los conocimientos teóricos en los que se basan, ya que se suprimieron las restricciones que implica depender de las horas de docencia presenciales en las aulas de informática.

Un aspecto destacable en la implementación de esta experiencia es el haber podido contar con el apoyo técnico y material generado por la comunidad de docentes comprometidos con las prácticas educativas abiertas. Existe un amplio abanico de materiales y herramientas de apoyo didáctico para PDI, abiertos y de libre acceso, que están a disposición de cualquier persona que se decida a embarcarse en el uso de REA. La propia filosofía de los REA y el tipo de licencia de la propiedad intelectual con la que son publicados, además, favorece la adaptación del material existente en función de las características de cada proyecto. Algunos ejemplos de material didáctico empleado para esta experiencia han sido los cursos "Undergraduate Statistics with JASP" (Buchanan, Hopke, \& Donaldson, 2020) y "Un curso de introducción a la estadística en psicología usando JASP" (Perakakis, 2019), así como los libros de texto "Statistical analysis in JASP: a guide for students" (Goss-Sampson, 2019), "Learning statistics with JASP: A tutorial for psychology students and other beginners" (Navarro, Foxcroft, \& Faulkenberry, 2019) y "PostData 1.0. Un curso de introducción a la Estadística, pensado para principiantes" (SanSegundo-Barahona \& Marvá-Ruiz, 2016).

\section{Conclusiones}

La implementación de prácticas educativas abiertas en la educación superior supone un importante compromiso en pos de la reducción de desigualdades sociales y el acceso universal a la educación. Además de las implicaciones éticas evidentes, la implementación de RAE puede 
llevar aparejadas unas ventajas económicas considerables para las universidades, especialmente en el apartado de suscripción de software.

Aunque se han identificado algunos obstáculos que pueden dificultar la implementación de dichas prácticas, muchos de ellos pueden ser salvados gracias al crecimiento progresivo de la comunidad internacional comprometida con estos tipos de prácticas, así como mediante la implicación de organismos gubernamentales e internacionales, los cuales pueden proporcionar el apoyo institucional y económico necesario para la consolidación de iniciativas de mayor calado. La evaluación y análisis sistemático del impacto que las prácticas de educación abierta puedan tener para la Comunidad Universitaria facilitará la adhesión de las instituciones, lo que a su vez fortalecerá y potenciará futuras iniciativas.

El desarrollo y la proliferación de herramientas digitales de identificación, como es el DOI, así como la consolidación de licencias tipo Creative Commons para el registro de la propiedad intelectual, facilitan el crédito y reconocimiento académico para los creadores de REA, garantizando al mismo tiempo la gratuidad y accesibilidad del material para la población.

\section{Referencias}

Andrade, A., Ehlers, U.-D., Caine, A., Carneiro, R., Conole, G., Kairamo, A.-K., ... Mundin, P. (2011). Beyond OER-Shifting Focus to Open Educational Practices: OPAL Report 2011.

Atkins, D. E., Brown, J. S., \& Hammond, A. L. (2007). A review of the open educational resources (OER) movement: Achievements, challenges, and new opportunities, 164. Creative common Mountain View.

Buchanan, E. M., Hopke, T. G., \& Donaldson, S. (2020). Undergraduate Statistics with JASP. https://doi.org/https://doi.org/10.17605/OSF.IO/T56KG

Goss-Sampson, M. (2019). Statistical analysis in JASP: a guide for students. JASP. https://doi.org/10.6084/m9.figshare.9980744

Hylen, J., \& Schuller, T. (2007). Giving knowledge for free. OECD Observer, 263, 21-22. 
IBM. (2021). IBM SPSS Pricing. Retrieved April 18, 2021, from https://www.ibm.com/eses/products/spss-statistics/pricing

JASP Team. (2019). JASP. Retrieved from https://jasp-stats.org/download/

Murphy, A. (2013). Open educational practices in higher education: Institutional adoption and challenges. Distance 201-217. https://doi.org/10.1080/01587919.2013.793641

Navarro, D. J., Foxcroft, D. R., \& Faulkenberry, T. J. (2019). Learning statistics with JASP: A tutorial for psychology students and other beginners.

Okagbue, H. I., Oguntunde, P. E., Obasi, E. C. M., \& Akhmetshin, E. M. (2021). Trends and usage pattern of SPSS and Minitab Software in Scientific research. Journal of Physics: Conference Series, 1734(1). https://doi.org/10.1088/1742-6596/1734/1/012017

Perakakis, P. (2019). Un curso de introducción a la estadística en psicología usando JASP. https://doi.org/https://doi.org/10.17605/OSF.IO/V5RJD

San Segundo-Barahona, F., \& Marvá-Ruiz, M. (2016). PostData 1.0. Un curso de introducción a la Estadística, pensado para principiantes. Retrieved from http://www.postdatastatistics.com/

The jamovi project, V. A. (2021). Jamovi. Retrieved from https://www.jamovi.org/

UNESCO. (2002). Forum on the impact of Open Courseware for higher education in developing countries. Retrieved from https://unesdoc.unesco.org/ark:/48223/pf0000128515 


\title{
Experiencias singulares en momentos de problemáticas globales: la inclusión en tiempos de pandemia desde los servicios de orientación
}

\author{
Lucía Forcadell \\ Mara Socolovski \\ Universidad de Zaragoza
}

Palabras clave: Covid-19; inclusión; prácticas educativas; equidad; Orientación educativa

Una crisis se convierte en desastre sólo si respondemos a ella con ideas preconcebidas, es decir, con prejuicios. Semejante actitud no sólo agudiza la crisis, sino que nos hace perder la experiencia de la realidad y la oportunidad de reflexionar que proporciona (Arendt, H. 1977).

\section{Introducción}

La situación de confinamiento y excepcionalidad provocada por la pandemia de la COVID19 que experimentaron casi todos los países del mundo a finales de 2019 y principios de 2020 supuso un periodo de "crisis" en los términos en los que definía Hannah Arendt: un momento entre el pasado y el futuro que nos invita a pensar, a plantearnos preguntas, porque la situación "destroza apariencias y borra prejuicios". En el tiempo del confinamiento y el curso posterior han emergido discursos que han considerado un año escolar "perdido", entendiendo ello a partir de que el hecho educativo se perdió y desdibujó en la no presencialidad, o porque se considera que los agentes (profesorado y alumnado) no realizaron esfuerzos suficientes. Frente a esto también se han constatado "creaciones pedagógicas, improvisaciones y experimentaciones de docentes que buscaron formas de sostener la escuela por otros medios" (Dussel, Ferrante y Pulfer, 2020, p. 12). El objetivo del texto es recoger experiencias que visibilicen los esfuerzos de los agentes escolares para sostener la relación educativa en tiempos de crisis. 
Atravesar nuestra mirada con el paradigma de la inclusión se hace necesario para analizar un contexto en el que una de las problemáticas comunes y globales es que "la salud de los principios de igualdad de oportunidades y equidad educativa se está viendo perjudicada" (Cáceres et. Al., 2020, 215). Uno de los factores que ha incidido en esta cuestión es el abordaje de la relación educativa mediada por la tecnología, solución provisional asumida por los agentes escolares en las distintas geografías. La modalidad de enseñanza on-line, concretada a su vez en diversos formatos, ha sido una realidad durante los meses de pandemia. En ese mismo ejercicio, ya pueden apreciarse distintas soluciones para aquellos colectivos sin acceso adecuado a recursos digitales. Pero más allá de la cuestión de los recursos han emergido otras muchas acciones encaminadas a sostener y cuidar la relación educativa.

\section{Descripción de la experiencia/Objetivo}

El contexto de la pandemia a nivel internacional ha generado ya numerosas reflexiones. Coincidiendo con Skilar (2020), podemos plantear que el marco de aquello que se referencia como acción escolar fue desbordado y en cada contexto se articularon actuaciones más o menos ordenadas tendientes a subsanar cuestiones des-cubiertas por la pandemia. Así pues, se organizaron repartos de comida y artículos escolares, distribución de ordenadores y recursos electrónicos, procesos de alfabetización de familias "no-conectadas", etc. Además, en un estudio exploratorio Aguaded y Martínez (2020) concluyen que desde los servicios de orientación se han generado multitud de recursos para adaptarse a la situación de un trabajo a distancia y han surgido muchos imprevistos derivados de la ausencia de contacto físico en una labor que se teje, mayormente, en una relación uno a uno. Desde estas consideraciones hemos querido poner el foco en la experiencia desarrollada desde el ámbito de la orientación en el contexto de una escuela pública, con el objetivo de recoger y reflexionar sobre las acciones educativas desarrolladas en momentos excepcionales desde el ámbito de apoyo, asesoramiento y ayuda que supone la posición del orientador.

\section{Contexto}

Describiremos y analizaremos las acciones llevadas a cabo en el contexto de una escuela pública situada en el estado de Massachussets (EEUU). Se trata de una escuela con un currículum 
acorde al Two-Ways Bilingual Program (Español-Inglés) donde la población hispana alcanza el $70 \%$. Por ello, vamos a recoger las experiencias educativas llevadas a cabo durante el periodo de confinamiento desde la figura de una orientadora para analizar sus posibles efectos y reflexionar sobre las condiciones en la que asentó la práctica educativa en dicho periodo. Nos centraremos en aquellas prácticas que desbordaron lo escolar y que se encaminaron a promover relaciones y condiciones que trataban de garantizar la equidad en aquellos momentos en lo que se acrecentaban las desigualdades.

\section{Aplicación y resultados}

A continuación describiremos, a modo de relato, las experiencias llevadas a cabo en el citado contexto. Es interesante destacar que en una primera aproximación, lo primero que surgió fue una sensación de que no se había realizado nada extraordinario. Sin embargo, fue necesario detenerse para analizar las acciones, los materiales o las relaciones que se establecieron en aquellos momentos para darse cuenta que lo hecho puede pensarse desde la acción educativa generosa y voluntaria a la que se refería Skliar (2020). En aquel momento la situación que sobrevino fue del todo novedosa, en el sentido en el que no habíamos experimentado una ruptura tan grande y en tan poco tiempo del formato escolar. No había recursos de situaciones similares y la situación afectaba a la salud socioemocional de todos los agentes educativos (alumnado, profesorado, familias). Si la prioridad en las funciones de un psicólogo escolar en EEUU es realizar evaluaciones psicopedagógicas en el ámbito escolar, ello se vio limitado al no poderse hacer en forma no presencial y con un contexto educativo totalmente alterado. Esto nos habilitó un tiempo para poder desarrollar otras acciones que a continuación relatamos, para después reflexionar sobre los efectos de nuestras acciones.

Previo a la pandemia, los recursos de Educación Emocional eran proporcionados por la administración a partir de programas que debían implementar las maestras en las aulas. Ninguno de ellos estaba adaptado para su práctica dentro de un modelo virtual. A partir de entonces, surge la necesidad de elaborar tareas para que alumnado y familias, pudieran hacerse un tiempo para hablar de valores y emociones. Surge así la preocupación por las formas de comunicarnos entre los distintos miembros de la familia que, de repente y por obligación legal, se encuentran confinados, conviviendo más horas de las habituales, obligados a realizar tareas en espacios no 
preparados, etc. Por ello, entendiendo que este tipo de educación no se realiza "sin el otro", se propusieron actividades que involucraran otra persona (un progenitor, un hermano, una abuela, etc.). Así, se trabajaron conceptos más personales como el autoconocimiento, la expresión del afecto y las emociones, etc., o sociales, como el reconocimiento de la labor de los trabajadores de primera línea. Se "inventaron" modos de comunicar y compartir el afecto evitando el contacto físico pero convocando una otra forma de presencialidad como el intercambio de anécdotas familiares, chistes o adivinanzas. Asimismo, teniendo en cuenta que toda relación entre humanos supone un espacio donde algo del orden de "poner el cuerpo" se pone en juego, se pensaron modos de arbitrar ello en tiempos de no-contacto, invitando a las familias a construir murales virtuales con fotos de los niños jugando en la nieve, o carteles en las ventanas para agradecer la labor de los sanitarios, etc.

En esta nueva forma de "hacer" en educación, surge la imperiosa necesidad de trabajar junto a las/los docentes en procesos de alfabetización digital. La función de la orientadora toma relevancia en su posibilidad de hablar con niños y familias para ayudar a conectar, caso por caso, a cada niño-familia con su clase mientras la maestra trabaja en línea. Entrar en el espacio de lo íntimo, aceptar el "no-sabemos" o "no-podemos" para abrir una grieta a la posibilidad se configura como una tarea desafiante y necesaria ${ }^{4}$. Así pues, con familias que tenían un ordenador por primera vez o adultos que no conocen el idioma, se comienza a entablar un lazo que va a permitir la conexión de los niños a lo escolar.

En otro orden de cosas, se apreciaba la sobrecarga que aparecía en los docentes. Por ello, todos los viernes mandaba una carta a las maestras para estimular el autoconocimiento (darse permiso para estar cansadas, cuidarse uno mismo, trabajar no solo desde lo positivo sino también reconociendo lo negativo). La demanda pública por parte del distrito y por parte de algunos padres de la "enseñanza" del currículum no sólo supone un pasaje en el modo de presentar los contenidos sino del contexto tanto propio como de los alumnos. Ya no se trata de un docente "en su clase con

\footnotetext{
${ }^{4}$ Es menester recordar que muchos de estos adultos están en situación de necesidad económica y
} social y esa apertura sólo puede instaurarse a partir de la confianza, ya que ellos tienen miedo de ser denunciados ante las autoridades en relación a su estatus legal. 
sus alumnos" sino de un educador que, desde su propia casa, se mete en la casa de sus alumnos. Surge así una necesidad de reflexión sobre cuestiones que antes podían "saberse" sobre las familias pero que ahora se "veían en directo". Las maestras deben hacer un doble movimiento emocional: construir un espacio de fortaleza interior para poder luego pensar en aquellas situaciones. Esta práctica detectó un espacio de necesidad que se sostiene hasta el día de hoy.

Es importante señalar que la pandemia abrió un espacio "reconocible y reconocido", que en EEUU no existe: el poder trabajar desde las propias limitaciones con los otros para el atravesamiento de situaciones comprometidas. Por ejemplo, los incesantes cambios y anuncios de vuelta al cole hicieron que una maestra pidiera ayuda para comunicar que, a finales del año 20192020, no regresaría a clases. La docente no estaba segura de poder sostener al grupo, por lo que nos pidió ayuda. Diseñar la forma de hablar de aquello que podía generar sentimientos controvertidos y seguir creando formas de lazos que habiliten al grupo como referencia fueron las directrices del trabajo realizado. En la misma línea, cuando se notificó un caso de agresiones, se intervino colaborando con la maestra a crear la referencia del grupo-clase como guía, además de las mediaciones individuales que debieron realizarse. La cuestión de la atención de la diversidad y el reconocimiento de la diferencia también llama a la puerta en tiempos virtuales.

Surge en todas las escuelas una nueva significación para dar cuerpo a "trabajar con la incertidumbre". Ya no sólo (aunque también) de no estar seguros de los efectos singulares de los procesos educativos en la subjetividad de cada alumno y en la creación de común-unidad, sino que ahora el marco de referencia que supone el sistema escolar había sido dinamitado por la pandemia. Como se comentó en el párrafo anterior, las decisiones políticas sobre los modos de escolaridad en las escuelas y los plazos eran cambiantes. Ello no sólo suponía movilizaciones emocionales sino necesidades concretas que el "espacio" educativo habilita. Por ejemplo, ¿cómo enseñar a escribir a un niño de 5 años ${ }^{5}$ que en su casa tiene una sola mesa y es integrante de una familia numerosa? ¿Cómo modelar la forma de coger el lápiz y trazar sobre hojas que no siempre son las apropiadas para esa edad? En el caso de muchas escuelas del estado, se arbitraron formas de suministrar ordenadores y material educativo a todas las familias. Pero vuelve a ponerse de relieve

\footnotetext{
${ }^{5}$ En EEUU, el primer año de escolaridad obligatoria es a los 5 años. Debido a la pandemia, muchos
} niños accedieron a la escuela por primera vez en forma virtual. 
la necesidad de pensar la escuela como promotora de equidad y atención a la particularidad. Así pues, distintas maestras junto con nosotros, diseñaron, prepararon y distribuyeron material didáctico para los niños con necesidades educativas especiales. Luego, se trabajó con las familias para encontrar lugares y tiempos para poder estar con los niños en forma individual, más allá de la programación general. Estas últimas acciones fueron "excepcionales" en todos sus sentidos: por salirse de lo normado, por no afectar a todos los estudiantes, por surgir desde el profesorado, etc. Se trata de acciones sostenidas desde la voluntad, la solidaridad y el compromiso de los educadores, dando relevancia a quienes le dieron cuerpo al proceso educativo.

\section{Conclusiones}

Este relato de experiencias corresponde a la realidad de un colegio que se inserta en un contexto desfavorecido y de carácter público, lo cual es destacable ya que los colegios privados tuvieron la libertad de volver a clase en los tiempos que procuraron pertinentes. Quedó patente que la educación no es igual para todos en EEUU.

El relato construido nos permite observar cómo la pandemia nos condujo a trabajar con la incertidumbre derivada del cambio estructural en las condiciones de la relación educativa (Sadovsky y Castorina, 2020, p. 212), "las intervenciones de los docentes se estructuran a partir de la lectura que hace del contexto de clase y es por eso que decimos que la enseñanza es orgánicamente interactiva. Esta organicidad fue interrumpida por la pandemia y, por lo tanto una parte de las referencias que enmarcaban la experiencia para enseñar dejó de funcionar", pero surgieron otras maneras de "poner el cuerpo" como se relató en el apartado anterior y armar la apuesta por la educabilidad de todos. La pedagogía se configura como un espacio de combate, en términos de Meirieu (2016, p.15) los agentes educativos "tienen la sensación de estar en el frente" para luchar porque nadie quede condenado al fracaso y a la exclusión. Así pues, los docentes se hacen cargo de realizar un seguimiento particular y voluntario que encuentra su fundamento más allá de lo establecido y articulan su práctica desde lo extra-ordinario, dando lugar a prácticas necesarias en momentos claves. Su participación se transforma en única, haciendo visible que "la educación es de hecho posible más allá de su propia imposibilidad" (Lajonquier, 2011, p. 221). Como se ha relatado, la organización de esta posibilidad se soporta en base a nuevas dinámicas grupales que no estaban diseñadas hasta ahora, pero que estructuran para sostener las nuevas 
formas de trabajo. La tarea de "enseñar" cobra una nueva dimensión a la que se enfrenta el docente con la siempre presente necesidad de un sujeto activo dis-puesto a aprender. Repensar la práctica educativa desde este lugar será clave para alcanzar la meta de una educación que permita que los estudiantes puedan aprehender los objetos culturales que le son "enseñados".

En síntesis, se han generado nuevos espacios de experiencia. Pero estos generan efectos más o menos deseados. La alfabetización digital se impuso casi como una obligación. Sin embargo, mientras algunas familias accedían a dichos recursos, otros niños experimentaron luego una adicción a las pantallas o problemas de desregularización de la ingesta que llegan hasta hoy día.

Por último, el relato ilustra cómo la presencia, la participación y el progreso del alumnado están situados en una cuerda floja. Más allá de las decisiones administrativas, son los agentes escolares quienes concretan y dan cuerpo a las condiciones y relaciones que articulan la inclusión, pues la igualdad se crea y se hace posible, se produce a través de acciones conscientes (Larrosa, 2020).

\section{Referencias}

Aguaded Gómez, M.C., Martínez Fernández, C. (2020). Estudio sobre Los Servicios de Orientación Educativa en España en el Periodo de Confinamiento. Revista DIM: Didáctica, Innovación y Multimedia, 38, 32.

Cáceres-Muñoz, J., Jiménez Hernández, A. S., \& Martín-Sánchez, M. (2020). Cierre de Escuelas y Desigualdad Socioeducativa en Tiempos del Covid-19. Una Investigación Exploratoria en Clave Internacional. Revista Internacional De Educación Para La Justicia Social, 9(3), 199-221. https://doi.org/10.15366/riejs2020.9.3.011

Dussel, I., Ferrante, P. y Pulfer, D. (2020). Pensar la educación en tiempos de pandemia II. UNIPE y CLACSO.

Lajonquier, L. (2011). Figuras de lo infantil. Nueva Visión.

Larrosa J. (2020). Una vez más la igualdad. En Dussel, I., Ferrante, P. y Pulfer, D. (Coords.), Pensar la educación en tiempos de pandemia II (pp.17-31). UNIPE y CLACSO. 
Meirieu, P. (2016). Recuperar la pedagogía. Paidos.

Sadosky, P. y Castorina, J.A (2020). Enseñar en tiempos de excepción, nuevos desafíos pedagógicos, incertidumbre y nuevo reconocimiento social. En Dussel, I., Ferrante, P. y Pulfer, D. (Coords.), Pensar la educación en tiempos de pandemia II (pp. 211-225). UNIPE y CLACSO.

Skliar, C. (2020). Sobre la incertidumbre educativa. Continuidades, discontinuidades, interrupciones y vacíos. En Dussel, I., Ferrante, P. y Pulfer, D. (Coords.), Pensar la educación en tiempos de pandemia II (pp. 31-45). UNIPE y CLACSO. 


\section{Teletrabajo sostenible: seguridad, salud y bienestar}

\section{Eva Lira}

Universidad de Zaragoza

Palabras clave: covid-19; teletrabajo; sostenibilidad; salud; bienestar.

\section{Objetivos}

Revisar los factores implicados en la sostenibilidad del teletrabajo y su impacto en la seguridad, la salud y el bienestar.

\section{Introducción}

La crisis pandémica del originada por el nuevo coronavirus (SAR-CoV-2), comúnmente denominado COVID-19, presenta desafíos sin precedentes y tiene profundas implicaciones para la forma en que las personas viven y trabajan, las tecnologías de la información y la comunicación (TICs) han desempeñado un papel crucial, ya que las medidas de bloqueo obligaron repentinamente a las personas de todo el mundo a trabajar a distancia, dejándolos a menudo desprevenidos y mal equipados (Abdel Hadi, Bakker y Häusser, 2021; Biron, Peretz y TurgemanLupo, 2020; Carillo, Cachat-Rosset, Marsan, Saba y Klarsfeld, 2020; Hiselius y Arnfalk, 2021; Lindsey et al., 2021; Mojtahedzadeh, Rohwer, Lengen, Harth y Mache, 2021). Un sector de la población se vio obligada a realizar su trabajo no presencialmente (categorizado como "no esencial" Lindsey et al., 2021) en un contexto no planificado debido al extraordinario distanciamiento social expresado en el trabajo a distancia, sin experiencia previa en muchos casos y con exposición a la salud por factores de riesgo psicosocial que condicionan el estrés (Venegas y Leyva, 2020). Estos riesgos resultan cruciales, ya que la capacidad de una organización para soportar una crisis y beneficiarse del trabajo desde casa (teletrabajo) depende de la capacidad de sus empleados para adaptarse con éxito a las condiciones del teletrabajo y del país teniendo en 
consideración las diferencias culturales (Biron, 2020). Sin embargo, se desconoce el posible impacto del teletrabajo en la salud y desempeño de los trabajadores (Hallman, Januario, Mathiassen, Heiden, Svensson y Bergström, 2021; Nagata et al., 2021), a pesar de ello, hay ciertas recomendaciones nacionales que incitan a adoptar modelos de teletrabajo o híbridos tras el confinamiento, por tanto, parece que han llegado para quedarse una vez este superada la pandemia (Hallman et al., 2021; Oakman, Kinsman, Stuckey, Graham y Weale, 2020).

Es por ello, que a continuación no centramos en revisar los estudios que podrían dar las claves para un teletrabajo sostenible, seguro y saludable, comenzando por revisar el trabajo antes y después de la pandemia. Una pandemia que ha tensionando hasta límites insospechados todas las estructuras de nuestra sociedad, haciéndolas tambalear y marcando los dos últimos años, sacando a flote las debilidades, oportunidades y desafíos a los que hacer frente, dejando una huella imborrable que marcará los años venideros.

\section{Trabajo antes de la COVID-19 (PreCo) y después (PostCo)}

Empleadores de todo el mundo han permitido, alentado o exigido que sus empleados trabajen desde casa, lo que ha desencadenado un incremento en la investigación del teletrabajo sin precedentes a escala mundial [e.g., EEUU (Hoffman, 2021), Suecia (Hiselius y Arnfalk, 2021); Bélgica (Hendrickx, Taes y Wouters, 2020), Francia (Carillo et al. (2020), Japón (Nagata et al., 2021), España (Ruiz-Frutos et al. (2020), etc.]. En este sentido, Hiselius y Arnfalk (2021) indicó que debido a la pandemia, se está probando un cambio hacia el teletrabajo y las reuniones virtuales en lo que puede verse como un experimento a gran escala, y el conocimiento y la experiencia de ese experimento puede tener efectos duraderos en la vida cotidiana, de tal manera que existe un gran potencial para que las herramientas digitales influyan en sí y cómo nos desplazamos y hacemos viajes de negocios, la pandemia ha demostrado que tales herramientas pueden hacer posible lo imposible.

Con este cambio abrupto, surgió el desafío de las líneas borrosas entre la carrera y la vida personal. Al carecer de espacios designados para oficinas en casa, innumerables personas tuvieron que crear configuraciones de trabajo improvisadas en salas de estar, cocinas, dormitorios, dondequiera que hubiera espacio (Toniolo-Barrios y Pitt, 2021). Además, el cierre de las escuelas obligó a muchos padres que trabajaban a intentar seguir siendo productivos mientras supervisaban 
simultáneamente a sus hijos. Como resultado de estos cambios, numerosos empleados han experimentado una menor productividad laboral, una menor motivación, un mayor estrés y una peor salud mental (Toniolo-Barrios y Pitt, 2021). Por tanto, este aumento en la prevalencia del teletrabajo debido a la COVID-19 trae consigo desafíos, incluida la interacción limitada cara a cara con colegas y supervisores, acceso reducido a información y recursos ergonómicos, mayor aislamiento social y definiciones de roles borrosas, que pueden afectar negativamente la seguridad, la salud y el bienestar de los teletrabajadores (Schall y Chen, 2021).

La literatura reciente ha destacado el papel de las ocupaciones en la cuantificación de la cantidad de teletrabajo posible bajo las medidas de distanciamiento social durante la pandemia, pero también el hecho de que el teletrabajo requiere no solo una ocupación teletrabajable, sino también insumos domésticos relacionados con la infraestructura básica (e.g., conexión a internet y otros servicios de vivienda) y disponibilidad de tiempo. Para llegar a esta conclusión, Berniell y Fernández (2021) realizaron encuestas en los hogares de 11 países de América Latina y encontraron que los gastos domésticos requeridos para teletrabajar no están disponibles para los trabajadores más vulnerables, que se une a la desigualdad procedente de si el trabajo es o no teletrabajable, y a si se requiere mayor proximidad personal, que implica una mayor exposición al virus. Por tanto, las personas en situación de vulnerabilidad, con ocupaciones menos teletrabajables y con alta exposición al COVID-19, están desfavorecidas debido a estos aspectos de desigualdad que deberían de tenerse muy en cuenta a la hora de diseñar medidas de "nueva normalidad PostCo tales como modelos híbridos.

Diab-Bahman y Al-Enzi (2020) analizaron el cambio en las condiciones de trabajo [antes de la COVID-19 (PreCo) y después de su aparición (PostCo)] y su impacto en los sentimientos y expectativas laborales convencionales de 192 empleados de Kuwait (entrevistados), que se vieron obligados a trabajar desde casa debido a las circunstancias del encierro. Los resultados mostraron un acuerdo en cuanto a que las condiciones laborales PreCo necesitan ser revisadas aunque el sentimiento general estaba dividido, pero la mayoría disfrutaba de las condiciones flexibles. Además, advirtieron que las condiciones de trabajo PreCo permanecían iguales o se habían visto afectados positivamente en lugar de negativamente. Por lo tanto, si se les daba la opción de un modelo híbrido que incluye trabajar en parte de forma remota y en parte en el sitio, una mayoría 
considerable informó que pueden realizar de manera eficiente al menos el $80 \%$ de sus expectativas laborales.

\section{Teletrabajo sostenible: la perspectiva ambiental}

En pro de un teletrabajo sostenible, algunos estudios han señalado algunas necesidades y mejoras laborales que ha destapado la covid-19 y que deben ser tenidas en consideración. Así, por ejemplo, Olivos, Castillo, Sernaqué y Joo (2021) analizaron el papel del ingeniero industrial en la etapa de desconfinamiento y reactivación económica PostCo en Perú. Este análisis se enfocó en resaltar las oportunidades y desafíos para el ingeniero industrial en los campos de seguridad y salud ocupacional, diseño de puestos, gestión ambiental y aplicación de las TICs. Desde el enfoque de la psicología ambiental, se han revisado métodos específicos para que las personas que teletrabajan los apliquen en pro de mejorar la productividad y la salud mental, señalando la importancia de estrategias para enfrentar las consecuencias negativas del aislamiento social y un peor desempeño (Craig et al., 2021). En este sentido, se ha mostrado que los entornos naturales tienen una variedad de efectos positivos: una mejor atención, un afecto positivo y una mayor satisfacción en el trabajo, y estos pueden traducirse en el entorno del espacio de trabajo en el hogar. La revisión de Craig et al. (2021) encontró una variedad de métodos relativamente simples y rentables que podrían ayudar a los trabajadores durante la pandemia de COVID-19, incluido tomar un descanso en la naturaleza e implementar la naturaleza en el espacio de trabajo.

En esta línea, Mojtahedzadeh et al. (2021) revisa la literatura disponible para explorar cómo se puede realizar el trabajo de promoción de la salud desde el hogar, señalando que, para evitar reacciones negativas de estrés físico y mental, se recomienda un diseño del lugar del teletrabajo ergonómico, organización del tiempo de trabajo (e.g., estructurando la jornada, respetando las pausas y momentos de reparación, y evitando disturbios e interrupciones). Asimismo, los componentes importantes de un diseño de trabajo que promueve la salud son la separación temporal, espacial y mental del trabajo y la vida privada. Abdel Hadi et al. (2021) se basaron en el modelo de demandas y recursos, para examinar las relaciones entre las demandas laborales, del hogar y el agotamiento emocional durante el teletrabajo y si la creación de ocio (es decir, la búsqueda proactiva y la realización de actividades de ocio dirigidas al establecimiento de objetivos, la socialización, el crecimiento y el desarrollo) se relaciona negativamente con el agotamiento emocional (relacionado con un peor desempeño laboral). Concretamente, realizaron un estudio de 
diario durante siete días consecutivos con 178 empleados (964 datos) mostrando como las demandas diarias del trabajo, y del hogar durante el teletrabajo se relacionaron con el agotamiento emocional. Mientras que el ocio (relacionado en positivo con la personalidad proactiva) fue capaz de combatir el agotamiento emocional.

\section{Teletrabajo y salud mental}

La literatura ha identificado impactos tanto positivos como negativos del teletrabajo en el bienestar de los empleados (Hoffman, 2021). En este sentido, la investigación se ha centrado en analizar la influencia del teletrabajo tanto en la salud como en el desempeño (Craig, Neilson, Altman, Travis y Vance, 2021).

Carillo et al. (2020) desarrollan un modelo de ajuste de teletrabajo inducido por epidemias derivado de la teoría del ajuste laboral y el modelo interaccional de ajuste individual en 1574 teletrabajadores de Francia. Los resultados mostraron la superioridad de la influencia de variables específicas de crisis (e.g., aislamiento profesional, el entorno de teletrabajo, el aumento de trabajo y el estrés) en el ajuste al teletrabajo. Siendo el aislamiento y el estrés las variables de mayor impacto negativo, y el entorno de teletrabajo el de impacto más positivo en el ajuste al teletrabajo. No obstante, no encontraron ningún efecto en el apoyo organizacional y ocupar un puesto de dirección estaba relacionado con un peor ajuste, lo que sugiere que los no gerentes tendían a adaptarse mejor a la situación del teletrabajo. Sin embargo, otros estudios si ponen de manifiesto la importancia del apoyo organizacional. Así, por ejemplo, Oakman et al. (2020) revisó 23 estudios sobre el impacto del teletrabajo en la salud física y mental en función del género, para desarrollar recomendaciones para empleadores y empleados con el fin de optimizar la salud de los trabajadores. Este estudio informa de diez resultados de salud derivados del teletrabajo: dolor, salud autoinformada, seguridad, bienestar, estrés, depresión, fatiga, calidad de vida, tensión y felicidad. El impacto en los resultados de salud estuvo fuertemente influenciado por el grado de apoyo organizacional disponible para los empleados, el apoyo de los compañeros, la conexión social (fuera del trabajo) y los niveles de conflicto entre el trabajo y la familia. En general, las mujeres teletrabajadoras tenían menos probabilidades de experimentar mejores resultados de salud. Por tanto, las organizaciones deberán implementar políticas formalizadas que consideren el apoyo a la gestión de los límites entre el trabajo y el hogar, la claridad de los roles, la carga de trabajo, los indicadores de desempeño, el apoyo técnico, la facilitación de la creación de redes de 
compañeros de trabajo y la capacitación de los gerentes. Estos efectos negativos también se han encontrado en docentes, así Villa et al. (2021) analizaron el teletrabajo (educación a distancia) desarrollado por docentes de primaria y secundaria en instituciones educativas públicas y privadas de Temuco-Chile, en el contexto de la pandemia de COVID 19 mediante entrevistas semiestructuradas a 10 docentes obtuvieron un aumento en la intensificación del trabajo, uso extendido de plataformas virtuales, disminución del tiempo de descanso, difuminación de los ámbitos público-privado, desgaste profesional-personal y carga existencial. También, Schall y Chen (2021) revisaron las estrategias prácticas basadas en evidencia que se pueden implementar para promover la seguridad, la salud y el bienestar de los teletrabajadores durante y después de la pandemia del COVID-19 para su sostenibilidad. Este estudio sugiere que las intervenciones destinadas a aumentar la motivación de los trabajadores para participar en comportamientos seguros y saludables se logran a través de un liderazgo centrado en la seguridad, la gestión de los límites de las funciones para reducir los riesgos de seguridad y salud ocupacional, y el rediseño del trabajo para fortalecer las interacciones interpersonales y la interdependencia de los teletrabajadores.

\section{Teletrabajo y salud física}

Los comportamientos físicos (e.g., conducta sendentaria, tiempo de estar de pie y en movimiento) no cambiaron de teletrabajar o trabajar en la oficina. Sin embargo, los días de trabajo desde casa durante la pandemia de COVID-19 en Suecia se asociaron con una mayor duración del sueño que los días de trabajo en la oficina, a expensas de una reducción del tiempo de trabajo y de ocio en 26 min y 7 min, respectivamente. Por tanto, este cambio de comportamiento puede ser beneficioso para la salud (Hallman et al., 2021). En el estudio de Lindsey et al. (2021) la actividad física durante la pandemia no se asoció con la situación laboral de 735 personas empleadas a tiempo completo que informaron cuánta actividad física habían realizado en los últimos 7 días. Sin embargo, encontró que los empleados "no esenciales" estuvieron más tiempo sentados y trabajaron más horas que los empleados "esenciales". Debido a que una mayor cantidad de tiempo total sentado diario se ha asociado con un mayor riesgo de mortalidad, es importante que el aumento del tiempo sentado sea atenuado por una mayor actividad física. En esta línea, Fukushima et al. (2021) compara los niveles de actividad física y sedentario de teletrabajadores y no de Tokio en 
1239 trabajadores concluyendo que los teletrabajadores eran menos activos físicamente y tenían más sedentarismo.

Por otro lado, en cuanto a la fatiga de la pantalla y otros aspectos, Toniolo-Barrios y Pitt (2021) plantean que la atención plena puede resultar beneficiosa para superar los desafíos asociados con el teletrabajo como: (1) desconectar mentalmente; (2) mejorar la atención laboral incrementando así el desempeño; y (3) manejar la fatiga de la pantalla. Por tanto, la atención plena podría ayudar a reestablecer el equilibrio entre el trabajo y la vida personal, además del bienestar y la productividad, y por tanto podrían ser herramientas útiles para gerentes y líderes.

Hoffman (2021) comparó las percepciones de las personas que teletrabajan y las que lo hacen desde el lugar de trabajo habitual. Los no teletrabajadores manifestaron más oportunidades de socializar con otras personas y experimentaron menos conflictos trabajo-familia. Sin embargo, los teletrabajadores indicaron que pasaban más tiempo de calidad con miembros de la familia y también con sus mascotas (los dueños de perros socializaban con otras personas, realizaban una cantidad saludable de actividad física y caminaban al menos 15 minutos durante la jornada laboral).

Otros estudios incluyen diversos aspectos como el de Nagata et al. (2021) examina los efectos del teletrabajo sobre la salud en el contexto inmediato de la crisis pandémica del COVID19 en Japón. El estudio incluye el análisis del trabajo, estilo de vida, enfermedad y atención médica, y hogar y comunidad en teletrabajadores, no teletrabajadores y familiares de teletrabajadores. En concreto, se centraron en medidas específicas del entorno laboral, la gestión empresarial, las comunicaciones y los estilos de vida de los teletrabajadores; directrices médicas y de seguridad, priorización del trabajo y comunicación regular para los no teletrabajadores; y responsabilidades compartidas dentro de las familias y comunicación fuera de las familias para los familiares de los teletrabajadores. Estas medidas se pueden aplicar y adaptar fácilmente en diversas industrias para mitigar los efectos negativos más amplios del teletrabajo y mejorar sus efectos positivos. 


\section{Conclusiones}

El teletrabajo es la solución y el problema en estos tiempos convulsos en los que nos enfrentamos a una pandemia sin precedentes, este capítulo plantea que para el teletrabajo sea sostenible se requiere que las personas se adapten, lo que incluye seguridad, salud y bienestar, y por lo tanto un adecuado desempeño imprescindible para la supervivencia de las organizaciones de todo el mundo en tiempos de crisis. Por tanto, este trabajo abre directrices de investigación futura en línea con los «objetivos de desarrollo sostenible»(ODS), desde una perspectiva del teletrabajo, que permite desvincular el crecimiento económico de la degradación del medio ambiente. Asimismo, este desarrollo sostenible ha de ser también social, analizando la satisfacción del trabajador en términos de conciliación familiar pero también considerando indicadores de salud, y las organizaciones en términos de beneficios desde una aproximación sostenible.

\section{Financiación o apoyos:}

El presente trabajo ha sido desarrollado en el marco del proyecto de investigación "Bienestar y Capital Social (BYCS)" (ref. S-51) financiado por el Gobierno de Aragón y la Universidad de Zaragoza

\section{Referencias}

Abdel Hadi, S., Bakker, A. B., y Häusser, J. A. (2021). The role of leisure crafting for emotional exhaustion in telework during the COVID-19 pandemic. Anxiety, Stress, \& Coping, 1-15.

Biron, M., Peretz, H., y Turgeman-Lupo, K. (2020). Trait Optimism and Work from Home Adjustment in the COVID-19 Pandemic: Considering the Mediating Role of Situational Optimism and the Moderating Role of Cultural Optimism. Sustainability, 12(22), 9773.

Carillo, K., Cachat-Rosset, G., Marsan, J., Saba, T., \& Klarsfeld, A. (2020). Adjusting to epidemicinduced telework: empirical insights from teleworkers in France. European Journal of Information Systems, 30(1), 69-88. 
Craig, C. M., Neilson, B. N., Altman, G. C., Travis, A. T., y Vance, J. A. (2021). Applying Restorative Environments in the Home Office While Sheltering-in-Place. Human Factors. https://doi.org/10.1177/0018720820984286

Diab-Bahman, R., y Al-Enzi, A. (2020). The impact of COVID-19 pandemic on conventional work settings. International Journal of Sociology and Social Policy, 40, pp. 909927. https://doi.org/10.1108/IJSSP-07-2020-0262

Fukushima, N., Machida, M., Kikuchi, H., Amagasa, S., Hayashi, T., Odagiri, Y., ... y Inoue, S. (2021). Associations of working from home with occupational physical activity and sedentary behavior under the COVID-19 pandemic. Journal of Occupational Health, 63(1), e12212.

Hallman, D. M., Januario, L. B., Mathiassen, S. E., Heiden, M., Svensson, S., \& Bergström, G. (2021). Working from home during the COVID-19 outbreak in Sweden: effects on 24-h time-use in office workers. BMC public health, 21(1), 1-10.

Hendrickx, F., Taes, S., y Wouters, M. (2020). Covid-19 and labour law in Belgium. European Labour Law Journal, 11(3), 276-285.

Hiselius, L. W., y Arnfalk, P. (2021). When the impossible becomes possible: COVID-19's impact on work and travel patterns in Swedish public agencies. European Transport Research Review, 13(1), 1-10.

Hoffman, C. L. (2021). The Experience of Teleworking with Dogs and Cats in the United States during COVID-19. Animals, 11(2), 268.

Lengen, J. C., Kordsmeyer, A. C., Rohwer, E., Harth, V., y Mache, S. (2020). Social isolation among teleworkers in the context of the COVID-19 pandemic: Indications for organising telework with respect to social needs. Zentralblatt fur Arbeitsmedizin, Arbeitsschutz und Ergonomie, 71, 63-68. 
Lindsey, B. W., Boolani, A., Merrigan, J. J., Cortes, N., Caswell, S. V., y Martin, J. R. (2021). Relationship Between Employment Status, Reported Physical Activity, and Sitting Time During COVID-19 Pandemic. Journal of Physical Activity and Health, 18(3), 325-328.

Mojtahedzadeh, N., Rohwer, E., Lengen, J., Harth, V., y Mache, S. (2021). Health-promoting work design for telework in the context of the COVID-19 pandemic. Zentralblatt fur Arbeitsmedizin, Arbeitsschutz und Ergonomie, 1-6.

Nagata, T., Ito, D., Nagata, M., Fujimoto, A., Ito, R., Odagami, K., ... y Mori, K. (2021). Anticipated health effects and proposed countermeasures following the immediate introduction of telework in response to the spread of COVID-19: The findings of a rapid health impact assessment in Japan. Journal of Occupational Health, 63(1), e12198.

Oakman, J., Kinsman, N., Stuckey, R., Graham, M., y Weale, V. (2020). A rapid review of mental and physical health effects of working at home: how do we optimise health? BMC Public Health, 20(1), 1-13.

Olivos, G. S. M., Castillo, C. A. D., Sernaqué, M. A. C., y Joo, L. A. P. (2021). La pandemia del Covid-19 en el Perú y la función del Ingeniero Industrial. Universidad y Sociedad, 13(1), $59-63$.

Schall Jr, M. C., y Chen, P.(2021). Evidence-based strategies for improving occupational safety and health among teleworkers during and after the coronavirus pandemic. Human factors. https://doi.org/10.1177/0018720820984583

Toniolo-Barrios, M., y Pitt, L. (2021). Mindfulness and the challenges of working from home in times of crisis. Business Horizons, 64(2), 189-197.

Venegas, C. E., y Leyva, A. C. (2020). Fatigue and mental workload among workers: about social distancing. Revista española de salud pública, 94.

Villa, N. B., Mansilla Sepúlveda, J., \& Veliz Burgos, A. (2021). Teleworking and work stress for teachers in times of COVID-19. Medisur-Revista De Ciencias Medicas De Cienfuegos, 18(5), 998-1008. 


\title{
Método, orientación y evaluación del bienestar con el programa NEREU: Educación para la Salud de familias y niños/as. Implicación con los Objetivos de Desarrollo Sostenible
}

\author{
Raquel Pérez-Ordás \\ José María Mur-Camon \\ Iván Francisco Castro Viñuales \\ Naila Martínez-Olmedo \\ Universidad de Zaragoza
}

Palabras clave: Sedentarismo, Alimentación, Juego, Multidisciplinariedad profesional, formación.

\section{Introducción}

Nereo es el nombre del dios griego que simboliza la metamorfosis, el cambio. De esta gran necesidad de cambio, nació el programa NEREU, hace 15 años. Se trata de un programa de educación para la salud en familia, donde se trabaja sobre el tratamiento, prevención y/o promoción, a través del ejercicio y la alimentación, para mejorar la calidad de vida de las personas, contribuyendo además a reducir desigualdades tantos sociales como económicas.

El programa NEREU es un proyecto de cambio, para que cada unidad familiar, paciente o participante, tenga una dosis adecuada de formación en educación para la salud. La trasferencia de lo adquirido y aprendido en la intervención del programa es lo que da valor y sentido al éxito del mismo. Esta trasferencia y éxito se consigue con el trabajo conjunto de numerosos agentes que trabajan en la misma dirección bajo el modelo ecológico de Bronfenbrenner donde se busca un cambio ambiental. Este foco en el modelo ecológico para conseguir una transferencia y adherencia a los buenos hábitos y la salud está siendo estudiada y validada por numerosos autores (Bogantes, 2016; Mendoza, Ledezma, Lezama, Hermenegild, y Saldaña, 2020; Schmidt, Bogantes, y 
González, 2021). Por lo tanto, el programa, aunque orientado específicamente a niños y niñas, lleva implícito la implicación de centros de salud, centros educativos, profesorado, familias, etc. Se elabora una red de trabajo alrededor de la familia, un completo sistema, ideal para trabajar día a día, contra algunos hábitos establecidos en numerosas unidades familiares, que han desencadenado en una vida pasiva y una mala alimentación. La obesidad infantil es considerada por muchos expertos la nueva epidemia del siglo XXI (Frauca, y García, 2021; Monroy-Parada, 2021; Pardos, Gou, Sagarra, Morales, y Concepción, 2021; Rivadeneira, Soto, Bello, Concha-Toro y Díaz, 2021). Además el sedentarismo infantil se está convirtiendo en un gran problema social (Ortiz-Sánchez, del Pozo-Cruz, Alfonso-Rosa, Gallardo-Gómez, y Álvarez-Barbosa, 2021).

Los centros de salud, y los centros educativos trabajan conjuntamente en el programa atacando los problemas de obesidad, sobrepeso, sedentarismo, baja autoestima y problemas sociales. Estos objetivos se vinculan principalmente con los Objetivos de Desarrollo Sostenible (ODS) de la Organización de Naciones Unidas (ONU) plasmados en el documento "Transformar nuestro mundo: la Agenda 2030 para el Desarrollo Sostenible”. Concretamente se vinculan con los ODS 3, 4 y 17 de manera directa (salud y bienestar, educación de calidad y alianzas para lograr los objetivos) y a otros objetivos ODS de manera indirecta:

Vínculo con ODS 3: Salud y bienestar: Garantizar una vida sana y promover el bienestar en todas las edades es esencial para el desarrollo sostenible. Desde el proyecto se busca el bienestar de las familias, trabajando específicamente en hábitos de vida saludables, ejercicio y alimentación.

Vínculo con ODS 4: Educación de calidad: Garantizar una educación inclusiva, equitativa y de calidad y promover oportunidades de aprendizaje durante toda la vida para todos. Desde NEREU se busca educar en salud, en hábitos saludables, en estilos de vida activo y actitudes que lleven al bienestar. En este sentido se educa a las familias, no solo a los niños/as.

Vínculo con ODS 17: Alianzas para lograr los objetivos. Para que un programa de desarrollo se cumpla satisfactoriamente, es necesario establecer asociaciones inclusivas (a nivel mundial, regional, nacional y local) sobre principios y valores, así como sobre una visión y unos objetivos compartidos que se centren primero en las personas y el planeta. El programa NEREU desde esa visión de modelo ecológico, que hemos hablado, establece alianzas entre distintos agentes e instituciones implicadas en la educación para la salud. 
El objetivo de este capítulo es presentar el programa NEREU, como programa metodológico, de orientación y evaluación en educación para la salud y el bienestar, testado para producir, realizar y/o adquirir un cambio de hábitos en la familia, un estilo de vida saludable que mejore el bienestar de las mismas, en una sociedad que incita a la comodidad, al sedentarismo y; analizar la contribución del proyecto con los ODS.

\section{Descripción de la experiencia/Objetivo}

El principal objetivo del programa es: Producir, realizar y/o adquirir un cambio de hábitos en la familia, un estilo de vida saludable que mejore el bienestar de las mismas. Para ello, tras la difusión del programa es el pediatra el que lo prescribe y tras informar sobre el mismo, se solicita a los familiares el consentimiento informado de querer participar en él. A partir de allí comienza el desarrollo del programa (figura 1).

Figura 1. Procedimiento de inclusión del programa.

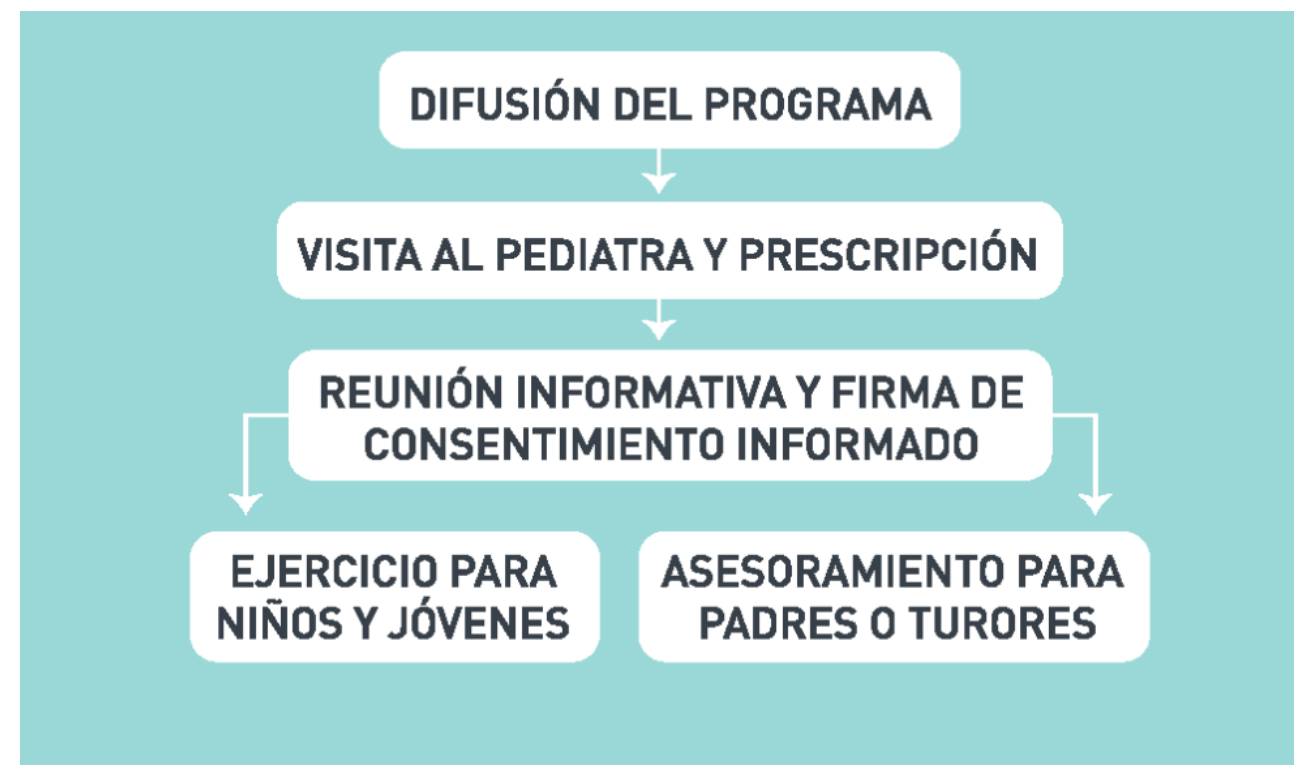

El primer año se realiza la intervención con más de 100 horas presenciales con los niños/as donde se abordan contenidos para trasferir a su día a día, hábitos de vida saludables. El programa se complementa con 23 sesiones teórico-prácticas con las familias que les asesora y les dota de herramientas. Además, se hace un seguimiento de las familias, hasta 5 años después de haber participado en el programa. 
El programa se divide en 3 fases:

\section{TRATAMIENTO}

El programa se aborda como una receta médica, una confianza que han depositado en el programa miles de médicos, pediatras las provincias de Lleida, Huesca y Andorra. Es la forma de alargar una consulta y dar respuesta a las miles de familias preocupadas por el estado de salud de su hijo o hija. Son las familias, junto al programa NEREU, los que colaboran en el tratamiento, haciéndoles partícipes y dejando constancia de que deben ser ellos los modelos y los que realmente deben hacer el esfuerzo para que puedan mejorar la salud sus hijos.

Todo se refleja en un informe individual que se adjunta a la historia clínica del niño/a, además de hacer un seguimiento de 5 años para comprobar que mantiene un estilo de vida activo y saludable. Los resultados más positivos y completos del proyecto se dan cuando participa, de una manera u otra, toda la familia. Está demostrado que cuanta mayor es la presencia del niño/a y de los padres en el programa, mayor es el porcentaje de éxito. La asistencia y la continuidad se consiguen gracias a los profesionales que trabajan en el proyecto, que aportan toda su formación, experiencia e ilusión en la lucha contra el sedentarismo y la obesidad infantil.

\section{PREVENCION}

La filosofía y los pilares del programa han servido para construir una base que forma parte del sistema educativo, como lo puede ser cualquier otra asignatura curricular. Por ello, este trabajo se hace desde la escuela. Se desarrolla una programación con sesiones de actividad física, talleres de alimentación y de emociones, juegos, experimentos, fichas, etc.

Aunque el programa se orientó inicialmente a niños/as en edad escolar, este proceso puede empezar desde edades tempranas. Muestra de ello es el programa Mini-NEREU con trabajo de hábitos saludables que comienzan desde los 6 meses a los 6 años, con la implicación imprescindible de las familias. La planificación del programa se coordina con el equipo directivo del centro, la colaboración del AMPA, donde todos se marcan un mismo objetivo: educar en estilos de vida activos y saludables. 
Puede producirse un cambio de hábitos si se sigue la receta para "cocinar" los siguientes ingredientes: actividad física, alimentación, hábitos saludables y las emociones, añadiendo como condimentos moverse, jugar y disfrutar, con la implicación del cocinero, y el apoyo del restaurante. Desde el mismo programa se organizan actividades conjuntas para familias donde pueden participar aquellos que han formado parte de los programas. Además se hace un seguimiento de la evolución del niño/a y las familias a través de los centros de salud. La figura 2, presenta algunos ejemplos de materiales utilizados por el programa en la promoción de la salud.

Figura 2. Actividades de promoción de la salud.
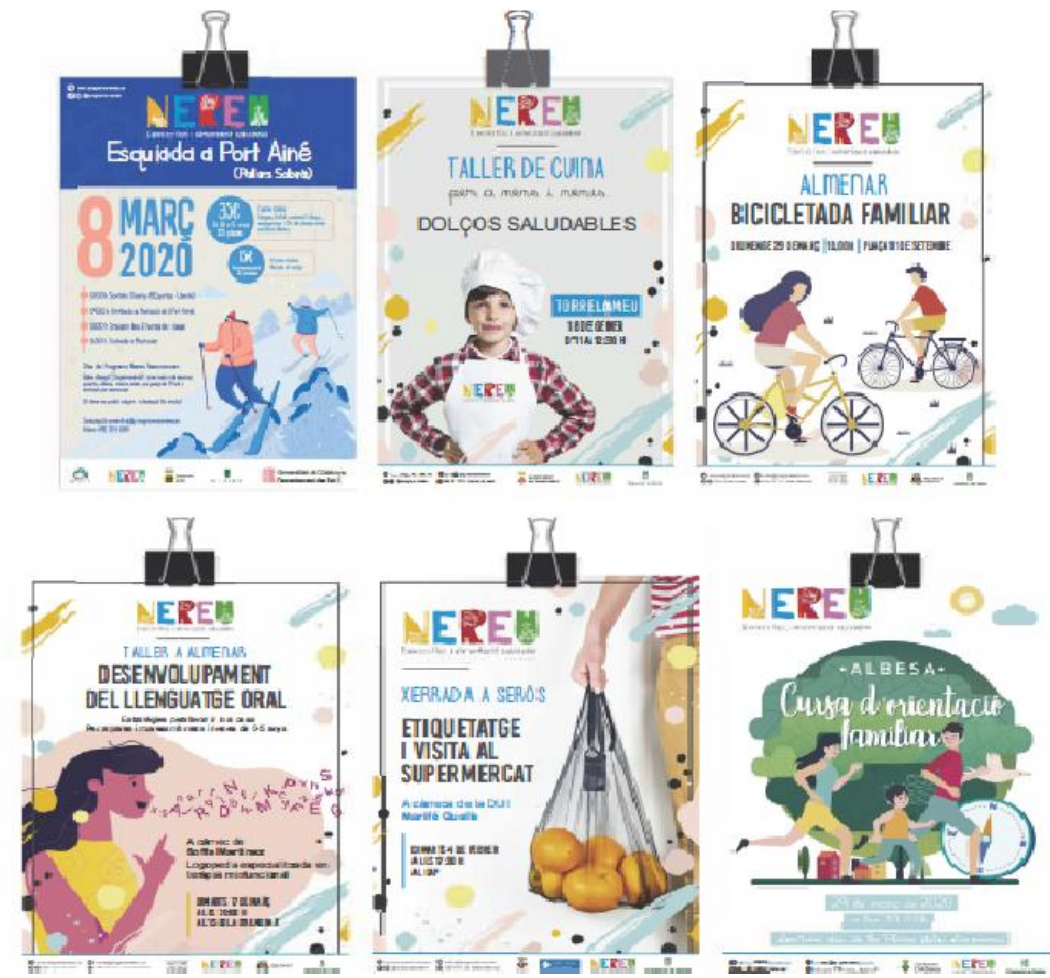

\section{Contexto}

Se trata de un programa educativo donde están implicados profesionales de educación, medicina, nutrición, psicología, investigación y deporte. El foco de acción surge desde los colegios o centros de salud y se ha convertido en un referente de educación para la salud donde padres y niños/as trabajan conjuntamente.

A lo largo de estos 15 años de trabajo han realizado actividades vinculadas al programa más de 200.000 familias, sumadas a las 1.000 que se han tratado anualmente. El proyecto comenzó 
en el 2006 y desde ese año al 2012, se realizó en la ciudad de Lleida y capitales de comarca a través de centros de salud y ambulatorios. A partir del 2013, se comenzó a trabajar a través de la Generalitat de Cataluña en los colegios, implantándose además como experiencia piloto en Andorra y llegando también a la ciudad de Huesca. En el próximo año, además de los lugares mencionados, será implantado también por el gobierno de las Islas Canarias, a través del Consejo Superior de Deportes de España (figura 3).

Figura 3. Desarrollo e inclusión del programa NEREU.

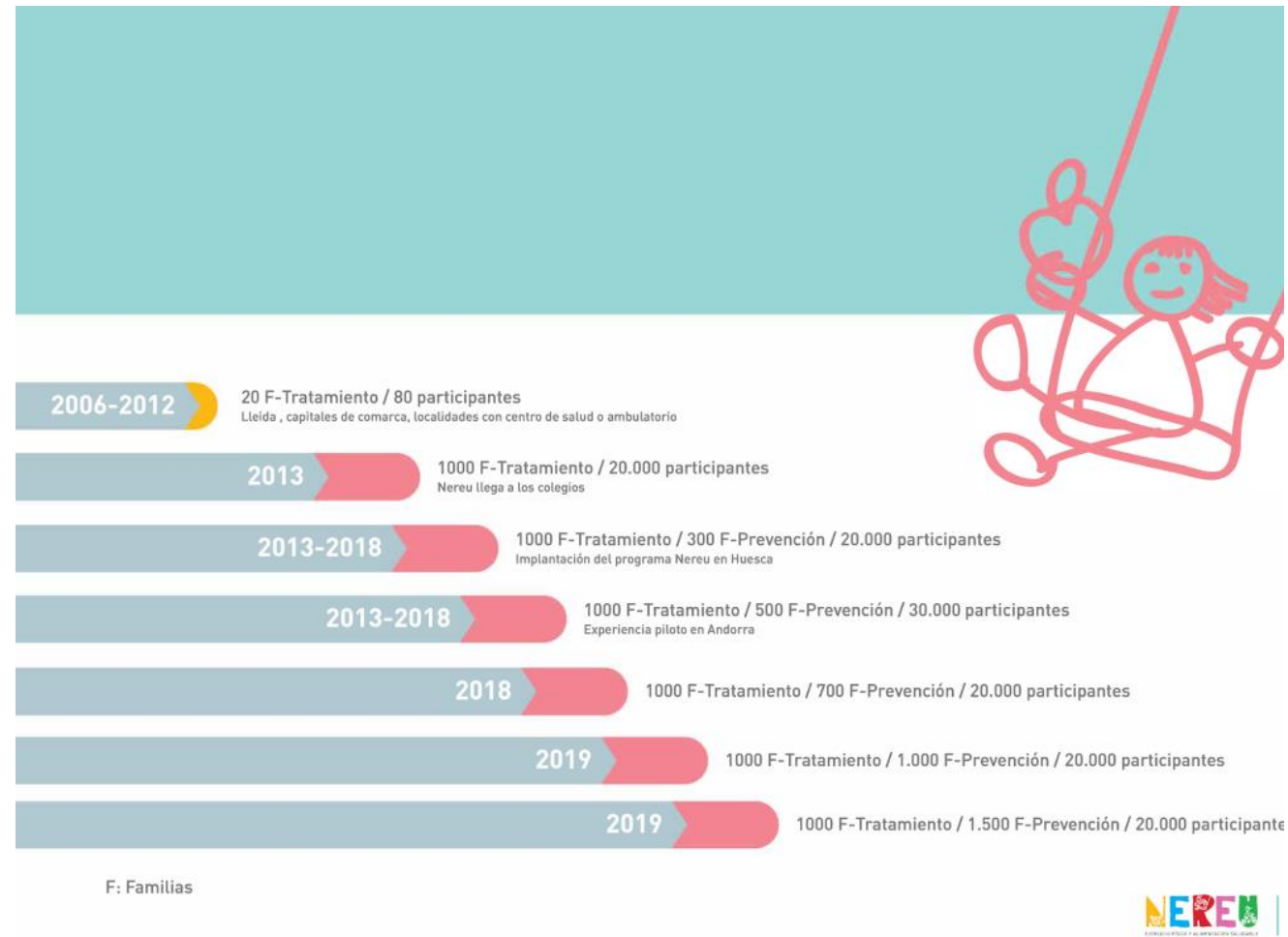

Aplicación y resultados

Actualmente el programa NEREU es, a nivel nacional e internacional, un referente en el tratamiento del sobrepeso, obesidad, sedentarismo y baja autoestima. Como asignatura saludable, es una prevención educativa que ayuda a concienciar al alumnado de la importancia de unos hábitos sanos. Además aporta promoción con acciones y actividades al resto del contexto familiar, provocando un ambiente activo y saludable alrededor de todos.

El programa siempre ha estado sustentado en la investigación y a través de él se han publicado en revistas científicas numerosos artículos. El objetivo principal de estos ha sido entre 
otros evaluar si el programa tenía un impacto favorable en los hábitos de actividad física, el sedentarismo y en la adiposidad en niños/as con sobrepeso y obesidad, como herramienta de intervención integral en salud pública para el tratamiento de la obesidad infantil. Entre otros estudios se realizaron estudios prospectivos longitudinal con post-test a los 9 meses (Serra-Paya, Solé, y Nespereira, 2014). La actividad física, las conductas sedentarias y la adiposidad se midieron a los 9 meses. Los niños/as expresaron pasar más tiempo ( $p<0,01)$ en actividades de intensidad moderada $(3,1 \pm 1,62 \mathrm{~h} \cdot$ set- 1$)$ y alta intensidad $(3,1 \pm 1,62 \mathrm{~h} \cdot \mathrm{set}-1)$ y menos tiempo $(\mathrm{p}<0,001)$ en actividades sedentarias $(5,4 \pm 6,3 \mathrm{~h} \cdot$ week-1). Otro de los objetivos de la investigación fue evaluar las diferencias en la frecuencia de los almuerzos escolares, la adherencia a la dieta mediterránea, la práctica deportiva y el nivel educativo de los padres en los niños/as en edad escolar según su estado de peso (Serra-Paya, Ensenyat, Serra-Paya, y Blanco-Nespereira, 2015). En este estudio se vio que el porcentaje de niños/as con peso normal que almorzaban en el colegio los días laborables era significativamente ( $\mathrm{p}<0,001)$ mayor que el porcentaje de niños/as con sobrepeso y/u obesidad. El porcentaje de niños/as con sobrepeso y/u obesidad que declararon practicar deporte estructurado fue significativamente menor $(\mathrm{p}<0,05)$ que en el grupo de niños/as con peso normal y el tiempo medio dedicado a ello también $(2,05 \pm 2,36$ vs. $2,99 \pm 3,03$ horas/semana; $\mathrm{p}<0,001$, respectivamente). No se encontraron diferencias en los estudios de los padres o en la variable de la dieta mediterránea entre los grupos. Los resultados apoyan el papel del educador en la escuela y se sugiere que una alimentación sana y regulada podría favorecer una menor adiposidad en los niños/as. La promoción del ejercicio físico en la escuela también podría ayudar al grado de obesidad.

Resulta interesante incluir los testimonios de las familias que han vivido el programa y que atestiguan el cambio actitudinal que provoca el programa. Sintetizamos algunas de sus ideas en la figura 4.

Figura 4. Testimonios de las familias. 

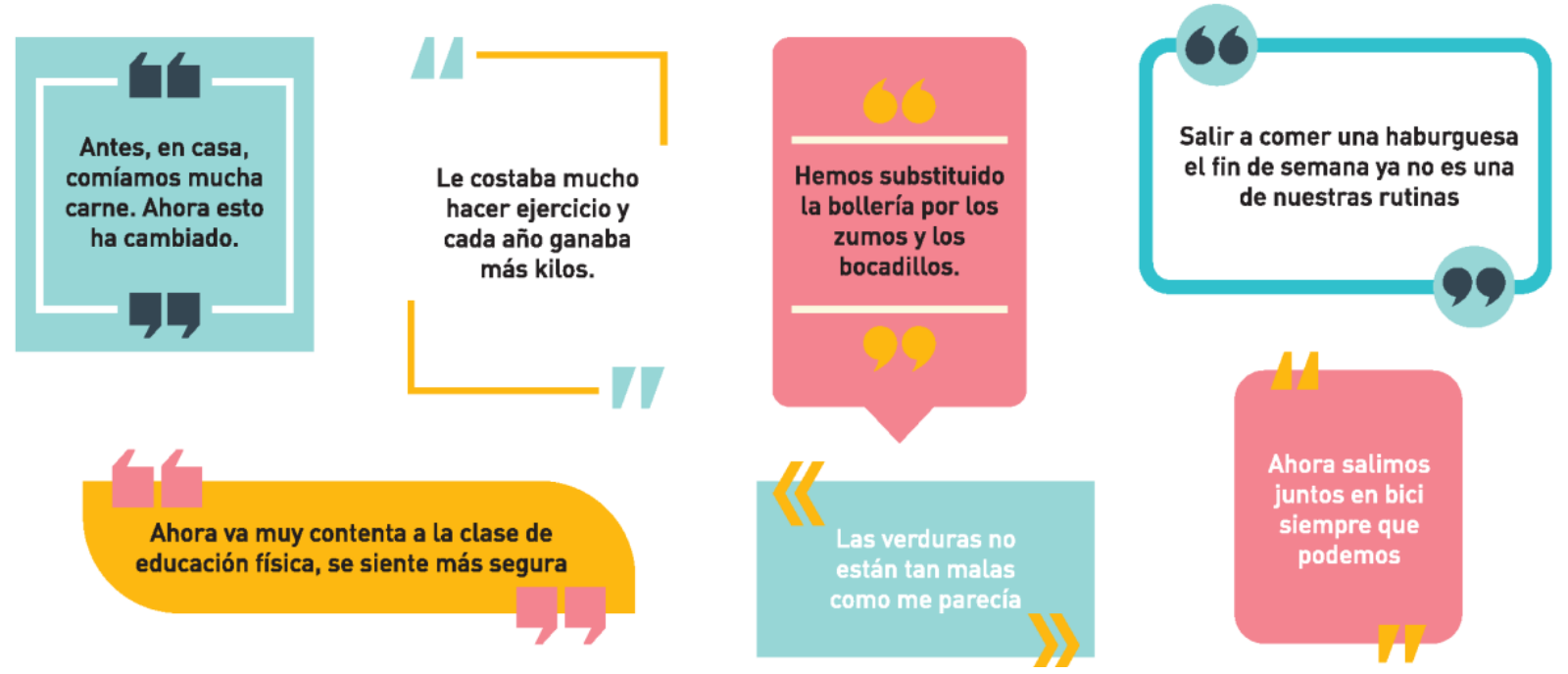

\section{Conclusiones}

Más de 100.000 familias, han participado en el programa y el $80 \%$ de ellas continúan con un estilo de vida activo y saludable. Programas bajo el modelo ecológico de Bronfenbrenner donde se busca un cambio ambiental y donde todos los agentes estén implicados, contribuyen a la consecución de los ODS 3, 4 y 17 de manera directa (salud y bienestar, educación de calidad y alianzas para lograr los objetivos) y a otros objetivos ODS de manera indirecta.

Estos resultados indican un cambio positivo en los hábitos de actividad física, las conductas sedentarias y del índice de masa corporal (IMC) en niños/as sedentarios con sobrepeso y obesidad y la influencia que tiene el colegio y la alimentación. Estas intervenciones son una interesante herramienta de intervención de salud pública para el tratamiento de la obesidad infantil.

\section{Referencias}

Bogantes, C. Á. (2016). Efectividad del programa ecológico Saltando por su salud en la promoción de la actividad física y la auto-eficacia en niños y niñas escolares de tercer grado. Ensayos pedagógicos, 11(1), 147-169. 
Frauca, J. R., y García, R. C. (2021). ¿ Sigue España ofreciendo brindis al sol en cuestión de obesidad infantil?. $\quad$ Atención Primaria, 53(1), 1-2. https://doi.org/10.1016/j.aprim.2020.11.002

Mendoza, F. G., Ledezma, J. C. R., Lezama, M. P., Hermenegild, A. y. I., \& Saldaña, R. G. (2020). Adherencia al tratamiento en personas con sobrepeso y obesidad. Enseñanza $e$ Investigación en Psicología, 2(1), 127-138.

Monroy-Parada, D. X., Prieto-Castillo, L., Ordaz-Castillo, E., Bosqued, M. J., Rodríguez-Artalejo, F., y Royo-Bordonada, M. Á. (2021). Mapa de las políticas nutricionales escolares en España. Gaceta Sanitaria, 35(2), 123-129. https://doi.org/10.1016/j.gaceta.2019.10.005.

ONU: "Resolución A/RES/70/1 Transformar nuestro mundo: la Agenda 2030 para el Desarrollo Sostenible”, 25 de noviembre de 2015. https://www.un.org/sustainabledevelopment/es/2015/09/la-asamblea-general-adopta-laagenda-2030-para-el-desarrollo-sostenible/.

Ortiz-Sánchez, J.A. del Pozo-Cruz, J., Alfonso-Rosa, R.M., Gallardo-Gómez, D. y ÁlvarezBarbosa, F. (2021). Efectos del sedentarismo en niños en edad escolar: revisión sistemática de estudios longitudinales. Retos: nuevas tendencias en educación física, deporte y recreación, 40, 404-412.

Pardos, E., Gou, B., Sagarra, L., Morales, S. C., y Concepción, R. R. F. (2021). Obesidad, intervención escolar, actividad física y estilos de vida saludable en niños españoles. Revista Cubana de Salud Pública, 47(2), 1-23.

Rivadeneira, J., Soto, A., Bello, N., Concha, M., y Díaz, X. (2021). Estilos parentales, sobrepeso y obesidad infantil: Estudio transversal en población infantil chilena. Revista chilena de nutrición, 48(1), 18-30. http://dx.doi.org/10.4067/S0717-75182021000100018.

Schmidt, H. F., Bogantes, C. Á., y González, E. H. (2021). Sistematización de la creación del modelo escuelas en movimiento: Intervención en salud escolar. MHSalud: Movimiento Humano y Salud, 18(1), 16-23. https://doi.org/10.15359/mhs.18-1.3. 
Serra-Paya, N., Ensenyat, A., Serra-Paya, P., y Blanco-Nespereira, A. (2015). How Important Is Focalizing On A Healthier Lunch At School? Procedia-Social and Behavioral Sciences, 191, 1201-1204.

Serra-Paya, N., Solé, A. E., y Nespereira, A. B. (2014). Multi-Disciplinary and Uncompetitive Intervention in Public Health for the Treatment of Sedentary and Overweight or Obese Children: NEREU Programme. Apunts Educación Física y Deportes, 117, 7-22. 
